\title{
Behaviour of tissue enzymes in the circulation
}

Citation for published version (APA):

van Dieijen-Visser, M. P. (1981). Behaviour of tissue enzymes in the circulation. [Doctoral Thesis, Maastricht University]. Rijksuniversiteit Limburg. https://doi.org/10.26481/dis.19810116md

Document status and date:

Published: 01/01/1981

DOI:

10.26481/dis.19810116md

Document Version:

Publisher's PDF, also known as Version of record

\section{Please check the document version of this publication:}

- A submitted manuscript is the version of the article upon submission and before peer-review. There can be important differences between the submitted version and the official published version of record.

People interested in the research are advised to contact the author for the final version of the publication, or visit the DOI to the publisher's website.

- The final author version and the galley proof are versions of the publication after peer review.

- The final published version features the final layout of the paper including the volume, issue and page numbers.

Link to publication

\footnotetext{
General rights rights.

- You may freely distribute the URL identifying the publication in the public portal. please follow below link for the End User Agreement:

www.umlib.nl/taverne-license

Take down policy

If you believe that this document breaches copyright please contact us at:

repository@maastrichtuniversity.nl

providing details and we will investigate your claim.
}

Copyright and moral rights for the publications made accessible in the public portal are retained by the authors and/or other copyright owners and it is a condition of accessing publications that users recognise and abide by the legal requirements associated with these

- Users may download and print one copy of any publication from the public portal for the purpose of private study or research.

- You may not further distribute the material or use it for any profit-making activity or commercial gain

If the publication is distributed under the terms of Article $25 \mathrm{fa}$ of the Dutch Copyright Act, indicated by the "Taverne" license above, 
Behaviour of tissue enzymes in the circulation

Marja P. van Dieijen-Visser 



\section{Behaviour of tissue enzymes in the circulation}

\section{Proefschrift}

ter verkrijging van de graad van Doctor in de

Geneeskunde aan de Rijksuniversiteit Limburg te

Maastricht op gezag van de Rector Magnificus

Prof. Dr. W.H.F.W. Wijnen, hoogleraar in de

Faculteit der Geneeskunde, volgens het besiuit

van het college van Dekanen in het openbaar

te verdedigen in de Aula van de Universiteit op

Vrijdag 16 januari 1981

des namiddags te 16.00 uur

door

Marja Pauline van Dieijen-Visser

geboren te Amsterdam 
Promotor : Prof. Dr. H.C. Hemker

Referenten : Prof. Dr. P.G. Spieckermann (Göttingen, Duitsland)

Prof. Dr. H.J.J. Wellens (Maastricht)

Het onderzoek beschreven in dit proefschrift is uitgevoerd onder leiding van Dr. W.Th. Hermens 
Aan mijn ouders voor Gerbrand 

CHAPTER I

CHAPTER II

II. 1 .

II. 2 .

II. 3 .

II. 4 .

II. 5 .

II. 6 .

II. 7 .

II. 8 .

CHAPTER III

CHAPTER IV

CHAPTER V

CHAPTER VI

CHAPTER VII

CHAPTER VIII
Introduction

Review of the literature

Introduction 13

Mathematical models to describe the catabolicm

and distribution of proteins that enter the circulation

Clearance and distribntion of circulating enzymes

Sites of catabolism of circulating enzynes

30

34

Catabolism of damaged macromolecules

37

Relation between cell death and enzyme release

Quantitation of myocardial tissue damage from increased plasma enzyne levels

Enzyme distribution in dog heart and Liver

Plasma volume determination by use of enzyme dilution

selection of a suitable model for the plasma clearance and distribution of cardiac enzymes in the dog

Quantitation of intravenously and intramuscularly administered doses of enzyme

In vitro thermal inactivation of different

enzymes. Relation with in pivo plasma clearance rates

Conclusions and summary

Conclusies en samenvatting

Appendix I "Presentation of complete data

147

Appendix II: Mathematical models used

Appendix III : Thermal inactivation of enzymes

Abbreviations

Nawoord / Acknowledgements

Curriculum Vitae 


\section{CHAPTER I}

\section{Introduction}

In this thesis the behaviour of tissue enzyes in the circulation is studied, in order to validate and improve methods of estimation of tissue damage on the basis of enzyme levels in plasma. Tissue enzymes catalyze specific biological reactions in the cell. Normally only very small amounts of tissue enzymes are present in the circulation, but after tissue damage the levels of tissue enzymes in plasma increase due to leakage of enzymes from damaged cells. At the same time however the enzymes are cleared from the circulation and eventualy enzyme levels in plasma return to normal.

In 1908 wohlgemut introduced a sensitive assay for amylase and demonstrated the presence of this enzyme in serum and urine of pathents with acute pancreatitis. New impetus to clinical enzymology was given by Bodansky, who demonstrated in 1933 that serum phosphatase activity is elevated in bone and liver diseases. The finding of elevated transaminase levels after acute myocardial infarction by LaDue et $a z$. in 1954 and also during 11 ver disease by wroblewsi et $a z$. in 1955, marked the start of an explosive development in this field. Determination of serum or plasma enzyme activities has presently become an important tool in the diagnosis and confirmation of a variety of diseases. The specificity of enzymatic reactions makes it possible to measure enzyme activity in plasma or serum with high sensitivity. Each organ has its own specific enzyme pattern and tissue specific enzymes, isoenzymes and typical ratios of enzyme activity in plasma are determined routinely to verify the site of tissue injury and the clinical course of iliness.

The level of tissue enzymes in the blood will depend on the quantity of cells damaged. In a number of studies a significant although not impressive correlation was found between peak levels of enzymes in plasma and histologically assessed infarct size. The latter method is based on specific staining technigues, marking elther the damaged tissue or the undamaged tissue. After excision and weighing of the damaged tissue the amount of tissue injury can be expressed in terms of grams of injured tissue. The fact that correlations betweer peak levels, of enzymes in plasma and histologically assessed infarct size were insufficient to allow accurate determination of in- 
farct size In individua cases was attributed to such factors as insufficient sampling and individual differences in enzyme clearance rates.

whe first study concerning quantitation of myocardial infarction, where clearance rates from the circulation and distribution of enzymes over different compartments were taken into account was performed by witeveen et a 2 . (1970, 1972). Since 1971 different models have been proposed for the determination of enzymatic infarct size and both good and poor correlations have been reported between enzymatic infarct size and histologically assessed infarct size. These contradicting results suggest that the events between cell death and enzyme release are not yet sufficiently understood and that existing methods to quantitate tissue damage from enzyme levels in plasma are inadequate. Modelis intended to describe the fate of proteins released into the circulation shoula account for the phenomena of (1) extravasation of protein (2) return of the protein from the extravascular pool to the circulation and (3) clearance of protein from the circulation.

Enzymes disappear from the plasma pool at rates, that are specific for the species as well as for the particular enzyme. In experimental animals enzyme clearance xates form the circulation can be estimated from phasma clearance curves after intravenous injection of purified or partially purifled enzyme preparations. In man intravenous injection of such doses of enzyme to abtain enzyme clearance rates from the circulation is not feasible in view of immunological risks. The only way to measure enzyme clearance rates in man is from plasma enzyme curves after tissue injury like for instance myocardial infarction, acute hepatitis etc. In most studies the clearance rates of intracellulat enzymes were estimated from the final part of the clearance curve after tissue injury. Such measurements can only give a rough approximation of enzyme clearance rates, because it is unknown when enzyne release from tissue has stopped, which may result in undexestimation of the enzyme clearance rate and consequently in overestimation of tissue damage.

Some other factors which may affect enzymatic quantitation of tissue damage are: (1) incomplete release of enzyme from necrotic cells, (2) local inactivation of enzyme activity at the place of tissue injury and (3) extravascular inactivation of enzyme activity. Enzyme release from the cells after tissue injury is caused as a rule 
by a relative or absolute lack of cellular energy, resulting in an increased permeability of the cell membrane. Hereater enzmes diffuse directly through the capillary wall or reach the plasma indirectly by lymphatic transport. These factors are however ther difFicult to inyestigate, because for clinical as well as experimental studies only the intravascular compartment is easily accessible for the investigator. Therefore to quantitate tissue injury on the basis of enzyme levels in plasma, enzymes have to be selected that show complete recovery in the plasma compartment, $i$.e. enzymes that are not inactivated locally at the site of injury or during transport through the interstitial fluid.

To obtain the weight of injured tissue ungrams, the calculated total activity of enzyme released into the circulation has to be divided by the mean enzyme activity per gram of normal tissue. Selection of enzymes with small intra- and intex-individual variations in tissue enzyme content will therefore minimize errors in the quantitation of tissue damage, due to the use of a mean value for the enzyme content per gram of normal tissue.

Several aspects of enzymatic quantitation of tissue damage have been investigated in the present study. Dogs were used in all experiments. These animals are commonly used in experimental models to study enzymatic infarct quantitation.

Chapter II presents a review of the literature on protein turnover and on quantitation of tissue damage.

In chapter III intra- and inter-individual variations in enzyme content of $\mathrm{dog}$ heart and dog liver are investigated.

In chapter IV a method is described to estimate plasma volume by use of enzyme dilution. This parameter is essential for calculations of enzyme release in plasma.

In chapter $V$ a model to estimate the plasma clearance and distribution of cardiac enzymes in the dog is presented. Intra- and inter-individual variations in model parameters are estimated.

In chapter WI a method 1 s presented which allows estimation of individual clearance rates, even when there is still release of enzyme into the circulation. The method presented in this chapter is based on analysis of simultaneously infused enzymes with different clearance rates. The estimated clearance rate is used to quantitate the infusions. Intramuscular injections of enzyme activity were given to investigate whether all enzyme activity administered into the muscle 
eventwally reaches the circulation. Total recovery in plasma would indicate that there is no local inactuation of enzyme activity in the tissue, but also that enzyme breakdown occurs in the plasma pool or in inmediate contact with that pool.

In chapter VII we deseribe a method to investigate the stability and homogeneity of enzyme preparations used for clearance studies. This method is based upon thermal inactivation of enzymes. Part of the contradictions $1 \mathrm{n}$ earliex work on the clearance of enzymes from the circulation were caused by use of different protein preparations. In chaptex VIII a summary of the main conclusions of our work is presented.

Three appendices containing respectively the complete data of experiments presented in this thesis, a description of the mathematical models used and a thermodynamical description of thermal inactivation of enzymes complete this thesis.

References

1. BODANSKY, 0.: Phosphatase studies: determination of serum phosphatase. Factors influencing accuracy of determination.

d. Btol. Chem, 101: $93,1933$.

2. LADUE, J.S., Wroblewsk., J., and Karmen, A.: Serum glutamic oxaloacetic transaminase activity in human acute transmurall infarction.

3. WITYEVEEM, S.A.G.J., Hermens, W.Th., Hemker, H.C., and Hollaar, L.: Quantitation of enzyne release from infareted heart muscle. In Ischemic Heart Disease (Eds. J. de Haas, H.C. Henker and H.E. Snellen) Leiden 1970, pp. 36-42.

4. WITTEVEEN, S.A.G.J.: Assessment of the extent of myocardial infarction on the basis of plasma enzyme levels. Thesis, Leiden 1972.

5. WOHLGEMT, J.: Obex eine neue Methode zur quantitativen Bestimmung des diastatischen Ferments.

Biochem, 2., 9: 1-9, 1908.

6. WroblewsKI, F., and Labue, J.S.: Serum qlutamic oxaloacetic transaminase arctivity as an Lndex of llver injury. A preliminary report.

Ann. Intom. Med. "43: $345,1955$. 


\section{CHAPTER II}

\section{Review of the literature}

\section{1. Introduction.}

When this investigation was started in 1977 our aim was to study guantitation of tissue damage from increased plasma enzyme levels. In order to be able to quantitate the amount of enzyme released from necrotic tissue, the rate at which enzymes are cleared from the circulation and the distribution of enzymes throughout different compartments have to be known.

Determination of (1) enzyme clearance rates from the circulation, (2) the rate of enzyme exchange with the extravascular compartments and (3) the intra- and inter-individual variations in these parameters covers an important part of this thesis. Therefore a review will be given of the literature on the turnover of circulating proteins, with emphasis on circulating enzymes."

In the second part a literature review on enzymatic quantitation of tissue damage will be given. Iiterature on the more specific problems like: (1) the mechanism of cell death and subsequent enzyme release, (2) local inactivation of enzymes in the tissue and (3) inactivation of enzymes during transport from tissue to plasma will be discussed.

Throughout the 1iterature the term protein turnover refers to different physiological processes like (1) turnover of circulating proteins, (2) hydrolysis of intracellular proteins to amino acids. (3) total protein turnovex of a given organ etc. The present review will concern the turnover of enzymes in the circulation. The literature on the turnover of circulating albumin is so voluminous that 1 t is impossible to sumarize it in a few pages. Although there is no lack of data on the turnover and distribution of labeled plasma proteins and enzymes, much of the early work was carried out with inferior protein preparations. It $1 \mathrm{~s}$ known that even silght damage of protein leads to a highly increased rate of catabolization as compared to the socalled native proteins. The mechanism responsible for this rapid elimination of protein from the circulation seems to be completely diffexent from that involved in nomal enzyme clearance from the circulation. Fallacious conclusions on the clearance anci distribution of proteins have been arawn from such experiments. 
wherefore in this review special attention will be payed to the clearance of damaged macromolecules.

II. 2. Mathematioat modete to dearibe the eataboltam and diatibution of proteing that onter the otrouration.

Models intended to describe the fate of proteins released into the circulation should account for the phenomena of: (1) extravasation of protein, (2) the return of protein from the extravascular pool to the eirculation and (3) catabolism in the circulation.

It is now generally accepted that proteins escape from the cirwlation through the caplliary nembrane and that the principal mechanisms of transport from plasma to interstitium are filtration (solvent drag), diffusion and vesicular transport. The question which contribution should be attributed to each of these phenomena is not yet settled (Renkin et al. , 1977; Rippe et al., 1979; Landis et al., 1963; Lassen et al., 1974 and Casley-Smith et al., 1976). Approaches to this problem are indirect and it seems that laboratories using different techniques obtain different answers.

Generally one conceives that convective transport of solvent and macromolecules and diffusion of macromolecules is possible by the existence of canals (pores) in the capiliary membrane. It is assumed that there exist a large number of small pores (diameter < $50 \AA$ ) and fewer large pores (diameter $>200 \AA$ ). The existence of pores of different sizes gives rise to a local paracapillary circulation. Through the large pores there is a bulk flow, consisting of solvent and proteins, from plasma to interstitium. This flow is mainly regulated by the hydrostatic pressure difference $\Delta \mathrm{P}$ between capillary and interstitium. This flow through the larger pores is partially compensated by osmotic absorption of solvent through the small pores and across the endothelial cells. From this pathway macromolecules are excluded. Ihig East flow is mainly regulated by both the hydrostatic pressure difference $\Delta P$ and the osmotic pressure difference between capillary and interstitium.

\section{Filtration}

The net result of these flows is a net volume flow F of solvent and a net solute flow $\mathbb{F}_{\mathbf{S}}$, resulting from the solvent arag transfer of solute by the solvent flow $\mathrm{F}_{\mathrm{v} 1}$ through the pores, which can be passed 
unhindered by macromolecules. Thus one obtains the following expression for the solute flow $\mathrm{F}_{1}$ " due to convection:

$$
F_{1}=E_{V 1} \cdot \bar{c}
$$

$F_{1}$ - the amount of the specific solute extravasated per hour (mol/h) $\mathrm{F}_{\mathrm{Wl}}$ - the wolume flow through the large pores per $\mathrm{kg}$ tissue $(1 / \mathrm{h})$

$\bar{c}$ - the concentration of solute in the large pores (mol/1); $\bar{c}$ has a value between the plasma concentration $C_{1}$ and the interstitial concentration $C_{e}$ "

In the literature (Renkin et al., 1977; Rippe at., 1977 and gaylor et at. , 1977), a variety of different expressions are used to relate $F_{v 1}$ to the hydrostatic and osmotic pressure differences and the lymph flow. Because of this lacking agreement we do not specify this flow further. Note that $F_{v 1}$ increases with increasing hydrostatic and osmotic pressure differences between plasma and interstitium, and that $F_{v 1}$ decreases with increasing molecular size. The same disagreement exists about the relation between $\bar{c}, c_{i}$ and $c_{e}$ expressions used are all in the form: $\bar{c}=(1-a) c_{1}+a c_{e}$ but the a's used vary widely. So we obtain instead of (1):

$$
F_{1}=F_{V I}\left((1-\alpha) C_{1}+\alpha C_{e}\right)
$$

The diffusional and vesicular transport is assumed to be proportional to a permeability surface factor PS, which is the product of the area of the vascular wall, which is permeable to the macromolecules and a diffusion constant in case of diffusion or a rate constant of the transport rate in case of vesicular transport.

Assuming Fick's law for the diffusion or symmetry in case of vesicular transport we obtain the following expression for the solute Elow, due to these mechanisms.

$$
\mathrm{F}_{2}=\mathrm{PS} \cdot \mathrm{C}_{\text {i }}
$$

$F_{2}$ - the amount of solute escaping from the vascular compartment pex hour $(\operatorname{mol} / \mathrm{h})$

PS - permeability-surface area product (1/h)

$c_{1}$ - plasma concentration of the solute $(m o l / 1)$.

$$
F_{\text {ex }}=F_{1}+F_{2}
$$

$F_{\text {ex }}{ }^{-}$the flow of protein to the extravascular space, the interstitium. 
The return of protein from interstitum to plasma is formed by the back alffusion term $\mathbb{P S} . \mathrm{C}_{e}$ and the return by lymph flow. Hence one obtains the expression for the return $F_{R}$ to $P l a s m a:$

$$
\mathrm{E}_{\mathrm{R}}=\mathrm{pS} \cdot \mathrm{C}_{\mathrm{e}}+\mathrm{F}_{\mathrm{L}} \mathrm{C}_{\mathrm{L}}
$$

$\mathbb{E}_{\mathrm{L}}-$ lymph flow per hour $(1 / \mathrm{h})$

$\mathrm{C}_{\mathrm{L}}$ - the concentration of solute in lymph (mol/1).

one generally agrees that catabolism of protein occurs in the vascular pool or in immediate contact with this pool. The evidence is indirect. Most information thus far is obtained from experiments with I-labeled proteins, especially albumin. It turns out that excretion of the lodine label ard the decrease of whole-body content of the label runs closely in parallel to the plasma concentration. While certalnly during the first 12 hours upon injection of the labeled albumin the extravascular concentration 1 s still rising, and the plasma concentration decreasing. Most direct evidence on this point could be obtained by recording the quantitative recovery in plasma of extravascularly injected protein, see chapter VI of this thesis. However we do not know of reports comparing this return of extravascularly injected protein to the amount injected.

In case of rapidly catabolized protein, with a half-life in plasma of say less than 5 hours it follows from the mono-exponential decay curves of plasma activity and the fact that extravasation cannot account more than $5 \%$ per hour, that the major part of the protein is catabolized intravascularly and that the catabolic rate is proportional to the plasma concentration.

Thus the assumption is made that the protein is catabolized only from the intravascular pool and that the rate is proportional to the plasma concentration.

$$
F_{c}=V_{1} k C_{1}
$$

$v_{1}$ - plasma volume (1), (intravascular volume)

$\mathbb{k}$ - rate constant of the first order reaction describing the cataboIism $\left(\mathrm{h}^{-1}\right)$

$C_{1}$ - plasma concentration of protein (mol/1)

$\mathrm{F}_{\mathrm{C}}$ - the amount of protein or label catabolized per hour. 
Collecting the different fows of protein, equations $(2),(3),(4)$, (5) and (6) we can describe the dynamics in the time of the intravascular concentration $C_{1}$ by:

$$
v_{i} \frac{d c_{i}}{d t}=-F_{c}-\mathbb{F}_{e x}+\mathbb{F}_{R}+V_{i} f(t)
$$

$F_{c}$ - the amount of protein or label catabolized per hour (mol/h)

Fex - the flow of protein to the extravascular space, the interstitium

$\mathrm{F}_{\mathrm{R}} \quad$ - the return flow of protein from the extravascular space to plasma

$f(t)$ - the input of enzyme.

Insertion of (2), (3), (4), (5), (6) in (7) results in:

$\frac{d C_{i}}{d t}=-\frac{P S}{V_{1}}\left(C_{i}-C_{e}\right)-\frac{F_{V I}}{V_{i}}\left((1-a) C_{i}+a C_{e}\right)+\frac{F_{L} C_{L}}{V_{i}}-k C_{i}+f(t)$

In order to relate the interstitial concentration $c_{e}$ to flows, we need the concept of the extravascular distribution space. Rutili et al. 1978 made a direct approach to the definition of this space by correlating the amount of extravascular macromolecules to the interstitial concentration.

It turned out that for increasing molecular size this distribution space $v_{d}$ decreased, but for molecules larger than 50,000 Daltons this dependence of $V_{d}$ on molecular size became rather faint. It is thought that the dependence of the distribution space on molecular size is due to exclusion of larger molecules from the gel phase in the interstitium (wiederhielm et at., 1979).

In this same study a direct comparison of lymph and interstitid fluid, sampled by a micropipette lead to the conclusion that lymph concentration and interstitidid concentration are identical $\left(\mathrm{C}_{\mathrm{e}}=\mathrm{C}_{\mathrm{L}}\right)$. Thus the change of the amount of protein or enzyme in the interstitium is described by:

$$
\frac{d C_{\mathbb{L}}}{d t}=+\frac{P S}{V_{d}}\left(C_{i}-C_{I_{i}}\right)+\frac{F_{I}}{V_{d}}\left((1-\alpha) C_{1}+\alpha C_{L}\right)-\frac{F_{L} C_{L}}{V_{d}}
$$

Ordexing of the terms in (8) and (9) results in:

$\frac{d C_{1}}{d t}=-\left(\frac{P S}{V_{i}}+(1-\alpha) \frac{F_{v 1}}{V_{i}}\right) C_{i}+\left(\frac{P S}{V_{i}}-\frac{a F_{1}}{V_{i}}+\frac{F_{L_{u}}}{V_{1}} C_{L}-k C_{i}+f(t)\right.$ 


$$
\frac{d C_{L}}{d t}=-\left(\frac{P S}{V_{d}}-\frac{F_{y I}}{V_{d}}+\frac{F_{L}}{V_{d}}\right) C_{L}+\left(\frac{P S}{V_{d}}+(L-a) \frac{F_{U l}}{V_{d}}\right) C_{p}
$$

Comparison of the equations (10) and (11) obtained by consideration of physiological processes with the more comoniy used two-compartment model (Mathews et QD., 1967 and Hermens $Q t Q 2 ., 1975$ ) leads to the conclusion that both have identical form and are equivalent:

$$
\begin{aligned}
& \frac{d C_{1}}{d t}=P / V_{i}\left(C_{1}-C_{e}\right)-k C_{1}+f(t) \\
& \frac{d C_{e}}{d t}=-P / V_{e}\left(C_{e}-C_{i}\right)
\end{aligned}
$$

The equations (12) and (13) are obtained from (10) and (11) by the transformations:

$$
P / V_{i}=\frac{P S}{V_{i}}+(1-a) \frac{F_{V 1}}{V_{i}}
$$

the quotient $P / V_{i}$ is also known as transcapillary escape rate (TER).

$$
\begin{aligned}
& P / Q_{e}=\left(\frac{P S}{V_{d}}-\alpha \frac{F_{V}}{V_{d}}+\frac{F_{L}}{V_{d}}\right) \\
& k=k ; V_{1}=V_{I} \\
& V_{e}=V_{d} \frac{P S+(1-\alpha) F_{V I}}{P S-\alpha F_{V I}+F_{L}} \\
& C_{e}=\frac{P S-\alpha F_{V 1}+F_{L}}{P S+(1-\alpha) F_{V I}} C_{I}
\end{aligned}
$$

The main difference between these models is that model (10), (11) allows for the filtration of the protein in the capiliary wall. In the steady state we find in this model the lymph concentration

$$
c_{L}=\frac{P S+(1-\alpha) F_{V I}}{P S-\alpha F_{V I}+F_{L}} C_{i}
$$

When $F_{L}$ is larger than $F_{y l}, C_{L}$ is smaller than $C_{1}$, which is in agreement wth the experiments, but in contrast with the diffusional model, where it is assumed that $c_{i}=c_{e}$.

Note however. that these models are a gross simplification by the fact that all caplilary walls and all tissues are considered to be 
equal and escape to and return from these tissues is lumped together in one term.

For the term representing the escape from plasma, this does not ham, as the summing up of several terms of this form leads to an expression of the same form. The problem however arises in the term representing the return from interstitium to plasma. The sum of this term over several tissues with a varying lymph flow and varying lymph concentration is not necessarily well represented by the same form.

Table I presents transcapillary escape rates (TER) and the ratio of the intra- and extravascular volumes $\left(\mathrm{V}_{\mathrm{e}} / \mathrm{V}_{\mathbf{i}}\right)$ for different plasma proteins, as obtained from the literature

Table I

\begin{tabular}{|c|c|c|c|c|c|c|}
\hline Plasma protein & $M N$ & Reference & Species & $\begin{array}{l}\text { Number of } \\
\text { exponentials }\end{array}$ & $\begin{array}{c}\text { TER } \\
(\mathrm{g} / \mathrm{h})\end{array}$ & $v_{e} / v_{i}$ \\
\hline Albumin & 69000 & Takeda 1963 & man & 3 & 3.9 & 1.2 \\
\hline Albumin & 69000 & Beeken 1962 & $\operatorname{man}$ & 3 & 4.2 & 1.3 \\
\hline Albumin & 69000 & Walker 1960 & $\operatorname{man}$ & 2 & 2.6 & 1.4 \\
\hline Albumin & 69000 & Reeve 1959 & rabbit & 2 & 4.3 & 1.44 \\
\hline r-globulin & 160000 & Walker 1960 & $\operatorname{man}$ & 2 & 1.7 & 0.50 \\
\hline$\gamma$-globul in & 160000 & Andiersen 1963 & $\operatorname{dog}$ & 2 & 1.8 & 0.72 \\
\hline Fibrinogen & 341000 & Tytgat 1971 & man & 2 & 2.5 & 0.41 \\
\hline$a_{1}-$ antitrypsin & 56.000 & Jones 1978 & $\operatorname{man}$ & 2 & 3.3 & 1.07 \\
\hline
\end{tabular}

TER $=$ transcapillary escape rate $(\% / h)$

$\mathrm{V}_{\mathrm{e}}=$ extravascular volume $(\mathbb{1})$

$\mathrm{v}_{\mathbf{i}}=$ intravascular volume (1)

MW $=$ molecular weight.

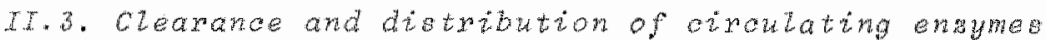

Most of the research on circulating protelns has been performed with labeled plasma proteins like, albumin, immuroglobulin, fibrinow gen etc. An extensive review on the turnover of plasma proteins in different species was given by schultze and Heremans (1966). In the present review results obtained from studies on the clearance and distribution of circulating enzymes will be compared with results obtained for plasma proteins. The general principles to describe the clearance and distribution of circulating plasma proteins (II.2.) can be applied to circulating enzymes. 
In turnover studies based on the measurement of enzyme activity some problems peculiar to enzymes may arise:

- Rapid elimination of partially denatured enzyme preparations. The higher the specific activity the less stable the enzyme becomes (Pogen et al., 1970 and sodetz et $\alpha$ t. "1977).

- Enayme activity may not parallel enzyme concentration when inhibitors ox activators are present in plasma.

- The measumement of enzyme activity is dependent on small changes in $\mathrm{pH}$ and temperature.

- Hemolysis of plasma samples may increase the plasma levels of enzymes which are present in erythrocytes.

In a few studies radioactively labeled enzymes have been used (Roberts et a $2 ., 1975$; Schapira etal., 1962; Masarat, 1968 and Qureshi et $a l, 1976)$. These preparations are subject to the same errors as descxibed for labeled plasma proteins (schultze et al., 1966; Luck, 1956 and IT.6.).

In experimental animals enzyme clearance rates can be estimated from plasma curves obtained after intravenous injection of purified or partially purified enzyme preparations. In man the only way to measure enzyme clearance rates is fxom plasma enzyme curves obtained after tissue damage like for instance myocardial infarction (witteveen, 1972), acute hepatitis etc. The clearance rates of intracellular engymes are often estimated from the last part of the clearance curve until the activity returns to normal. Such measurements can however only give a rough approximation of enzyme clearance rates, because it is unknown when enzyme release from the tissue has stopped, which may result in an underestimation of the enzyme clearance rates.

one of the few studies on intravenous injection of intracellular tissue enzymes in man was performed by Dawson et al. (1969). In this study enzyme rich plasma of an alcoholic suffering from rhabdomolysis was infused into the same patient after recovery (Table II).

For human clotting factors VIII and IX plasma clearance and distribution could be measured after intravenous infusion of factor VIII and Ix concentrates in patients suffering from bleeding disorders.

Table II shows the model parameters obtained after intravenous injection of various intraceliular tissue enzymes in different species. Although the table is not complete it gives a general survey of the literature available on this subject. For most enzymes more than 
one disappearance rate is recognizable from the plasma dearance curve. Plasma kinetios of intravenously injected proteins is based on the description of plasma curves as a sum of exponentials, each exponential corresponding to a separate compartment (II.2.). However until now many conflicting results have been reported on the diearance of tissue enzymes from the circulation and the distribution over different compartments because:

- purification and or labeling may cause molecular changes such that fractions of different in vivo stability may arise, resulting in a multi-exponential clearance pattern.

- isoenzymes or enzymes of different stability present in the preparations may cause the same problem.

These factors were not always recognized and as a consequence fallacious conclusions were drawn from such enzyme disappearance curves. As can be seen from table II even in the recent literature large discrepancies on the clearance and distribution of enzymes become apparent. For instance for AST and CK clearance in the dog both double-exponential (Dunn, 1958; wakim et az., 1963; Shel1 et al., 1971 and Sobel et $a z ., 1977$ ) and mono-exponential (Rapaport, 1975; Roberts et a.., 1975; Roberts et al., 1977 and the present study) clearance has been reported.

Shel1 $a t, 1971$ and sobel et $a z$, 1977 measured extremely rapid diffusion of $\mathrm{CK}$ to the extravascular space. In both studies equilibration with the extravascular space occurred within two hours. The transcapillary escape rate (TER) as observed by sobel et al. was 54. per hour. In sheep Boyd et al., 1967 measured a TER of $73 \%$ per hour for LD-5. These values are in striking contrast with TER"s as observed for plasma proteins of comparable molecular weight (see II.2.). For plasma proteins ranging in moleculax weight from 69000 to 156000 Daltons TER"s of less than $5 \%$ per hour were measured in different species.

As the blood-lymph barrier does not discriminate in the passage of molecules with molecular weights exceeding 40000 Daltons (Grotte, 1956; Pappenheimer, 1953 and Rutili, 1977) such Large TER's as observed in some studies for CK, AST and LD (TableII) are not to be expected, because the respective molecular welghts are $81000, \mathbb{1 1 0 0 0 0}$ and 140000 Daltons.

In dogs we were able to demonstrate that for CK and AST clearance rates as calculated from equilibrium conditions obtained after constant rate infusion of the enzyme equal the apparent clearance con- 


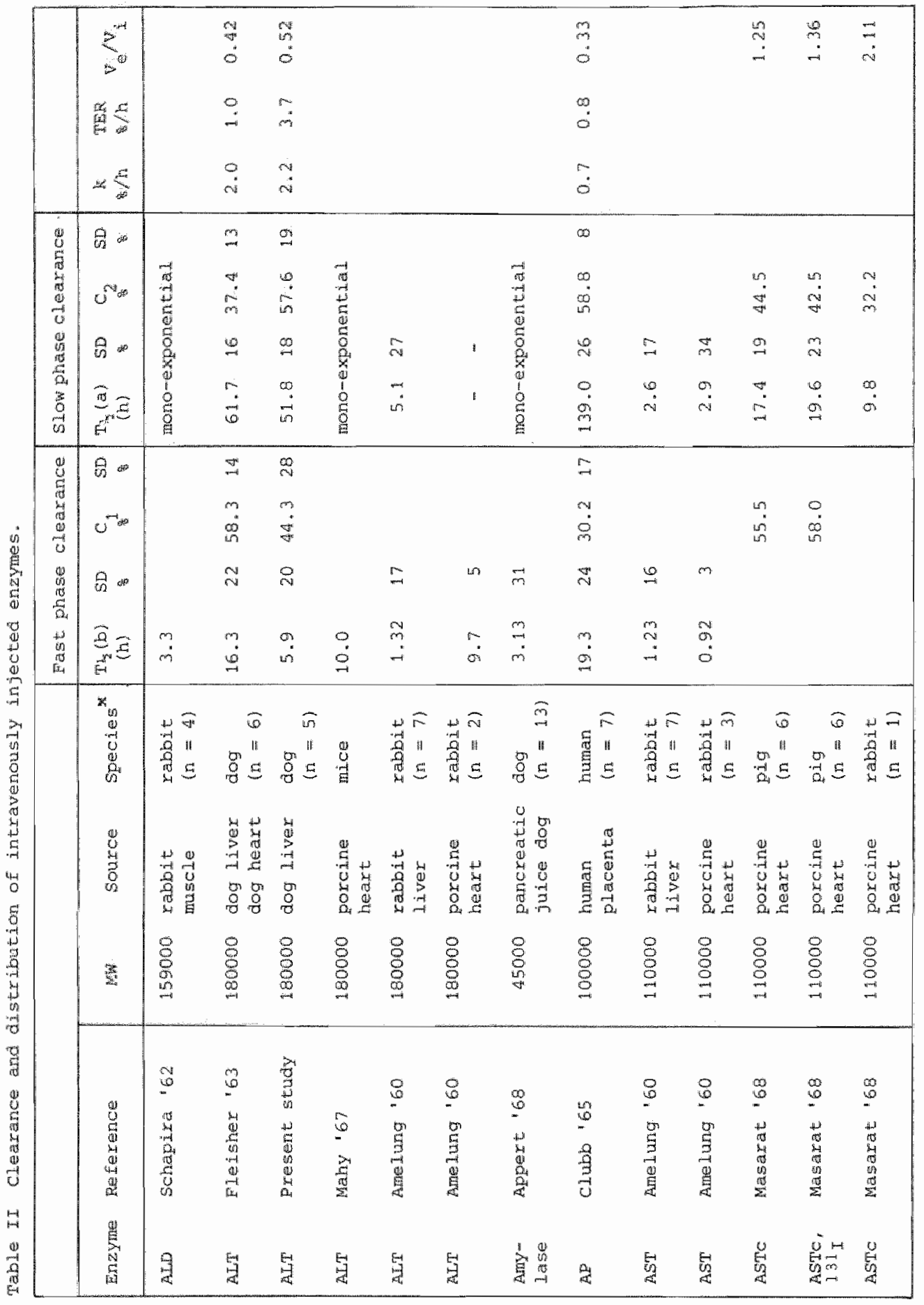




\begin{tabular}{|c|c|c|c|c|c|c|c|c|c|c|c|c|c|c|c|}
\hline & 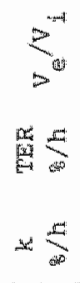 & & & $\begin{array}{l}\stackrel{0}{0} \\
0 \\
0 \\
\dot{0} \\
0 \\
0\end{array}$ & $\begin{array}{l}\text { s } \\
\dot{0} \\
\dot{m} \\
\dot{m} \\
\dot{0} \\
\dot{0}\end{array}$ & & & & $\begin{array}{l}\infty \\
+1\end{array}$ & & & & & 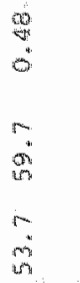 & \\
\hline 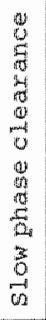 & 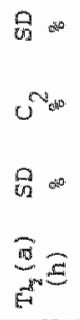 & $\stackrel{0}{0}$ & $\because$ & 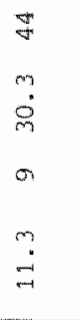 & $\begin{array}{l}\stackrel{0}{m} \\
0 \\
\dot{m} \\
m \\
\dot{m} \\
\ddot{\sim}\end{array}$ & 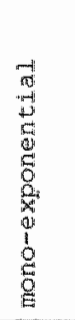 & 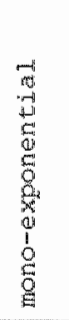 & 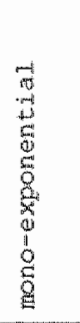 & $\begin{array}{l}\ddot{v} \\
\dot{v}\end{array}$ & 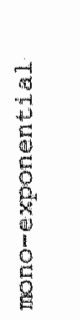 & 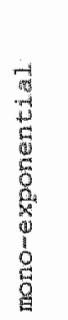 & 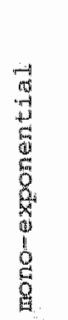 & 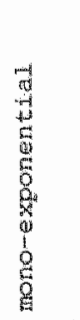 & 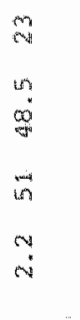 & 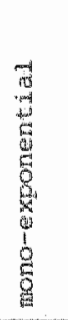 \\
\hline 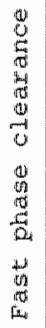 & $\begin{array}{l}0^{\circ} \\
\frac{a}{0} \\
\frac{a}{a}\end{array}$ & & $\because$ & 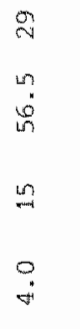 & $\begin{array}{l}\qquad n \\
n \rightarrow 1 \\
\infty \\
\dot{0} \\
0\end{array}$ & $\begin{array}{l}\stackrel{y}{r} \\
\dot{m} \\
\dot{m}\end{array}$ & $\begin{array}{l}\vec{j} \\
\tilde{m} \\
\vec{m}\end{array}$ & $\begin{array}{l}m \\
m \\
\stackrel{m}{m} \\
m\end{array}$ & & $\begin{array}{l}\vec{~} \\
m \\
m\end{array}$ & $\begin{array}{l}\stackrel{p}{d} \\
m \\
r \\
r\end{array}$ & 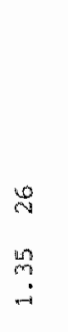 & $\begin{array}{l}m \\
9 \\
\dot{0}\end{array}$ & 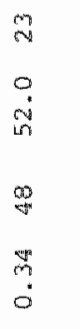 & 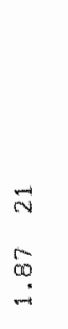 \\
\hline & 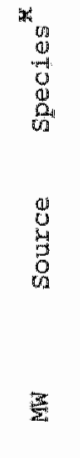 & 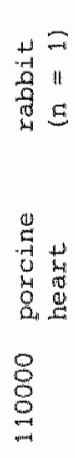 & 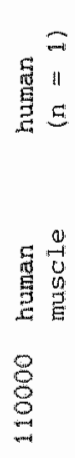 & 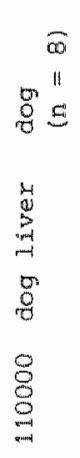 & 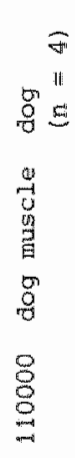 & 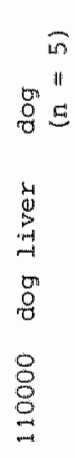 & 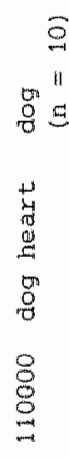 & 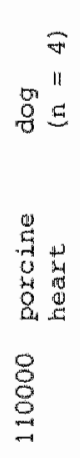 & 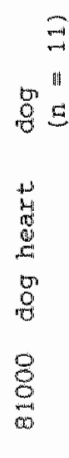 & 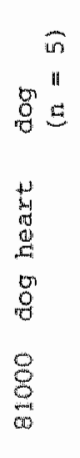 & 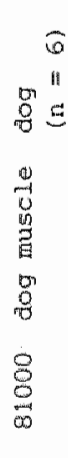 & 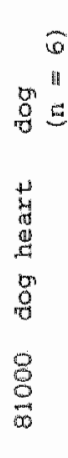 & 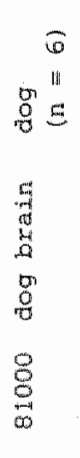 & 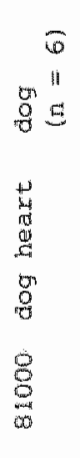 & 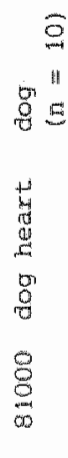 \\
\hline & 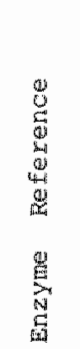 & 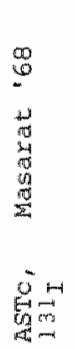 & $\begin{array}{l}0 \\
0 \\
0 \\
0 \\
0 \\
3 \\
3 \\
0\end{array}$ & 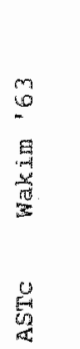 & 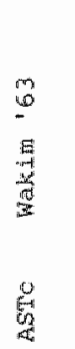 & 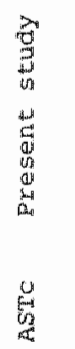 & 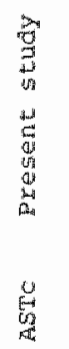 & 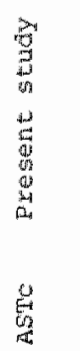 & $\begin{array}{l}= \\
= \\
= \\
= \\
=0 \\
0 \\
0\end{array}$ & 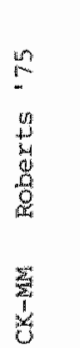 & 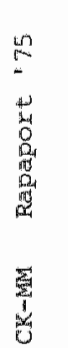 & 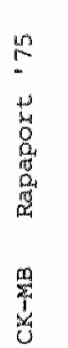 & 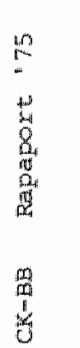 & 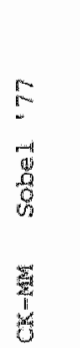 & 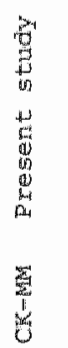 \\
\hline
\end{tabular}




\begin{tabular}{|c|c|c|c|c|c|c|c|c|c|c|c|c|c|c|}
\hline & $\sum_{\infty}^{\infty}$ & & & $\begin{array}{l}2 \\
0 \\
0 \\
\infty \\
\infty \\
\infty \\
0 \\
0\end{array}$ & $\begin{array}{l}8 \\
0 \\
0 \\
4 \\
\infty \\
\infty \\
8\end{array}$ & & & $\begin{array}{l}8 \\
0 \\
0 \\
\because \\
\because \\
\dot{\square}\end{array}$ & $\begin{array}{l}m \\
0 \\
0 \\
0 \\
\dot{D} \\
m \\
m \\
0 \\
0\end{array}$ & $\begin{array}{l}m \\
0 \\
0 \\
\dot{0} \\
m \\
m \\
m \\
m \\
m\end{array}$ & $\begin{array}{l}9 \\
0 \\
0 \\
0 \\
0 \\
n \\
\infty \\
\infty \\
\infty\end{array}$ & & & \\
\hline 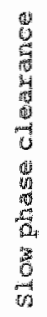 & 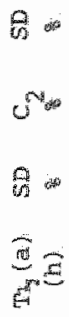 & 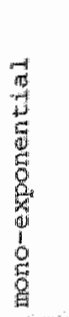 & 4 & $\underset{b}{\circ}$ & $\vec{m}$ & 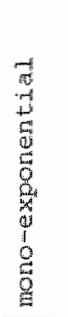 & 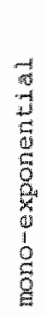 & 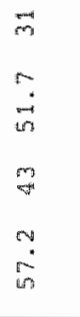 & $\begin{array}{l}m \\
m \\
\dot{m} \\
\dot{m} \\
\vec{\sigma} \\
\dot{n}\end{array}$ & $\begin{array}{l}\infty \\
\infty \\
\dot{0} \\
m \\
m \\
m \\
m\end{array}$ & 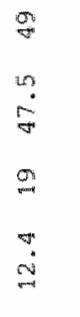 & 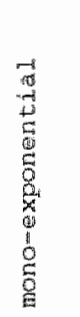 & 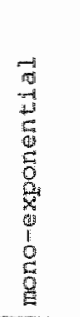 & $\begin{array}{l}7 \\
0 \\
-1 \\
5 \\
5 \\
5 \\
0 \\
0 \\
0 \\
0 \\
0 \\
0 \\
0 \\
0\end{array}$ \\
\hline 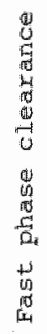 & 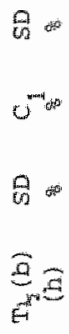 & 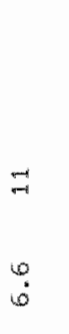 & $\dot{m}$ & $\stackrel{m}{m}$ & $\stackrel{0}{\dot{m}}$ & $\begin{array}{l}\stackrel{\infty}{\sim} \\
\stackrel{\infty}{\infty} \\
\stackrel{\sim}{\sim}\end{array}$ & $\begin{array}{l}\infty \\
-1 \\
-1\end{array}$ & $\begin{array}{l}\stackrel{\infty}{m} \\
m \\
\infty \\
\infty \\
\& \\
\stackrel{\infty}{\circ} \\
\cdots \\
\cdots\end{array}$ & $\begin{array}{l}0 \\
\infty \\
\dot{8} \\
\mathbb{8} \\
m \\
m \\
m\end{array}$ & $\begin{array}{l}a \\
-1 \\
m \\
0 \\
0 \\
0 \\
0 \\
0 \\
0 \\
0\end{array}$ & $\begin{array}{l}8 \\
- \\
-\vec{v} \\
0 \\
0 \\
0 \\
0\end{array}$ & $\begin{array}{l}n \\
\sim 1 \\
+1\end{array}$ & 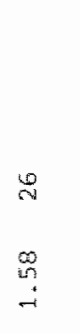 & 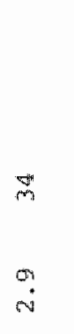 \\
\hline & 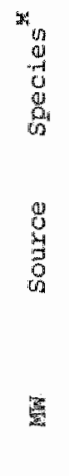 & 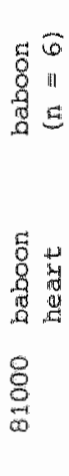 & 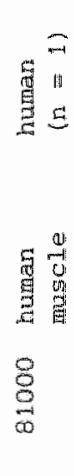 & 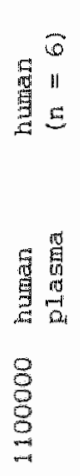 & 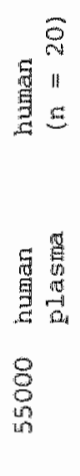 & 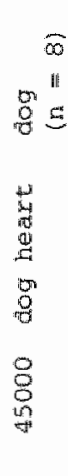 & $\begin{array}{l}4 \\
4 \\
0 \\
0 \\
0 \\
8 \\
8 \\
4 \\
4 \\
4\end{array}$ & 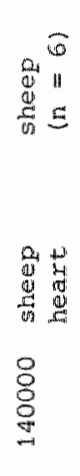 & 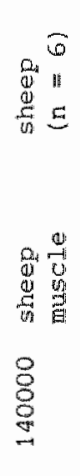 & 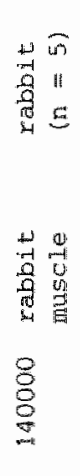 & 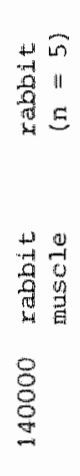 & 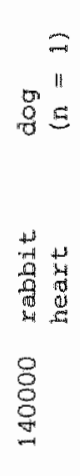 & 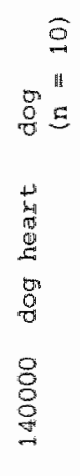 & 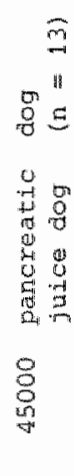 \\
\hline & 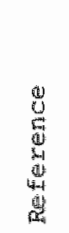 & 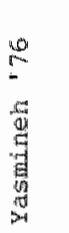 & $\begin{array}{l}0 \\
0 \\
0 \\
0 \\
0 \\
0 \\
30 \\
0 \\
0\end{array}$ & 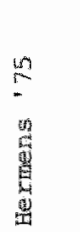 & 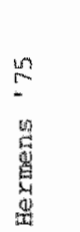 & 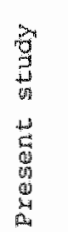 & $\begin{array}{l}0 \\
- \\
2 \\
2\end{array}$ & $\begin{array}{l}6 \\
= \\
0 \\
0\end{array}$ & 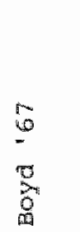 & 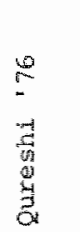 & 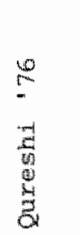 & 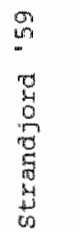 & 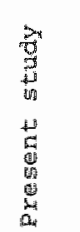 & 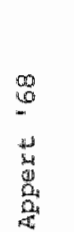 \\
\hline & 量 & $\frac{9}{4}$ & 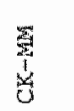 & 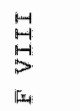 & $\begin{array}{l}x_{n \rightarrow H} \\
a_{i}\end{array}$ & 朐 & $\begin{array}{l}n-1 \\
\mathrm{M}_{1}\end{array}$ & $\vec{i}$ & $\begin{array}{c}0 \\
9 \\
9\end{array}$ & $\stackrel{1}{a}$ & $\hat{b}_{n \rightarrow-1}^{\infty}$ & 品 & $\begin{array}{l}n \\
i \\
9\end{array}$ & 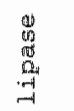 \\
\hline
\end{tabular}




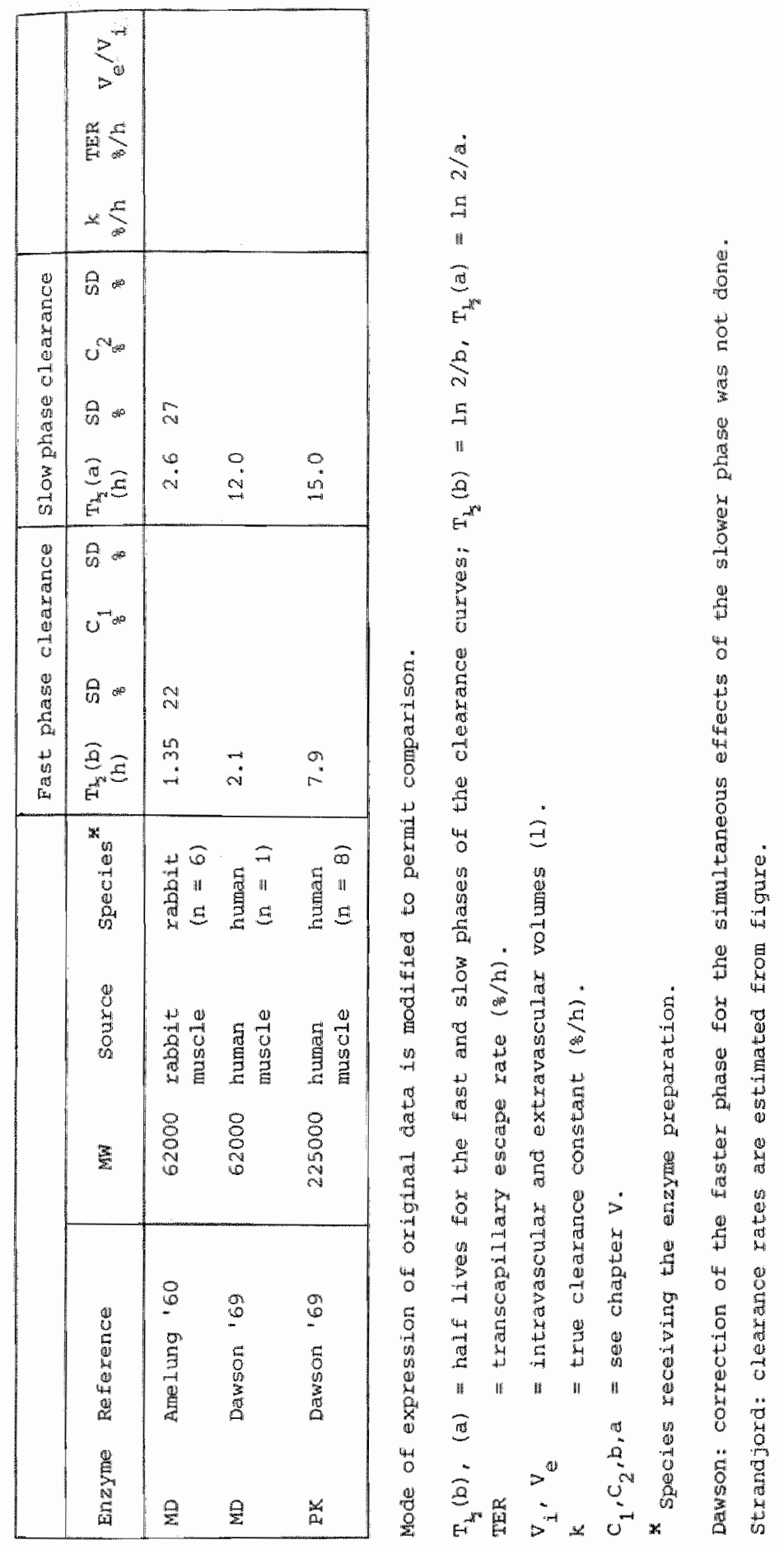


stants $k_{d}$ as calculated from the clearance pattern after a loading dose of enzyme given 90 minutes before the infusion was started (chapter $b$ ). Constant rate infusion of enzyme permits airect calculation of enzyme clearance rates independent of the specific model used. It 1 s concluded that for rapidy cleared enzymes like ck and Asir the rate of transport to the extravascular compartment could be neglected in comparison to the plasma clearance rate and moreover in our study no initial rapid disappearance of enzyme activity occurred. This implies that double-exponential clearance, as presented throughout the 1.iterature for enzymes cleared as iast as CK Or AST do not reflect aistributional effects.

For ALT a slowly cleared enzyme $\left(T_{\frac{1}{5}}=31 \mathrm{~h}\right)$ a TER of $1.0 \%$ per hour was observed by wakim et at. (1963). Comparable results were obtained in the present study (chapter VI). These values are comparable to TER's as observed for plasma proteins of about the same molecular weight (II.2., table II).

Enzymes like plasma proteins have characteristic biological half-lives depending on the (iso) enzyme, its source and the species involved. As can be seen in table II porcine AST disappears at about the same rate as observed for rabbit AST, while porcine ALI and rabbit $A L^{\prime}$ are cleared at completely different rates (Amelung et $a z$. 1960). Masarat (1968) also measured AST clearance in the rabbit resulting in a different value as obtained by Amelung. Injection of porcine AST in plgs resulted in a considerably smaller clearance rate as observed in the rabbit (Masarat, 1968). In the dog no significant differences in AST clearance rates were observed after injection of dog heart, dog 1 iver and porcine heart AST.

For plasma proteins large inter-species variations in the biological half-lives have been observed. Allison t at. (2960) showed that the logaxithm of the half-lives of albumin and $\gamma \mathrm{G}$-immumoglobulin are airectly proportional to the logarithm of the body weights. At this moment too few reliable data are present to examine such a relation for enzyme clearance rates.

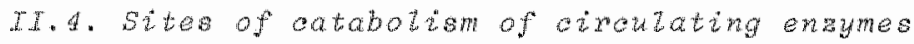

The mechanism of catabolism of proteins present in the circulation and the sites at which such catabolism takes place are still very much uncertain. 
Digestive and renal routes of loss of protein are described as exogenous catabolism.

The role of the kisineys

Conflicting results have been published on the role of the kidneys in the catabolism of circulating plasma proteins. Using unscreened 131 I-albumin Gitin et al. (1958) demonstrated that in mice bilateral nephrectomy prolonged the half-life of $13 \mathbb{I}$-albumin from 0.7 to 1.4 days. In the rabbit Katz at a2. (1960) and Rosenfeld al. (1962) demonstrated that in vivo bilateral nephrectomy reduced umscreened albumin breakdown by about 20: but had no effect on the breakdown of biologically screened iodoalbumin. To eliminate rapidly degrading fractions of damaged molecules, the biological filter method was developped (McFarlane, 1963). This involves intravenous ingection and successive harresting of the injected substance from plasma i.e. biologically screened preparations. The same results were observed in the perfused kidney. It was concluded that at most 10 of of the turnover of native albumin in the body may occur in the kidneys. Normally intracellular tissue enzymes also are hardly excreted in the urine. Dunn et az. (1956) and wakim et a. (1963) demonstrated respectively that no measurable amounts of AST and ALT were found in the urine after intravenous bolus injections or following myocardial infarction in the dog. In bilateraldy nephrectomized dogs no slgnificant effect on CK and AST clearance rates has been observed (Dunn ot al., 1956 and Roberts et al., 1975), as compared to sham operated controls.

Appert et al. (1968) demonstrated that after injection of pancreatic juice in the dog, less than 18 of amylase and lipase activity was detected in the urine.

Bladney et al. (1967) found however that enzymes such as amyllase, which have low molecular weights are readily filtrable by the glomerulus .

Kemp et az. (1960) demonstrated that in the rabbit and the cat aldolase (ALD), AST, ALT and LD are, - if at all excreted in very small amountes in normal urine.

strandjord et al. (1959) obtained the same resultis for ICD and ID in dogs. Further studies are necessary to determine whether lnactive enzyme is excreted in the urine, subsequent to their infusion into the 
blod strean. For labeled plasma proteins it has been demonstrated that protein bound lable is not excreted in the urine. This has not been examined for labeled enzymes.

The role of the gastrolmtestinal tract

An extensive review on the role of the gastrointestinal tract on the turnover of plasma proteins has been given by schultze and Heremans (1966).

In the rat, splenectomy and combined or separate hepatectomy and evisceration depressed plasma albumin by 50 as compared to sham operated controls. It was demonstrated that the whole of the digestive tract may be responsible for about 50 of the fractional catabolism of albumin. If this assumption is correct it would consolidate the concept of an entero-hepatic cycle of protein nitrogen, since the amino acids liberated via the portal route reach the liver, which could straightforwardly use then for synthesis of plasma proteins. Rats given an intravenous injection of iodoalbumin excreted practically no protein bound label in their faeces, but if they received soybean trypsin inhibitor in their drinking water the trichloracetic acia precipitable faecal activity corresponded to a dailey excretion of 17-29. $\mathrm{mg}$ of protein (Tarver et al., 1961). This represents 15-25\% of the total mass of this protein degraded per day in this animal. Andersen (1963) demonstrated a significant correlation between intravascular, extravascular exchange rates of yG-immunoglobulin and its intestinal degradation rate. This would imply that the leakage of plasma proteins into the gut is mainly a matter of capillary permeability. In the dog Andersen et at. (1961) demonstrated that intestinal clearance contributes substantially ( \pm 348 ) to the metabolic clearance of rG-immunoglobulin.

The observation that plasma proteins are able to cross the intestinal mucosa suggest that enzymes may do the same. In the dog intestinal clearance contributes for $18 \%$ to the metabolic clearance of $A L T$ and only for 38 to that of CAST. For MAST the corresponding data were not calculated but it was assumed that its intestinal clearance (Wakim) contributes no more than tracers to its metabolic clearance. Masarat (1968) also observed no AST in the intestinal lumen of the dog after intravenous AST injections.

The small quantities of enzymes present in bile $e \cdot g$. transaminases are out of proportion to the plasma turnower. After intravenous injections of LD and AST there is no increase of enzyme activity in the 
bile (Dunn, 1958: Ame Iung, 1958).

Endogenous catabolism

Endogenows catabolism is the active uptake of proteins from plasma or interstitial fluid by tissue cells. Analogous to the behaviour of serum proteins, it may be assumed that the breakdown of serum enzymes takes place to the level of amino acids. Breakciown in the reticuloendothelial system (RES) has been demonstrated for a number of enzymes. Wakim and Fleisher (1963) demonstrated that in the dog zynosan, an insoluble polysaccharide from yeast cell walls has a marked inhibitory effect on the rate of disappearance from blood of injected CAST, MAST and LD, but not on the rate of clearance of ALT. This inhibitory effect was most noticeable during the first few hours after the administration of zymosan. Some time later the effect wore of and after $1-2$ days there frequent]y were indications for enhanced enzyme clearance. Blockade of the reticuloendothelial system was without effect on the intestinal clearance rate of these enzymes. In I975 Roberts et al. observed a significant effect of zymosan on CK clearance rate after bolus injections in the dog.

Injection of mice with RES blocking agents causes an increase in the levels of $\mathrm{LD}-5$ and GPI, which enzymes are also raised after infection. with Riley virus (Mahey et $a$., 1967). For ALT and LD-1 no effect was observed on clearance rates after Riley virus infection and after injection of RES blocking agents. The effect of Riley virus infection is probably caused by inhibition of plasma enzyme clearance by the RES system.

The RES system can be seen as a diffusely distributed tissue with protein catabolizing properties. The major portion of this tisue $1 \mathrm{~s}$ represented by the Kupffer cells. Furthermore the RES conststs to a significant degree of fixed macrophages, localized along the vacular bed of the liver, spleen and bone maxrow.

There is now plenty of evidence that Kupffer cells are the ones responsible for the swift clearance of particulate mater or denatured protein from the circulation. As described above, blockade of this system also influences the clearance rate of part of the intraceliular enzymes. Blockade of the RES does not decrease the rate of breakdown of screened 131 I-albumin or biosynthetic labeled plasma proteins (Schultze et al., 1966).

The liver, which may be regarded as a concentrated form of RES plays 
only minor role in the catabolism of native albumin. Cohen et $2 \mathrm{t}$.

(1958) estimated that the liver accounted to as much as 12-18: of the albumin catabolism in $\%$. Cohen et ab. (1958) demonstrated that the liver catabolized screened $13 !$ I-yG-imminoglobulin much more actively than screened albumin.

In the case of enzmies strandjord at al. (1959) demonstrated that ICD and LD Clearance patterns were not altered in hepatectomized dogs, as compared to control animals. Injection of the enzymes in the portal vein resulted in similar clearance rates as found for intravenous injections.

Roberts et a (1.975) demonstrated that in the dog $\mathrm{CK}$ clearance rate decreased with about 10 after hepatic artery occlusion.

The influence of RES blocking agents on the rate of breakdown of biologically filtered enzyme preparations has not been examined.

For ck Sobel et al. (1977) demonstrated that the rate of clearance of blologically filtered CK diminishes with 44 as compared to purified CK. Wevers et at. (1978) demonstrated post-synthetic changes in creatine kinase isoenzymes. An in vivo more stable MM-band could be detected at latest 16-24 hours after myocardial infarction. This more stable M-band was formed in the course of myocardial infarction and appeared to be induced by a thermolabile factor.

Sodetz et al. (1977) demonstrated that zymosan only inhibits the rate of breakdown of aggregated or denatured Factor VIII/won willebrand molecules and not of native Factor VIII/von Willebrand Factor. From the literature available until now it can be concluded that the RES plays a role in the clearance of part of the intracellular tissue enzymes. However caution is needed because an influence of RES blockIng agents on enzyme clearance from the circulation, can wrongly be suggested when the enzyme preparations contain aggregated or denatured molecules (II.6.).

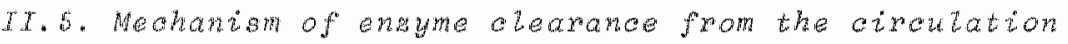

Clinical and experimental studies have established that the disappearance rates of circulating enzymes are relatively constant in a given species (CV 20\%), but very little is known on the mechanism. In the previous section the sites at whllch protein catabolism takes place have been discussed, but most of these results give little information on the clearance mechamism. 
In the dog the clearance pattern of 35 and $\mathrm{C}$ is equal in doubly labeled lysine $34 \mathrm{C}+$ cystine 35 fibrinogen, albumin, y globuIin and - globulin (Goldsworthy, 1958). The authors interpreted these results as an indication for protein degradation after complete removal of the protein from the circulation.

In a few studies the disappearance of radioactive labeled enzymes was measured simultaneous with the disappearance of enzyme activity (Schapira et a2., 1962; Masarat et at., 1965; Roberts a at. 1975 ana qureshi et al., 1976). Masarat concluded that enzyme activity and radioactivity disappeared at comparable rates after AST injections in the pig. However in the second part of the clearance curve, the disappearance rate of 131 was 108 slower than the disappearance rate of AST activity. Schapira et al. (1962) measurea aldolase (ALD) activity and labeled AID clearance after bolus injections in the rabbit and concluded that $A L D$ was not inactivated in plasma. In the dog Roberts et al. (1975) found that during the first several hours after injection, radioactivity and enzyme activity of CK decline in parallel suggesting again that the removal of enzyme molecules from the circulation accounted for the disappearance of activity. After about 3 hours radioactivity began to decline at a significantly slower rate. The same results were obtained by Qureshi et al. (1976) for LD-5 in the rabbit.

However Morin et at. (1.979) demonstrated that in 6 out of 7 patients the cleaxance of $\mathrm{CK}-\mathrm{MB}$, released into the circulation after myocardial infarction, is due primarily to the loss of activity and not to the physiological removal of $M B$ protein from the circulation. These results were obtained from immunological measurements to detect MB protein in the circulation. During the release phase after AMI the MB activity curve and the $\mathrm{MB}$ proteln curve ran in parallel. These results suggest either intravascular breakdown resulting in disappearance of the enzyme activity, while the radioactive label remains in the circulation, or degradation of the enzyme after remowal from the circulation followed by release of labeled fragments into the circulation.

Demonstration that enzyme and label disappear simultaneous does not necessarily conflict with the view that circulating enzymes are denatured by circulating proteases (Posen, 1970), If the time interwal between denaturation and removal of the enzyme from the circulation is small (IT.6.). 
The view that enzmes may be destroyed by circulating proteases is supported thy work of Henley et at. (1960) who observed that the Michaelis constant $\mathrm{K}_{\mathrm{m}}$ of malate dehydrogenase increased progressively in successive samples taken from a patient with acute myocardial infarction. Smith et al. demonstrated however that these results are introduced because after myocaralal infarction the relative amounts of mitochondrial MD and cytoplasmic MD are changing, as is introduced by differences in clearance rates af these isoenzymes. Gradual lass of substrate affinity was not confinmed by wakim et at. (1963) who were unable to detect any change in $\mathbb{K}_{\mathrm{m}}$ value for purified cAST in successive samples after a bolus injection in the dog. From above mentioned results it remains therefore unanswered whether inactivathon of enzymes causes immediate clearance from the circulation or whether cleaxance from the clrculation causes subsequent breakdown of the enzymes.

In a number of studies a possible relation between molecular welght, susceptibility to proteolytic attack, thermal stability of enzymes and in vivo clearance rates has been examined. Dehlinger and schimke (1970) found that the intracellular turnover rate is related to the logarithm of the subunit molecular weight of proteins. A higher intraceliular turnover rate was found for the larger proteins. This observation led these workers to propose that a relation between size of a protein and its rate of degradation is based on the overall greater chance of a protein to be hit by a protease, producing an inItial rate limiting peptide bond cleavage. Dice and Goldberg (1975) made the same observation for a larger group of intracellular proteins.

From our results it has become apparent that in the dog CK, LD, AST, ALT and GPI clemrance rates from the circulation are not related to the logarithm of the respective subunit molecular weights (chapter VIT). The same results had already been obtained for ICD, LD and AST cllearance rates in the dog (strandjord et al., 1959). Moreover for dsoenzymes of the same molecular weight completely different clearance rates from the circulation have been measured, which makes the theory of Dehlinger et at. (1970) rather improbable for the clearance of enzymes from the circulation.

Bond et al. (1971) demonstrated that in rat liver, enzymes with a short in $p w_{0}$ intracellular turnover rate were especially vulnerable to proteolytic attack as measured by the loss of activity in vitwo. 
In contrast to the long 1 ived enzymes th wyo, which were nore resistant to proteolytulc attack in vituo.

In chapter VII we demonstrated that there is no relation between in ve clearance rates from the cixculation and $n$ vitho thermal stability of the enzymes.

However from above mentioned relations no important indications on the mechanism of enzyme clearance from the circulation have become apparent.

Until now the only well documented clearance mechanism is the rapid elimination of asialoproteins from the cixculation. More11 et al. (1971) and $\mathbb{R i j k} e t a l$. (1970) demonstrated that upon injection into rats all of the desialylated plasma proteins (ceruloplasmin, haptoglobin, $2_{2}^{-m a c r o g l o b u l i n ~ e t c .) ~ w i t h ~ t h e ~ e x c e p t i o n ~ o f ~}$ transferrin were promptly removed from the circulation and were recovered in the iver. The removal of sialic acid residues provides a means by which defective molecules can be recognized and quickly catabolized by the liver. Asialoproteins bind to specific receptors on the liver parenchym cells, from which they could be recovered apparently intact. Homogenated liver tissue binds desialylated proteins with great avidity, whereas rat tissue. of the kidney, heart and brain exhibits no affinity to the modified proteins.

More11 also demonstrated that the uptake of aslaloproteins by the liver was not inhibited by fully sialylated proteins or thelr glycopeptides. Denatured albumin a potent agent. of hepatic Kupferer cell uptake was without effect on the clearance of asialoproteins. Sodetz et az. (1976) demonstrated that infusion of asialo-o 1 -glycoprotein, a protein known to bind to hepatic asialoglycoprotein receptors, dramatically extended the intravascular survival time of asialio 125 IFactor VIII/von Willebrand Factor.

Although it has not been demonstrated, whether the removal of silic acid residues $\mathbb{1 s}$ of physiological significance, the presence of receptors specific for a group of proteins with common characteristics is a very attractive mechanism as compared to a separate clearance mechanism for each protein present in the circulation. The presence of such receptors specific for a group of enzymes with common characteristics are to be examined.

However the exact sites and mechanjsms of enzyme clearance not necessarily have to be known for the cuantitation of tissue damage from increased enzyme levels in plasma. In those studies it is essential. 
to obtan the cleaxance rate ard the total distribution volume of the enzynes.

From studies on albumin turnover (Schultze et al., 1966, IT.2.) and enzyme clearance from the circulation (II.3.), it has been conciuded that protein clearance from the circulation is a first order rate process and that the clearance is strictly regulated by the protein levels in plasma, $i$. there is no extravascular breakdown.

From intramuscular injections of enzyne activity we conclude that at least 75-85: of the enzyme activity injected in the muscle is released in plasma, (chapter VI). Enzyme rellease from muscle continued. to up to 40-50 hours. Even for Ast an enzyme with a half-life of 3 hours as estimated from plasma curves after intravenous injection of the activity, release in plasma after intramuscular injection continues to up to 40-50 hours. These results indicate that the extravascular breakdown rate or local inactivation rate must be extremely small as compared to the clearance rate of AST activity from the circulation.

Moreover immediate blockade of enzyme clearance as observed for several enzymes after injection of zymosan (II.5.) also suggests that enzyme clearance malnly occurs at sites along the vascular bed and not in the extravascular space.

\section{C. Catabolism of damaged maeromotecules}

Early turnover studies, carried out with labeled proteins or wth purified enzyme preparations have been misleading because it was not realized that even the slightest damage to a protein molecule may cause a complete alteration of its metabolic fate. In the present section special attention is therefore payed to the clearance of danaged macromo lecules.

In most studies on the turnover of plasma proteins isotoplcaily labeled proteins are used. The most frequently used labels are: ${ }^{13} I_{\text {r }}$ $15 \mathrm{~N}, 14 \mathrm{C}$ and ${ }^{35} \mathrm{~S}$. The values reported in the 11 terature for the biological half-life of albumin cover a wide range, depending in the first place on the type of label used (schultze et $a 2$, 1966). For biosynthetic labels ${ }^{15} \mathrm{~N},{ }^{14} \mathrm{C}$ and ${ }^{35} \mathrm{~S}$ slow clearance was found as compared to clearance of 13 I-labeled plasma proteins, suggesting that biosynthetic labeling causes less molecular damage. However one of the main problems concerning biosymthetic labels is reutilization 
of the label, resulting in an underestimation of the half-life. For II-labeled plasma proteins used in turnover stuales it has been demonstrated that in watro labeling proceaures may induce subtle alterations in the protein molecule. Freeman (1959) and Berson et a:. (1953) denonstrated that most of their lots of ${ }^{131} \mathrm{I}$-labeled albumin, contained variable guantities of rapidly degrading components due to self-irradiation damage. The major components in the best lots were degraded at a rate of about $4 \%$ per day or less, which agrees with turnover values for albumin with biosynthetic labels. As a rule the true half-life of a plasma protein was assumed to be approximated by the longest values obtained for radiolodine and by the shortest values for the biosynthetic methods of labeling.

For $131 \mathrm{I}-\mathrm{albumin}$ Freeman (1959) demonstrated that iodination of albumin should be minimal, not exceeding the ratio of one atom of iodine per molecule. The damage due to self-irradiation can be minimized by diluting the preparation with unlabeled protein.

To eliminate rapidly degrading fractions of damaged nolecules the biological filter method was developped (McFalane, 1963). This invalves intravenous injection and successive harvesting of the injected substance from plasma. These socalled bjologically screened preparations are used for turnover studies. This method can however not be used for experiments in humans. Until now no simple method is available to detect subtle alterations in the stability and homogeneity of protein preparations used for in wivo turnover studies.

Several authors have attempted to characterize the alterations in the protein molecules that give rise to rapid clearance. Berson et al. (1953) and Rossing et az. (1967) demonstrated the relative insensitivity of electrophoretic, chromatographic and ultracentrifugal methods in the detection of alterations in albumin molecules. only heavily labeled albumin gave some evidence of heterogenelty upon electrophoretic or ultracentrifugal analysis (Berson et $a$. , 1953 and Fahey et at., 1958). Rossing et a . (1967) compared two different albumin preparations, one prepared by alcohol fractionation (SS-albumin) and the other prepared by salt fractionation (BW-albumin). These preparations were studied both in wivo and in vitro. Paper-, immumo-, moving boundary electrophoresis gel filtration and ultracentrifugation revealed that both preparations contained at least 90 of monomeric albumin. Simultaneous injection of $S S-125 \mathrm{I}-\mathrm{albumin}$ and $\mathrm{BW}-{ }^{13} \mathrm{I}$ albumin or SS-13I I-albumin and BW-125 I-albumin resulted in a higher 
metabolic clearance rate and distribution volume of the SS-albumin $(\mathrm{p}<.001)$. These results appeared therefore to be independent of the label used, but to depend on the method of isolation of the albumin preparation.

The rapid clearance of partially damaged proteins as mentioned above can be seen as a protection of the organism against damaged or otherwise changed molecules. Rapid clearance from the circulation was also observed in several studies on the clearance of enzymes after bolus injection (table II). For alkaline phosphatase (Clubb, 1965), AST (Wakim at $a t, 1963$ ), LD-5 (Qureshi at $a z, 1976$ ) and human clot-

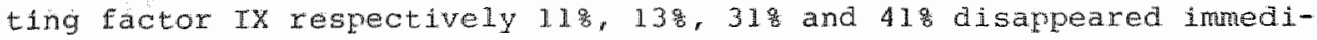
ately after injection of the enzyme preparations. For CK we demonstrated that disappearance of 10 of the activity, immediately after injection in the dog was caused by an inhibition of enzyme activity in plasma. As has been described in II.3. in several studies (Shell et al., 1971; Sobel ef al., 1977; Boyd et at., 1967 and qureshi et a 2. 1976) this raptid elimination of enzyme activity from the circulation has been interpreted erroneously as a distribution of enzyme over different compartments.

In chapter VII we demonstrate that the thermal inactivation rate of enzymes at higher temperatures is very sensitive to inhomogeneities and instabilities of enzyme preparations. Intra-individual variation in $A S T$ clearance rates appears to be greatly reduced when homogeneous enzyme preparations of the same thermal stability are used.

Bernacerral et al. (1957) showed that when denatured proteins and carbon particles are administered simultaneously, there is prefexential uptake of the protein and the rate of removal of the carbon from the blood is temporarily decreased. Freeman (1958) demonstrated that both in the living animal and in the perfused liver, carbon injections resulted in large reduction of the rate of uptake and breakdowm of thermally denatured proteins.

proteins subjected to various forms of denaturation are known to be catabolized by the reticuloendothejidi system and predominantly in the Kuptfer cells. When fluorescein-conjugated proteins were used, the dye was detected in the Kupffer cells only (Freeman, 1958). Gordon al. (1957) also found a much higher catabolism for denatured $13 \mathrm{I}$-albumin by the perfused rat liver $i n v i t x^{2}$, as was found for undenatured biologically screened albumin. He showed that the 
liver plays an important role in the clearance of partially denatured material; 80-1008 of 1 mg of heat denatured albumin is cleared in the Iiver, whereas the liver accounts to as much as 12-18 to the catabolism of biologically screened albumin (Cohen eta.; 1958). It was also shown that blockade of the RES with carbon particles does not decrease the rate of breakdown of biologically filtered albumin although it significantly reduces the rate of breakdown of heat denatured albumin.

\section{II.7. Felation between cell death and enzme peloase}

permeability of the cell membrane is a necessary condition for the release of enzymes into plasma. In case of exo-enzymes, enzymes may be excreted actively. Contrasted with this is a passive release of enzyme. We shall be concerned with the passive release of enzyme. under physiological conditions the cell membrane retains intracellular enzymes at high concentrations, while extracellular enzyme activities are extraordinarily low.

Not much is known on the mechanism of retention of macromolecules in the cell. It is likely to be a function of the size of the membrame pores and the charge of the membrane components on the one hand and of the protein on the other.

Maintainance of a physiologicaliy intact memorane requires energy on part of the cell. Disturbances of the permeability of the cell membrane may be the result of an insufficient oxygen supply to the cell. membrane. Henley et a 2 . (1969) found that heavy muscular activity resulted in considerable changes in the distribution pattern of serum enzymes. The pattern resembled that of the enzyme distribution pattern of skeletal muscle. It appears that physiological anaeroblosis of skeletal muscle leads to a change of membrane permeability. It is presently unknown whether this change in permeability is reversible. Lohr et al. (1959) demonstrated a critical ADP/ATP ratio, above which the continuity of the cellular membrane can no longer be maintained and hemolysis occurs. Zierler (1958) demonstrated aldolage eftux from peroneus longes muscle in young rats in glucose free medium and due to anoxia. Aldolase efflux was also greatly increased in muscles that had been stimulated. The amount of aldolase appearing in the medium could also be increased by agents that alter the muscle metaboIism; iodoacetate, dinitrophenol or cyanide. Dawson (1966 a,b) measured the rate of exit of seven glycolytic enzymes from chicken biceps 
into physological saline. It was found that the erymes left whe masle at approxlmately the same rate in spite of the wide variations in molecular weight and tissue concentration.

Pathological condtions may amage the incact cell membrane reversibly or irreversibly. Irreversible damage to the cell is identical whth cell death.

After an infarction, when the myocardium is deprived of both oxygen, and glycolytic substrates like glucose and glycogen, intracellular energy depletion and increasing levels of waste products will soon leac to severe cellular injury. This has been studied in a variety of cardiac preparations perfused with eithex deoxygenated blood (Bornet et at., 1977) or with axygen-free perfusates (weissler, 1968; Hearse et al. , $1975 \mathrm{a}, \mathrm{b}$; Ganote et $22 ., 1975,1976$ ). It has been shown that when the period of anoxia is terminated by perfusing a preparation with an oxygenated substrate-containing perfusate a paradoxical acceleration of cell damage occurs, socalled repertusion damage.

For the quantitation of tissue damage from increased plasma enzyme levels it is important to know whether (1) there may be leakage of enzyme from cells which are not dying and (2) whether incomplete enzyme release from necrotic tissue or local inactivation, $i$, e. inactivation before the blood stream is reached occurs.

Van der laarse (1979) investigated whether enzyme release reflects impairment of the cellular structure and function in rat heart cells in monolayer cultures. The authors concluded that the activity of HBD released from the culture is closely related with both functional damage (assessed by measuring depression of post anoxic frequency of steady-state beatingl and structural damage. It was concluded that a transient period of amoxia lasting 3 hours or less causes necrosis of a number of cardiac cells in culture (irreversible injuxy), leaving the other celis still wable (reversible injury). After 16-20 hours cells had become totally depleted of enzyme.

Nordbeck at. (1977) demonstrated that myocardial lymph under normal conditions shows a distributiom of the LD and CK isoenzymes specific for heart muscle. Furthermore the concentrations of all determined enzynes in lymph are higher than in plasma, while the concentration of total protein, not only of globulin, but also of albumin in lymph is lower than in plasma. It was concluded that enzyme release 1 a normal physiological process. Hearse et a 2 . (1979) concluded however that for the heart the onset of myocardial enzyme re- 
lease indicates the onset of irreversible damage. The above mentioned controversy is still unsolved.

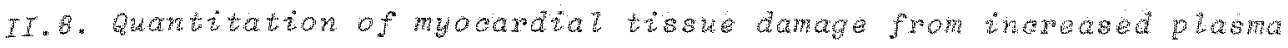
ename tevels

In 1954 LaDue et $a z$. reported that after myocardial infaxction AST activity in human serum is increased. This observation has been confirmed and accepted by many authors. Further investigations showed that apart from the increase in AST activity other enzymes such as CK, HBD, LD, GPI and ALD 1 so show increased levels in serum. This elevation of plasma (serum) enzyme activity can be ascribea to a release of enzyme from necrotic cells. A number of authors have demonstrated loss of enzyme from infarcted areas of cardiac muscle after coronary occlusion with simultaneous increase of enzyme levels in serum (Nydick et al., 1955; Strandjord et at., 1959 and Kjekshus at al., 1971). Several authors investigated the rellation between enzyme release and infarct size. In these studies aspartate aminotransferase (AST) and lactate dehydrogenase (LD) were measured in dogs during the acute phase of experimentally induced myacardial infarction and the results were related to infarct size as assessed morphologically post-mortem (Agress at al., 1955; Nydick et $a b, 1955$ and Reugsegger et al., 1959). In these studies a significant al though not impressive correlation was found between peak levels of the enzymes in plasma and morphologically assessed infarct size. Comparable results were obtained in human studies (Kibe et at. , 1967; Meurman et a2., 1963 and sjögren, 1970 ).

With the exception of one investigation (Meurman etal. "1963) where clearance rates from the circulation were alxeady taken into account. these studies also used only maximal serum activities and the fact that correlations were insufficient to allow accurate determination of infarct size in individual cases was attributed to such factors as insufficlent sampling, differences in clearance rates and non cardiac sources of enzyme release.

Since the observation by Dreyfus et at. in 1960 , that CK is elevated in serum of patients with acute myocardial infarction, attention in infarct diagnosis is mainly focussed on this enzyme, because it $1 s$ predominanty found in myocardial and skeletal muscle and only negligible amounts are found in liver, kidney, lung and intestine. ck plays a role in the metabolism of high energy phosphate compounds in- 
timaly related to the process of muscle contraction. The specific isoenzyme CK-MB has becone very important in the diagnosis of myocardial infaxction. In man about 14 of total ck activity in heart tissue consists of this heart specific isoenzyme, whereas in dogs and baboons, arimals Exequenty used in expeximental studies on myocardial infarction, respectively 2 (chapter III) and 18 if (Yasmineh et at. 1975,19761 of total CK consists of CK-MB.

Kjekshus et al. (1971) showed that myocardial ck activity is reduced in whole left ventricular homogenates of the rabbit heart within 24 hours aftex experimental coronary occlusion. Although depression of CK activity is linearly related to the proportion of infarcted tissue a considerable scatter was demonstrated. This may well reflect the difficulty in excising infarcted tissue, as judged by morphological changes. These results partly explain the rough correlations observed between enzymatically estimated infarct size and morphologically assessed infarct size (Roe et a $2,1975,1977$ and Jarmakani et $a z$. $1976 \%$.

Serum myosin light chains (Trahern et al. "1978) and myoglobin (Sylven et al., 1978) have also been advocated as sensitive markers in the diagnosis of infarction.

The first study concerning guantitation of myocardial infarct size, where diffexent compartments were taken into account was performed by witteveen et al. (1970, 1972). The authors used a two-compartment model in which the change in enzyme activity is described in terms of release of enzyme from the infarcted area, intravascular and extrawascular volumes, the diffusion constant governing the passage of enzymes between intravascular and extravascular space and the disappearance constant expressing the rate at which the enzyme is broken down (table IV). The model is based upon turnover studies in man. The total release of enzyme was expressed in grams of myocardial tissue and was calculated for CK, HBD and AST. Correlation between the amounts of enzyme are: HBD/AST $=0.88 ; \mathrm{HBD} / \mathrm{CK}=0.63$ and $\mathrm{AST}: \mathrm{CK}=$ 0.64 (witteveen et $a t .1972$ ).

In experimental studies both poor (Jarmakani et $\mathrm{t} z, 1976$ and Roe et a., 1977) and good correlations (Bleifeld et a . 1977) between the morphological assessment of infarct size and the calculated total release of $\mathrm{CK}$ in the circulation have been observed. Estimation of infarct size strongly depend upon the specific model. used and each parameter influences the final estimate of infarct 
size. In the study by Roe da a. (1977) enzymatio infarct size (RIS) as calculated according to the model parameters by shell at at. (1971), Norris et at. (1975) and Roberts et ad. (1975) was related to histologically assessed infarct size (HIS) (see table III).

Table III Enzynatic estimation of infarct size, based on a one-compartment model.

Enzyatic Infarct size $=\frac{o^{t} f(t) d t \cdot K_{W} \cdot B W}{C K_{D} \cdot K_{R}}, E(t)=\frac{d E}{d t}+k_{d}$

Sheil et at., 1971

norris etat. 1975

Roberts et at. " 1975

\begin{tabular}{|c|c|c|c|c|}
\hline \multicolumn{5}{|c|}{ recommenaed parameter palues } \\
\hline $\operatorname{kg}\left(\mathrm{n}^{-1}\right)$ & $K_{\text {W }}$ & $\mathrm{CK}_{\mathrm{D}}(\mathrm{U} / \mathrm{g} x)$ & $\mathbb{K}_{\mathrm{R}}$ & species \\
\hline 0.27 & 0.114 & 800 & 0.30 & dog \\
\hline from curve & 0.114 & 800 & 0.30 & maิก \\
\hline Erom curve & 0.044 & 800 & 0.15 & $\operatorname{dog}$ \\
\hline 0.06 & 0.05 & 1105 & 0.15 & 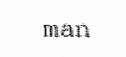 \\
\hline
\end{tabular}

Bleifeld et $a, 1977$

$K_{\mathrm{R}}$ : the ratio of the amount of enzyme entering the serum, compared to the amount of enzyme depleted from the myocardium.

$K_{W}$ : the designation for the percentage of body weight (BW) in which enzynes are distributed. Therefore $f^{t} f(t) d t . K_{W}$. BW represents the total anount of enzyme in the distribution space ( $K_{W}$. BW $)$.

$k_{a}$ : apparent cleaxance constant $\left(\mathrm{h}^{-1}\right)$.

$\mathrm{CK}_{\mathrm{i}}$ : the estimated amount of enzyme (U) clepleted per gram of infarcted myocardiun $(\mathrm{U} / \mathrm{gr})$.

E : enzyge activity $(0 / 1)$.

Especially for the larger infarcts poor correlations were observed between EIS and HIS. It has however been demonstrated that CK shows accelerated denaturation in lymph (Robison et al., 1975 and Clark et a.. 1978). Crains et at. (1978) found an inverse relation between the ratio of the amount of enzyme entering the plasma pool to the aw mount of enzyme depleted from the myocardium $\left(\mathrm{K}_{\mathrm{R}}\right)$ and Ers. It was postulated that prolonged contact of $\mathrm{CK}$ with cardac lymph during siow transport from the centex of a large zone of homogeneous infarction might lead to extensive local inactivation of enzyme activity. Above mentioned results may clarify why in the study by Roe et at. (1977) better correlations between HIS and ErS were found for the smaller infarcts. This explanation is however in contradiction with the observation by spieckermann et al. (1979) that only 15 of the encyle is transported by lymph. 
As for the other model paramerers presented in table IT the model by shell et a. (1971) is based upon bolus injections of Ck preparations in dogs and consists of a one-compartment model with a total distributlon volume ( $K_{W}$. BW), which is almost three times plasma volume. In the model by Morris at a (1975) individualized clearance rates $(\mathrm{k})$ were obtalned from the final part of the CK clearance curve after myocardial infarction. For the distribution volume the same value as observed by shell et az. (1971) was used.

The model by Roberts et al. (1975) was a one-compartment model including plasma volume only and individual clearance rates were obtalned as described by Norris et al. (1975).

As stressed by 5 lutsky $(1978)$, individually estimated values for $\mathrm{k}_{\mathrm{d}}$ contain errors, because when $C K$ appearance in the circulation is tailing, plasma ck activity weras time may still be mono-exponential. Determination of apparent $c k$ clearance rates from this part of the curve will therefore result in an underestimation of CK clearance rate.

Willems et al. (1979a) demonstrated that release of enzyme from the infarcted area continues even to up to 96 hours and estimation of individual clearance rates of $\mathrm{CK}$ from the final part of the plasma curve results into large underestimations. The obtained value for CK clearance (table IV) was about 3 times higher than the clearance rate reported by Norris et at, and Bleifeld et at. (see table III). wable IV Enzymatic estimation of infarct size, basec on a two-compartment model.

\begin{tabular}{|c|c|c|c|c|c|}
\hline & \multicolumn{5}{|c|}{ recommended parameter values } \\
\hline & $v_{\mathrm{e}} / V_{\mathrm{i}}$ & $\begin{array}{c}\mathrm{TER} \\
(\mathrm{s} / \mathrm{h})\end{array}$ & $\begin{array}{c}k_{C K} \\
(\mathrm{~m}-1)\end{array}$ & & $\begin{array}{l}k E B D \\
\left(h^{-1}\right)\end{array}$ \\
\hline Wtever ot al. 1972 & 0.30 & 6.0 & $0.07 \pm 0.0177$ & 0.015 & $=0.0042^{x}$ \\
\hline Willoms et al., 1979 & $0.80 \pm 0.5^{87}$ & $1.7+1.1^{w}$ & $0.20+0.12^{z}$ & 0.015 & $\pm 0.066^{x}$ \\
\hline
\end{tabular}

mean $+5 D$

He : transcapilary acape rate $(\mathrm{b} / \mathrm{h})$. also indicated as $\mathrm{p} / \mathrm{W}$.

W : extrowacular volume.

W. : intravascular volume.

f. alarance constant.

The method used by willems et at. (1979a) was based upon a two-compartment model with a mean transcapillary escape rate, as estimated from the individuad plasma curves of $1.7 \%$ per hour, which is a factor 
3 lower than the value used by witteween et dz. (1972).

Willems al. (1979b) also concluded that using HBD as an refence enzyne individual clearance constants of CK, AST and GPI can be obtained from the first 36 hours after infarction, when there is stil1 release of enzyme into the circulation. The ratio of the released quantities of different enzymes agreed with heart tissue content. The released quantities of $\mathrm{CK}$ showed considerable variation in proportion to the other enzymes, as is in agreement with the bad results for $\mathrm{CK}$ in other studies (Roe et at., 1977 and Craig et al., 1978).

The method of willems et al. has thus far only been applied to patient curves after acute myocardial infarction. From the experiments presented in chapter VI; quantitation of continuous infusions, we validated that this method can indeed be used to obtain individual clearance rates resulting in an improvement of the quantitations.

Indiwidual variations in enzyme content of nomal myocardium.

In order to obtain the weight of injured tissue in grams, the calculated total activity of enzyme released into the circulation has to be aivided by the mean enzyme activity per gram of normal tissue. selection of enzymes with small intra- and inter-individual variations in tissue enzyme content will therefore minimize errors in the quantitation of tissue damage, due to the use of a mean value for the enzyme content per gram of normal tissue.

In chapter III we examine the distribution of several enzymes in heart and liver tissue of the dog and conclude that CK, LD and GPI can be used to quantitate heart tissue damage and ALT can be used to quantitate liver tissue damage. Variations for samples taken from different sites of the same organ are less tham 5 mo . Inter-individual variations in enzyme activity are less than 10 for these enzymes. Comparable results have been obtained from other studies, although in these studies only a limited amount of data was used (She11 et al., 1971; Witteveen 1972; Witteveen et al., and Hermens $e$ ab., 1979). Further details on this subject will be given in chapter III.

Factors that prevent enzymes from reaching the blood steam.

Incomplete recovery of enzymes from necrotic tissue in blood can be caused by incomplete cellular release or by local denaturation. 
6. e. Inactivation before the blood stream is reached. Localization 1.y organelles or adsorption to local structures can retard release of enzymes and enhance the possbility of local denaturation. For instance it has been shown in rat myocardium that mitochondrial ck was not released irto the circulation after hypoxic damage (Baba et al., 1976) and the same phemomenon was demonstrated for mitochondrial Ast aftar infarction in dogs (Malmberg, 1973). Even cytoplasmic enzymes undergo a time delay in their release into the blood, caused by impalment of the local circulation and this increases the possibility of local denaturation (CLark ot a2., 1978).

From studies on cultures of beating rat heart cells (Van der Iaarse et al., 1975 and 1978l it has been concluded that enzyme release Exom myoblasts in these cultures started about 3 hours after anoxia and lasted for 16-20 hours, after which time the cells had become totally depleted of enzyme. Release of CK and HBD after anoxia in rat heart cell cultures xuns completely parallel $(x=0.996)$. However $\mathrm{CK}$ was inactivated much more quickly than was HBD.

Studies on experimental infarction in dogs have shown that although cardiac lymoh obtained directly after experimental infarction showed the same enzyme composition as cytonlasmic heart extracts (Malmberg, 1973), CK shows accelerated denaturation upon in witpo incubation of dog lyroh in contrast to HBD (Robinson, 1975), while interuption of carajac lymph flow resulted into significantly less $C K$ anpearing in plasma (clark et a 2 . 1978). These data are supported by a study on in vitro enzyme release from human myocardium (Hermens et al., 1975), showing that $A S T, C K$ and $H B D$ are released in quantities representing $35 \%, 43 \%$ and $82 \%$ respectively of the amounts originally present. only for $\mathrm{HBD}$ could the remaining $18 \%$ be recovered in the residual tissue. For AST and CK only $33 \%$ and 168 could be recovered in the tissue, limplyng that 32 and 42 were respectively inactivated locally. This shows that HBD is remarkably stable compared to AST and CK. Blelfeld at a . (1977) demonstrated that 15 of of CK depleted from the myocaidfum reaches the circulation. Taking however parameter values as estimated by willems et al. (1979a), 50 of the quantity of both CK and HBD is recovered in the plasma of patients ("Table TV).

Rapid washout of enzymes, as is characteristic for reperfusion, leaves no tine for local denaturation. This rapid washout should therefore cause a marked increase in the total amount of CK released. Such an increase should become apparent by comparing the total amount of ck released to the total release of $\mathrm{HBD}$, which is not subject to 
Iocal denaturation. This was tested by comparing patients with acute mocardial infarction with patients undergoing heart surgery. skeletal muscle damage is present in the surgery group the specific isoenzyme CK-MB was compared to HBD. Determination of the linear regression equations between calculated amounts of CK-MB and HBD gave the fallowing ratios: Infarction group $0.27 \pm 0.08$ (n=17) and in the surgery group $0.23 \pm 0.03(\mathrm{n}=32)$, indicating that no significant inactivation of CK-MB occurs (Hermens et $a t, 1979$ ).

From in wivo experiments in dogs (Roberts a $2 \%$, 1975) 1t was calculated that 24 hours after myocardial infarction 118 of ck activm ity originally present in the infarcted tissue had reached the blood stream, while 26 rema ined in the myocardium. This implies that 63 \% of the original CR activity was not recovered. Using a different model to study enzyme release in patients with acute myocardial infarction (Witteveen, 1972) it was calculated that AST" CK and HBD are released in quantities representing 258,45 and 80 is respectively of the amounts originally present in the damaged area. Considering the discrepancies between $i n v i r o$ and $i v$ vivo recovery of $\mathrm{CK}$, one has to keep in mind that in vivo results strongly depend upon the parameter values of the circulatory model used, such as the magnitude of the extravascular pool and the rate of exchange of enzyme between the vascular and extravascular space (Hermens, 1975).

From the results presented by Hermens et $a$. (1979) and w11ems et $a i$. (1979) and from the experiments presented in chapter VI it can be concluded that in order to minimize errors in calculations of enzymatic infarct size, one should use enzymes that are slowly metabolized and show a complete washout from the infarcted tissue. In both respectes $\mathrm{HBD}$ is to be preferred to $\mathrm{CK}$ for quantitation of myocaralal infarction in man.

\section{References}

1. AGRESS, C.M., Jacobs, H.I., Glassner, H.F., Lederer, M.A., Clark, W.G. Wroblewskd, F. Karmen, A., and LaDue, J.5.: Serum txangaminase Level in experimental myocardial infarotion.

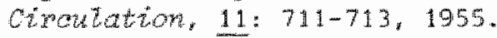

2. ALISON, A.C.: Turnover rate of albumin in various specles in trelation to body weight.

Watine, 37: 188, 1960 .

3. AMELUWG, D.: Untersuchungen zur Grösse der Eliminationgeschwindigkelt wor Fermenten aus dem Kaninchenserum.

2. Physiol. Chem, 319: 219-228, 1960 . 


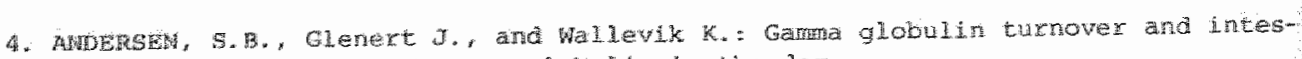
tinal degradation gatwa globwin in the dog.

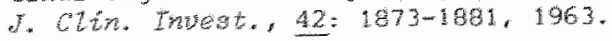

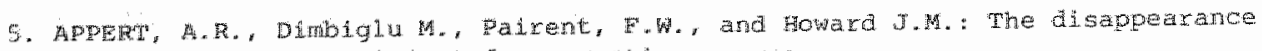
of intravenous iy injerted pancreatic enzyes.

Surg. Gyecot. Obotetn, $127: 1281-1297.1968$.

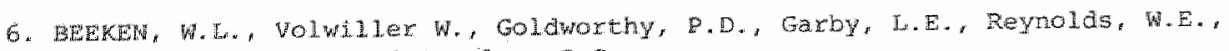
strogsdill, fa, and stemler, R.S.

J. GLt. Truest., 41: $1312-1333,1962$

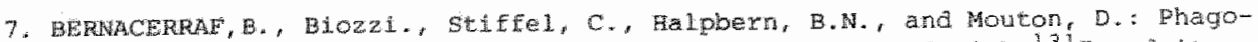
cytosis of heat denatured hum serum albumin abeled with 13 and its use as a means of investigating liver blood fiow.

br. J. Fop. Pathot, $38: 35-48,1957$.

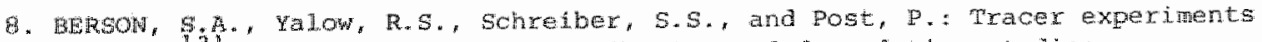
with i3l laboled albumin: distribution and degradation studies.

f. Cutr. Thuegt., 32:746-763, 1953 .

9. BLATNEY, J.D., and Northam, B.E. A Amylase excretion by the humen kidney. Cin. Sot. 32: $377-383,1967$.

10. BLOOM, H.G.J., crocket, D.J. and stewart, F.S.: The eftects of radiaton or the stablity of rado-iodinated human serum album.

Br. J. Radiot., 31: 377-383, 1958.

11. BOND, J.S.: A comparison of the proteolytic susceptibltily of sevexal rat livex enzymes.

growhem. Biophys. Tes. Comm, 43: 333-339, 1971.

12. BoRleT, E..., Wood, J.M., Goldstein, M.A., Entruan, M. L. , Lewis, R.M., Durn, F. A. and schwaxtz, A.: physiological, biochemical and morphological characteristios of myocardial anoxia: the use of a semi-perfusion cianine preparation.

Gridrovara. Rea., 11: $568-575,1977$.

13. BOYD, J.W.: The rates of disappearance of L-1actate dehydragenase isomzymes from pilasma.

Ame. Thterm. Med., 70:799-805, 1969.

14. CASLEX-SMIRH, I. R. : The fine structure and functions of blood capillaries, the interstitial tissue and the Lymphatics. Prgebnisse der Angiologie 12: Basic Lymphology Ed. M. Fäldi, Schattauer Verlag stuttgart, 1976.

15. CLARK, G.I., Robinson, A.K., Gnepp, O. .., Roberts, R., and Sobel, B.E.: Effects of lymphatic trangort of enzyne on plasma creatrie kinase themativity curves after myocardial infarcton in dogs.

crog. Rea., 43: 162-169, 1978 .

16. CugB, J.S." Neale, F.C., and posen, S.: The behavioux of infused human placental akdine phosphatase in human subjects.

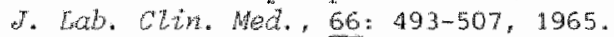

17. COHEN, S., and Coraon, $\mathrm{A}$. H. Catabolism of plasma albumbin by pertused rat lliver.

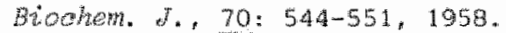

19. CRATNS, I. A. Missirlis. E., and Fallen, E. L.: Myocaralal infarction size Eran serial cpk: variability of CPK serum entry ratio with size and nodel of infacotion. Circulation, 58: 1143-1153, 1978.

19. DAwson, M.D.: Leakage of enzymes from denervated and dystrophic chicken muscle. Arch. Newnol. 14: $321-325,1966 \mathrm{a}$. 


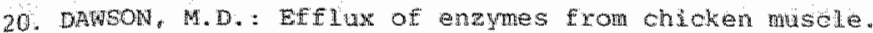
Brochan, Diophys. Acta, 113: 144-157, $1966 \mathrm{~b}$

21. DAHSON, N.1.,Alper, C.A., Seidman, J., and Mendelsohn, J, Measurement of parum entyme turnover rates.

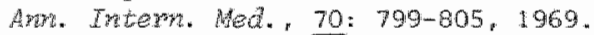

22. DEHLINGER, P.J., and Schime, R.T.: Effect af sire on the relatwe xate of degradation ot rat 1 iver soluble proteins.

Biochen. Biophys. Res. Comman, 40: 1473-1480, 1970.

23. DTCE, J.F., and Goldberg, A.H.: A statistical analysis of the relationship between degradative rates and molecular wightes of proteins.

Arah. Brochem. and Buphys., 170: 213-219, 1975 .

24. DONATO. L. . Mathews, C.M.E. "Nosslin, B., Segre, G. "and Vitek, F.: Applioations of tracer theory to protein turnover studies. Round table conference: J. Met. Biot, 10: 3-30, 1966.

25. DREYFUS, J.C1., Shapira, G., Rencus, J. "and Scebat, I.: Rev. Fr. C2in. Biol. 5: 384, 1960.

26. DUNN, M., Maxtins, J., and Reissman, K. R. : The disappearance rate of glutamid oxalacetic transaninase from the ciroulation and its distribution in the body's fluid compartments and secretions.

J. Lab. G Cin. Wed., 51: 259-265, 1958.

27. FAHEY, J.L., MCCOY, P.F., and Goulian, M.: Chromatography of serum proteins in normal and pathologic sera: The distribution of partein-bound carbohydate and chollesterol, siderophilin, thyroxin-binding protein, alkaline and acid phosphatases, madiojodinated albumin and myelome proteins. $J_{*}$ Clin. Invest., 37: 272-284, 1958 .

28. FLEISHER, G.A., and wakim, K.G.: The fate of enzymes in body Eluids, an experimental study: I. Disappearance of glutamic-pyruilc transaminase under various conditions.

t. Lab. Clan. Tnpest., 61: 76-85, 1963.

29. FLETSHER, G.A., and wakin, K.G. "The rôle of the small tntestine in the disposal oE enzymes from blood.

Enzym. Bzoz. Clin. 9: B1-96, 1968 .

30. PREEMAN, T. Gordon, A.H., and Humphrey, T.H.: Distinction between catabolism of native and dematured proteins by the isolated perfused jiver aftex carbon loading.

Br. J. Exp. Pathol. 39: 459-471, 1958.

31. FREEMAN, T.: The biological behaviour of norinal and denatured human plagma albumin.

CLin. Chm. Acta, 4:788-792, 1959.

32. GANOFe, C.E., SeabramGomes, R., Nayler, W.G., and Hennings, R. B.: Irreverstble myocardial injury in anoxic perfused rat hearts.

Am. Fathot. Bo: 419-450, 1975 .

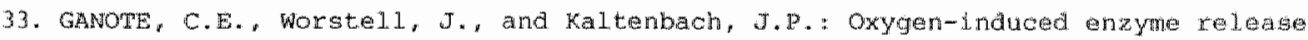
and irreversible myocardial injury: Effects of cyande in perfumed rat hearts.

Am. T. Pathot., 84: $327-350,1976$.

34. GITIN, D., KLinenberg, J.R., and Hughes, W.L.: Site of catabolism of serum alburin.

Nature, 181: $1064-1065,1958$.

35. GoLDSWORTHY, R.D., and Volwillex, W.: Mechanism of protein turnovex studled with cystine- $35 \mathrm{~g}$, lysine- ${ }^{14} \mathrm{C}$ doubly labeled plasma proteins in the dog. J. Biol. Chem., 230:817-831, 1958. 


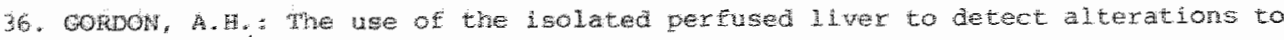
plastitid protelns.

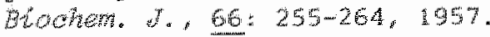

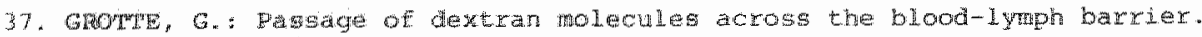

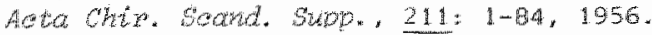

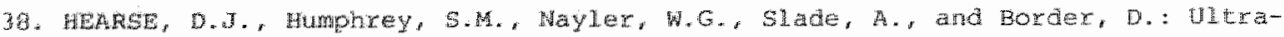
stuctural danage associated with reoxygnation of the aroxic myocardin. I. Wot. Celt. Candiol. 7: 315-324, 1975a.

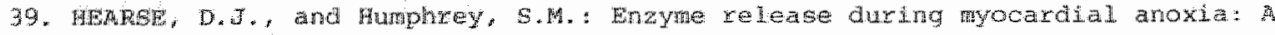
study of metabolic protection.

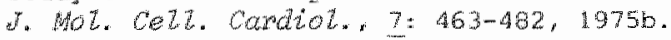

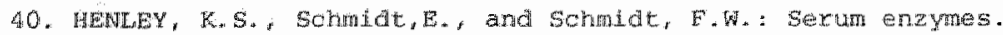
\%. Ari Hed. Asboe., 174: $977-991,1960$.

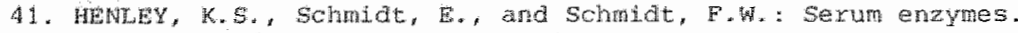
Wtin. got. 174: 119-123, 1960.

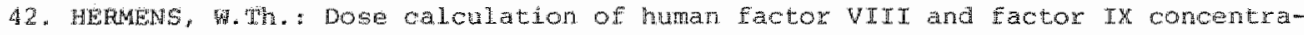
tes in Handbook of Hemophilia (Eds. Brinkhous, K.M. and Henker, B.C.), Merlean Elsevier Publishing Company, New York, 1975, pp. 569-589.

43. Hempos, W.Th., and witteveen, S.A.G.J.: Problems in estimation of intarct ize.

J. Mol. Med., 2:233-239, 1977.

44. WRMENS, W.Th. Van der Laarse, A., and witteveen, S.A.G.J.: Enzymatic intarct sizing: factors influencing the cholce of the marker enzyme.

Enzymes in dardiology, diagnosis and research. D.J. Hearse; I. Wiley sons Iimiterd, $339-353,1979$.

45. HISS, B.: Enzymes in blood. Academic Press. New York and London, 1963.

46. HOPGOOD, M.F., and Ballard, J.F.: The relative stability of liver cytosol enzymes incubated in witwo.

Biochem. I. 144: 371-376, 1974 .

47. JARMAKANI, J.M., Limbird, L., Grahan, T.C., and Marks, R.A.: Effect of repexfuslon on myocardial infarct, and the accuracy of estinating infarct size from serum creatine phosphokinase in the dog.

Cordiovase. Bes., 10: 245-253, 1976.

48. JOMES, E.A. Vergalle. J., steer, C.J., Bradley-Moore, P.R., and Kerling, J.M.: Metabolisn of intat and cesialyated 1 -antitrypsin.

Clin. Bat. Mol, Mod, 55: 139-148, 1978.

50. KAld, J. "Rosenfeld, S., and Sellers, R. L. Role of the kidney in plasma albuwilin catabolism.

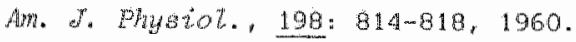

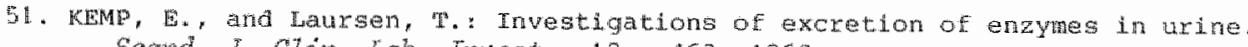

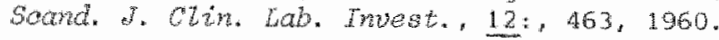

52. KJEKSHUS, I.K., and Sobel, B.E.: Depressed myocardial phosphokinase actillity following experimental ryocardial Infarction in rabbit.

Ciro. Rez., 27: $403-414 * 1970$.

53. LaDUE, J.S., Wroblewsk1, F, and Karmen, A. seateree, $120: 497,1954$.

54. WANDIS, E.M., and Pappenheimer, J.R.: Exohange of substances through the capm illary walls. In handbook of physiology: section 2: circulation. W. F. Hamilon, and P. Dow eds). Chaptex 29 pp. $961-1034$, 1963. American Physiom logical society. Washington DC. 


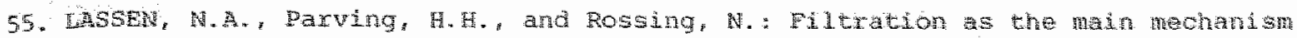
of overall transcapillary protein escape from the plasma.

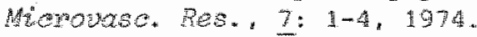

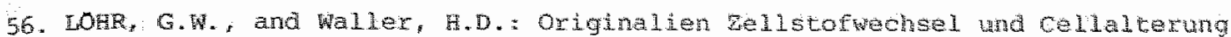

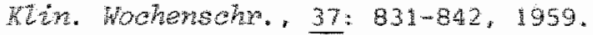

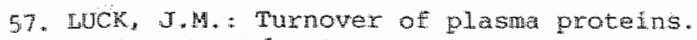
Ar. th. Hed. 20: $317-321,1956$.

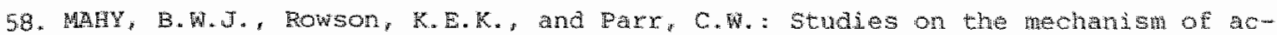
tion of Riley Virus $I V$. The reticuloendothelialsysten and inpaned enzye clearance in infected mice.

J. Bxp. Hed. 125: 277-288, 1967.

59. MALMEERG, P.: Aspartate aminotransferase activity in dog heart lymph after mocardial infarotion.

Soand. J. Clin. Het. Muest., 30: 153-158, 1972.

60. MALMBERG, P.: Enzyme composition of dog heart lymph after myocardial infarcm tion. Upsala.

7. Med. Ser., 78: 73-77, 1973.

61. MAROKo, P., and Vatner, S.F." Alterated relationship between phosphokinase and infarct size with reperfusion in conscious dogs.

J. MoZ. Med. 2: 309-315, 1977.

62. MASARAT, S.: Verhalten und Schwundrate dier Glutamat oxalacetat pransaminase in der Blutbahn.

2. Gesante Exp. Med. 148: 56-71, 1968 .

63. MATHEWS, C.M.E.: The theory of tracer experiments with 131 I-Iabelea plasma proteins.

Physios in Med. and biol. 2: 36-53, 1957.

64. MCFARTANE, A.S.: Catabolism of plasma proteins.

Loncet, 2: 131-132, 1963 .

65. MclendoN, A.: A correlation between myoglobin thermodynamic stabilities and species metabolic rates.

Biochem. Brophys. Res. Commun. 77: 959-966, 1977.

66. McLENDOW, $G$, and Radany, E.: Is protein turnover thermodymamically controlled? J. Biot. Chem. 253: 6335-6337, 1978.

67. MEUPMAN, L., and orde11, R.: Pathophysiological interpretations of serum enzyme activity vs. time curves in mocaxdial infarction.

Scond. J. Gin. Lab. Invest. Suppl., 76: 70, 1973.

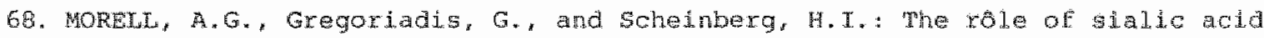
in determining the survival of glycoproteins in the chrculation. J. Grol. Chem., 246: 1461-1467.

69. MORIM, L, G.: creatine kimase lsoenzymes-antibody reactiong in limunoinhibiton and immunonephelometry.

Clive. Chem. 25: 1415-1419, 1979.

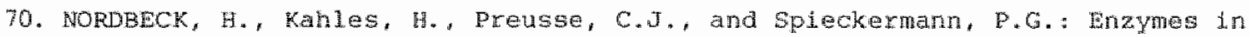
cardiac Iymph and coronary blood under nomal and pathophstological conditions:

J. Hoz. Hed. 2: $255-263,1977$.

71. NORRIS, R.M., Howe11, D., Whitlock, R.M.L., Heng, M.K., and Peter, T.: Enzyme rellase after myocardial infaction: compaxison of serial serum a-hydroxybutyrate dehydrogenase with creatine phosphokinase levels.

Eur. e. Cardiol. 4: 461-468, 1976. 


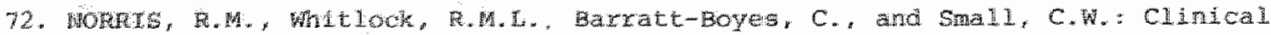

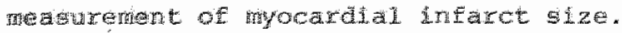

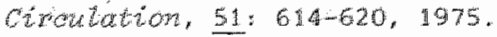

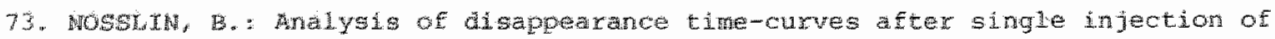
labeled protedns. Protein turnover Ciba Foundation Symposinn 9. Elseviet exerpta hedicai, korth-mollad, $110-130$.

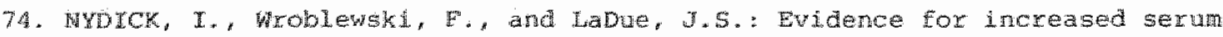
glutamic owalacetc terangminase (SGCP) activity following graded myocardil intarcts in dogs.

Ciraulation, 12: 161-169, 1955.

75. PApprenther, J.R.: passage of molecules through caplinary walls. Physol. Rev." 33: 387-423, 1953.

76. POSEN, 9.: Turnover of circulating enzymes. Clin. Chem, $16: 71-84,1970$.

77. QUREgA, A.R., and Hikinson, J.H.: The Eate of circulating lactate dehydrogenase-s in the rabbit.

Clin. Soi. Hot. Med. 50: 1-14, 1976.

79. RAPAFOR, E. The Eractional disappearance rate of separate creatine phosphom kinase in the dog. Cardionde. Res., 9: $473-477,1975$.

79. FEvVE, E. B., and, Roberts, J.E.: "The kinetics of the distribution and wreakdrun of 131 -albumin in the rabbit.

T. Gen. Prystol. 43: 415-453, 1959 .

80. RENKTN, E.M.: Maltiple pathays of capdllary permeablitity.

Citro. Res., 41: 735-743, 1977 .

81. RIJK, P.P. " and Hamex, C.J.A.: ${ }^{31}$ I-asial-ai-acid glycoprotein. Investigation of its use for liver tests; metabolism in the rat. Lab. Hevtods, B8: 142-150, 1976.

92. RIPFE, B. Kamya, A., and Folkow, B.: Transcaplilary passage of albumn effects of tissue cooling and of increases in filtration and plasma colloid asmotic pressure.

Aota Phystot. Sachd. 105: 171-187, 1979.

83. ROBERTS, R., Henry, P.D., and Sobel, B.E.: An improved basis for enzymatic estimation of infarct size. Crialation, $52: 743-754,1975$.

34. ROBERT, R., and Sobe1, B.E: Effect of selected arugs and thocardial infarction on the disapperance of creatine kinase from the circulation in conscious dog. Cardionas. Res. , 11: 103-112, 1977.

85. ROBISON, A. K, Grepp, D.R., and Sobe1, B.E.: Iractivation of CPK in 1ymph.

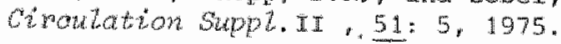

06. RoE, $\mathbb{R}_{, \mathrm{C}}$, and starmer, C.F.A.: A sensitivity analysis of enzymatic estimation ot infatet crimation, 52:1-5, 1975.

97. ROE, R.C., Cobb, F.R., and starmer C.F.: The relationship between enzyatic and histologic estimates of the extent of myocaratal infarction in conscious dogs with permenent coronary occlusion. Corculation, 55: $438-449,1977$.

97. ROSENFELD, S., Katz, J., and SeLLers, A.L.: Effect of nephrectomy on 131 I-a $1 \mathrm{bu}-$ min turnover in the dog.

H. Lab. Clin. Med., 59: 381-386, 1962. 


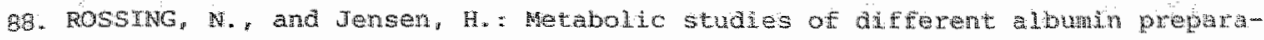
tions.

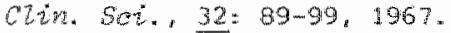

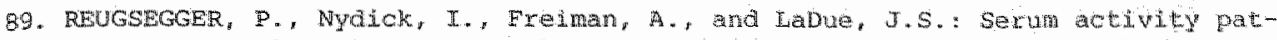
terns or glutamic oxaloacetic tranaminase, glutamic pyuvio transamase and lactio dehydrogenase following graded myocaraid infarotion in aogs. Gro. Res., 7: 4-10, 1959.

90. RUTILI, G., and Arfors, K.E.: Protein concentration in interstitial amd lymphatic Fluid from the subcutaneous tissue. Acta Phystot. Scand. "99: 1-8, $197 \%$.

91. RUTTI, G.: Transpowt of macxomolecules in subcutaneous tissue. studiea by FTTC-dextrans. Acta Universitatis Upsaliensis 306 Thesis, Jppsala, 1978.

92. SAKAI, K., Gebhard, M.M., Spieckemann, P.G., and Hxetschneider, M. . : Engye release resulting from total ischemia and repertusion in the isollateg perfused guimea pig heart.

J. Moz. Cezt. Cardiot., 7: 827-840, 1975.

93. SCHAPLRA, F., Dreytus, J.C., and Schapira, G.: La duré de sej jour dans le plasma de I'aldolase chez le lapin: etude de l'alde d'une aldolase marque a l'ipde radioactif.

Bev. Fr. Etudes Clin. Bet. 7: $829-832,1962$.

94. SCEMIDT, E., and Schmidt, E. W. Dber Anderungen der Substrat-Afeinitit von Malat-Dehyarogenase.

K2:H, Wochenselst, 38: 310-811, 1960 .

95. SCHULTZE, H.E., and Heremans, J.F.: Molecular Biology of human proteins, Chap 2. Elsevier Publishing Compary. Amsterdam, 1966.

96. SHELL, W.E., Kjekshus, J.K., and sobel, B. E. : quantitative assessnent of the extent of myocardial infarction in the conscious dog by means of analysis serial changes in serum creatine phosphokinase activity. J. C2in. Invest., 50: 2614-2625, 1971.

97. SIBLEX, J.A.: Significance of serm aldolase levels. Arm. NY. ACod. Soi., 75: 339-348, 1958.

98. SJOGREN, A.: Left heart failure in acute myocardial infarcion. Aoth Hed. Soand. Suppt., 501: 7-32, 1970.

99. SLUMSKY, A.S.: Individualized values for the disappearance rate parameter k in the enzymatic estimation of infarct size.

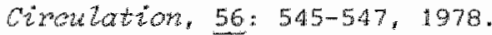

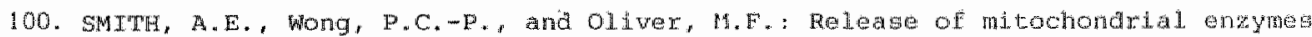
in acute mirocardal infarction. J. Mot. Med. 2: 265-269, 1977.

101. SOBEL, B.E., Markham, J., 掞arlsberg, R.P., and Roberts, R. : Whe nature of: disappearance of creatine kinase from the circulation and its infuence on enzymatic estimation of inevarot size.

Ciro. Res., 41: 836-844, 1977.

102. SODEm, J.M., Pizzo, S.V., and Mokee, P.A.: Relationship of silalid acid to function and in wivo survival of human tactor VIII/ vor Willebrand factor protein.

t. Biol. Chen. 252:5538-5546, 1977 .

103. SPIECKERMANN, P.G., Wordbeck, F. "and Preusse, C.J. : From heart to plasma, Enzymes in cardiology dagnosis and resectroh. D.d. Hearse:

J. Wiley \& Sons Linited, Chapter IV, pp: 81-95, 1979. 


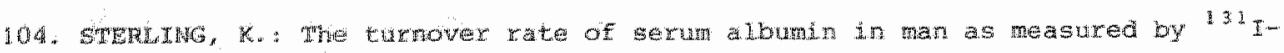
tagged a burian.

4. Ctim. Thuet, $30: 1228-1237,1951$.

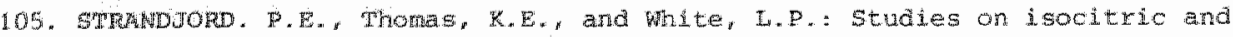
Lacte denydrogenase in experimental mocardal infarction.

J. Ctin. Thuest, 38: 211-2118, 1959.

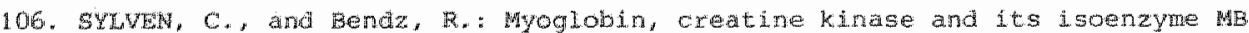
1h arum after acute myocandal infarction.

Wus . T. Cordiol. $3: 515-521,1973$.

107. MKKED, Y., and Rewe, E.

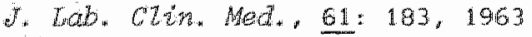

108. Thaver, A. Arnstrong, F., D., Debro, J.B., and Margen, S." Catabolism of plasma protein in the gut. Anti. Wy. Acad. Sat., 94: 23-30, 1961.

109. ThYoR, A.E., Granger, D. N. and Brace, R.A.: Analysis of lymphetic flux data. Wetimation of reflection coefficient and permeability surface area product for total protein.

Mitrovasa. Res., 13:297-313, 1977 .

110. TRAmRN, C.A., Brewster, J. .Krauth, G.H., and Bigham. D. A. : Clinical assessm ment of serum myosin light chains in the diagnosis of acute myocardial intarction.

Am. J. Cardiol. 41: 641-645, 1978.

111. MYTGAT, G. W.: Metabollsm and distribution of fibrinogen in clinical and exper imental conditions. Thesis , Leuven, 1971.

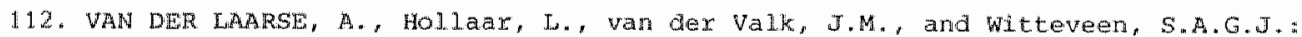
Enzyme release from rat heart culures during anoxia.

W. Hol. Med., 3: 123-131, 1978.

113. VAN DER IAARSE, A. Hollaar, L., and van der Valk, J.M. Release of alpha hydroxybutyrate dehydrogenase from neonatal rat heart cell cultures exposed to anoxid and reoxygenation: Comparison with impairment of structure and Eanction of damaged caxdiac cells.

Cardiovase. Res., 13: $345-353,1979$.

114. VAN DER LAARSE, A., Dijkshoorn, N.J., Hollaax, L., and Caspers, Th.: The (1so)enzyme activities of lactate dehydrogenase, owylroxybutyrate dehydrogenase, creatine kinase and aspartate amimotransfexase in human biopsies and autopsides.

Clin. Chim. Acta. 104: 381-391, 1980.

115. WALKER, W.G., Ross, R. "and Harmond, J.D.S.: Study of the relationship between plasma volume and transcapil1ary proteir exchange, using il I- labeled al-

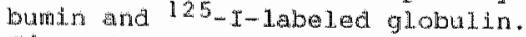

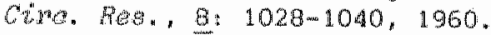

116. WAKIM, K.G., and Flelshex, G.A.: Whe fate of enzymes in body fluids. II. Disappearames of glutamic oxalacetic transaminase $I$ and II under various con ditions.

4. Lab. Clin. Mad., 61: 86-103, 1963.

117. WEISSLER, A.M., Krugez, F.A., Baba, N., Scarpelli, D.G., and Galldmore, J.K.: Roje of anaerobio metabolism in the preservation of the functional capacity and strmcture of anoxic mocardiur.

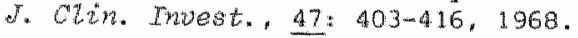

118. WEVERS, R.A., Delsing, M., K1ein-Gebbink, J.A.G., and Soons, J.B.J.: Postsynthetic changes in creatine kirase hoenzymes.

Clin. Chtin. Acta. 86: 323-327, 1978. 


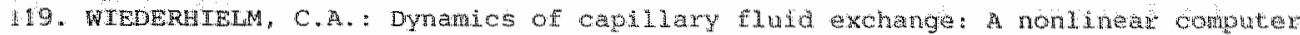
Sinulation.

Wicrovase. Fes. 18: 48-82, 1979.

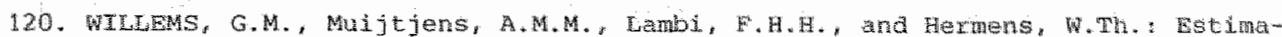
thon of axculating parameters in patients with acute myocamal infaro-

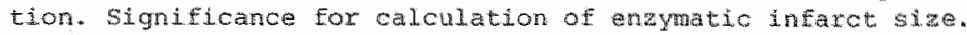

Cordiovase. Res., 13:578-587, 1979.

121. WILLEHS, G.M., and Hermens, W. Th. : quanttated release of a fifent anzyes in pationts wh acute myocardial infarction. (AMI), compared to engym contente in human myocarditum.

J. Mol. Celt. Cardiat. 11 , suppl 2: 66, 1979.

122. WITHEVEEN, S.A.G.J., Hermens, W.Th., Hemker, H.C, anc Holladr, L.: Quantitation of enzyme release from infarcted heart muscle. In Ischemic heart disease (Eds. De Haas, J., Henker, H.C., and Snellen, H.E.), Leiden University press, Leiden, 1970, Pp. 36-42.

123. MITHEVEEN, S.A.G.J. : Assessment of the extent of myocardiall infarction on the basis of plasma enzyme levels. Thesis, Leiden, 1972.

124. WITHEVEEN, S.A.G.J., Hemker, H.C., Hollar, L., and Hermens, W. Mh.: guantitation of infarct size in man by means of plasma erizyme levels.

Br. Heart. J., 37: 795-803, 1975.

125. WhLW, R.S., and Berson, S.A.: Chemical and biological alternations induced by irradiation of 13 Imabeled human serum albumin.

J. Glin. Thvest., 36: 44-50, 1957 .

126. WASM LNEH, W.G., PYle, R.B., Cohn, J.N., Nicolof, D.M. "Hanson, N.Q., and Steels, B.W.: Serial serum creatine phosphokinase MB isoenzyme activity atter myacaraial infarction. Circulation, 55: 733-738, 1977 .

127. YASMIMEH, W.G., and Hanson, N.Q.: Electrophoresis on cellulose acetate and chromatography on DEAE-Sephadex $A-50$. Compared in the estimation of creatine kinase isoenzymes.

citin. Chem. $21: 381-386,1975$.

128. YASMINEH, W.G., Pyele, R.B., Hanson, N.Q., and HuItman, B.K.: Creatine kinase isoenzymes in baboon tissue and argans.

cin. Chem. 22: 63-66, 1979.

129. ZIERLER, K.L.: Muscle membrane as a dynamic structure and its permeability to aldolase.

Ann. WH. Acod. Soi., 75: 227-232, 1958. 


\section{Enzyme distribution in dog heart and liver}

Sumprat

In studies on the quantitation of tissue damage from increased plasma enzyme levels it has been assumed that enzymes are homogeneously distributed throughout the tissue and that the inter-individual variation in enzyme content of the tissue is small. In this study we checked the validity of these assumptions by examining the distribution of several enzymes throughout heart and liver tissue of the dog. This species is comonly used in experimental models to study quantitation of tissue damage by means of increased plasma enzyme levels.

In liver tissue alanine aminotransferase (ALT), aspartate aminotransferase (AST) and glucosephosphate isomerase (GPI) activities, expressed in units per gram wet tissue, were determined in samples taken from different liver lobes. Intra-assay variations ${ }^{*}$ in enzyme measurements are within 5 . The enzymes are almost homogeneously distributed throughout the liver and the intra-individual ${ }^{*}$ variations were less than $6 \%$ for all three enzymes. For AST a 5 \% higher activity was observed in the left liver lobes, as compared to the activity in the right liver lobes $(\mathrm{p}<.01)$.

In heart tissue creatine kinase (CK), lactate dehydrogenase (LD), AST and GPI activities have been determined in samples taken from various sites of the left ventricle, right ventricle and septum. In the left ventricle and septum transmural samples were taken. We found a significant transmural CK gradient in the left ventricle, with a 10 o higher $C K$ activity at the epicardial side of the levt ventricle wall as compared to the activity at the endocardiall side $(\mathrm{p}<.0001)$.

\footnotetext{
"Coefficlent of wariation (CV): standard deviation axpressed as a porcontage of the romean.

Intra-assay wariation

: coefficlent of variation for enzyme measurements on the same day.

Inter-assay variation

: coefficient of variation for enzyme measurements on different days.

Intra-individual wartation

- coefficient of variation for samples taken from different sites of the same orgar.

Inter-individual variation

: coefficient of vaciation for samples taken from different organs.
} 
In the septum a 5 highex wo activity $(\mathrm{p}<.01)$ and in the left ven-

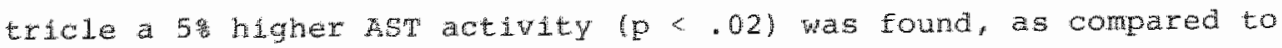
the activity in the right ventricle.

Inter-individual variations of $7.08,7.68,12.6$ and 5.7 were respectively found for CK, LD, AST and GPI activities of the dog heart.

We conclude that $C K$, LD and GPI are suitable for the quantitation of heart tissue damage and ALT can be used to quantitate liver tissue damage. The use of these enzymes for quantitation of tissue damage will introduce exrors of less than $10 \%$.

\section{Introduetion}

Normaliy only very small amounts of intracellular tissue enzymes are present in plasma. This normal steady state plasma enzyme concentration is assumed to be related to the normal tissue breakdown. After tissue injury the intracellular enzymes are released into the circulation and a qualitative indication of tissue damage can be obtained fxom tissue specific enzyme or isoenzyme elevations in plasma or from typlcal enzyme ratios (schmidt et al, 1970 and Wilkinson et at. 1970$)$.

A quantitative assessment of tissue damage is based on the plasma enzyme pattern after acute tissue injuries like for instance myocardial infarction (She11 et $a z,, 1971$; witteveen et $a z, 1975$ and Hermens et $a 2 ., 1979)$. In these studies the total activity of enzyme released from necrotic tissue into the circulation was calculated. In order to obtain the weight of injured tissue the calculated total activity of enzyme released was divided by the mean enzyme activity per gram of normal tissue. In addition the enzyme activity remaining in the tissue and the localdy inactivated activity should be known. The amount of enryme activity remaining in the tissue has been estimated from experimental studies in the rabbit and the dog (Kjekshus et al. 1970 and shel1 et a . , 1971). In such computation of tissue damage, using the mean enzyme activity for a specific organ, it is assumed that inter- and intra-individual variations in enzyme activity of the tussue are small.

In human and porcine hearts it has been demonstrated that variations in CK, HBD (a-hydroxybutyrate dehydrogenase), AST and GPI activities, in samples taken from the same heart are small. Inter-individual variations of $7-13 \%$ were observed for these enzymes (Witteveen, 
1972, Van der Laarse et $a d ., 1980$ and Hemens, 1979).

In studies on the local metabolism of the ventricles and the septum of the heart significant transmural gradients in enzyme activity have been observed for 4 out of 8 glycolytic enzymes (Lundsgamaminsen 2 al., 1967), phosphorylase (Jedeikin t al, 1964), succinate cytochrome c reductase (Tota et al. , 1973) and citrate synthase (Dowell. at $a z .1978)$.

The aim of the present study is to analyze the homogeneity in enzyme activity throughout dog heart and dog liver and to estimate inter-individual variations in enzyme activity of dog heart and liver tissue.

These questions are rellevant to the selection of enzymes suitable for the quantitation of acute heart or liver damage from increased plasma enzyme levels. Dog heart and dog liver were taken, because dogs are commonly used in experimental models to study the quantitation of myocardial infarction by means of plasma enzyme levels (Shell et al." 1971; Roberts et a.., 1975; Roe et al., 1977 and Sobel bt az., 1977).

\section{Matenials and methods}

Mongrel dogs of either sex, unknown age and ranging in weight from 15 to $35 \mathrm{~kg}$ were used in all experiments. Dogs were killed and

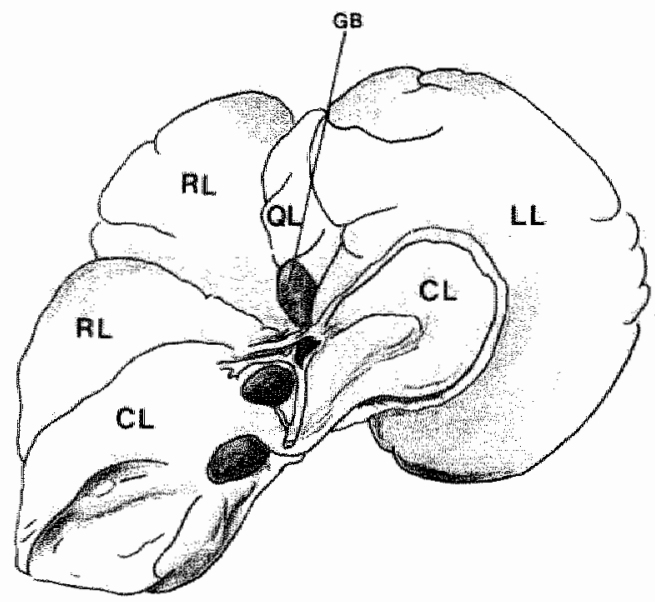

Fìn. I

$\mathrm{RL}=\mathrm{right}$ Lobe

$I_{S}=1 \mathrm{eft}$ Iobe

$\mathrm{CL}$ = cauclate lobe

ow = quadrate lobe. 
heart and liver were rapidly exclsed and hereafter rinsed in saline: Samples ranging in weight from $200-400 \mathrm{mg}$, were taken from different regions of the livex; 4 samples from the right lobe (lobus dexter). two samples from the left lobe (lobus sinister), two samples from the quadrate lobe (1obus quadratus) and two samples from the caudate lobe (Iobus caudatus) (ig. I).

For the heart, three left ventricle samples, taken from apex to base were cut transmurally and each sample was divided in an epicardial, a middle and an endocardial sample. Three transmural samples were also taken from the septum and divded in an endocardial sample at the left ventricle side, a sample from the middle and an endocardial sample at the right ventricle side. For the right ventricle three adjacent transmural samples were taken at three different regions of the right ventricle. The right ventricle wall was mostly too thin to be accurately divided in an epicardial, midale and an endocardial sample (Fig. II).

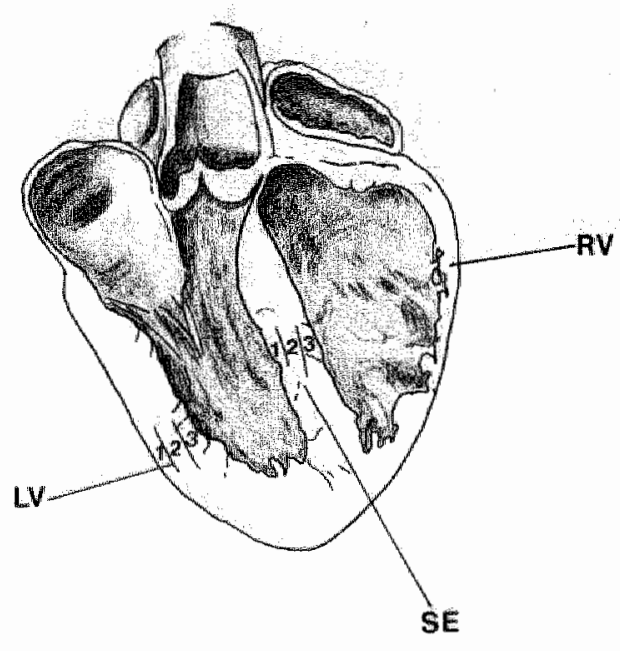

Fig. II

IVI = left ventricie epi

LV2 = left ventricle miadle

LV3 = left ventricle endo

SEL = septum left

$\mathrm{SE} 2$ = septum midale

SE 3 = septum richt

RV = right ventricle

All samples were homogenized in $15 \mathrm{ml}$ pasteurized plasma protein soLution with a colloid osmotic pressure equivalent to that of plasma (albumin $85 \mathrm{gr} / 1$, glucose $30 \mathrm{gr} / 1$, $\mathrm{Na}^{+} 1.3-1.6 \mathrm{gr} / 1$ and $\mathrm{K}^{+}<2 \mathrm{mmol} / 1$ ). Homogenization occurred in 8 bursts of 4 seconds and hereafter the 
homogenized sample was sonicated in 8 bursts of 15 seconds. Sonlcation was performed using a MSE Mark II 150-watt disintegrator set at 12 microns peak to peak amplitude. During homogenization and sontcation the tubes were kept in ice. The supernatant fraction was inmediately frozen at $-70^{\circ} \mathrm{C}$ until determination.

All enzyme determinations were carried out in duplicate in an Eppendor $\tilde{I}$ spectrophotometer and enzyme activities are expressed in units per litre $(U / I)$. One unit converts one micromole of substrate per minute under the given conditions. For CR and AST the Technicon Autom analyzer continuous flow system was also used.

With the Eppendorf spectrophotometer the change in extinction caused by the appearance or disappearance of the reduced form of either nicotinamide adenine dinucleotide (NADH) or nicotinamide adenine ainucleotide phosphate (NADPH) was measured over a fixed period of time at a wavelength of $334 \mathrm{~nm}$. NADH or NADPH disappeared or was formed in the reaction catalyzed by the enzyme, which was measured as such or in a reaction coupled to $i t$. The change in extinction was measured at a constant temperature $\left(25.0 \pm 0.05^{\circ} \mathrm{C}\right)$ in a sarstedt disposable cuvette with a light path of one $\mathrm{cm}$ and the enzyme activity in $\mathrm{U} / \mathbb{1}$ was calculated using the following formula:

$$
\begin{aligned}
& \mathrm{U} / 1=\frac{\Delta \mathrm{E} / \mathrm{min} \times \mathrm{V} \times 10^{3}}{E \times \mathrm{V} \times \mathrm{d}}=\Delta \mathrm{E} / \mathrm{min} \times \mathrm{F} \\
& \Delta \mathrm{E} / \mathrm{min}=\text { change in extinction in one minute } \\
& \mathrm{V}=\text { total test volume (mL) } \\
& E=\text { extinction coefficient of } \mathrm{NADH} \text { or NADPH at } 334 \\
& \text { millimicron : } 6.18 \times 10^{6} \mathrm{~cm}^{2} / \text { mole } \\
& \mathrm{v}=\text { volume of sample in cuvette (m1) } \\
& \text { d = light path of cuvette (cm) }
\end{aligned}
$$

Enzyme activities in tissue homogenates are expressed in units per gram wet tissue.

The following enzymes were determined:

1. LACTATE DEHYDROGENASE (LD) (EC 1.1.1.27)

This enzyme catalyses the reaction:

$$
\text { pyruvate }+\mathrm{NADH}+\mathrm{H}^{+}=\mathrm{I} \text {-lactate }+\mathrm{NAD}^{+}
$$

The rate of disappearance of NADH, measured as a diminution of extinction is proportional to the LD activity of the reaction mixture $(F=5097)$. Boehringer test kits (124893) based on the method of Wroblewski and IaDue (1955) were used. 
2. CREATTHE KMASE (CK) (EC 2.7.3.2)

This enzyme catalyses the reversible transfer of a phosphate group:

phosphocreatine + adenosine 5'-diphosphate (ADP) $\Rightarrow$

creatine * adenosine $5^{\prime}-t r i p h o s p h a t e$ (ATP)

Whe reation is carried out at $37^{\circ}$, using the Technicon Autoanalyzer continuous flow system, according to the method of siegel et a). (1967). It is a colorimetric method dependent upon the color complex formed by creatine with diacetyl-orcinol. The colored solution is pumped through the flow cell colorimeter fitted with 520 nin filters. This method, based on direct assay of creatine is not generally used, therefore the first two hearts were assayed both or the Eppendorf and Autoanalyzer.

For a spectrophotometric determination the first reaction is coupiled to an indicator reaction catalyzed by hexokinase (HK) (EC 2.7.1.1):

ATP + D-hexose \# ADP + D-hexose 6-phosphate which is than coupled to a reaction catalyzed by glucose 6-phosphate dehydrogenase (G6P-D) (EC 1.1.1.49)

D-glucose 6-phosphate + NADP $^{*} \rightleftharpoons$ D-glucono-8-lactone 6-phosphate + NADPH $+\mathrm{H}^{+}$

Baker test kits (3107 and 3108$)$, based on the method of oliver and modified by Rosalki (1967) were used ( $F=3733)$.

The conversion factor for CK activity measured on the Eppendorf to $\mathrm{CK}$ activity measured on the Autoanalyzer is:

$\mathrm{CK}$ (Autoanalyzer, $37^{\circ} \mathrm{C}$ ) $/ \mathrm{CK}$ (Eppendorf, $\left.25^{\circ} \mathrm{C}\right)=3.13 \pm 0.08$ (mean \pm $\mathrm{SD}, \mathrm{n}=54$ ).

This conversion factor is obtained by measuring the first two hearts both on Eppendorf and Autoanalyzer.

3. GLUCOSEPHOSPHATE ISOMERASE (GPI) (EC 5.3.1.9)

The following reaction is catalyzed:

D-fructose 6-phosphate $\Rightarrow$ D-glucose 6-phosphate

and is coupled to a reaction catalyzed by glucose 6-phosphate dehydrogenase

D-glucose 6-phosphate + NADP $^{+} \rightleftharpoons \mathbb{D}-\mathrm{glucono}-8$-l.actone

6 -phosphate + NADPH + $\mathrm{H}^{+}$ 
Sigma test kits $(355 \mathrm{~A}, \mathbb{B})$ based on the method of Bueding et at. (1955) were used $(F=5016)$.

4. ALAMINE AMINOTRANSFERASE (ALT) (EC 2.6.1.2)

This enzyme catalyses the reaction:

$$
\text { L-alanine + 2-oxoglutarate } \mathrm{I} \text {-glutamate + pyruvate }
$$

and is coupled to a reaction catalyzed by LD:

$$
\text { pyruvate + NADH }+\mathrm{H}^{+} \rightleftharpoons \text { L-lactate + } \mathrm{NAD}^{+}
$$

Boehringer test kits (124559) based on the reaction conditions of Wroblewski et al. (1955) were used ( $F=1197$ ).

5. ASPARTATE AMINOTRANSFERASE (AST) (EC 2.6.1.1)

The reaction catalyzed is:

$$
\text { L-aspartate + 2-oxoglutarate L-glutamate + oxaloacetate }
$$

The activity of AST is measured by coupling it to the following reaction catalyzed by malate dehydrogenase (MD) (EC 1.1.1.3.7)

$$
\text { oxaloacetate }+\mathrm{NADH}+\mathrm{H}^{+} \Rightarrow \text { L-malate }+\mathrm{NAD}^{+}
$$

On the Eppendor spectrophotometer Boehringer test kits based on the reaction conditions of Karmen were used (1955) ( $\mathrm{F}=1197$ ). In chapter $V$ AST determinations have been performed on the Autoanalyzer using a procedure modified by kessler et ot. (1971). In this procedure the same reactions as described for the spectrophotometric method were used and the change in absorbance at $340 \mathrm{~nm}$, caused by the disappearance of $\mathrm{NADH}$ is measured at $37^{\circ}$.

The conversion factor for AST activity measured on the Eppendorf to AST activity measured on the Autoanalyzer is:

AST (Autoanalyzer, $37^{\circ} \mathrm{C}$ )/AST (Eppendorf, $25^{\circ} \mathrm{C}$ ) $=2.25 \pm 0.12$ (mean $\pm \mathrm{SD}, \mathrm{n}=25$ ).

Isoenzyme separation of CK and LD was performed with a colum chromatographic method based on stepwize elution of isoenzymes fitom the column (Mercer, 2975 ). For $\mathrm{CK} 98 \pm 0.4 \%$ (mean $\pm \mathrm{SD}, \mathrm{n}=8$ ) of the total activity in dog heart consisted of the muscle type isoenzyme CK-M. The analytical recovery of $\mathrm{CK}$ from the colum was: $99.3 \pm 3.0$ : (mean $\# \mathrm{SD}, \mathrm{n}=8$ ).

For LD $5.8 \pm 0.4$ (mean $\pm S D, n=8$ ) consisted to the isoenzymes $L D-3,4,5$. The analytical recovery of $L D$ activity from the column $w$ $98 \pm 2.1$; (mean $\pm \mathrm{SD}, \mathrm{n}=8$ ).

For separation of AST isoenzymes, $1 . e$. cytoplasmic AST (CAST) and 
mitochondrial AST (mASt), a colum chromatographic method of sampson (1978) was used. The analytical recovery of AST activity from the columin was: $97.4 \pm 7.6$ (mean $\#$ SD, $n=32$ ). In dog 11 ver and dog heart resp. $54.2 \pm 4.58(\mathrm{n}=5)$ and $54 \pm 38$ (mean $\pm \mathrm{SD}, \mathrm{n}=3$ ) of the activity consisted of mAST.

In order to standardize our enzyme determinations, a standard was prepared by homogenizing about 1 gram of dog left ventricle in 2 1itre pasteurlzed plasma protein solution. Aftex centrifugation in a JA-20 rotor at $30,000 \mathrm{~g}$ for one hour, the supernatant fraction was alvided in small aliguots of $1 \mathrm{ml}$ and frozen at $-70^{\circ} \mathrm{C}$. For ALI the standard was obtained from dog liver on a similar way as described for the standard obtained from dog heart.

Intra-assay variations of the enzyme measurements were obtained by measuring 5 aliquots of this standard on the same day, under the same conditions. This procedure was repeated on 5 different days. For CK, LD, AST, GPI and ALT mean intra-assay variations of resp. 3.98, 2.88, $2.28,2.4 \%$ and $2.4 \%$ were found.

Inter-assay variations of the enzyme measurements were obtained by measuring 2 aliquots of the standard on 5 different days during one month.

Inter-assay variations of $C K, \mathbb{L D}, \mathrm{AST}, \mathrm{GPI}$ and $\mathrm{ALT}$ are respectively $8.18,3.78,2.98,6.68$ and 4.18 .

Each day at least two different aliquots of the standard were measured together with all other samples in order to correct all our measurements for inter-assay variations. This implies that the interIndividual varlations, calculated from mean enzyme activities of all samples of the same organ do not contain inter-assay variations. For each enzyme, activities from one and the same heart were determined on the same day.

All enzyme activity determinations of dog heart and liver were performed within 6 months. During this time no significant decline of the enzyme activity of the standard was observed.

statistical significance was judged from a paired student $t$ test.

roalto

Distribution of enzymes in dog liver

The mean AST, ALT and GPI activities of 10 different dog livers are given in table I. I. For complete data see appendix I, table I. 


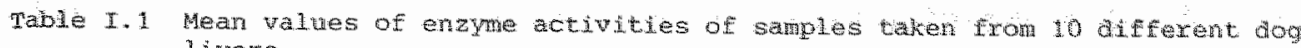
1 ivers.

In each liver samples were taken from: right lobes. $n=4$ (tur)

lete lobes, $n=2(1, i n)$. camere: lobe, $n=2(\mathrm{CL})$ and quadrate lobe, $n=2$ (QL).

\begin{tabular}{|c|c|c|c|c|c|c|}
\hline \multirow{2}{*}{$\begin{array}{c}\text { Sample } \\
\text { site }\end{array}$} & \multicolumn{2}{|c|}{ ALm activity } & \multicolumn{2}{|c|}{ Ast action } & \multicolumn{2}{|c|}{ GPI actury } \\
\hline & $\begin{array}{l}\text { mean } \\
\mathrm{U} / \mathrm{gx}\end{array}$ & CV & $\begin{array}{l}\text { mean } \\
\mathrm{U} / \mathrm{gr}\end{array}$ & $\begin{array}{c}\mathrm{CV} \\
\mathrm{B}\end{array}$ & $\begin{array}{l}\text { niseath } \\
\mathrm{u} / \mathrm{gx}\end{array}$ & $\begin{array}{c}\mathrm{CV} \\
8\end{array}$ \\
\hline $\mathrm{RI}$ & 88.2 & 10.4 & 110.2 & 11.7 & 113.2 & 17.4 \\
\hline Lid. & 91.0 & 12.0 & 115.2 & $13 \cdot 3$ & $\mathbb{1 1 5 . 2}$ & 19.6 \\
\hline $\mathrm{QL}$ & 87.2 & 10.8 & 110.5 & 13.6 & 111.3 & 16.4 \\
\hline $\mathrm{CL}$ & 86.7 & 12.0 & 109.9 & 11.4 & 112.6 & 15.0 \\
\hline Mean & 88.3 & $10.4^{x}$ & 111. & 12.5 & 113.1 & 17.5 \\
\hline
\end{tabular}

* Inter-individual variation of the mean enzyme activity of afferent: Iivers.

The only significant difference found is a 5 higher AST activity in the left liver lobes $(p<.01)$. For sample sites as used in our study the intra-individual variations for AST, ALT and GPI activities were respectively $4.7 \%, 5.7 \%$ and $5.7 \%$. These values were determined by averaging the intra-individual variations of all livers.

Inter-individual variations of respectively $12.5 \%, 10.4 \%$ and $17.3 \%$ were found for the mean AST, AIT and GPI activities of different Livers.

Table I.2 presents intra- and inter-assay variations of measured enzyme activities and intra- and inter-individual variations for enzyme activities of liver tissue.

Table I.2 Intra- and intex-assay variatlons of measured activitigs and intar- and inter-individual variations of enzyme activities of dog ifwer.

\begin{tabular}{ccccc}
\hline Enzyme & $\begin{array}{c}\text { intra-assay } \\
\text { variation (8) }\end{array}$ & $\begin{array}{c}\text { intex-assay } \\
\text { variation (o) }\end{array}$ & $\begin{array}{c}\text { intra-individual } \\
\text { variation (b) }\end{array}$ & $\begin{array}{c}\text { inter-individual } \\
\text { variation (fo }\end{array}$ \\
\hline ALT & 2.4 & 4.1 & 5.7 & 10.4 \\
AST & 2.2 & 2.9 & 4.7 & 12.0 \\
GPI & 2.4 & 6.6 & 5.7 & 17.3 \\
\hline
\end{tabular}

Variation coefficients for enzyme ratios in samples taken from the same lifwer and inter-individual vaxiations in mean enzyme ratios are presented in table II. 


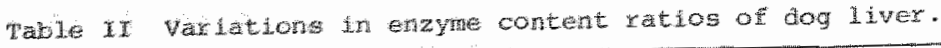

\begin{tabular}{|c|c|c|c|}
\hline 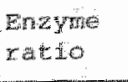 & ritedn & $\begin{array}{c}\text { Inter-indidual } \\
\text { yatiation }\end{array}$ & $\begin{array}{c}\text { intex-individua } \\
\text { wriation }\end{array}$ \\
\hline 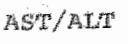 & 1.28 & A. & 15.8 \\
\hline MST/GPI & 1.01 & 5.4 & 23.7 \\
\hline$M L T / C T$ & 0.80 & 5.4 & 19.8 \\
\hline
\end{tabular}

Intra-Indy ldual yax atrons were obtaned by averaging intra-individual variations of al 1 ivert

Inter-indidual variations wexe obtaned from mean enzme ratios of different i. ivers .

Distribution of enzyme activity in dog heart

The mean enzyme activities of 10 different dog heartsare presented in table IrI. I. For completa data see appendixI; tables II. ITI, IV, V.

Table II.1 Mear valueg of anzyme activities of samples taken from a different dog hearts.

m each heart samples were taken from: left ventricle, $n=9$ (Lv), septum, $n=9$ (SE) and right ventricle, $n=9$ (RV).

\begin{tabular}{|c|c|c|c|c|c|c|c|c|}
\hline \multirow{2}{*}{$\begin{array}{l}\text { Sample } \\
\text { site }\end{array}$} & \multicolumn{2}{|c|}{ LD activity } & \multicolumn{2}{|c|}{ CW activity } & \multicolumn{2}{|c|}{ AST activity } & \multicolumn{2}{|c|}{ GPI activity } \\
\hline & $\begin{array}{l}\text { mean } \\
\mathrm{U} / \mathrm{gr}\end{array}$ & $\begin{array}{c}C V \\
w_{b}\end{array}$ & $\begin{array}{l}\text { mean } \\
\text { u/gr }\end{array}$ & $\mathrm{CV}$ & $\begin{array}{l}\text { mearn } \\
v / g r\end{array}$ & $\frac{\mathrm{cV}}{\mathrm{q}}$ & $\begin{array}{l}\text { mean } \\
\mathrm{v} / \mathrm{gr}\end{array}$ & $\begin{array}{c}\mathrm{CV} \\
\mathrm{z}\end{array}$ \\
\hline$L \mathrm{~W}-\mathrm{eP}$ & 311 & 8.5 & 3733 & 5.4 & 177 & 15.2 & 160 & 4.4 \\
\hline$I V-m i d$ & 315 & 6.6 & 3476 & 7.6 & 175 & 15.2 & 159 & 7.9 \\
\hline wV-endo & 312 & 7.0 & 3407 & 7.3 & 179 & 13.6 & 161 & 8. 2 \\
\hline SE-left & 328 & 7.9 & 3548 & 8.5 & 179 & 13.0 & 170 & 8.9 \\
\hline 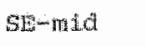 & 321 & 10.0 & 3472 & 8.5 & 177 & 14.0 & 166 & 7.3 \\
\hline 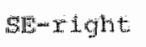 & 318 & 10.1 & 3551 & 8.5 & 180 & 12.3 & 165 & 5.4 \\
\hline RV & 306 & 7.9 & 3689 & 9.0 & 187 & 10.4 & 167 & 6.6 \\
\hline Mean & 313 & $7.6^{x}$ & 3583 & 7.0 & 181 & 12.6 & 165 & 5.7 \\
\hline
\end{tabular}

* Inter-individual variation of the mean enzyme activity of different livers.

A Sinjflcant transmural CK gradient has been observed ir the left ventricle with a lon higher CK activity at the eplcardial side (p<.0001), as conpared to ck activity at the endocardial side. For LD a 5 higher activity in the septum and for AST a 5 s higher ac tivity in the left ventricle, as compared to their activities in the 
right ventricle have been observed.

Intra-individual variations of $6.8 \%, 5.28,6.8 \%$ and 6.28 were respectively found for CK, LD, ASI and GPI activities of the dog heart. These values were also obtained by averaging the intra-individual variations of all hearts. It should be noted that intra-individual variations in this case depend on the specific sample scheme. Inter-individual variations for the mean CK, LD, AST and GPI activities of different dog hearts were respectively $7.08,7.68,12.68$ and $5.7 \%$.

Table III. 2 presents intra- and inter-assay variations for the determination of enzyme activity and intra- and inter-individual varlations for the enzyme activity of dog heart.

Table III.2 Intra- and inter-assay variations of neasured activities and intraand inter-individual vartations of enzyme activities of dog hart.

\begin{tabular}{|c|c|c|c|c|}
\hline Enzyme & $\begin{array}{l}\text { intra-assay } \\
\text { variation ( })\end{array}$ & $\begin{array}{l}\text { Lintex-assay } \\
\text { variation (b) }\end{array}$ & $\begin{array}{l}\text { intra-individual } \\
\text { variation (v) }\end{array}$ & $\begin{array}{l}\text { inter-1ndividuad } \\
\text { variation (a) }\end{array}$ \\
\hline $\mathrm{LD}$ & 3.9 & 8.1 & 5.2 & 7.0 \\
\hline $\mathrm{CK}$ & 2.8 & 2.9 & 6.8 & 7.6 \\
\hline AST & 2.2 & 3.7 & 6.8 & 12.6 \\
\hline GPI & 2.4 & 6.6 & 6.2 & 5.7 \\
\hline
\end{tabular}

Variation coefficients for the enzyme ratios in samples taken from the same heart and inter-individual variations in enzyme ratios are presented in table IV.

Table IV Variations in enzyme content ratios of dog heart.

\begin{tabular}{lccc}
\hline $\begin{array}{l}\text { Enzyme } \\
\text { ratio }\end{array}$ & mean & $\begin{array}{c}\text { intra-individual } \\
\text { variation }\end{array}$ & $\begin{array}{c}\text { intex-individual } \\
\text { variation }\end{array}$ \\
\hline CK/LD & 11.3 & 4.9 & 9.7 \\
CK/AST & 19.8 & 3.1 & 12.3 \\
CK/GPI & 21.7 & 3.9 & 8.6 \\
LD/AST & 1.76 & 2.9 & 18.2 \\
LD/GPI & 1.93 & 2.4 & 12.9 \\
GPI/AST & 0.92 & 2.4 & 11.0 \\
\hline
\end{tabular}

Intra-individual variations were obtained by averaging intra-individual. variations of all organs.

Inter-individual variations were obtained from mean enzyme ratios of different or gans. 
In order to estimate heart or liver tissue damage in grams of tissue, from increased plasma enzyme levels, the mean enzyme activity expressed ifl units per gram of nomal tissue should be known. To make a reliable estimation possible intra-and inter-individual variations in enzyme activity per gram of normal tissue should be small. When these requirements are fulfilied the mean enzyme activity, as estimated from different hearts or from different livers can be used to quantitate tissue damage.

In human left and right ventricles (Van der Laarse et $a t ., 1980$ ) and in porcine left wentricle (Hermens, 1979) the intra-individual varlationg in $\mathrm{CK}$, HBD (a-hydroxybutyrate dehydrogenase) and AST activities per gram wet tissue are sinall.

In the dog we conclude that the intra-individual variations in $\mathrm{CK}$, LD, AST and GPI activities in 27 samples taken from various sites of the same heart are less than 6.8 for all four enzymes. In the left ventricle and septum the existence of transmural gradients in enzyme activity was investigated. A significant transmural gradient was only observed for $C K$. CK activity is 10 s higher at the epicardial side as compared to the activity at the endocardial side of the left ventricle wall, whereas in the septum no transmural gradient in $C_{K}$ activity was observed. After myocardial infarction tissue necrosis seldomly remains confined to the epicardial side of the left ventricle wall. The intra-individual variation in CK activity estimated from 27 samples taken throughout the dog heart was only 6.8 r and therefore this transmural gradient in CR activity as observed in the left ventricle wall will not disturb the quantitation of the myocardial tissue damage as described above.

The epicaraial side of the left ventricle wall has the potential to generate ATP at a 108 higher rate than the endocaraial side. It remains to be seen whether the observed gradient in left ventricle ck content is of physiological significance, $i$.e. that the ck content of normal heart muscle is rate limiting in the generation of ATP during exerdise.

The myocardial CK content of $3600 \mathrm{U} / \mathrm{l}$ implies a maximal rate of ATP turnover of 3.6 mol/min/gr. Assuming that ATP transport from the mitachondria to the myofibrils occurs only by creatine phosphate, in steady state conditions $\mathrm{CK}$ catalyses the forward reaction at the same 
rate as the backward reaction, so net consumption of Arp coula be maximally $1.8 \mathrm{mmol} / \mathrm{min} / \mathrm{gr}$. In rest ATP consumption as computed from $\mathrm{O}_{2}$ consumption is $0.015 \mathrm{mmol} \mathrm{ATP} / \mathrm{min} / \mathrm{gr}$ (Personal communication G. v.a. Vussel.

During exercise myocardial $0_{2}$-consumption increases by factor of about 5 (Restorfe $a 2 ., 1977$ ). Therefore about 20 times as much ATP as is consumed can be supplied by $C K$ during exercise.

At first sight the extra potential of the epicardium to generate ATP seens contradictory to the supposed higher energy demand of the endocardium.

However, from model studies it has been inferred that both epi- and endocardial side of the heart perform the same amount of work (m. Arts, 1978 ).

Lundsgaard-Hanssen et al., 1967 measured transmural gradients for the glycolytic enzymes in the left ventricle of the dog heart. A significant transmural gradient was observed for 4 out of 8 glyoolytic enzymes. The authors reported extremely large variations in enzyme activities of the dog heart. The variations were caused, for a considerable part by the inherent scatter of the assay methods available at that time. Their data are in striking contrast with all more recent studies on enzyme activity determinations per gram wet tissue. For the glycolytic enzymes we studied LD and GPI no transmural gradients were found in the dog left ventricle and septum. Dowell $e t a z$. 1978 found no transmural gradient in LD activity in samples taken from the same heart, whereas for citrate dehydrogenase a log higher activity was observed at the epicardial side of the left ventricle wa11.

For CK, LD and GPI both intra- and inter-individual variations, corrected for intra-assay variations are small and allow quantitation of heart tissue damage using mean values for enzyme contme per gram heart tissue.

variations in enzyme ratios are in accordance with the assumption of uncorrelated variation in the enzyme content of heart tissue. A higher activity of one of the enzymes not necessarily implies a higher activity for the other enzymes.

For the enzymes AST, CK, HBD and GPI Witteveen (1972) reported variation cofficients of $14,14 \%, 13 \%$ and $6 \%$ between rat hearts and Hermens (1979) reported variation coefficients of respectively 7.4 , 12.5 and $10.2 \%$ for $\mathrm{AST}, \mathrm{CR}$ and HBD activity between porclne left 
ventricles. In samples obtained from 15 patients at thoracic surgery coefficients of variation of 19\%, $10 \%$, 11 \% and 10 \% were found for AST, CW, HBD and GPI activities (Witteveen 1972). Large variations as found for Ast activity were caused by insufficient homogenization. resulting in incomplete release of AST from the mitochondria. In oux study total ASP actiyity was determined after homogenization, sonication and freezing, in order to release all cytoplasmic (cAsT) and mitochondrial AST (mMST) present in the cell. Hereafter a coefficient of variation of 6.29 was abserved as 15 in agreement with variation coefficients of cytoplasmic enzymes, $11 k e C K$, LD and GPI.

Heter acute myocardial infarction very few mitochondrial AST is released into the circulation. Therefore to quantitate tissue damage from the total AST activity released into the circulation, the amount of cytoplasmic AST per gram tissue shoula be known. Cytoplasmic AsT content in the dog heart is: $46 \pm 5$ (mean $\pm \mathrm{SD}, \mathrm{n}=4$ ) of total AST activity. In human heart tissue van der Laarse $e t a z$. (1980) demonstrated that differences in enzyme and isoenzyme activity in different regions of the same heart are minimal and inter-individual variations in enzyme and isoenzyme content per gram wet tissue vary from 10-208. Variations in isoenzyme activity were somewhat larger, because of the inherent larger experimental errors of column chromatographic and electrophoretic separation techniques as compared to the simple spectrophotometric assay of total enzyme activity. In our study isoenzyme contents have not been studied in all samples. For CK 98 of total activity in the dog heart is of muscle type (CK-MM). For LD 5.8\% of total activity is of heat labile type LD-3,4,5. ID-1 and LD-2 have not been separated in this study.

ALT, AST and GPT contents in samples taken from different regions of the same liver were rather constant, coefficients of variation were less than 5.7 comparable results have been obtained for AST and ALT in samples from the human liver (Schmidt et az., 1970b). Liver tissue contains completely different cell types, hepatocytes and Kupfer cells. The small variations in enzyme activity throughout liver tissue indicate that these different cell types are homogeneously distributed in liver tissue.

we observed that in the dog inter-individual variations in enzyme activities of liver tissue are somewhat larger than inter-individual variations in enzyme activities of different hearts. Especially for GPI activity in Iiver tissue large variations have been observed 
(17\%). Therefore this enzyme is not suitable for quantitation puxposes.

Until now increases in plasma of intracellular liver enzymes are commonly used as a qualitative indication of liver damage (somidt et al., 1970). We conclude that ALT can be used for a quantitative assessment of liver tissue damage, using a mean value for the ALT content per gram wet tissue.

\section{Referenees}

1. ARTS. M.G.J.: A mathematical model of the dynamics of the left ventricle and the coronary circulation. Thesis, Mastricht, 1979.

2. BUEDING, E., and Mackinnon, J.A.: Studies of phosphoglucose isomerase of schistosoma mansoni.

J. Brot. Chem., 215: 507, 1955.

3. DOWELL, R.T.: Transmural citrate synthase and lactate dehydrogenase leveis in hypertrophied rat left ventricle.

Proc. Soc. Exper. Biot. Med. 158: 599-603, 1978.

4. HERMENS, W.Th., Van der Laarse, $A_{x}$, and witteveen, S.A.G.J.: Enzymatic infazct sizing: factors influencing the choice of the maxker enzyme. In Enzymes in cardiology, diagnosis and xesearch, edited by D.J. Hearse, Lonäon, J. Willey \& Sons Itd., 1979, 339-353.

5. JEDEIKIN, I.A.: Regional distribution of glycogen and phosphorylase in the ventxiciles of the heart.

Crre. Res., 14: 202-211, 1964.

6. KARMEN, A.: A note on the spectrophotometric assay of glutamic-oxaloacetic transaminase in human blood serum.

J. Clin. Inzest., 34: 131-133, 1955.

7. KESSLER, G., Rush, R., Leon, L., Delea, A., and Cuplola, A.: Automated 340 mim measurement of GOT, GPT and LD. Advances in antomated analysis. Technicon International Congress 1970, Miami, Florida, "Thurnan associates 1: 67-74, 1971 .

8. KJTKSHUS, J.K., and Sobel, B.E.: Depressed myocardial creatine phosphokinase activity following experimental myocardial infarction in the rabbit. Gire. Reo., 27: 403-413, 1970 .

9. LUMDSGARD-Hansen, P., Meyer, $C .$, and Riedwy $1, H_{n}$ : Manimural gradiente of glycolytic enzyme activities in left ventricular myocardjun. The normal state. Pfutigers Aroh., 297; 89-106, 1967.

10. MERCER, D.W.: Simultaneous separation of serum creatine kinase and lactate dehycrogenase isoenzymes on ionexchange collumn chromettography.

Clive Chem., 21: 1102-1106, 1975.

11. RESTORFF, W., Holtz, J., and Gassenge, E.: Excexcise induced augmentation of myocardial oxygen extraction in spite of nomal coronary dilatory capacity in dogs.

Pflugers Aroh., 372: 181-185, 1977.

12. ROBERS, R., Henry, P.D., and Sobel, B.E.: An improved basis for enzynatic esm timation of infarct size.

Circulation, 52: 743-754, 1975. 


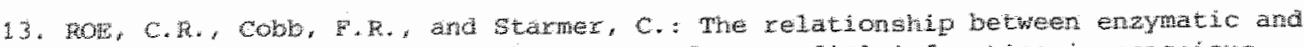
mistologic etwates of the extent or mocaraid infarction in conscious

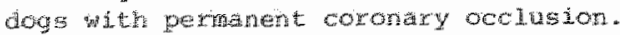

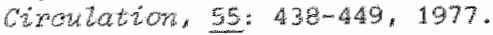

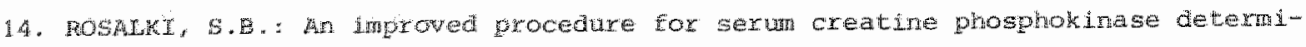
nation.

7. Lab. CZin. Hed. 69:696-705, 1967 .

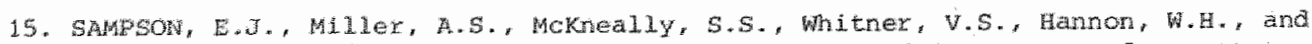
Murtig, C. . : Colum chromatographe separation of isoenzymes of aspartate manotrans ferase.

C2in. Ghem, 24:1805-1812, 1970.

16. SCHMTDr, E., and Schmidt, F.W.: Fspekte der Enqum-Diagnastic. Wed. WeLt, 18: $805 \times 916.1970$.

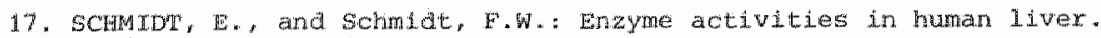

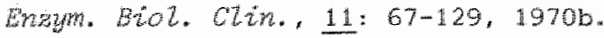

18. SHELA, W.E., KJekshus, J.K., and sobed, B.E.: Quartitative assessment of the extenstve mocardial infarction in the conscious dog by means of analysis of serial changes in serum creatine phosphokinase activity.

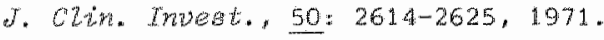

19. SIEGEL, A.I., and Cohen, P.S.: An autonated determination of creatine phosphom

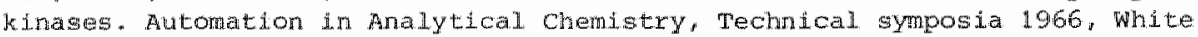
P.telns: New York, Mediad. Inc.: 474-476, 1967.

20. SOBEL, B.E., Markham, J., Karlsberg, M.P., and Roberts, a.: The Mature of disappearance of creatine kinase from the cixculation and its influence on enwhrtate extimation of infaret gize.

Cune. Res. $41: 836-844,1977$.

21. Toras B.: on the regional metabolisn of beef heart wentricles.

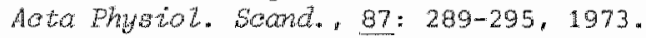

22. VAN DER IAARSE, A. Diljkshoorn, N.J. "Hollaar, L., and Caspers, Th.: The (1so) enzyme activities of lactate dehydrogenase, $\alpha$-hydroxybutyrate dehydrogenase, creatine kinase and aspaxtate aminotransferase in human biopsies and autopsiles.

Clizh. Chim. Acta, 104: 381-391, 1980.

23. WILKINSON, J.H.: Chinical älificarce of enzyme activity measurements. C2n. Chem. 16: $882-390,1970$.

24. WITHEWEN, S.A.G.J.: Assessment of the extent of a myocardial infarction on the

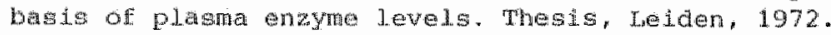

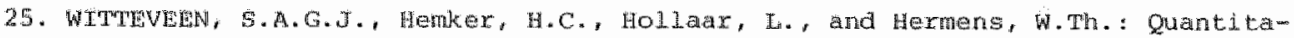
titon of infarct size in man by means of plasma enzyne levels.

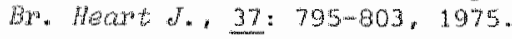

26. WroBs.jWSKI, $\mathrm{F}$. , and LaDhe, J.s.: Lactate dehydrogenase activity in blood.

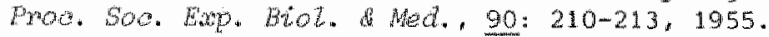




\title{
Plasma volume determination by use of enzyme dilution
}

\author{
Sumrary
}

In this study the use of enzymes for plasma volume measumenents has been examined. In dogs plasma volume was determined from dilution of intravenously injected enzymes. A comparative study with high molecular weight fluorescein isothiocyanate labeled dextrans (FITC-dextrans) was used as an independent check on the validity of these plasma volume measurements. For simultaneous plasma volume measurements with aspartate aminotransferase (AST) and alanine aminotransferase (ALT), obtained from liver tissue, no significant differences were found. For ALT a single sample point, taken within ten minutes after intravenous injection of the enzyme preparation, is sufficlent for an accurate plasma volume determination. Simultaneous plasma volume measurements with creatine kinase (CK), lactate dehydrogenase (LD) and AST resulted in a significantly higher plasma volume for both $C K$ and $L D$ as compared to AST. This overestimation in plasma volume determinations, as obtained from $C K$ and $L D$ dilution can be explained by inhibition of enzyme activity in plasma. Thus CK and LD can only be used when the amount of injected activity is determined Erom in vitro dilution of the enzyme preparation in plasma of the same dog.

It is concluded that plasma volume can be determined with less than $0.045 \mathrm{mg}$ enzyme per $\mathrm{kg}$ of body weight. This method offers an attractive alternative to methods presently used, especially because no radiactive isotopes are needed.

\section{Introduction}

All current methods used for plasma volume determination are based on the dilution principle. Dilution of Evans Blue dye (T-1824) and especially of ${ }^{131} \mathrm{I}$-1abeled albumin have become widely accepted as measures for plasma volume determinations. Both methods use tagging of albumin and plasma volume is estimated from the dilution immediately after injection. Comparative studies have however lead to conflicting results. Several authors suggested that $\mathrm{T}-1824$ dilution results in an overestimation of the plasma volume, because part of the injected dye escapes from the vascular system before binding to albu- 
min has occurred kreger et di., 1948; Storaasil eta $2 ., 1950$ and Aust et az., 1951). Especially in the rabbit and the rat $1-1824$ is less firmly bound to plasma protelns (Allenet at., 1953 and zizza at a2., 1958). other authors, however, did not find significant differences between the two methods (Freinkel $a z ., 1953$ and schultz et a.. 1953). It has also been show that both hemolysis and turbidity of the plasma samples interfere with the dye method (Gregerson et 2 . 1958 .

The use of labeled albumin has also been criticized by several authors, who demonstrated the presence of labile fractions in their preparations, caused by self-irradiation damage (Yalow et at., 1957; Bloom et at., 1958 and Ereeman, 1959). As a result several authors advocated the use of high moleculax weight dextrans for plasma volume determinations (Wasserman ot al. "1955; Semple, 1956; Craig et ad., 1957 and Jaenike et al., 1957). Indirect estimation of the plasma volume from the labeled red cell volume together with the hematocrit has also been criticized. This method does not take into account $10-$ cal differences in hematocrit values (Berson et $a \tilde{z} ., 1952$ and Belcher et at., 1957).

It is clear that most methods do not fulfil the exact standards reguired for accuracy, ease of preparation or stability of the injected preparation. Because of the high specificity and sensitivity of the current routine enzyme determinations, dilution curves of enzymes could form an attractive alternative to the methods presentiy used. We investigated whether a number of enzymes, which are normally present in plasma, can be used to this end. Such a method could possibly replace the use of radioactivity with its inherent precautions and initations.

Haterasis and methods

Mongrel dogs of both sexes and $15-35 \mathrm{~kg}$ of body weight were used in all experiments. The enzyme preparations were obtained from dog heart or dog liver. pieces of about 1 gram of freshly cut tissue were suspended in dog plasma $(2 \mathrm{ml} / \mathrm{gram})$. Nitrogen was led through the medium in order to maintain hypoxic conditions during 15-20 hours at $4{ }^{\circ} \mathrm{C}$. Undew these conditions enzymes are released from the tissue into the plasma. Hereafter the preparation was centrifuged first in a Beckman $J A-20$ rotor at $30,000 \mathrm{~g}$ for 30 minutes and thereafter in a 
II-45 rotor at 100,0009 for 24 hours.

Enzyme activities of creatine kinase (CK) (BC 2.7.3.2), lactate dehydrogenase (LD) (EC 1.1 .1 .27 ), aspartate aminotransferase (AsT) (EC 2.6.1.1) and alanine aminotransferase (ALI) (EC 2.6.1.2) were assayed spectrophotometrically at $25^{\circ} \mathrm{C}$, using a Boehringer test kit for ID, AST and ALT, and a Baker test kit for CK determinations. Enzyme activities were determined in duplicate and expressed in units per Iitre plasma (U/1) (see chapter III).

Isoenzyme separation of CK, LD and AST was performed as described in chapter III. For CK $98 \pm 0.48$ (mean \pm SD) of total activity was of the MM-type while for AST $90 \pm 2.6$ of total activity consisted of the cytoplasmic isoenzyme. For LD $5.8 \pm 0.48$ of total activity consisted of the "heat labile" isoenzymes $L D-3,4,5$.

Fluorescence measurements were performed with an Aninco Bowman spectrophotofluorometer. The excitation wavelength of Firc-dextran is $490 \mathrm{~nm}$ and the emission peak occurs at 510-515 nim. A bandwidth of 5 $\mathrm{nm}$ was taken for both excitation and emission (Rutili et al., 1970 ). A 5 solution of FITC-dextran, in isotonic buffered saline $(0.14 \mathrm{M}$ NaC1, $0.01 \mathrm{M}$ Tris-HCl), containing 1 is of dog plasma was used to obtain reference curves (Fig. I). Each point in this reference curve

Fig. I

A reference curve for FITC-dextran.

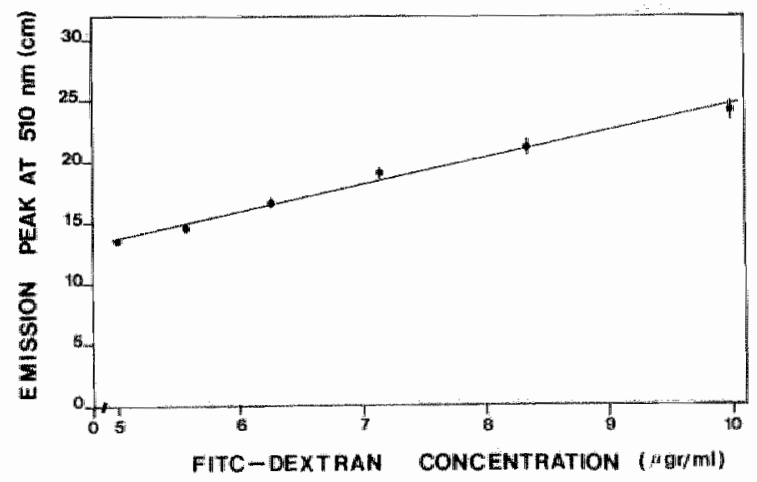

was obtained from five different dilutions (SE indicated in Fig. II). Determination of fluorescence in undiluted plasma introduced errors. Therefore, plasma samples after FTTC-dextran injections were diduted in buffered saline and all samples were measured in triplo. For the reference curves dilutions were performed in buffered saline contalning plasma of the same dog. In order to prevent light scattering all 
buffers were passed through a cathivex disposable filter unit 10.22 (wh). Protein detcminations were perfomed with a commercially available Biorad protein assay, based on the binding of Coomassie Brilliant Blue Gw250 to protein, resulting in a shift of the absorption maximum of the dye from 465 to 595 (Bradford eta., 1976).

Enzymes and fluorescein isothiocyanate labeled dextrans (EITCdextran, phaxmacia fine chemicals $A B$ dpsala Sweden, mean molecular welght 150,000 D were injected through a venous catheter (Braunule B. Braun Melstingen $\left.A_{.}, G_{.}\right)$in the foreleg vein (vena cephalis). A simultareous bolus injection of enzymes and FITC-dextran was not possible, because FITC-dextran interferes with our enzyme determinations. For a bolus injection $\pm 0.20 \mathrm{ml}$ of the enzyme preparation was injected per kg of body weight. The preparations contained about $10 \mathrm{mg}$ tissue protein per ml (spec. act. AST: $3 \mathrm{U} / \mathrm{mg} ; \mathrm{CK} 36 \mathrm{U} / \mathrm{mg}$ and LD IJ. o/mg). Enzyme preparations used in this study were not purified. purification and or labeling may cause rapidly cleared fractions, which could result in an overestimation of plasma volume (sodetz et a 2 . 1977 and Hermens, 1975). These preparations can, however, only be used for laboratory animals and therefore plasma volume determinations with purifled AST From porcine heart were also performed. In these experiments $0.045 \mathrm{mg}$ of AST from porcine heart (Sigma 62751: spec. act. $90 \mathrm{0} / \mathrm{mg}$ at $25^{\circ} \mathrm{C}$ ) was injected per $\mathrm{kg}$ of body weight. For FITC-dextran dilution $20 \mathrm{mg}$ per $\mathrm{kg}$ body weight of the same 5 solution as used for the reference curve was injected 2 hours after injection of the enzyme preparation (Fig. II).

Injected quantities were determined from weighing and reweighing of syringes (density plasma: $1.025 \mathrm{gr} / \mathrm{cm}^{3}$; dextran: $1.020 \mathrm{gr} / \mathrm{cm}^{3}$ ). The syringe was cleaxed by repeated drawing and expeling of about $5 \mathrm{mi}$ blood, hereafter $5 \mathrm{ml}$ of saline was injected twice in order to clear the catheter.

Blood samples of about 4 mi. were collected from a venous catheter in the other foreleg vein. The first 0.5-1.0 ml were always discarded, as well as hemolytic samples. Clotting was prevented with 5 u of heparin per ml blood. After a bolus injection of enzymes a first sample was taken after approximately 10 minutes and thereafter blood samples were collected at regular intervals during 90 minutes. All samples were centrifuged immediately $(1000 \mathrm{~g}, 20$ minutes) and plasma was separated. For enzyme determinations platelet free plasma was obtained by centrifuging at $30,000 \mathrm{~g}$ for 30 minutes and plasma samples 
were stored at $-70^{\circ} \mathrm{C}$ until determination.

After FITC-dextran injection $4-5$ samples were taken during the first 20-30 minutes. Fluorescence measurements were performed immediately after centrifugation of plasma samples at $30,000 \mathrm{~g}$ for 60 minutes. Normal steady state plasma enzyme activities were detemined from three successive plasma samples taken at 5 minute intervals before the bolus injection was given.

The influence of ten different dog plasma's on the enzyme activity was measured by diluting the enzyme preparation both in plasma and saline. Six different dilutions were made. The activity in each plasma was expressed as a percentage of the activity in saline. Hematocrit values were determined routinely in all blood samples with the microcapillary centrifuging technique by centrifuging at $15.000 \mathrm{~g}$ for 5 minutes. During successive plasma volume determinations with FITC-dextran and enzymes, hematocrit values remained constant within $2-3$.

In our experiments the dogs were not fed at least eight hours before the experiments were started, because an effect of feeding on the plasma volume has been reported (Reece et al., 1970).

Analysis of data

Plasma enzyme activity and FrTC-dextran concentration immediately after injection (zero time) were estimated from the best fit to a straight line (least square procedure) in the logarithmic plot,

$$
\ln \left(C(t)-C_{n}\right)=k t+\ln C_{0}
$$

where $C(t)$ is the plasma activity at time $t, C_{n}$ is the steady state activity before injection, $k$ is the clearance constant and $\mathrm{c}_{\mathrm{o}}$ ws taken as the plasma activity extrapolated to zero time. A standard linear regression computer program was used. 95 confidence limits of $C_{0}$ were calculated and expressed as a percentage of obtalned values. Because the error in enzyme determinations is mainly percentual, a linear fit to the logarithmic plot should be preferred to direct exponential fitting of obtained data. The latter procedure would result into exaggerated influence of data points with the highest enzyme activities. Plasma volume was calculated by dividing the total injected amount of activity by $C_{0}$. Tests of statistical significance were performed using a paired student te test. 
Wabe I shows results of simulaneous plasma volume measurements by enzyme dilution of $C K$, LD and AST in 26 experiments, using enzyme Table I plasmat volune determinations from simultaneous ailution of CK, LD and AsT.

\begin{tabular}{|c|c|c|c|c|c|c|c|}
\hline $\begin{array}{l}\text { Exper menent } \\
\text { nuxber }\end{array}$ & $\begin{array}{l}\mathrm{CK} \\
(\mathrm{mL} / \mathrm{kg})\end{array}$ & 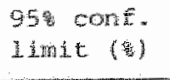 & $\begin{array}{l}\mathrm{LD} \\
(\mathrm{m} 1 / \mathrm{kg})\end{array}$ & 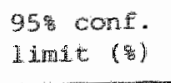 & $\begin{array}{l}\text { Ast' } \\
(\text { min/ } / k g)\end{array}$ & $\begin{array}{l}95 \text { cone. } \\
\text { linit (s) }\end{array}$ & $\begin{array}{l}A S^{M} \\
(\mathrm{ml} / \mathrm{kg})\end{array}$ \\
\hline 1 & 55.3 & 2.1 & 55.5 & 3.3 & 54.4 & 3.0 & 55.6 \\
\hline 2 & 60.0 & 5.2 & 60.2 & 3.3 & 56.4 & 1.9 & 56.5 \\
\hline 3 & 59.4 & 5.8 & 58.2 & 2.3 & 58.2 & 3.2 & 58.0 \\
\hline 4 & 74.8 & 6.1 & 67.8 & 7.7 & 55.2 & 3.7 & 54.7 \\
\hline 宊 & 52.4 & 6.4 & 50.6 & 3.8 & 53.3 & 2.4 & 51.5 \\
\hline 6 & 51.1 & 3.3 & 50.4 & 5.7 & 49.8 & 4.7 & 48.5 \\
\hline 7 & 45.0 & 5.5 & 45.8 & 6.2 & 48.8 & 5.1 & 49.2 \\
\hline 9 & 56.2 & 5.0 & 55.8 & 6.3 & 53.8 & 1.8 & 52.5 \\
\hline 9 & 42.0 & 3.7 & 40.5 & 5.7 & 39.9 & 5.5 & 39.4 \\
\hline 10 & 46.9 & 3.3 & 48.3 & 3.6 & 43.7 & 2.4 & 44.6 \\
\hline 11 & 47.4 & 1.7 & $47 \cdot 3$ & 3.0 & 46.1 & 1.4 & 48.2 \\
\hline 12 & 49.8 & 2.3 & 57.5 & 4.4 & 42.9 & 4.0 & 42.8 \\
\hline 13 & 44.4 & 2.7 & 45.4 & 5.4 & 42.7 & 4.5 & 41.5 \\
\hline 14 & 50.8 & 3.6 & 50.1 & 3.9 & 47.3 & 3.2 & 45.1 \\
\hline 15 & 55.2 & 4.6 & 52.0 & 4.2 & 50.1 & 1.5 & 49.6 \\
\hline 16 & 46.4 & 2.1 & 45.3 & 4.0 & 42.2 & 2.5 & 42.4 \\
\hline 17 & 53.8 & 4.2 & 42.1 & 7.6 & 44.8 & 4.2 & 45.1 \\
\hline $18^{*}$ & 49.1 & 3.0 & 47.8 & 3.1 & 48.1 & 1.3 & 47.4 \\
\hline $19^{*}$ & 46.8 & 2.9 & 46.4 & 5.6 & 42.0 & 2.2 & 42.0 \\
\hline $20^{x}$ & 51.2 & 2.7 & 53.3 & 3.6 & 46.9 & 2.3 & 45.8 \\
\hline $21^{3 *}$ & 49.2 & 3.6 & 49.4 & 6.1 & 43.5 & 1.9 & 43.1 \\
\hline $22^{x}$ & 41.9 & 0.6 & 41.0 & 3.0 & 34.7 & 3.1 & 34.3 \\
\hline $23^{N}$ & 50.7 & 2.4 & 49.9 & 5.9 & 45.6 & 4.6 & 44.5 \\
\hline $24^{\pi}$ & 50.7 & 9.1 & 46.0 & 11.3 & 49.0 & 8.0 & 46.5 \\
\hline $25^{*}$ & 52.9 & 6.3 & 48.5 & 5.7 & 48.6 & 2.3 & 49.8 \\
\hline $26^{x}$ & 43.0 & 5.1 & 43.2 & $4 \cdot 3$ & 43.5 & 4.5 & 42.0 \\
\hline Mean & 51.0 & 4.0 & 49.7 & 5.0 & 47.4 & 3.3 & 47.0 \\
\hline SE & 1.35 & 0.37 & 1.26 & 0.98 & 1.10 & 0.31 & 1.10 \\
\hline
\end{tabular}

- For experiments indjated by $(x)$ a subsequent plasma volume determination with ETC-aextran is performed (see Table II).

- The last colum represents plasma volume, by Ast dilution, as estimated from sample points taken during the first 20 minutes after injection. 
preparations obtained from heart tissue. The difference in plasma volumes estimated from $C K$ and AST dilution after bolus injection is statistically highly significant $(p<.02)$. So overestimations of about $8 \%$ and 5 were respectively found for plasma volume determinations obtained from $C K$ and $L D$ dilution.

In the last 9 experiments indicated by $x$, subsequent plasma volume determinations with FITC-dextran were perfoned. The results of these experiments are indicated in Table II. No significant difference is

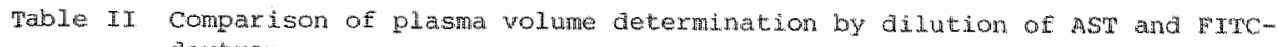
dextran.

\begin{tabular}{|c|c|c|c|c|}
\hline $\begin{array}{l}\text { Experiment } \\
\text { number }\end{array}$ & $\begin{array}{l}\mathrm{AST} \\
(\mathrm{mI} / \mathrm{kg})\end{array}$ & $\begin{array}{l}958 \text { cont. } \\
\text { Limit (n) }\end{array}$ & $\begin{array}{l}\text { FITC-ax } \\
(\mathrm{m} \cdot \mathrm{k} / \mathrm{kg})\end{array}$ & $\begin{array}{l}958 \text { coner. } \\
\text { limit (in) }\end{array}$ \\
\hline 18 & 48.1 & 1.3 & 44.6 & 0.7 \\
\hline 19 & 42.0 & 2.2 & 45.3 & 6.9 \\
\hline 20 & 46.9 & 2.3 & 51.7 & 2.4 \\
\hline 21 & 43.5 & 1.9 & 41.1 & 6.5 \\
\hline 22 & 34.7 & 3.1 & 33.5 & 1.9 \\
\hline 23 & 45.6 & 4.6 & 46.3 & 0.8 \\
\hline 24 & 50.0 & 8.0 & 43.6 & 2.3 \\
\hline 25 & 48.6 & 2.3 & 48.2 & 7.2 \\
\hline 26 & 43.5 & 4.5 & 43.5 & 1.9 \\
\hline $27^{\square}$ & 57.2 & 4.9 & 57.7 & 3.3 \\
\hline $28^{17}$ & 53.5 & 3.9 & 58.4 & 5.5 \\
\hline $29^{17}$ & 53.0 & 3.4 & 57.2 & 6.3 \\
\hline $30^{17}$ & 47.3 & 3.5 & 43.5 & 1.3 \\
\hline $31^{\square}$ & 51.1 & 5.1 & 49.3 & 5.6 \\
\hline Mean & 47.5 & 3.6 & 47.4 & 3.8 \\
\hline $\mathrm{SE}$ & 1.50 & 0.46 & 1.87 & 0.65 \\
\hline
\end{tabular}

- Im experiments indicated by (n) purified AST from porcine heart was uged.

obtained for plasma volumes determined from $A S T$ and FTTC-dextran dLlution. The last column of Table I shows plasma volumes obtalned from the first 20 minutes of decay curves of AST.

Enzymes have different clearance constants and depending on the requirements a fast or a slow cleared enzyme can be chosen (clearance constants; CK $0.37 \pm 0.024 \mathrm{~h}^{-1} ; A S$ A $0.20 \pm 0.015 \mathrm{~h}^{-1} ; \mathrm{LD} 0.44 \pm 0.037$ $\mathrm{h}^{-1}$, mean $\pm S E, n=10$ and $A L T: 0.023 \pm 0.034 \mathrm{~h}^{-1}$, mean $\left.\pm S D, n=3\right)$. Fig. II shows clearance curves of CK, LD, AST and ExTC-dextran. From Table II it can be concluded that purified AST from porcine heart is 


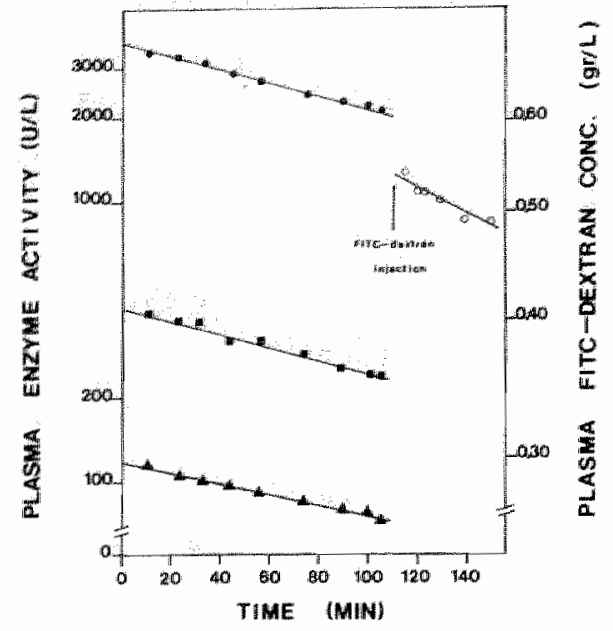

Fig. II

Plasma enzyme and FITC-dextran clearance curves after successive intravenous injections.

- $=\mathrm{Cr}$

$-1 \mathrm{LD}$

$\Lambda=A S T$

$0=$ FTC-dextran.

also sultable for plasma volume determination.

Table III shows that there is mo significant difference between plasma volumes estimated from AST or ALT dilution, using enzyme preparations obtalned from liver tissue. The last column presents plasma volumes calculated from only the first sample point of ALT.

Table IV shows the influence of twelve different dog plasma"s on $C K, \mathbb{L D}$ and $\mathrm{AST}$ activity of an enzyme preparation obtained from dog

Table III Flasma volume determination from simultaneous dilution of AST and ALT.

\begin{tabular}{|c|c|c|c|c|c|}
\hline $\begin{array}{l}\text { Experiment } \\
\text { number }\end{array}$ & $\begin{array}{l}\text { A.ST } \\
(\mathrm{m} 1 / \mathrm{kg})\end{array}$ & $\begin{array}{l}95: \text { conf. } \\
\text { linit (z) }\end{array}$ & $\begin{array}{l}\mathrm{ALT} \\
(\mathrm{m} \perp / \mathrm{kg})\end{array}$ & $\begin{array}{l}958 \text { conf. } \\
\text { limit (b) }\end{array}$ & $\begin{array}{l}\text { ALT ml/kg from } \\
\text { first sample point }\end{array}$ \\
\hline 32 & 47.5 & 8.6 & 46.3 & 5.3 & 46.7 \\
\hline 3.3 & 49.2 & 7.3 & 47.9 & 4.8 & 49.2 \\
\hline 34 & 45.2 & 3.1 & 45.8 & 2.1 & 46.6 \\
\hline 35 & 53.2 & 2.2 & 52.3 & 2.9 & 54.0 \\
\hline 36 & 45.1 & 4.2 & 47.3 & 2.0 & 46.8 \\
\hline 37 & 43.7 & 6.6 & 47.2 & $A .1$ & 48.4 \\
\hline 38 & 49.6 & 2.8 & 50.3 & 1.3 & 50.5 \\
\hline 39 & 43.7 & 1.4 & 43.6 & 1.7 & 43.9 \\
\hline 40 & 49.7 & 1.6 & 47.0 & 1.8 & 48.1 \\
\hline 41 & 47.9 & 4.1 & 46.5 & 1.6 & 47.3 \\
\hline Mean & 47.5 & 4.2 & 47.4 & 2.8 & 49.2 \\
\hline $\mathrm{SE}$ & 0.97 & 0.79 & 0.76 & 0.46 & 0.86 \\
\hline
\end{tabular}


heart. For $C K$ significant inhibition of enzyme activity occur $(p<.02)$. For LD tris trend does not become significant.

Table $v$ shows the influence of ten different dog plasma $s$ on Asmand ALT activity of an enzyme preparation obtained from liver tissue. For these enzymes no important influence of plasma on the measured activity has been observea.

Table IV Influence of 12 different aog P.asma's on CK, ID and AST from dog heart.

\begin{tabular}{crrr}
\hline Plasma & AST & CK & ID \\
\hline 1 & 101 & 100 & 103 \\
2 & 101 & 99 & 103 \\
3 & 105 & 100 & 104 \\
4 & 100 & 86 & 94 \\
5 & 99 & 108 & 103 \\
6 & 103 & 94 & 94 \\
7 & 95 & 96 & 99 \\
8 & 99 & 93 & 88 \\
9 & 100 & 90 & 95 \\
10 & 101 & 93 & 85 \\
11 & 98 & 84 & 100 \\
12 & 97 & 83 & 103 \\
\hline MEan & 100 & 94 & 98 \\
\hline (8) & 0.8 & 2.2 & 1.8 \\
\hline
\end{tabular}

Table $v$ Influence of 10 different don plasma "s an AST and Ax! Hom dog iner.

\begin{tabular}{ccc}
\hline $\begin{array}{c}\text { P.asma } \\
\text { numbex }\end{array}$ & AST & ALT \\
\hline 1 & 103 & 101 \\
3 & 111 & 110 \\
4 & 101 & 101 \\
5 & 98 & 98 \\
6 & 93 & 104 \\
7 & 98 & 108 \\
8 & 100 & 98 \\
9 & 102 & 91 \\
10 & 100 & 101 \\
\hline Mear & 100 & 101 \\
SE (8) & 1.5 & 1.7 \\
\hline
\end{tabular}

Activities are expressed as a percentage of acturity in saline.

Discussion

A first requirement for plasma and blood volume determinations is that no unknown fraction of the injected substance is lost from the circulation before mixing is completed. This would result in an overestimation of plasma volume. Although dilution of ${ }^{13}$ I-labeled albumin and $\mathrm{T}-1824$ are widely used for plasma volume determinations methodological problems, as mentioned above have been reported.

Jaenike et al. (1957) found a significant difference between the distribution volume of high molecular weight dextxan and 131 -labeled albumin. An overestimation of $6 \pm 0.3 \%$ was found for albumin dilution as compared to dextran dilution. The ${ }^{131} \mathrm{I}$-labeled albumin preparation 
used In thif study contained 50-140 microcuries per ng albumin and 50-100 microcuries have to be injected for a plasma volume determination in man. In several atudies it was demonstrated that even slightIy overiodinated albumin preparations contain fractions of denatured abumin, which are rapidy cleared, resulting in overestimation of plasma volume (Kalow et a., 1957; Bloom et al, 1958 and Freeman 1959:. In 1957 Bloom ot a 2 . demanstrated that the effects of self-irradiation becone significant when the specific activity exceeds 100 microcuries ${ }^{131}$ I per mg of albumin. Moreover, a comparative study of 131 -labeled albumin and $\mathrm{T}-1824$ might be disputable because both methods are based on the dilution of tagged albumin. rhese results indicate that an independent check on the validity of plasma volume measurements is necessary. In our study fluorescein labeled dextrans were used. Schröder et al. (1967) showed that FITCdextrans have the same in vivo and $i_{n}$ vitro lability as found for unlabeled dextrans.

our results show that overestimation of plasma volume can also be found using dilution of enzymes. Enzyme determinations are assays of activity, not of concentration of a protein in plasma, accordingly the apparent activity ma be influenced by the presence of inhibitors, activators or cofactors. In our case especially for cK inhibition of enzyme activity in plasma was found, resulting in an overestimation of plasma volume. This effect of inhibition on CR activity has been described (wong et al., 1976 and Morin et al., 1977). Some examples of inhibitors of $\mathrm{CK}$ activity are maleate, succinate and anions ( $\mathrm{I}^{-}, \mathrm{SO}_{4}^{2-}, \mathrm{NO}_{3}^{-}$etc.). For $\mathrm{UD}$ inhibition is less pronounced although significant in some of the cases. Therefore the amount of injected $C K$ and $L D$ has to be estimated from in vitro dilution of the enzyme preparation in plasma of the same dog.

overestimation of plasma volume as estimated fxom LD dilution might also be introduced, because preparations obtained from heart tissue contain (5.8 \pm 0.43 ) (mean $\pm S D$, $n=4$ ) of "heat-lablle" LD (isoen$2 y$ mes $L D-3,4,5)$. Although our AST preparations contain \pm 10 of the mitochondrial isoenzyme (mAST) no overestimations of AST plasma volumes are observed. For CK, the enzyme preparations we used contain $(98 \pm 1.0)$ of muscle type isoenzyme CK-MM. For AST and ALT no significant inhibition or activation is observed, which makes these enzymes especially suitable for plasma volume determinations. Moreover we demonstrated that there is no significant difference between plasma volume determinations with purifled AST from porcine 
heart and plasma volume determinations with FIC-dextrans. From these results it is concluded that purified AST preparations do not contain quickly metabolized fractions, resulting in an overestimation of plasma volume.

From the 95 confidence limits in table I and table II 1 t follows that plasma volume determinations with AST and ALT are accurate to approximately 3\%. Moreover it follows from table II that determination of ALT plasma volume from the first sample point only does not result into decreased accuracy. For AST, estimation from a single sample point introduces a systematic overestimation of plasma volume, because the half-life time for AST clearance is less than two hours in some dogs. Estimation from the first 20 minutes of AST clearance curves, $i . e$. from at least two sample points gave however satisfying results ( $c f$. Table I). In man the half-life for AST clearance is approximately 9 hours and a single sample point for AST would probably be sufficient (Willems et $a l ., 1980$ ).

The enzymes we used in our study normally occur in the circulation and by chosing an enzyme with a short half-life, the presence in the plasma can be of short duration and the risk for immunological effects is minimized. Several dogs received 15 repeated injections of the same enzyme preparation, obtained from heart or liver tissue, during ten weeks and no fever or immunological complications were observed. BY contrast FITC-dextrans are not suitable for routine plasma volume determinations, because hypersensitivity was observed after two injections. Also the method is very laborious.

References

1. ALLEN, T.H. , Ochoa, M. "Roth, R.F., and Gregerisen, M.I.: Spectral absorption of T-1824 in plasma of various specles and recovery of the dye by extraction. Am. T. Pfoysiot. 175: 243-246, 1953.

2. AUST, J.B., Chou, S.N., Marwin, J.F., Brackney, E.I., and Moore, G.E.: A rapld method for clinical total blood volume cetermination using radioative lom dinated human serum albumin (RTHSA).

Proc. Soc. Exper. B202. Med. 77: 514. 1951.

3. BELCHER, E.E., and Haxis, E.B.: Studies of plasma volume, red cell volume and total blood wolume in young growing rats.

t. Phystot., 139: 64-78, 1957.

4. BERSON, S.A., and Yalow, R.S.: The use of ${ }^{4} \mathrm{~K}$ or ${ }^{32} \mathrm{p}$ labeled erythrocytes and ili I tagged albumin in simultaneous blood volume measurements.

H. Clin. Invest., 31: $572-580,1952$.

5. BLOOM, H.G.J., Crockett, D.J., and Stewart, F.S.: The effects of radiation on the stability of xadlo-iodinated human serum albumin.

$B x^{*}$. Radiot, $31: 377-383,1958$. 


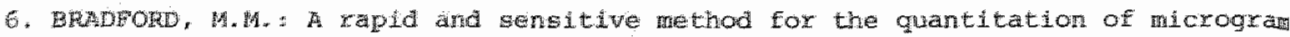
quatcites of protein utiluzing the primeiple of protein dye binding. And. Buodem. $72: 248-254,1976$.

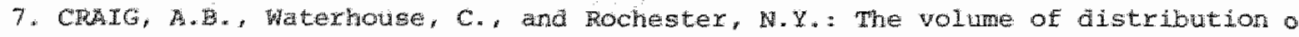
high molecular melght dextran and its relation to plasma volume in man.

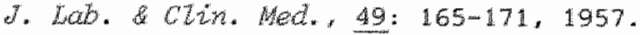

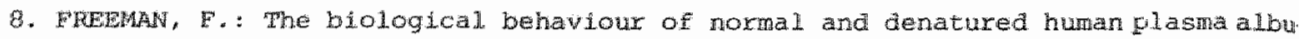
mistr.

Clink. Chrm. Acta, 4: 788-792, 1959.

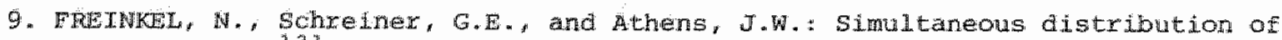
$T$ m 1824 and $131-1$ abe led human sexum a lbumin in man.

T. C2n. Irvest. $32: 138-148,1953$.

10. GREQRSEN, M.I., and RawSOn, R. H.: Blood volume. Physiot. Rev. 39: 307-342, 1959 .

11. HEMENS, W.Th.: Dose calculation of human factor VII and factor IX concentrates For lnfusion therapy. In hardbook of hemofile, part II, edited by $k$.M. Brinkhous and H.C. Hemker, New rork. Amexcian Elsevier, 1975, pp. 569-589.

12. JAFNKE, J.R., Schre.ner, B.F., Waterhouse, C., and Rochester, N. Y: The relative volumes of alstribution of 131 -tagged albumin and high molecular weight dextran in rormal subjects and patients with heart aisease. J. Lab. Glin. Med. 49: 172-181, 1957.

13. KRTEGER, H., Storaasi1, J.P. , Frieden, H.L., and Holden, W.P. A conparative study of blood volume in aogs.

Proc. Soc. 7. Exp. Diot. Med. 68: 511-516, 1948.

14. MORIN, L.G.: Creatine kinase: Re-examination of optimum conditions. cin. Chim. Aeta, 23: 1569-1575, 1977.

15. REECE, W.O., and Wahistron, J.D.* Effect of feeding and excitement on the packed ce 11 volume of dogs.

Lab. Anim. Cane, 30: 1114-1117, 1970 .

16. RUTILI, G., ArFors, K.E*, and Ufend, H.R.: Fluorescence measurements in nanolitre samples.

Anat. Biochem. 72: 539-545, 1970.

17. SCHULTZ, A.L., Hammarsten, J.F., Heller, B.I. " and Ebert, R. V.: A critical compaxison of the T-1824 dye and iodinated albumin methods for plasma volume measurements.

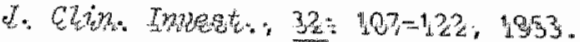

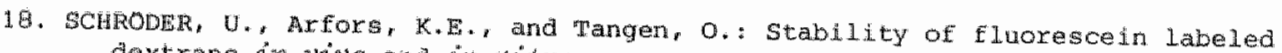
cextrans in vivo and in vitho.

Marovase. Pea. 11: 33-39, 1976.

19. SEMPLA, R.E. Method for determining plasma volume of aninals with dextran. Fed. Proa. 15, 166, 1956 .

20. SOD function and $27 n$ vivo survival of human factor VIII/ won willebrand factor
proteln. *. Biot. Chem. 252: 5538-5546, 1977 .

21. STORAASLI, J.P., Krieger, H., Friedel1, H.L., and Holden, W.D.: The use of radioactive lodimated plasma protein in the study of blood volume.

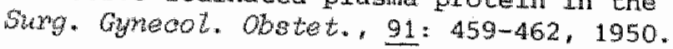

22. YALOW, R.S., and Berson. S.A.: Chemical and biological alternations induced by Irradiation of 131 I-labeled hum sexum albumin.

d. Cint. Jwost. $36,44-50,1957$. 
23. WHSSERMAN, K., and MaYerson, H.S.: PLasma volume changes compared with hamatocrit and plasma protein chasges arter infusion. Am. o. Phuspl., 182: 419-427, 1955.

24. WTLEEHS, G.M., Lambi, F.H.t., and Fermens, w.Th.: Analysis of simitaneously sampled plasma activities of aspartate aminotransferase (Astr), whowroxybutyrate dehydrogenase (HBD) and creatine kinase (Ck) in patients with acute myocardial infarction. In: Quantification of Myocardial Ischemid. Adwances in clinical cardiology, vol. I, edjted by H. Kreuzer. W. W. palmley, P. Rentrop and E.W. Heiss, Gerhard Witzstrock Verlag, $1980,482-493$.

25. WONG, P.C.P., and Smith, A.T.: Biochemical difference between MB and MA 1soenzymes of creatine kinase.

Cith, Chim, Acto, 68: 147-158, 1976.

26. ZIZZA, F., and Reeve, R.B.: Exroneovs measurement of plasma volume in the rabbit by $\mathrm{T}-1.824$.

Am. J. Physitol., 194, 522-526, 1958. 
•

(3) 


\section{CHAPTER V}

\section{Selection of a suitable model for the plasma clearance and distribution of cardiac enzymes in the dog}

\section{Sumaray}

This study concerns the existing controversy about the validity of a one- vs. a two-compartment model for the distribution of intravenously injected enzymes in the dag. Enzyme preparations were obtained by leakage of enzyme from heart tissue under hypoxic conditions.

It is shown that infusion of the enzyme preparation at a constant rate permits airect calculation of the enzyme clearance constanta, independently of the specific model used.

The plasma clearance constants $k$ of creatine kinase (Ck) and aspartate aminotransferase (AST) are respectively $0.36 \pm 0.030 \mathrm{~h}^{-1}$ and 0.21 $\pm 0.014 \mathrm{~h}^{-1}$ (mean $\pm \mathrm{SE}, \mathrm{n}=8$ ). These values were compared with clearance rates as estimated from a bolus injection of enzyme given $90 \mathrm{min-}$ utes before the infusion was started. For both enzymes the value of $k$, as estimated from the infusion equals the apparent disappearance constant $k_{d}$, as obtained from the preceding bolus injection. From these experiments it is concluded that plasma clearance of CK and AST is adequately described by a one-compartment model.

In 10 experiments plasma CK and AST clearance after bolus injection was sampled during 8 hours. Disappearance of AST was strlctly mono-exponential, while for $\mathrm{CK}$ a slight biphasic effect was observed in 5 out of 10 cases.

It is concluded that this effect is not due to exchange of enzyme with an extravascular pool but is caused by a fraction of enzyme with a slightly higher elimination rate. This phenomenon is illustrated by showing that AST also shows biphasic disappearance upon injection of an enzyme preparation obtained by mechanical disruption of cells.

Individual and day to day varlations in $k$ values obtained for CK and AST do not show any correlation. This suggests an independent clearance mechanism for both enzymes.

\section{Introduction}

Following the appreciation of the clinical importance of serum 
enzyme determinations in the aianosis of acute myocardial infarction. several authors investigated the relation between enzyme release and infarct stze. In the dog a rough correlation was demonstrated between peak serum levels of Ast and histologically assessed infarct size (Agress et al., 1955; Nydick et al., 1955; Ruegsegger et al., 1959). In 1970 myocardial $c k$ depletion was demonstrated after experimental Infarction (Kjekshus et $a 2 ., 1970$ ) and ever since most studies on eniymatic infarct quantitation are based on CK clearance curves. However, a model which adequately describes the plasma clearance of CK in the $\operatorname{dog} 1 \mathrm{~s}$ still at issue. Shell et al. (1971) introduced a two-compaxtment model with a total aistribution space of about 3 times the plasma volume. This model was based upon observed double-exponential clearance curves of CK. Rapaport (1975) reported monomexponential clearance for different $C K$ isoenzymes. Roberts et al. (1975, 1977) also found mono-exponential clearance and rejected the two-compartment model used by sheil et at. (1971). They suggested that the formerly proposed double-exponential function was an artefact introduced by a partially denatured enzyme preparation. However, these authors thereafter reconsidered their data and proposed a two-compartment model with an extravascular space of about $48 \%$ of the plasma volume (Sobel et a $2 ., 1977$ ). All cited studies were based upon bolus injections of enzyme preparations im the dog.

In the present study this controversy is investigated by successive determination of the enzyme clearance rate on the same day in the same dog, by the traditional bolus injection technique and by an infusion technique. The latter technique permits direct calculation of clearance constants from infusion equilibrium conditions, independently of the specific model used.

\section{Materiate and methods}

Mongrel dogs of either sex, unknown age and ranging in welight from 15 to $35 \mathrm{~kg}$ were used in all experiments. Enzyme preparations were obtalned fxom dog heart as described in chapter IV.

CK and AST activities were assayed in a Technicon Autoanalyzer contilnuous flow system at $37^{\circ} \mathrm{C}$ (chapter III). Enzyme activities were determined in duplicate and expressed in units per litre plasma (U/1). Methods used for the separation of isoenzymes have been described in chapter III. For CK $98 \pm 0.4 \%$ (mean \pm SD) of total activity was of 
the M-type, while for AST $90+2.68$ of the total activity consisted of the cytoplasmic isoenzyme (CAsT).

one of the enzyme preparations was obtained by homogenizing 2 grams of dog heart in $2 \mathrm{ml}$ of dog plasma at $0{ }^{\circ} \mathrm{C}$ by using an ultra-turrax (Janke \& Kunkel type 18-10) in 8 bursts of 4 seconds. Hereafter the enzyme preparation was sonicated in 8 bursts of 15 seconds and centrifuged as described for the other enzyme preparations (chapter IV). Sonication was performed using a MSE Mark II 150-Watt disintegrator set at $12 \mu$ peak to peak amplitude.

This preparation contained $98 \pm 1.08$ of CK-M and $54 \pm 1.0$ (mean \pm SD) of mitochondrial AST (MAST). Before administration the preparations were sterilized by filtration through a Millipore disposable filter unit $(0.22 \mathrm{~mm})$.

Blood samples were collected as described in chapter IV. For the continuous infusion experiments the following protocol. was used. First a bolus injection of enzyme was given. The apparent disappearance constant $\mathrm{k}_{\mathrm{d}}$ and the plasma volume was calculated from a mono-exponential fit on sample values taken 3 minutes after injection and at 10 minute intervals during 90 minutes. This first bolus of enzyme has the effect of a Lading dose and considerably shortens the period of time needed to attain cquilibrium after subsequent constant rate infusion. After this 90 minute period the same enzyme preparation as used for the bolus injection was diluted with physiological saline and infused at a constant rate of approximately $6 \mathrm{mi} / \mathrm{hour}$, using a Harvard pump (model 903). During infusion samples were taken every 30 minutes for another 6 to 7 hours.

In experiments involving only bolus injections a first sample was taken 3 minutes after injection and hereafter every 20-30 minutes for 8 hours.

During continuous infusion dogs were premedicated at the start of the experiment with vetranquil $1 \mathrm{mg} / \mathrm{kg}$ (azepromazin base) "symoron $1 \mathrm{mg} / \mathrm{kg}$ and atropine $0.1 \mathrm{mg} / \mathrm{kg}$. A possible effect of premedication on enzyme clearance rates was verifled by control experiments in which premedication was given 2 to 3 hours after the bolus injection. The normal steady state plasma enzyme activities were determined from three successive samples taken at 5 minutes intervals at the start of each experiment. 
Elg. I shows the one- and two-compartment models as proposed in the literature. In both model first-order clearance is assumed $i . \varepsilon$. a clearance rate proportional to the plasma activity with a proporthonaldty constant $k$.

When an enzyme preparation is infused at a constant rate and for a sufficlent length of time an equilibrium state will be established for the one- as well as the two-compartment model. This saturation by means of continuous infusion has been used in pharmacological studies (Wagner, 1975). During equilibrium the rate of enzyme entry into the plasma equals the rate of enzyme clearance, thus:

$$
f=k\left(c_{e q}-c_{n}\right)
$$

where $C_{e q}$ is the attalned equilibrium activity (U/I), $C_{n}$ is the normal steady state plasma activity $(U / 1), k$ is the clearance constant $\left(h^{-1}\right)$ and $f i s$ the rate of input of enzyme $(0 /(1 . h))$. Expression (1) allows airect calculation of $k$ from $c_{e q}, c_{n}$ and a known rate of input of enzyme $f$.

Analysis of bolus injections

For the one-compartment model, the time-activity curve after an intravenous bolus injection of enzyme is a mono-exponential function (Hermens, 1975):

$$
c(t)=c_{0} \exp (-k \cdot t)+c_{n}
$$

where $C(t)$ is the plasma activity at time $t, C_{0}$ is the amount of enzyme injected at $t$ is zero and $c_{n}$ is again the normal steady state plasma activity.

For the two-compartment model the combined effect of plasma clearance and exchange with the extravascular pool results into a biphasic disappearance and the time-activity curve after an intravenous bolus injection of enzyme becomes a double-exponential function (Hermens, 1975):

$$
c(t)=c_{1} \exp (-b t)+c_{2} \exp (-a t)+c_{n} \quad(0<a<b)
$$


where $a$ and $b$ are respectively the slow and the fast alsappearance

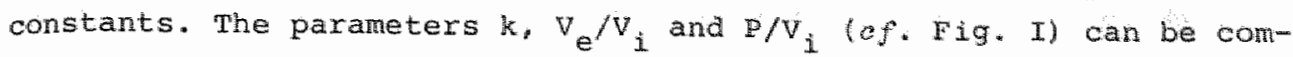
puted from $C_{1}, C_{2}$, a and b (Hermens, 1975):

$$
k=\frac{\left(c_{1}+c_{2}\right) a b}{c_{1} a+c_{2} b} ; \frac{v_{e}}{v_{i}}=\frac{c_{1} c_{2}(b-a)^{2}}{\left(c_{1} a+c_{2} b\right)^{2}} ; \frac{p}{v_{1}}=\frac{c_{1} c_{2}(b-a)^{2}}{\left(c_{1}+c_{2}\right)\left(c_{1} a+c_{2} b\right)}
$$
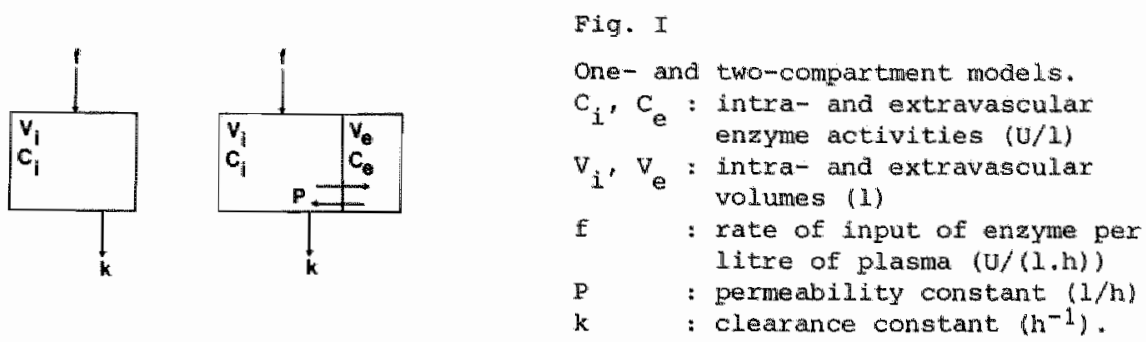

To fit mono- and double-exponential functions a standard least squares procedure (Dell et al., 1973) was used which minimizes the mean deviation of all datapoints to the fit functions (2) and (3). As the error in enzyme determinations is mainly percentual, the mean deviation expressed as a percentage of observed activities was minimized. This implies a weighted fit with the reciprocal activity as a weight function. The quality of obtained fits is expressed in the residue, $i . e$. the residual mean percentual deviation per observation. The significance of improvement of the fits was tested by a Fisher test for the ratio of residues (Beck et al., 1977). For all parameters 95 confidence limits were computed.

\section{Results}

Fig. II shows plasma enzyme activities as obtained after constant rate infusion following an initial loading dose. Table I preserts the results of 8 such experiments. No significant differences were observed between clearance constantsk as calculated from equilibrium

The quotient $P / V_{1}$ is also known as transcapillary escape rate (TER). 


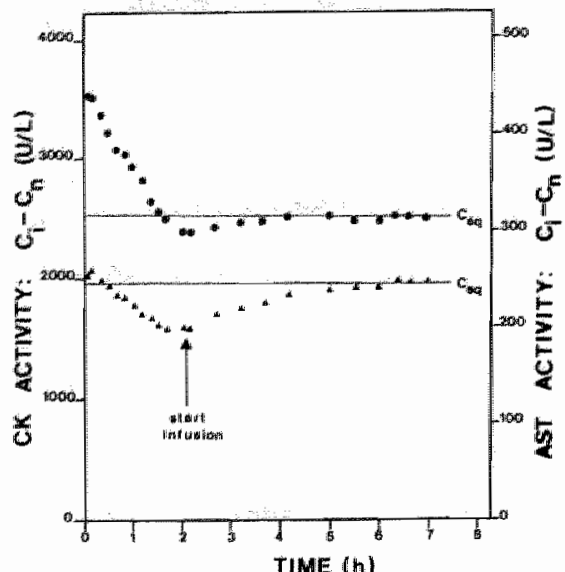

Fig. II

Plasma activities of CK to and AST after an initial loading dose and subsequent constant rate infusion.

Expeximent nr. 5 of table I is shown.

pable I Constant rate intusions of AST and $\mathrm{CK}$.

\begin{tabular}{|c|c|c|c|c|c|c|c|c|c|c|}
\hline \multirow[b]{2}{*}{ Exp. } & \multirow[b]{2}{*}{ Dog } & \multirow[b]{2}{*}{$\begin{array}{l}\text { Enzyme } \\
\text { prep. }\end{array}$} & \multicolumn{4}{|c|}{$A S^{t}$} & \multicolumn{4}{|c|}{$C K$} \\
\hline & & & $\begin{array}{c}f \\
(u / 1 . h)\end{array}$ & $\mathrm{eq}_{(\mathrm{U} / 1)}^{-\mathrm{C}_{\mathrm{n}}}$ & $\begin{array}{c}\mathrm{k} \\
\left(\mathrm{h}^{-1}\right)\end{array}$ & $\frac{k a^{-1}}{\left(h^{-1}\right)}$ & $\begin{array}{c}f \\
(\mathrm{U} / \mathrm{d} \cdot \mathrm{h})\end{array}$ & $\begin{array}{c}\mathrm{C}_{\mathrm{eq}}{ }^{-\mathrm{C}_{\mathrm{n}}} \\
(\mathrm{U} / 1)^{-}\end{array}$ & $\frac{k}{\left(h^{-1}\right)}$ & $\left.\mathrm{k}^{-1}{ }^{-1}\right)$ \\
\hline 1 & $\mathrm{D} 2$ & P3 & 49.3 & 215 & 0.23 & 0.22 & 636 & 1356 & 0.47 & 0.36 \\
\hline 2 & D3 & P3 & 5.4 .4 & 193 & 0.28 & 0.26 & 702 & 1996 & 0.35 & 0.28 \\
\hline 3 & D4 & P6 & 31.3 & 196 & 0.16 & 0.17 & 467 & 1700 & 0.27 & 0.31 \\
\hline 4 & DS & P3 & 30.2 & 165 & 0.18 & 0.19 & 390 & 1053 & 0.37 & 0.33 \\
\hline 15 & $D G$ & $\mathrm{P} 4$ & 44.2 & 246 & 0.18 & 0.16 & 659 & 2442 & 0.27 & 0.24 \\
\hline 6 & 106 & p3 & 41.4 & 221 & 0.19 & 0.18 & 534 & 1963 & 0.27 & 0.26 \\
\hline 7 & 07 & $P 4$ & 41.6 & 178 & 0.23 & 0.24 & 620 & 1339 & 0.46 & 0.52 \\
\hline$B$ & 07 & 25 & 24.7 & 125 & 0.20 & 0.17 & 356 & 822 & 0.43 & 0.40 \\
\hline Me an & & & 38.9 & 188 & 0.21 & 0.20 & 545 & 1584 & 0.36 & 0.34 \\
\hline $8 \mathrm{E}$ & & & 3.5 & 11 & 0.014 & 0.014 & 46 & 191 & 0.030 & 0.032 \\
\hline
\end{tabular}

fi : Infusion rate of enzyme (U/M.h).

$\mathrm{C}_{\mathrm{q}}$ : plasma activity during equilibriun (U/L)

$\mathrm{C}_{n}$ : nomal steady state plasm activity (0/1)

k : clearance constant daloulated from equilibrium conditions $\mathrm{h}^{-1}$ )

$\mathrm{k}$ : apparent disapparance constant calculated from the first 90 minutes aftex an initidid loading dose $\left(h^{-1}\right)$.

Complete data see appendix I; data of chapter $W$, table $I$. 
conditions and apparent disappearance constants $k_{d}$ as calonlated from the first 90 minutes after the initial loading dose. This lmples that the rate of transport to the extravascular space can be neglected in comparison to the plasma clearance rate and no initial. rapia disappearance occurs.

Fig. III and table II present results of mono-exponential fits after intravenous bolus injections. Reasonable accurate values of $k_{d}$ were obtained as shown by $95 \%$ confidence limits. Comparison of values for $k_{d}$ from tables I and II shows no significant difference between values calculated over 90 minutes and 7-8 hours respectively.

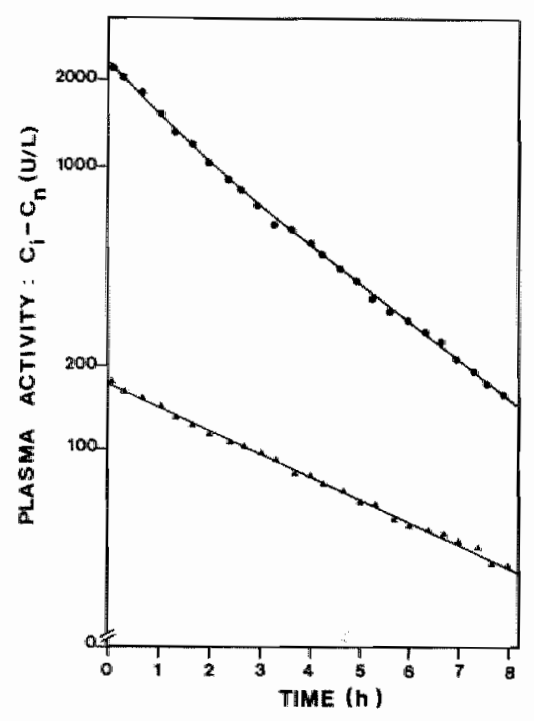

Fig. Jit

cluearance curves for CK (e) and ASP (4) after a single bolus jnjection. Experiment nr. 6 of table II is shown.

As shown by the small residue of 3.18 , AST time-activity curves conformed very closely to a monomponential function and convergence to a double-exponential function was never obtained.

For $\mathrm{CK}$ however, 5 out of 10 experiments (af. table II) showed significantly improved double-exponential fits. The results of these 5 fits to equation (3) and the parameter values calculated from these results by use of equation (4) are presented in table IrI. As is apparent from the large 958 confidence 1imits, the double-exponential fit is ill-conditioned in these cases and extremely sensitive to experimental error. This fact also became apparent from computer simulations. Although the random error added to the simulated $c K$ curves was 7.5 for mono-exponential fits against only $3.5 \%$ for double-exponential fits (of. tables II and III), the mean value for dk as calcu- 


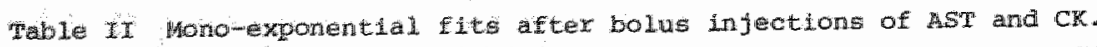

\begin{tabular}{|c|c|c|c|c|c|c|c|c|c|}
\hline . . & \multirow[b]{2}{*}{ Dog } & \multirow[b]{2}{*}{$\begin{array}{l}\text { Drayme } \\
\text { prep. }\end{array}$} & \multicolumn{3}{|c|}{ 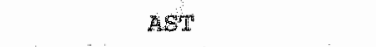 } & \multicolumn{4}{|c|}{$\mathrm{CK}$} \\
\hline Exp. & & & $\left(h^{-1}\right)$ & $\frac{d k_{a}}{\left(n^{-1}\right)}$ & $\begin{array}{c}\text { respidue } \\
\text { (2) }\end{array}$ & & $k a$ & $\left(h^{-1}\right)$ & $\begin{array}{c}\text { residue } \\
\text { (v) }\end{array}$ \\
\hline 1 & $D 1$ & 1 & 0.115 & 3.7 & 3.0 & $x$ & 0.35 & 3.6 & 7.5 \\
\hline 2 & 152 & P1 & 0.27 & 4.5 & 4.0 & $x$ & 0.41 & 6.3 & 12.6 \\
\hline 3 & $D 2$ & 82 & 0.23 & 6.4 & 4.6 & & 0.41 & 3.3 & 7.2 \\
\hline 4 & 13 & $P 2$ & 0.27 & 3.9 & 4.0 & & 0.52 & 4.6 & 9.2 \\
\hline 5 & D3 & P2 & 0.23 & 1.9 & 1.8 & & 0.43 & 1.9 & 3.8 \\
\hline 6 & D4 & $P 3$ & 0.19 & 3.5 & 2.3 & $x$ & 0.33 & 2.9 & 4.1 \\
\hline 7 & $\mathrm{DA}$ & D3 & 0.22 & 1.9 & 1.7 & & 0.36 & 4.3 & 4.8 \\
\hline 8 & $\mathrm{D4}$ & $P 3$ & 0.17 & 7.0 & 5.7 & $x$ & 0.26 & 12.4 & 10.9 \\
\hline 9 & D5 & P3 & 0.15 & 3.5 & 2.4 & & 0.29 & 5.7 & 7.3 \\
\hline 10 & 05 & P3 & 0.14 & 1.9 & 1.4 & $x$ & 0.31 & 4.8 & 7.8 \\
\hline Meari & & & 0.20 & 3.8 & 3.1 & & 0.37 & 5.0 & 7.5 \\
\hline $\mathrm{SE}$ & & & 0.015 & 0.56 & 0.44 & & 0.024 & 0.92 & 0.90 \\
\hline
\end{tabular}

k $\mathrm{a}$ : apparent alsappearance constant calculated from samples taken during $7-8$ hours.

aka : 95 confldence Iim.ts of $k_{d}$ expressed as a percentage of $k_{d}$.

residue : quality of fit expressed as the mean residual deviation per datapoint expressed as a percentage of measured activity*

Curves indicated with $x$ in the $C K$-colum showed improved double-exponential fits (table III). Complete data see appendix I; data of chapter $V$, table II.

Table III Dowble-exponential fits after bolus injections of CK.

\begin{tabular}{|c|c|c|c|c|c|c|c|c|c|c|c|c|c|}
\hline Exp. & $\begin{array}{c}C_{1} \\
(u / 1)\end{array}$ & $\begin{array}{l}d C_{1} \\
(1)\end{array}$ & $\frac{C_{2}}{(D / 1)}$ & $\begin{array}{l}\mathrm{dc}_{2} \\
(\mathrm{~g})\end{array}$ & $\mathrm{C}_{(\mathrm{D})}$ & $\left(h^{-1}\right)$ & ab & $\left(h^{a}-1\right.$ & $\frac{d a}{(8)}$ & $\begin{array}{l}\text { res: } \\
(8)\end{array}$ & $\frac{k}{\left(h^{-1}\right)}$ & $v_{e} / v_{i}$ & $\begin{array}{l}P / V_{1} \\
\left(h^{-1}\right)\end{array}$ \\
\hline 1 & 3003 & 24 & 541 & 140 & 40 & 0.50 & 21 & 0.14 & 95 & 2.3 & 0.36 & 0.43 & 0.08 \\
\hline 2 & 3595 & 15 & 408 & 164 & 42 & 0.63 & 25 & 0.12 & 153 & 4.7 & 0.44 & 0.76 & 0.13 \\
\hline 6 & 718 & 67 & 1569 & 33 & 99 & 0.77 & 56 & 0.29 & 14 & 2.1 & 0.36 & 0.13 & 0.08 \\
\hline 8 & 2468 & 39 & 697 & 157 & 77 & 0.55 & 54 & 0.53 & 370 & 4.6 & 0.18 & 1.60 & 0.26 \\
\hline 10 & 1421 & 52 & 559 & 145 & 43 & 0.53 & 43 & 0.18 & 75 & 3.8 & 0.35 & 0.31 & 0.09 \\
\hline Men & 2241 & 39 & 755 & 128 & 60 & 0.60 & 40 & 0.25 & 141 & 3.5 & 0.34 & 0.65 & 0.13 \\
\hline $\mathrm{SE}$ & 522 & 9 & 209 & 24 & 12 & 0.05 & 7 & 0.08 & 137 & 0.6 & 0.10 & 0.58 & 0.08 \\
\hline
\end{tabular}

Dxperiment number correspond to thable II.

$c_{1}, c_{2}, c_{n}, a, b$ : abtained best-fit values for the double-exponential function (see text).

H. $v_{e} / v_{1}, h / v_{1}$ : calculated circulatory parameters (see text).

$\mathrm{dc}_{1}, \mathrm{dC}$, $\mathrm{da}, \mathrm{db}: 958$ confidence 1 imits expressed as a percentage of obtaimed parameter values.

restat : of. table II. 
lated for simulated curves was only $6.5 \%$ while the mean values of $\mathrm{dc}_{1}, \mathrm{dc}_{2}$, da and $\mathrm{db}$ were $66 \%, 216 \%, 146 \%$ and 45 respectively. So the biphasic behaviour of $\mathrm{CK}$ is insufficiently pronounced to allow accurate discrimination between fast and slow phases. This is also shown by the fact that $k_{d}$ as determined from the first 90 minutes (table I) does not differ significantly from $k_{d}$ as determined from 7-8 hours (table II) or from $k$ as calculated from the double-exponential flt (table III).

Fig. IV shows that premedication, as used during infusions, does not interfere with clearance rates of $\mathrm{CK}$ and AST.

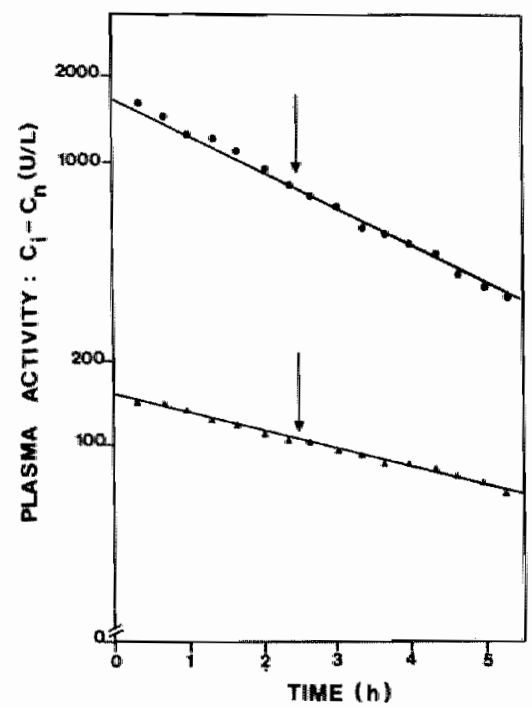

Fig. IV

Administration of premedication during the clearance phase after a single bolus of CK $(\bullet)$ and AST (4). Thme of administration is indicated.

Fig. vhows clearance as observed after injection of a preparation obtained by mechanical disruption of cells. Four bolus injections of the latter preparation resulted into biphasic disappearance for AST with a faster disappearing fraction of $37 \pm 8 \%$ (mean \pm SE, $n=4$ ) cleared at a rate of $b=1.42 \pm 0.44 \mathrm{~h}^{-1}$ and a remaining fraction cleared at a rate of $a=0.17 \pm 0.03 \mathrm{~h}^{-1}$. The mean residue improved from $6.5 \%$ for the mono-exponential to $2.3 \%$ for the double-exponential fit. Improvement of the residue was significant at $p<0.001$ for all 4 cases. For $\mathrm{CK}$ a value of $\mathrm{k}_{\mathrm{a}}=0.32 \pm 0.02 \mathrm{~h}^{-1}$ was found in these 4 cases while a significant improvement of the residue for a double-exponential fit occurred in 2 cases. 


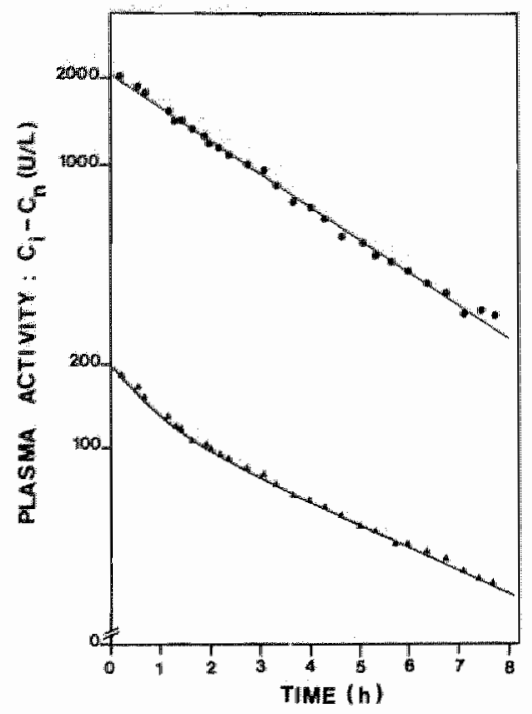

Fig. v

clearance of CK (•) and AST (4) using an enzyme preparation obtained from mechanical distuption of cells.

From table II a considerable day to day variation in clearance rates is apparent, even for the same preparation in the same dog. Fig. VI shows 8 experiments in dog D7. Large day to day variations in clearance constants of AST and $\mathrm{CK}$, which are apparently uncorrelated, are observed. However, from the small residue for AST (af. table II) it follows that variations in clearance constant during the experimental period of 8 hours must remain small.

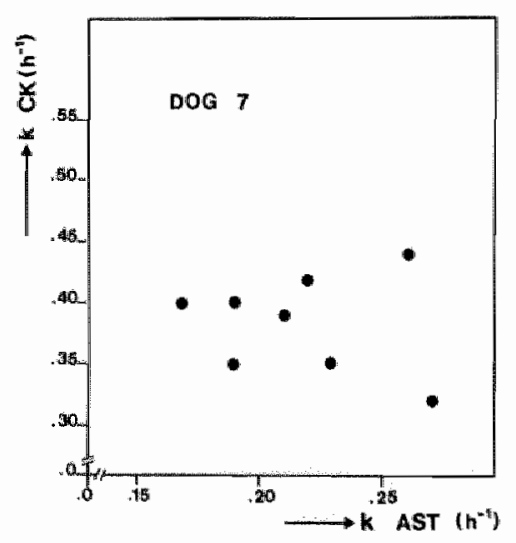

Fig. VI

Variation in apparent disappearance constants $k_{\mathrm{d}}$ for $\mathrm{CK}$ and $\mathrm{AST}$. 
Since Sterling's work on radioactive labeled albumin (sterling, 1951) many clinical and experimental studies on plasma kinetics of intravenously injected proteins have been based upon description of plasma curves as a sum of exponentials, each exponential corresponding to a separate compartment (Jacquez, 1972). However, many conflicting results were reported and it gradualdy became apparent that purification and/or labeling of proteins may cause molecular changes such that fractions of different in vivo stability may arise. For instance it was shown that the clearance rate of 131 I-labeled albumin depends upon the degree of labeling (Freeman, 1959). A well known clinical example is clotting factor IX which, after purifucation and infusion into patients with hemophilia $B$, shows a rapid elimination of about 508 of infused activity (Hermens, 1975). The presence of fractions with different in vivo lability wild result into multi-exponential clearance curves even if only a single distribution compartment is present. In this respect it should be noted that although anatomically extravascular compartments are obviously present in most animals, one-compartment behaviour occurs if the rate of exchange of protein between compartments is much slower than the rate of plasma clearance.

Data on clearance of infused AST and CK preparations in the dog have also been conflicting. Double-exponential clearance (Dunn et az., 1958; Wakim et al., 1963; She11 et at., 1971; Sobel et al., 1977) as well as mono-exponential clearance (Rapaport, 1975; Roberts et at.. 1975; Roberts et al., 1977) has been reported. As these results were interpreted by compartmental analysis, different circulatory models were proposed as mentioned in the introduction. Model Independent determination of clearance constants, as presented in this study, offers the possibility of checking the results from the 1 iterature.

From the fact that clearance constants as determined from infusions equal the mono-exponential aisappearance constants it is concluded that a one-compartment model allows adequate description of plasma kinetics of $C K$ and AST in the dog. This implies that double-exponentials as presented in the literature do not reflect alstributional effects. CK and AST are of comparable size. The molecular weights are 81,000 Daltons and 90,000 Daltons respectively (Noda et al., 1954, Martinex-Carrion et a2., 1967). As the blood-1ymph barrier does not discriminate in the passage of molecules with molecular weights ex- 
ceeding 40, 000 Daltons (Gxotte, 1956; Pappenheimer, 1953; Rutili, 1977 differences in distribution space for CK and AST are not to be expected.

The conclusion that biphasic clearance does not reflect distributional effects is further strengthened by showing that AST may show mono- or double-exponential clearance depending upon the specific enzyme preparation used. Although in this specific case one is tempted to explain the biphasic clearance of AST by the fact that a mixture of mitochondrial and cytoplasmic enzymes was injected, this hypothesis 1 s weakened by the fact that the preparation contained $54 \pm 18$ of mitochondrial AST while the faster disappearing fraction formed only $37 \pm 8$ of total activity. So only part of the mitochondrial pool could be of a more labile form. Different explanations such as differences in exposure to lysosomal proteolytic activity are equally well tenable.

The same holds true for the biphasic effect in the clearance of $\mathrm{CK}$ as found in 50 of the cases. The percentage of mitochondrial $\mathrm{CK}$ in dog heart is still a matter of debate and pH-dependent binding of mi tochondrial CK to membrane structures has been described (VIal et al., 1979). Moreover, it follows from table II that the biphasic clearance was not consistently found even if the same preparation was used in the same dog.

Several authors have demonstrated that within a few hours after intravenous injection of enzyme in the dog, enzyme levels of lymph have reached plateau values (wakim et al., 1963; Dunn et al., 1958). At first sight this finding may seem to contradict our conclusion that diffusion of AST and CK to the extravascular space can be neglected when compared to clearance. However, although locally measured enzyme activities in lymph may soon reach steady state values, total transport of enzyme through the lymphatics is limited and complete equilibration between intra- en extravascular pools may need a considerable period of time.

It would be of interest to know if use of different batches of enzyme preparation could explain part of the variation in clearance constants. However, from table II we conclude that large variations are found even if the same preparation is used. Varlations within the same dog are somewhat less although still considerable. This is in contrast to a report in the literature (Roberts et al., 1977). Even 1 we conclude that variations in clearance constants are mainly 
animal dependent, it follows from fig. VI that dogs having a relatively high clearance constant for $\mathrm{CK}$ may have a relatively low clearance constant for AST and vice versa. So enzyme clearance is not determined by some overall property of the dog and clearance mechanisms for CK and MST seem to be independent.

In conclusion our results show that for enzymes which are cleared as fast as CK and AST, or faster, diffusion to the extravascular space can be neglected and the one-compartment model allows adequate description of plasma time-activity curves in the dog.

\section{References}

1. AGRESS, C.M., Jacobs, H.I., Glassner, H.F., Lederer, M.A., Clatk, W.G., Wroblewski, F., Karmen, A., and LaDue, J.S.: Serum transaminase levells fin experimental myocardial infarction.

circulation, 11: $711 \mathrm{~m}=713,1955$.

2. BECK, J.V., Arnold, K.J.: Parameter estimation in engineexiug and science. New York, Wiley and Sons, 1977, pp. 386-387.

3. DELI, R.B., Sciacca, R. Lieberan, K., Case, D.B., and Canon, P.J.: A weighted least square technique for the analysis of kimetic data and its application to the study of renal. 133 xenon washout in aogs and $\mathrm{man}$.

Cire. Res., 22: 71-84, 1973 .

4. DUNN, M., Martins, J., Reissmann, K.R.: The djsappearance rate of glutamic oxalacetic transaminase from the circulation and its distribution in the body's fluid compartments and secretions.

J. Lab. \& Clin. Med. , 51:259-265, 1958.

5. FREEMAN, T.: The biological behaviour of normal and denaturea human plasma albumin.

Clin. Chim. Acta, 4: 788-792, 1959.

6. GROTTE, G.: Passage of dextran molecules across the blood-lymph barrier. Acta Chit. Scand. Supp. $211: 1-84,1956$

7. HERMENS, W. Ih. : Dose calculation of human factor VIII and factor IX concentrates fox infusion therapy. In Handbook of Hemophilia part II. edited by K.M. Brinkhous and H.C. Hemker, New York, Anerican Edseviex, 1975, pp. 569589.

8. JACQURz, J.A.: Compartmental analysis in biology and medicine. Amsteraam, Elsevier publishing Company, 1972.

9. KJEKshus, J.K., and Sobel, B.E. : Depressed myocardial creatine phosphoklnase activity following experimental myacardal infaretion in rabblt. Gire. Res., 27: 403-414, 1970

10. MARTINEZ-CARRTON, M., Turrano, C., Chiancone, E., Bossa, F., Giartosio, M., kiva, F., and Faselia, P.: Isolation and characterization of mitiple forms of glutamate-aspartate aminotransferase from plg heart.

J. Biol. Chem. 242: 2397-2409, 1967 .

11. MODA, I., Juby, S.A., Laxdy, H.A.: Adenosine- triphosphate-cxeatine transphosphorylase Ir. Homogeneity and physioochemical properties.

J. Btol. Chem. 209: 203-210, 1954. 


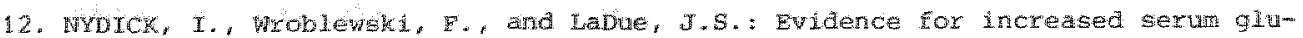

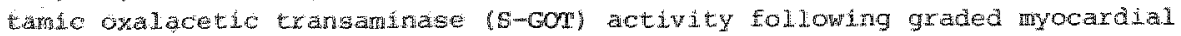
Lritarete in doge.

Croulation, 12: 16:-168, 1955,

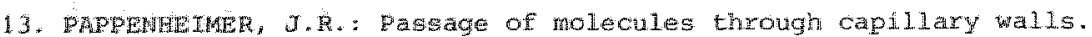
Prystot. Pev., 33: $387-423,1953$.

14. Raphori, E.: The fractional alsappearance rate of separate isoenzymes of creatine phosphokinase in the dog.

Cortiowaso. Rea. 9: 473-477, 1975.

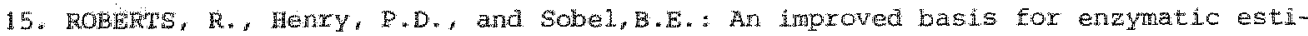
mation of infaret size.

Ciroulation, 52:743-754, 1975 .

16. RoBErT, R. and sobe1, B.E.: Effect of selected arugs and myocardial infarction on the disapearance of creatine kinase from the circulation in conscious dog.

Cardiotaba. Rea. * 11: 103-112, 1977.

17. NuEGSEGEF, P., Nydick, I., Freiman, A, and LaDue, J.S.: Sexum activity patterns of glutamic oxaloacetic transaminase, glutamic pyruvic transaminase and lactic dehydrogenase following graded myocardial infarction in dogs. Cricu. Res. 7: 4-10, 1959.

18. RUTIII, G., and Arfors, K.E." Protein concentration in interstitial and 1ymphat lo fluid from the subcutaneous tissue. Aota physiot. Scand., 99: 1-8, 1977.

19. SHEL, W.E. KJekshus, J.K., and Sobel, B.E.: Quantitative assessment of the extent of myocardial infarction in the conscious dog by mears of dinadysis of sexial changes in sexum creatine phosphokinase activity. I. C2in. Invest., 50: 2614-2625, 1971.

20. SOBEL, B.E., Markham, J., Karlsberg, R.P., and Roberts, R.: The nature of alsappearance of creatine kinase from the circulation and its influence on enzymatic estimation of infarct size.

Ciro. Res., 41: 836-844, 1977 .

21. STERLING, K.: The turnover rate of serum albumin in man as measured by 131 Itagged alloumin.

d. Clin. Invest., 30: 1228-1237, 1951 .

22. VIAL, C., Font, B., and Goldschmidt, D. : Phosphate and pH dependence of creatine kinase with heart mitochondxia (abstract).

J. Mol. Cetz. Cardiol. (suppl. III), 11.62, 1979.

23. WhGNER, J.C.: Fundamentals of clinical pharmacokinetics. Hamiltan, Hamijton Press Inc. 1975, PP. 90-94.

24. WAKM, K.G., and Flessher, G.A.: The fate of enzymes in body fluids. II. Disappeatince of glutamic oxalacetic transaminase I and II wher various conditions.

d. Lab. Clik. Med., 61, 86-103, 1963. 


\section{Quantitation of intravenously and intramuscularly administered doses of enzyme}

Sumang

This study regards the validation of methods presently used for the quantitation of tissue necrosis. Intravenously and intramuscularly administered doses of liver enzymes were quantitated from the enzme activity in serial plasma samples. The calculated release in plasma was compared to the dose administered.

For quantitation of the total activity infused in plasma a method was used, which allows estimation of the individual clearance constants of rapidiy cleared enzymes (AST and GPI), using a simultaneously measured slowly cleared enzyme (ALT) as a reference (WHllems et a., $1979 b$.

It was demonstrated that using ALT as a reference enzyme, simultaneous $1 Y$ measured ASI infusions could be quantitated with a mean recovery of $95.8 \pm 12.2 \%$ (mean $\pm S D, n=12$ ), whereas simultaneous measured GPI infusions were quantitated with a mean recovery of $98 \pm$ $17.7 \mathrm{~g}$ (mean $\pm \mathrm{SD}, \mathrm{n}=12$ )

Using the mean plasma volume value and the mean value for the clearance rate of ALT, as estimated from separate bolus injections, the infused amount of this slowly metabolized enzyme could be quartitated with a mean recovery of $100 \pm 7.70$ (mean $\pm S D, n=12$ ).

The proportionality constants $\rho, i . e$. the ratios of the enzyme activities $\rho$ (ALT/AST), $D$ (ALT/GPI) and $\rho$ (AST/GPI), as obtained from the fit corresponded very closely to the ratios of enzyme activities in the enzyme preparations used for the expertments.

We conclude that for rapidly metabolized enzymes AST and GPI, the use of individualized clearance constants as obtained from the fit, gives an improwement of the results, as compared to results obtained with fixed mean values of the clearance constants. The best results for quantitations of enzyme levels in plasma were however obtained with a slowly metrabolized enzyme ALI, s using the mean value of the clearance constant in all experiments.

After intramuscular injections at least $75 \%$ of the ALT activity 
administered was recovered in plasma, whereas for AsT $B 6$ of the activity injected was reased into the plasma compartment. These results indicate that for AST there is very few lacal inactivation of enzyme activity at the site of injection, or during transport through the interstitial fluid. Release of enzyme from the muscle continued up to $40-50$ hours.

We conclude that in order to minimize errors in calculations of tissue damage from enzyme levels in plasma, one should select enzymes that are slowly metabolized, and show complete washout from the tissue.

rntroduction

Since 1970 several authors have investigated the quantitative relation between total enzyme release in plasma and myocaraial infarct size. Estimation of enzymatic infarct size strongly depends on the specific circulatory model used and each model parameter influences the final estimate of infarct silze.

In experimental studies in dogs poor correlations between the morphological assessment of infarct size and the calculated total release of creatine kinase have been observed (Jarmakani et a ., 1976 and Roe et at., 1977).

In the study by Roe et al. (1977) enzymatic infarct size (EIS) has been calculated according to model parameters by shell et al. (1971), Norris et al. (1975) and Roberts at at. (1975).

The model. by shell et al. is based upon bolus injections of CK preparations in dogs and consists of a one-compartment model with a total. distribution volume, which is almost 3 times plasma volume; a fixed value of the clearance rate was used in all experiments. In chapter $V$ we demonstrated however that $\mathrm{ck}$ clearance after bolus injection is best described by a one-compartment model including plasma volume on$1 y$.

In the model by Norris et at. (1975) individualized clearance rates were obtained from the final part of the $\mathrm{CK}$ clearance curve after myocardial infarction. For the distribution volume the same value as observed by she11 et al. (1971) was used.

The model by Roberts et a. " (1975) was a one-compartment model includimg plasma volume only and individual clearance rates were obtained as described by Norris et al. (1975).

willems et al. (1979a) demonstrated that release of enzymes from the 
infarcted tissue continues even up to 96 hours and therefore estimation of individual clearance rates of CK from the plasma curve after for instance 36-48 hours, as advocated by Norris at al. results in a large underestimation of $\mathrm{CK}$ clearance rate. The observed ck clearance rate by Willems et al. (1979a) was about three times higher than the value measured by Norris. In this study the transcapiliary escape rate between $V_{1}$ and $V_{e}$ was about 1.7 per hour and is a factor three lower as observed by Witteveen et al. (1975). The extravasculan volume was about 80 of the plasma volume.

Errors in the model parameters will result in errors in EIS, but also errors in histologically assessed infarct size (HIS) may explain the lack of a correlation between EIS and HIS after coronary occlusion. This possibility is suggested by a number of studies in dogs (shell et $42 ., 1.971$ ) and baboons (Yasmineh et a., , 1976) demonstrating a good correlation between time-integrated $\mathrm{CK}$ activities and myocardial ck depletion.

Willems et al. concluded (1979b) that using HBD as a reference enzyme individual clearance constants of AST, CK and GPI can be obtained from the first 36 hours after infarction, when there is still release of enzyme in the circulation. The ratio of the released quantities of different enzymes agreed with heart tissue content. The released guantities of CK showed considerable variance in proportion to the other enzymes.

The aim of the present study is validation of the method by Wilems et $a t$, which thus far has only been applied to patients with acute myocardial infarction. In the present study different types of infusions have been quantitated from plasma enzyme levels. plasma enzyme patterns comparable to those obtained after acute myocardal infarction, were obtained by varying the rate of infusion.

Also in the present study intramuscular injections of AST and ALT activity were quantitated in order to estimate the total recovery of enzyme activity in plasma.

Materiats and methods

Mongrel dogs of either sex and ranging in weight from $15-35 \mathrm{~kg}$, were used in all experiments. D1, D2, D3, D10 and D1 1 were labradors. Enzyme preparations were obtained from dog liver as described in chapter IV, AST, ALT and GPI activities were assayed spectrophotomet- 
rically at $25^{\circ} \mathrm{C}$, as described in chapter III. Enzyme activities were expressed in units per 1itre plasma $(0 / 1)$. Methods used for the separation of soenzymes have been described in chapter III. For AST 90.5 \pm 0.4 (mean \pm SD) of the total activity consisted of the cytoplasmic isoenzyme (CASt).

Intused and injected enzyme preparations were used as a standard to correct for inter-assay varlations ( $c f$. chapter III).

Aaministration of enzyme preparations and collection of blood samples was performed as described in chapter IV. After bolus injections samples were taken at regular intervals during 5 days (see fig. I). No premedication ( $f$ " below) was administered during these experiments.

Enzyme preparations as used for infusions were diluted $4-5$ times in physiological saline. A Harvard pump (type 903) was used to infuse the enzyme preparations. During infusion of the enzyme preparations, samples were taken every 15 minutes for 3 to 4 hours. In the first 5 experiments the enzyme preparations were infused at a constant rate of of $6.108 \mathrm{ml} / \mathrm{hour}$. In the last 7 experiments the enzyme preparations were infused at wariable rates $(3-10 \mathrm{ml} / \mathrm{hour})$.

The infusion pump was stopped after 3-4 hours and hereafter samples were taken every 15 minutes, during $1-2$ hours, in order to obtain an independent indication of the apparent enzyme clearance rate from a mono-exponential $F i t$ on the latter part of the curve $\left(\mathrm{k}_{\mathrm{d}}\right)$.

The total number of units infused was read from the syringe. Calibration of the syringe was checked by weighing and reweighing; the number of $\mathrm{ml}$ infused could be read within 2-38 accurately. The total number of units infused could be estimated within 4-6: accurately.

For each dog the individual value of the plasma rolume was obtalned from ALi dilution after bolus injection, using the same enzyme preparations as used for the infusion experiments.

During continuous infusion expeximents the dogs were premedicated with vetrangui. ${ }^{1}$ l. $\mathrm{mg} / \mathrm{kg}$ (azepromazin base), symoron $1 \mathrm{mg} / \mathrm{kg}$ and atropine $0.1 \mathrm{mg} / \mathrm{kg}$. given at the start of the experiment. A possible effect of premedication on enzyme clearance rates was verified by controll experiments, in which premedication was given 2 to 3 hours after the bolus injection (af. chapter $v)$; no effects were observed.

Hematocrit values were determined in most of the experiments (see complete data, appendix I), using the micracapillary centrifug- 
ing technique, by centrifuging at $15,000 \mathrm{~g}$ for 5 minutes.

Intramuscular injections were given deep into the gluteus muscle. Enzyme preparations were not diluted and about 7 mi of the preparation was injected at each side. No premedication was administered during these experiments. $\mathrm{CK}$ activity was measured in all samples in order to estimate muscle damage, caused by the intramuscular injeotions. In all experiments CK activity remained below $250 / 1$ (see complete data, appendix I). Dog muscle contains about 30 times as much CK activity as AST activity per gram wet tissue. Therefore the amount of AST released because of muscle damage was less than 1 unit per litre.

Normal steady state plasma enzyme activities were determined from 3 successive samples taken at 5 minute intervals before the enzyme preparations were administered.

Analysis of bolus injections

Mono- and double-exponential fits on the plasma curves were performed as described in chapter $V$.

Amalys is of infusions

For rapidly cleared enzymes, like AST and GPI, the quantity of enzyme diffused to the extravascular space can be neglected, if compared to the amount of enzyme cleared. This implies that a one-compartment model can be used in good approximation. As the infusions were given during 3-6 hours a fixed mean value can be used for the clearance constant of the slowly metabolized reference enzyme ALT. We used the value of $k_{a}=0.034 \mathrm{~h}^{-1}$ as estumated from bolus injections of ALT, sampled during the same period as taken for the infusion experiments (ef. results).

The amount of enzyme released into plasma at any time tis:

$$
Q(t)=c(t)+k \int_{0}^{t} c(s) d s
$$

If the release of enzymes into plasma runs in paraliel:

$$
Q_{E 1}=\rho \cdot Q_{E 2} \quad\left(k_{E 1} \ll k_{E 2}\right)
$$




$$
C_{E 1}(t)+k_{d E 1} \int_{0}^{t} C_{E 1}(s) d s=\rho C_{E 2}+k \rho \int_{0}^{t} C_{E 2}(s) d s
$$

Using EL (ALT) as a reference enzyme, individual values of enzyme clearance constants of E2 (AST or GPI) can be determined. Hereafter the amount of enzyme released in plasma can be computed from (1).

AnaTysts of intratiscular injections

Enzyme release in plasma after intramuscular injection of enzyme activity is stretched over a considerably longer period, $i$. $e$. 40-50 hours. Therefore a one-compartment model approximation is no longer sufficient and a two-compartment model, taking into consideration the diffusion to $V_{e}$, should be applied to these data. The fitting procedure as described above was not yet available for the two-compartment model. Therefore the intramuscular injections were quantitated with mean values of AST and ALT clearance constants as obtained from bolus injections: $k_{A S T}=0.19 \mathrm{~h}^{-1}$ and $k_{A L T}=0.022 \mathrm{~h}^{-1}$. For AST, enzyme activity in plasma after intramuscular injections had returned to normal values and total. release in plasma could be quantitated from (1). For ALT the slowly cleared enzyme in most experiments activity had not returned to normal values and the total release in plasma was calculated from:

$$
Q(t)=C(t)+k \int_{0}^{t} C(s) d s+P / V_{1} \int_{0}^{t} e^{-P / V_{e}(t-s)} c(s) d s
$$

When extravascular breakdown or local inactivation of enzyme activity occurs, the total recovery in plasma as computed from the above mentioned equations w111 be less than $100 \%$.

Computer sinulations

Computer stmulations were used to evaluate the variation in the estimated parameter values. Simulated curves were computed from equations (1) and (2) by substituting the mean values of the parameters indicated in tabel II. The sample scheme of the simulated curves was comparable to that of the experimental curves. A random error equal to the mean percentage of deviation as found for the experimental curves was added to the data polnts of the simulated curves, which thereupon were used as if they were obtained from dogs. The mean pa- 
rameter values and the $95 \%$ confidence limis were computed from 25 simulations.

Res $34 t \operatorname{tin}$

Fig. I.1. shows ALT, AST and GPI activities ir plasma samples taken during 100 hours after an intravenous bolus injection. In fig. I.2. the first 10 hours are represented separately.

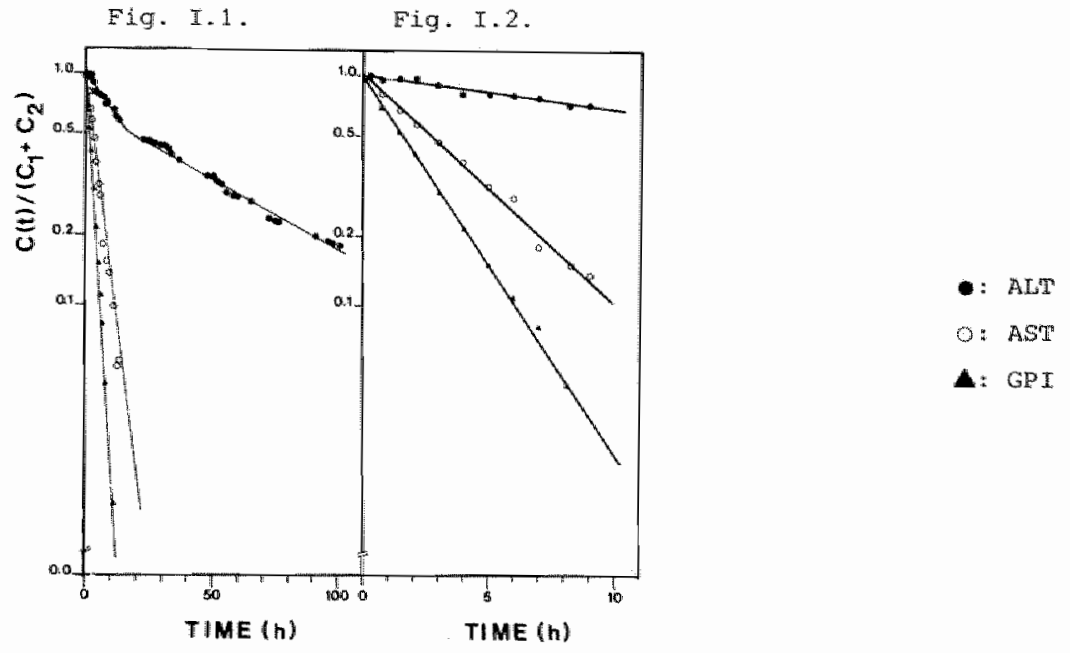

Fig. I.1.,2. Clearance curves of ALT, AST and GPI after a single bolus injection. Fig. I.2.: The first 10 hours of the experiment (Experiment 3, table I).

Complete equilibration between intra- and extravascular ALT pools occurred atter about 20 hours. During this period AST and GPI were already cleared from the circulation. Therefore equilibrium between intra- and extravascular concentrations was not attalned for these fast cleared enzymes and AST and GPI clearance curves wexe best degcribed by a mono-exponential function.

Table I shows results of double-exponential fits on ALT clearance curves. Large inter-individual variations in model parameters were observed, whereas repeated bolus injections in the same dog resulted in very much similar results.

Fig. II.1. and fig. II.2. show respectively plasma enzyme patterns during and after (1) constant rate infusions and (2) infu- 


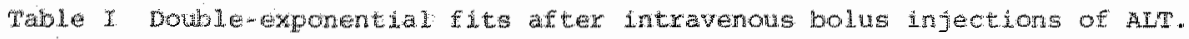

\begin{tabular}{|c|c|c|c|c|c|c|c|c|c|c|c|c|c|}
\hline $\operatorname{Dog}$ & $\begin{array}{c}c_{1} \\
(U / D)\end{array}$ & $\begin{array}{l}\mathrm{dC}_{1} \\
(\mathrm{a})\end{array}$ & $\begin{array}{c}\mathrm{C}_{2} \\
(\mathrm{U} / \mathrm{I})\end{array}$ & $\begin{array}{r}d c_{2} \\
\left(w_{1}\right.\end{array}$ & $\frac{b}{n^{-1}}$ & $\begin{array}{l}d b \\
b j\end{array}$ & $\frac{a}{\left(\mathrm{~h}^{-1}\right)}$ & $\begin{array}{l}d a \\
(\mathrm{w})\end{array}$ & $\begin{array}{c}C_{Y y} \\
(U / 1)\end{array}$ & $\begin{array}{c}\text { res } \\
(x)\end{array}$ & $\frac{\mathrm{k}^{2}}{\left(\mathrm{~h}^{-1}\right)}$ & $W_{e} / w_{i}$ & $\begin{array}{l}P / v_{i} \\
\left(h^{-1}\right)\end{array}$ \\
\hline $\mathrm{DI}$ & 194.5 & 9 & 181.2 & 8.8 & 0.12 & 23 & 0.015 & 8 & 22.1 & 3.5 & 0.027 & 0.62 & 0.042 \\
\hline$D 1$ & 244.2 & 10 & $275+0$ & 5.4 & 0.15 & 19 & 0.015 & 6 & 16.3 & 3.1 & 0.026 & 0.61 & 0.052 \\
\hline$D 3$ & 125.7 & 20 & 284.6 & 8.4 & 0.11 & 40 & 0.014 & 9 & 7.8 & 3.7 & 0.019 & 0.30 & $0.02 A_{3}$ \\
\hline$D 2$ & 233.4 & 7 & 282.7 & 6.6 & 0.10 & 15 & 0.010 & 11 & 42.0 & 1.1 & 0.016 & 0.56 & 0.031 \\
\hline $\mathrm{D3}$ & 181.0 & 14 & 298.6 & 9.1 & 0.09 & 27 & 0.014 & 8 & 11.9 & 2.5 & 0.021 & 0.35 & 0.021 \\
\hline Man & 193.6 & 12 & 265.0 & 7.7 & 0.11 & 25 & 0.014 & 9 & 20.0 & 2.8 & 0.022 & 0.49 & 0.034 \\
\hline $\mathrm{EV}$ & 24.5 & 42 & 17.9 & 21 & 20.2 & 40 & 15.0 & 22 & 66.9 & 39.0 & 21.4 & 31.1 & 38.0 \\
\hline
\end{tabular}

$e_{1}, C_{2}, C_{n}$, a, $b$ : obtalned best-fit values for the double-exponential function. See analysis of bois injections chapter $\mathrm{V}$.

K. $V_{e} / V_{i}, p / V_{i}$ : calculated drculatory parameters (chapter $v$.

$P / V_{i}$ (TER) : transcaplilary escape rate $\left(h^{-1}\right)$

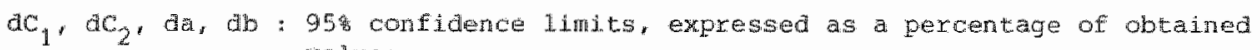
vajues.

res. $\quad$ resldue quality of fit expressed as the mean residual deviation pex datapoint expressed as a percentage of the neasured activity.

Complite data see appendix I; complete data chapter VI, table II.

Fig. II. 1. constant rate infusion

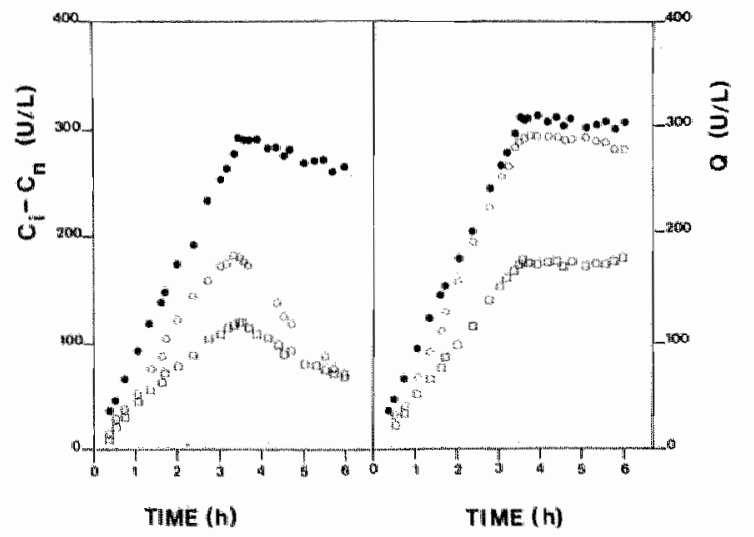

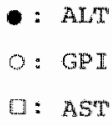

Experiment nr. 5 of table II is shown.

$Q$ : total number of units infused per litre plasma, as estimated from plasma enzyme pattern auring and after intusion. 
Fig. M. 2. Infusion at varying rates

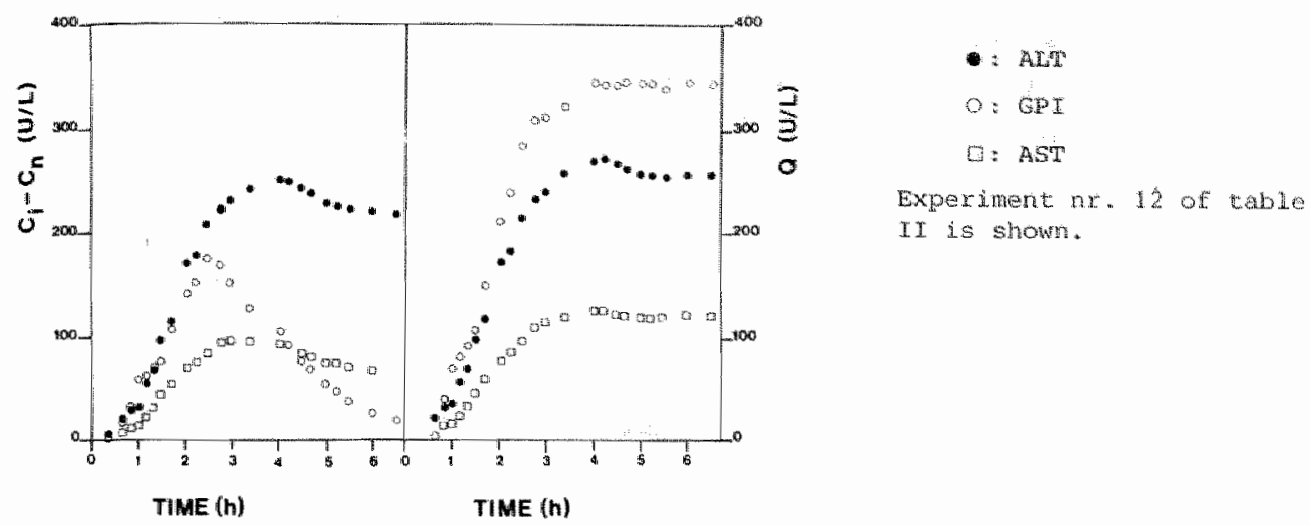

$Q$ : total number of units infused per litre plasma as estinated
from plasma enzme pattern during and atem infusion.

sions at varying rates.

The computed enzyme release functions are also depicted $(Q)$. The fitting procedure based upon equations (1) and (2) was applied to AST, GPI and ALT activities determined simultaneously in 12 different experiments. Table II.1. presents results of quantitation of AST infusions using $\mathbb{A L} T$ as a reference enzyme. The reference $k_{d}$ was obtained from a mono-exponential fit on ALT clearance curves after boIus injections, sampled during the same period as taken for the infusion experiments. The apparent clearance constant k was measured in the same dogs as used for the infusion experiments $\left(k_{d}=0.034 \pm 12 \%\right.$, mean $\pm S D, n=5$ ).

Using the mean value for the apparent disappearance constant $k_{d}$ of ALT and the mean value for the plasma volume $(47.4 \mathrm{ml} / \mathrm{kg})$, ALT infusions were quantitated with a mean recovery of $100 \pm 7.7$ (nean \pm SD, $\mathrm{n}=12$ ) : Quantitation of AST infusions using ALT as a reference enzyme resulted in a mean recovery of $95.8 \pm 12.2 \%$ (mean $\pm S D, n=12$ )

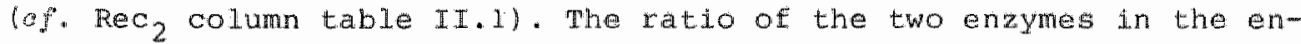
zyme preparation $p$ (ALT/AST) was estimated within 13 accurate $1 y$. Table IT.2. presents results of quantitation of GPI infusions, using ALT as a reference enzyme. GPI infusions were quantitated with a mean recovery of $98 \pm 17.7 \%$ (mean $\pm \mathrm{SD}, \mathrm{n}=12 \mathrm{y}$ (c.\%. Rec column table II.2.). Using individual plasma volume values, as obtained from enzyme dilution after bolus injection (chapter IV), ALT, ASP and GPI infusions were quantitated wh mean recoveries of respectively $100 \pm$ 


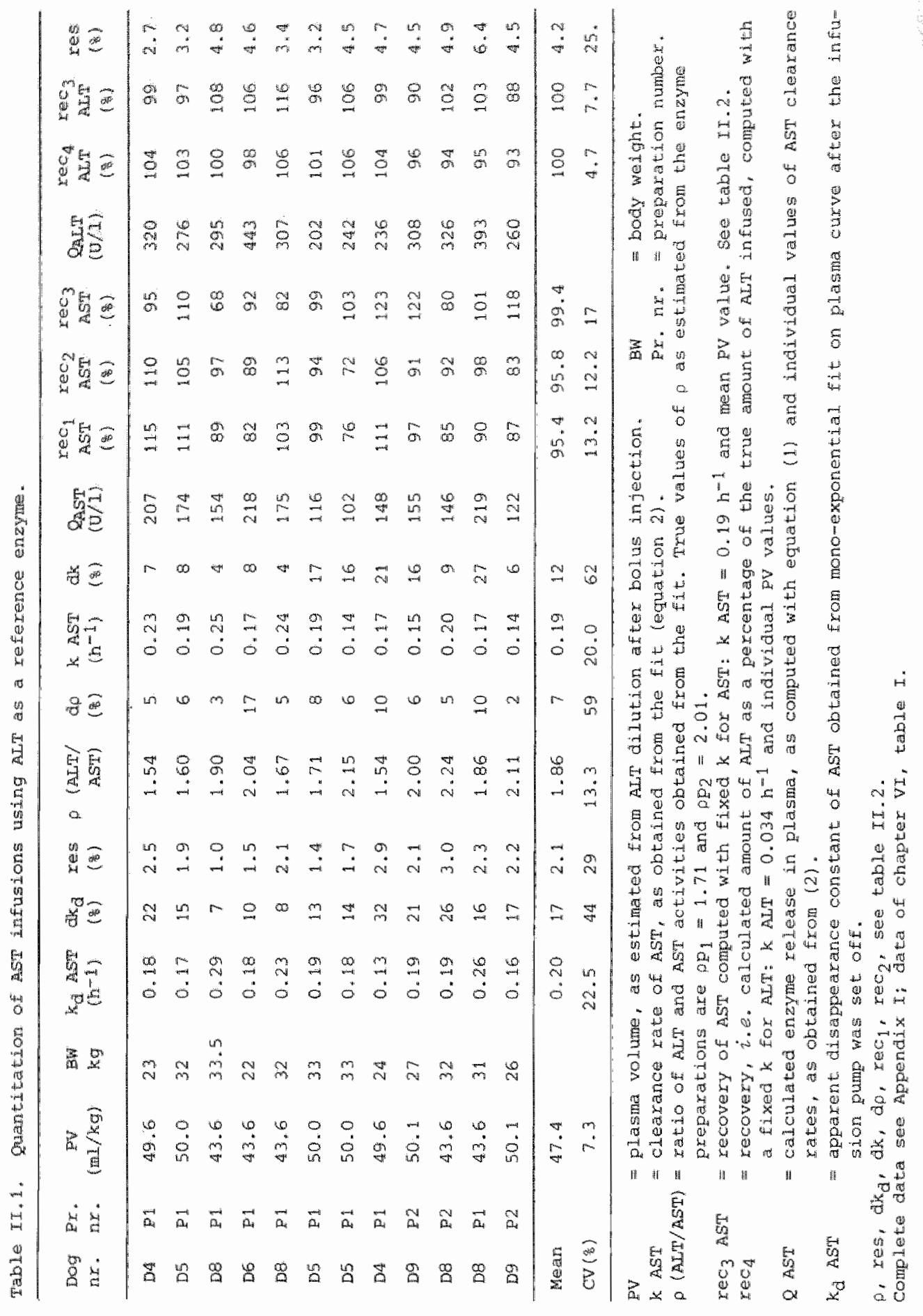


Table Id.2. Guantitation of GPI infusions using ALn as a keterence oumm.

\begin{tabular}{|c|c|c|c|c|c|c|c|c|c|c|c|}
\hline $\begin{array}{l}\mathrm{Exp} \\
\mathrm{nI}^{*}\end{array}$ & $\begin{array}{c}\mathrm{K}_{\mathrm{a}} \text { GQI } \\
\left(\mathrm{h}^{-1}\right)\end{array}$ & $\underset{(\mathrm{ag})}{\mathrm{ak}}$ & $\begin{array}{r}\text { (ALT/ } \\
\text { GPI) }\end{array}$ & $\begin{array}{l}\text { ap } \\
\text { (as }\end{array}$ & $\begin{array}{l}k G E I \\
\left(h^{-1}\right)\end{array}$ & 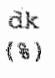 & $\begin{array}{l}26 \mathrm{P} \\
(\mathrm{O} / \mathrm{I})\end{array}$ & $\begin{array}{c}r e c_{1} \mathrm{dP} \\
(\mathrm{s})\end{array}$ & 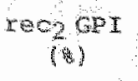 & $\begin{array}{c}100 \mathrm{CPI} \\
(3)\end{array}$ & $\begin{array}{l}\text { yes: } \\
\text { (4) }\end{array}$ \\
\hline 1 & 0.39 & 7 & 0.606 & 5 & 0.38 & 5 & 514 & 142 & 136 & 136 & 2.7 \\
\hline 2 & 0.37 & 15 & 0.662 & 15 & 0.37 & 7 & 410 & 130 & 124 & 126 & 3.2 \\
\hline 3 & 0.74 & 3 & 0.884 & 8 & 0.56 & 4 & 320 & 93 & 101 & 68 & 4.3 \\
\hline 4 & 0.32 & 8 & 1.05 & 7 & 0.26 & 9 & 011 & 79 & 86 & 125 & 4.6 \\
\hline 5 & 0.37 & 8 & 0.957 & 5 & 0.34 & 4 & 290 & 86 & 93 & 104 & 3.4 \\
\hline 6 & 0.39 & 16 & 0.845 & 7 & 0.34 & $B$ & 235 & 100 & 95 & 106 & 3.2 \\
\hline 7 & 0.38 & 16 & 1.174 & 7 & 0.38 & 7 & 193 & 72 & 68 & 68 & 4.5 \\
\hline 8 & 0.20 & 18 & 0.929 & 7 & 0.28 & 7 & 250 & 97 & 93 & 126 & 4.7 \\
\hline 9 & 0.42 & 20 & 0.785 & 6 & 0.31 & 7 & 379 & 103 & 97 & 119 & 4.5 \\
\hline 10 & 0.59 & 14 & 0.836 & 8 & 0.40 & 7 & 360 & 92 & 100 & 95 & 4.9 \\
\hline 11 & 0.42 & 10 & 0.973 & 9 & 0.32 & 12 & 396 & 92 & 89 & 105 & 6.4 \\
\hline 12 & 0.69 & 2 & 0.802 & 1 & 0.59 & 4 & 329 & 102 & 97 & 62 & 4.5 \\
\hline Mean & 0.44 & 12 & 0.879 & 7 & 0.38 & 7 & & 98 & 98 & 103 & 4.3 \\
\hline $\mathrm{CV}(\mathrm{s})$ & 35.3 & 46 & 17.9 & 45 & 26.9 & 35 & & $20 \cdot 6$ & 17.7 & 24.5 & 2.4 \\
\hline
\end{tabular}

Experinent numbers correspond to experiments in table II.1.

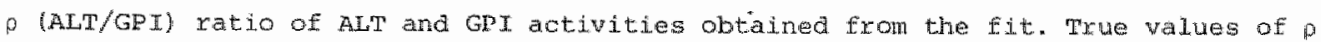
as estimated from the enzyme preparations: $\mathrm{P}_{1}=0.855$ and $0 \mathrm{p}_{2}=0.872$.

$\mathrm{k}_{\mathrm{d}} \quad$ = apparent disappearance contant $\left(h^{-1}\right.$, see table II. I.

Q = calculated enzyme release in plasma, see table II. 1 .

$k$ = clearance rate af GPI as obtained Fron the fit (equation (2)).

res = guality of fit expressed as the mean residual deviation pex data point expressed as a percentage of measured activity.

$a k, d p, a k_{d}=95 \%$ confidence limits, expressed as a percentage of the parameter

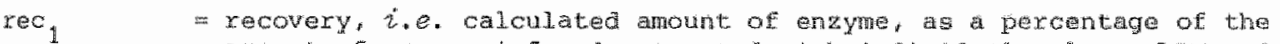
amount of enzyme infused, computed with individual value of PV and $k$.

$\operatorname{rec}_{2} \quad$ recovery, computed whth the mean pw walwe, and individual values ob the clearance constants.

$\mathrm{rec}_{3} \quad=$ recovery, 2. a. calculated amount of enzyme, as percentage of the true anount of anzyme infused, computed with fixed $k$ for GPI: kAst $=0.38 h^{-1}$ and rmean $P$ value.

complete data see appendix I; data of chapter VI, table $I$.

$4.78,95 \pm 13.28$ and $98 \pm 20.6 \%$ (mean $\pm 5 D, r=12)\left(0 f^{\circ}\right.$ rec and rec $_{4}$ columns tables II.1. and $\left.\mathrm{II} .2.\right)$. These results were not significantly different from the results obtalned with a mean plasma volume

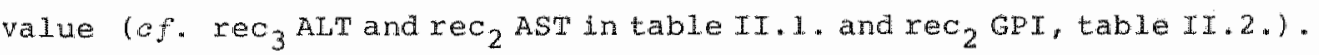
The use of fixed mean values for the clearance constants $i^{*} e . k n j=$ 
$0.0342 \mathrm{~h}^{-1}, \mathrm{k}_{\mathrm{nSp}}=0.19 \mathrm{~h}^{-1}$ and $\mathrm{k}_{\mathrm{GPI}}=0.38 \mathrm{~h}^{-1}$ resulted in variations of $17 \%$ and $24 \%$ for the mean recoveries of respectively AsI and GPI activities in plasma 60 rec $_{3}$ columns in tables II.1. and II.2. . comparison of these values with variations of respectively 12 and 178 obtained with individual estimates of the clearance constants of AST and GPI ( $c f$. rec 2 colums in Tables II.1. and II.2.) and variathons of respectively 11 and 9 ar due to errors in the fitting procedure $\left(0 f^{\prime}\right.$. computer simulations, table III) we conclude that for AST. as we 11 as GPI the use of individual estimates of clearance constants results in reduced variation in the calculated recovery.

Table III computer simulations.

\begin{tabular}{|c|c|c|c|c|c|c|}
\hline & $\rho \quad(G P \mathrm{~T} / \mathrm{A} S \mathrm{~T})$ & $\begin{array}{l}k_{G P I} \\
\left(n^{-1}\right)\end{array}$ & $\begin{array}{l}\operatorname{xes} \\
(a)\end{array}$ & $\rho \quad(\mathrm{AST} / \mathrm{ALT})$ & $\begin{array}{l}k_{\text {PAST }} \\
\left(h^{-1}\right)\end{array}$ & $\begin{array}{c}\text { res } \\
(\text { is }\end{array}$ \\
\hline $\begin{array}{l}\text { Parametex values off the } \\
\text { smuldted curves }\end{array}$ & 0.80 & 0.39 & - & 1.70 & 0.21 & $\sim$ \\
\hline $\begin{array}{l}\text { Mean parameter values after } \\
25 \text { silnulations }\end{array}$ & 0.78 & 0.40 & 4.8 & 1.65 & 0.22 & 4.8 \\
\hline CV (A) & 6.9 & 8.8 & 20.3 & 5.2 & 11.4 & 17.0 \\
\hline
\end{tabular}

For AST the remaining errors can satisfactorily be explained by exrors from the fitting procedure. Although the improvement in the calculated infused quantities from $17 \%$ ( $\left.\operatorname{rec}_{3} A S T\right)$ to 12 ( $\mathrm{rec}_{2}$ AST) is not statistically significant, improvement of the procedure by increase of the number of samples seems pronising.

For GPI however additional variation in plasma levels is present. The random error as used in the computer simulations forms only part of the variation found in the actual data.

Fig. II shows plasma enzyme pattern and computed enzyme release
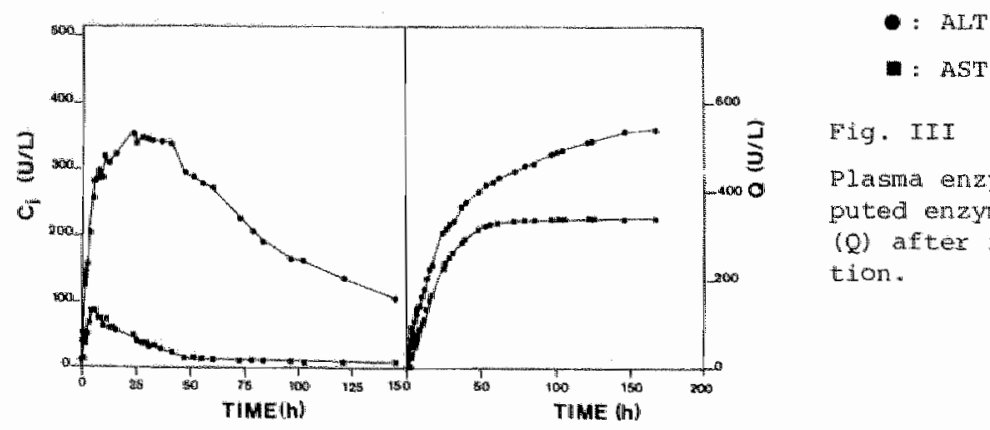

F⿻丷木 III

Plasma enzyme pattern and conputed enzyne release Function (Q) after intramuscular irjecm tion. 
function (Q) after intramuscular injection of AsT and ACT activity in the dog. Table IV shows the recoveries of AsT and Alt activities; after intramuscular injection of the envyme activity deep into the gluteus muscie. The recovery in piasma is expressed as a percentage of the true amount of enzyme injected into the gluteus muscle.

Table IV Intramuscular injections

\begin{tabular}{|c|c|c|c|c|c|}
\hline \multirow{2}{*}{ nog } & \multirow[b]{2}{*}{$\begin{array}{l}\text { prep. } \\
\text { rumiber }\end{array}$} & \multicolumn{2}{|c|}{ One-compartment model } & \multicolumn{2}{|c|}{ Two-conpaxtment model } \\
\hline & & HeC AST $(y)$ & rec ALT: & $\operatorname{rec} A I^{\prime}(\%)$ & rec $\left.\operatorname{AST}()_{3}\right)$ \\
\hline D3 & $P 1$ & 99 & 68 & 86 & 98 \\
\hline D3 & $\mathrm{P2}$ & 72 & 67 & 72 & 74 \\
\hline 010 & $D 2$ & 94 & 64 & 69 & 94 \\
\hline D11 & $\mathrm{P} 2$ & 80 & 70 & 77 & 82 \\
\hline Mean & & 86.3 & 60.8 & 75.5 & 87 \\
\hline$C V(5)$ & & 14.4 & 17 & 10.5 & 12.7 \\
\hline
\end{tabular}

rec = amount of emzyme released into plasma after intramusular injection, expressed as a percentage of the activity adninistered into the gluteus muscle of the aog.

Complete data, see appendix I; data of chapter VI, table III.

Discussion

In the literature both good and poor correlations have been observed between total enzyme release in plasma and infaxct size. A number of factors may interfere in the final relationship between cell death and enzyme release in plasma thus accounting for the occassionally observed poor correlations. In most experimental studies EIS has been related to llS. The latter method may however have a large inherent error of itself and errors in His may wrongly suggest bad results for EIS.

In some other studies the validity of the results on is have been checked by estimating infarct size for at least two different enzymes (Witteveen 1972, Norris et az., 1975 and Willems et az., 1979a). Comparable results for different enzymes have been interpreted as an indication for a reliable estimation of infarct size, although it mut be remembered that systematic errors interfering in the same extent in estimations of infarct size as calculated with different enzymes will not aisturb the observed correlations. 
In our study plasma enzyme patterns comparable to those after myocatial infarction, although stretched over a considerably shorter pexiod, wexe obtaned by varying the rate of the infusion pump. The total amount of enzyme infused was estimated from plasma enzyme levels according to the method of willens et az. (1979b). This method has already been applied to plasma enzyme levels in patients after AMI. In this study HBD was used as a reference enzyme in order to estimate Individual clearance rates of CK, $\mathrm{BST}^{\mathrm{x}}$ and GPI. Obtained values for the clearance rates were used to calculate EIS. Direct validation of this method in the dog, using the same enzymes as mentioned above was not possible, because in the dog HBD is cleared at a rate comparable to the clearance rates of CK, AST and GPI. One of the requirements of the method is that the reference enzyme is cleared at a rate considerably slower as compared to the clearance rate of the other enzymes. For enzymes in dog heart no such large differences in clearance rates were measured and therefore enzyme preparations obtained from liver tissue have been used in our study.

Als from dog liver is cleared at a rate about $10-15$ times slower than AST and GPI and was therefore used as a reference enzyme to allow estimation of individual clearance rates of AST and GPI.

As has been demonstrated in chapter $V$, behaviour of enzymes cleared as fast as AST and GPI can be approximated by a one-compartment model. For these enzymes the clearance rate from the circulation is very much largex than the rate of diffusion to the extravascular compartment (fig. I.). From bolus injections of ALT it has been estimated that the half-life for equilibration of ALT between different compartments is about 20 hours $(T E R=3.48)$. Comparable results have been obtained from a study by wakim et az. (1963).

As the bloodmymph barrier does not discriminate in the passage of molecules with molecular weights exceeding 40,000 Daltons (Grotte, 1956, Pappenhetmer, 1953 and Ruti11, 1977) comparable transcapi1lary escape rates are to be expected for AsT and GPI. These enzymes are however cleamed from the circulation before equilibration between different compartments could have occurred (fig. I.2.). Therefore clearance of these enzymes from the circulation is best described by a mono-exponential function; $i$.e. a one-compartment model. During infusion experiments, enzyme preparations were alministered for about 3-6 hours. Within this period equilibration between different compartments could not have occurred for either of the enzymes and the 
reference $k$ of ALT was therefore best approximated by the apparent clearance constant $k_{d}$ of $A I T$, consisting of both clearance and diffusion to $V_{e}$. It was demonstrated that using ALT as a reference enzyme, AST infusions can be quantitated within 12 accurately, whereas for GPI much larger variations were observed. From computer simullations it can be concluded that varlations found for AST can be fully explained by experimental error, whereas for GPI much unexplained var1ance is left.

It was also shown that for AST and GPI quantitation of the infusions with individual clearance constants as obtained from the fit did result in a reduction of the total variation in the recovery of these enzymes, although it was not significant. The best results were nowever obtained for ALT, using the mean value of the apparent clearance rate, as obtained from separate bolus injections. The advantage of a slowly metabolized enzyme for quantitation purposes, becomes apparent when it is considerea that the contribution of the clearance term will be much smaller for such an enzyme and errors in the estimated clearance rate will therefore influence the final quantitation much less than in case of a rapidly cleared enzyme.

In order to obtain an independent check on the estimated individual clearance rates of AST and GPI, apparent clearance rates were estimated from enzyme activities in samples taken during $1-2$ hours after the infusion pump was set off. Values for the apparent clearance constants $\left(k_{d}\right)$ correspond to values as obtained from the $f 1 t(k)$. From 5-7 sample points only a rough indication of the apparent clearance constant is obtained, as becomes apparent from the 95 confidence limites.

We conclude that the method of willems a $h$. can indeed be used to obtain individual values for AST and GPI clearance rates using ALT as a reference enzyme, even when there is still release of enzyme into the circulation.

sstimation of individual clearance rates gave an improvement of the results for both $\mathrm{AST}$ and GPI.

In 1975 Roberts et $a \%$. demonstrated that 63 of the original $\mathrm{CK}$ activity present in dog heart was not recovered in plasma after myocardial infarction. For the quantitation of tissue damage from plasma enzyme levels, it is of great importance to know the total amount of enzyme that will be released in plasma and to know the inter-individ- 
Ual variation in the recovery in plasma between individuals.

In the present study intramuscular injections were given in order to estimate the amount of enzyme recovered in plasma. In 1963 wakin et al. observed that after intramuscular injection of AsT in the dog the maximal activity in plasma corresponded to one fifth of the activity of this dose linjected, as is in agreement with our results. These anthors did not calculate the total integrated amount of enzyme recovered in plasma. In the present study the total integrated recoveries of the amount of AST and ALT in plasma, were respectively $95 \%$ and $75 \%$ using the mean values for the clearance constants as obtained from bolus injections.

These results are in striking contrast with the low recovery observed for CK in plasma after acute myocardial infarction (Roberts et al., $1975 \%$, which is probably introduced because CK shows accelerated denaturation in dog lymph (Robison, 1975).

We conclude that in order to minimize errors in calculations of tissue damage one should selectenzymes that are slowly metabolized and show a complete washout from the injured tissue, $i . e$. that do not show accelerated denaturation in lymph.

\section{Referenged}

1. BIEIFELD, W., Mathey, D., Hanrath, P., Buss, H., and Effert, 5. : Infarct size estimated from serial sexum creatine phosphokinase in relation to left ventricular hemodynamics.

Cixaulation, 55: 303-311, 1977 .

2. ClARK, G.L. "Robison, A.K., Gnepp, D.R., Roberts, R., and Sobel, B.E.: Effects of lymphatic transport of enzyme on plasma creatine kinase time-activity curves aftex myocardial infarction in dogs. Curce. Res. 43: 162-169, 1978.

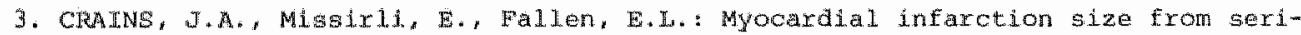
a CPK serum entry ratio with size and model of infarction. Clroulation, $58: 1143-1153,1978$.

4. GIROIn, G.: Pasage of dextran molecules across the blood-1ympla barrier. Aota Chin Sadnd. Supp. 211: 1-94, 1956.

5. JAMAKANI, I.M., Limbird, L., Graham, I.C., and Marks, R.A.: Effect of repertuslion on myocadial infarct, and the accuracy of estimating infarct size froth saxum exeatine phosphokinase in the dog.

Condtovaso. Ras., 10: $245-253,1976$.

6. NORRIS, R.M., Whitlock, R.M.L., Barratt-Boyes, C., and Sma11, C.W.: Clinical. measurenent of myacamdial infarct size. Curoudztom, 51: $614-620,1975$.

7. PAPPENHEINER, J.R. : Passage of molecules through caplilary wals. physiok. Rew. 33: $387-423,1953$. 


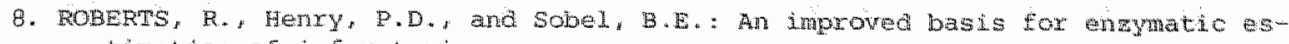
tination of ineret size.

Cryotution, 52:743-754, 1975 .

9. ROBISON, A.K., Gmepp, D.R., and Sobel, D.E. . In motiwation of cpk in lymph. Crincitation Stppl. IT, 51: 5, 1975.

10. ROE, R.C., Cobb, F.R., and Stamer, C.F.: The relationship between anzymatic and histologic estimates of the extent of myocardial infarcion im consctous dogs with permanent coronary occiusion.

Circulation, 55: 438-449, 1977 .

11. RUTLLI, G., and Axfors, K.E.: Protein concentration in interstitial and lyn phatic fluid from the subculaneous tissue.

Acto Physiol. Scond., 99: 1-8, 1977 .

12. SHELL, W.E., Kjekshus, J.K., and Sobel, B. E: Quantitative assessment of the extent of mycardial infarction in the conscious dog by means of analysis of serial changes in serum creatine phosphokinase activitut.

I. Clin. Intest. 50:, 2614-2625, 1971.

13. WAKIM, K.G., and Fleisher, G.A.: The fate of enzymes in body fluids. II. Disapm pearance of glutamic oxalacetic transaminase I and II under various conditions.

7. Lab. Ctim. Hed. 61: 86-103, 1963 .

14. WILLEMS, G.M., Muijtjens, A.M.M., Lambi, F.H.H., and Hermens, W. Th.: Estimation of circulating parameters in patients with acute myocardial infarction. Significance for calculation of enzymatic infarct size.

Cordiavare. Res., 13: 578-587, 1979.

15. WIHLMS, G.M., and Hermens, W.Th.: Quantitated release of diferent enzmeg in patients with acute myocardial infarction (AMI), compaxed to enzyme content in human myocardium.

J. Moz. and CeZ2., 11: suppl. 2, 66, 1979 .

16. WITTEWEEN, S.A.G.J., Hexmens, W.Th., Hemken, H.C., and Hollaar, In : Quant1tation of enzyme release from infarcted heart muscle.

In: Ischemic Heart Disease. Eas. J.H. de Has, H.C. Hemker and H.E. Smedlen. Leinden Univesity press, Leiden, 1970, pp. 36-42.

17. WITTEVEEN, S.A.G.J.: Assessment of the extent of a myocardial hinfrotion on the basis of plasma enzyme levels.

Thesis, Leiden, 1972 .

18. WITTEWEEN, S.A.G.J., Hemker, H.C., Hol.laar, L., and Hermens, W.Th. Q Quntitiation of infarct size in man by means of plasma enzyme levels.

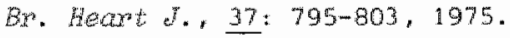

19. YASMINEH, W.G., Pyle, R.B., Cohn, J.N., Nicololf, D.M., Hanson, N.Q., and Steels, $\mathrm{B}$. W : Serial serum creatine phosphokinase MB hoenzyme activity alter myocardial infarction.

Circulation, 55: $733-738,1977$. 


\section{CHAPTER VII}

\section{In vitro thermal inactivation of different enzymes. Relation with in vivo plasma clearance rates}

Summan

In vitro thermal inactivation of CK, AST, GPI, ALT and LD was studied in enzyme preparations obtained from dog heart or dog liver. For CK, GPI and ALT monophasic inactivation curves were obtained, while AST in some cases and LD consistentIY showed biphasic denaturation, indicating fractions of different thermal stability. For LD these fractions probably correspond to the quantities of isoenzymes LD-1 and LD-2, but for AST no relation could be demonstrated with relative amounts of cytoplasmic and mitochondrial isoenzymes, cAST and mAST.

Inactivation rates of enzyme preparations obtained from different animals were compared. For $\mathrm{CK}\left(49^{\circ} \mathrm{C}\right.$ and $\left.53^{\circ} \mathrm{C}\right), \mathrm{GPI}\left(53^{\circ} \mathrm{C}\right)$ and ALT $\left(62^{\circ} \mathrm{C}\right)$ variation coeficients of thermal inactivation rates of different preparations were respectively $48,4 \%$ and $19 \%$ against $38,2.5 \%$ and 3.38 for mean variation coefficients within one and the same batch. Corresponding values for the slow phase of LD inactivation $\left(62^{\circ} \mathrm{C}\right)$ and mono-exponential approximation of AST inactivation $\left(62^{\circ} \mathrm{C}\right)$ were respectively $9.9 \%$ and $18.7 \%$ against $4.0 \%$ and 3.28 within batches.

For CK, GPI and ALT thermodynamic activation parameters, i.e. the free energy $\Delta \mathrm{G}^{*^{\prime}}$, enthalpy $\Delta \mathrm{H}^{*}$ and entropy $\Delta \mathrm{S}^{\dagger}$ of activation, were determined from inactivation rates measured at different temperatures.

Finally it was investigated whether variations in in vivo clearance rates of enzymes can be explained by differences in thexmal.stability of the enzyme preparations.

With the same $C K$ and $A S T$ preparations as used for $i v i t r o$ studies, in vivo clearance rates in dogs were measured. For different AST preparations a relation between in vitro thermal inactivation rate and in vivo clearance rate was observed. variation in in vivo clearance rates of AST was drastically reduced by using preparations which are homogeneous and of equal stability with respect to thermal inactivation. 
For CK the variation irin $v i v o$ clearance rates is much smaller and cannot be explabred by differences in the preparations, because all ck preparations were homogeneous and of equal themal stability. The remalning variation in $C K$ clearance rates seems to be animal dependent.

\section{Introduetion}

In chapter we mentioned that besides the inter-individual varLation in enzyme clearance rates, there is also a considerable variation in the biological half-1ife of an enzyme injected several times in the same dog (intra-individual variation). An explanation for this phenomenon could not be given, because the mechanisms responsible for protein removal from the circulation are still poorly understood. It appears that subtle changes in molecular properties may introduce instabilities and inhomogenelties with respect to in vivo clearance from the circulation.

Albumin preparations were found to have increased clearance rates after isolation and labeling (Freeman, 1958 and 1959; Yalow et al., 1956 and Bloom at. 1958).

Berson et $a z$. (1953) and Rossing et al. (1967) demonstrated the relative insensitivity of electrophoretic, chromatographic and ultracentrifugal methods in the detection of alterations in the albumin molecules. Only heavily labeled albumin gave some evidence on heterogeneity on electrophoretic or ultracentrifugal analysis (Berson et al., 1953 and Fahey et at. , 1958).

One well documented molecular change, which leads to increased clearance rates from the circulation is the removal of sialic acid residues from glycoproteins (Morell et al., 1971; Rijk et al., 1976 and sodetzet al., 1977).

Gritter et a . (1979) demonstrated that differences in thermal stability may be due to changes in hydrophobic interactions or hydrogen bonds and do not necessitate large changes in the tertiary structure. He showed that the tertiary structure of lysosyme from bacteriophage fif, as determined by X-Ray diffraction was virtually identical to the tertiary structure of a temperature sensitive mutant of $\mathbb{T}^{4}$ phage 1 sosyme. It was shown that except for the replacement of a partially exposed arginine to a histidine the amino acid seguence of the temperature sensitive lysosyme is identical to the amino acid sequence 
of the wild type lysosyme. This amino acid replacement resulted, however in a completely different themal stability of the molecule.

Failure of detecting molecular changes by existing physical techniques has resulted into "biological screening", injection and successive harvesting of the injected substance from plasma (McFarlane et al., 1963).

In the present study thermal inactivation of enzymes is investigated as a possible means of detecting inhomogeneities in enzyme preparations used for in vivo clearance studies. If the variation in in vivo clearance rate could be partially predicted by 4 w vito characterizations, this technique could find an application in quantitation of organ damage by means of plasma enzyme levels. These quantitations are depending on values of clearance constants which show large inter-individual variations and can only be estimated by analyzing clearance curves for several days. If a reasonable estimate of the clearance constant could be made from in vitro thermal inactivation of a plasma sample the procedure could be drastically simplified.

Materinals and methods

Mongrel dogs of both sexes and $15-35 \mathrm{~kg}$ of body weight were used for all in vivo experiments.

Enzyme preparations used for intravenous bolus injections and thermal inactivations were obtained from dog heart or dog liver as described in chapter IV. Collection of blood samples and administration of enzyme preparations was also performed as described in chapter IV. Bolus injections of enzyme in the dog were sampled during $2.0-2.5$ hours, taking samples every 10 minutes. During this period enzyme clearance curves were best described by a mono-exponentlal. function (see chapter $V$ ).

Enzyme activities were determined as described in chapter II. CK determinations were performed, using the autoanalyzer continuous flow system $\left(37^{\circ} \mathrm{C}\right)$. For the other enzymes the Eppendorf spectrophotometer was used $\left(25^{\circ} \mathrm{C}\right)$.

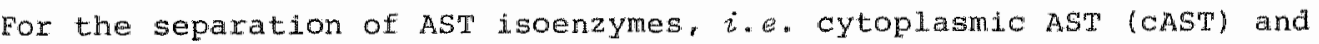
mitochondrial AST (MAST), a column chromatographic method was used (Sampson et al., 1978). The analytical recovery of AST activity from the collumn was $97.4 \pm 2.48$ (mean $\pm S D, n=33$ ). For 5 separation of the same preparation $(\mathrm{P} 6)$ the results are $19 \pm 2.38$ mAST. The analyt- 
leal recovery of AST activity from the column was $94 \pm 6.9$ mean \pm SD, $n=5)$. A11 further separations were carried out at least in duplicate.

Isoenzyme separation of $\mathrm{CK}$ and $\mathrm{LD}$ was performed according to the method of Mercer (1975). For CK $98 \pm 0.4 \%$ (mean $\pm \mathrm{SD}, \mathrm{n}=8$ ) of total activity in heart preparations was of muscle type CK-MM. The analytical recovery of total $\mathrm{CK}$ activity from the column was $99.3 \pm 3.0$ ? (mean $\pm \mathrm{SD}, \mathrm{n}=8$ ). For LD $5.8 \pm 0.4$ (mean $\pm \mathrm{SD}, \mathrm{n}=8$ ) of total activity consisted of the heat labile isoenzymes LD-3,4,5. The analytical recovery of $L D$ from the column was $98 \pm 2.18$ (mean $\pm S D, n=8$ ). The isoenzymes $L D-1$ and $L D-2$ could not be separated with this method.

For the in vitro thermal inactivations a closed circulating waterbath with thermostat was used (Lauda Electronic). Before thermal inactivations were started the enzyme preparations were diluted in a pasteurized plasma protein solution (see chapter III). Thermal inactivations of different enzyme preparations were performed simultaneous, in order to prevent day to day calibration errors of the waterbath. Each preparation was divided over a number of closed tubes and for all preparations 8-16 tubes were placed simultaneous into the waterbath at zero time. At different times a sample was taken from all preparations and immediately frozen at $-20^{\circ} \mathrm{C}$. At zero time $4-5$ samples were frozen from each preparation, for an accurate determination of enzyme activity before thermal inactivation was started $\left(c_{0}\right)$. In order to obtain variations in thermal inactivation rates within one and the same batch the above described procedure was performed in duplicate or triplicate.

For thermal inactivations at different temperatures 4 tubes of each enzyme preparation were placed into the waterbath at zero time and were inactivated during approximately 25 minutes. Hereafter the tubes were immediately frozen at $-20^{\circ} \mathrm{C}$. Activity at zero tume was determined as described above. At each temperature the same procedure was followed and thermal inactivation rate was estimated at 10 different temperatures.

The apparent $k_{+1}\left(\sec ^{-1}\right)$ was computed from the following formula:

$$
k_{+1}=\left(\ln C / C_{o}\right) / t
$$

C : activity after approximately 25 minutes of thermal inactivation (U/1). 
$C_{0}$ : activity before thermal inactivation was started (U/1).

$t$ : number of seconds inactivated (sec).

$k_{+1}$ : apparent inactivation rate $\left(\sec ^{-1}\right)$.

From the apparent $k_{+1}$ 's at different temperatures thermodymamic activation parameters can be computed as described in appendix III.

$$
\begin{aligned}
\Delta G^{*} & =R T \ln \frac{k T}{k_{+1} h} \\
\Delta H^{*} & =-R \frac{d \ln k_{+1}}{d l / T}-R T \\
\Delta S^{*} & =-\frac{R}{T} \frac{d l n k+1}{d 1 / T}-R-R \ln \frac{k_{B} T}{k_{+1} h}
\end{aligned}
$$

where, $R$ is the gas constant $(8.3143 \mathrm{~J} /$ degr.mol)

$h$ is planck's constant $\left(6.6256,10^{-34} \mathrm{~J} . \mathrm{sec}\right)$ and

$k_{B}$ is Boltzman's constant $\left(1.381 \cdot 10^{-23} \mathrm{~J} / \mathrm{deg}.\right)$

Mono-exponential fits in thermal inactivation curves were obtained as described in chapter $v$. Double-exponential fits were also performed as described in chapter $V$. The significance of improvements of fits was tested by a Fisher test for the ratio of residues (Beck bt a 2. , 1977). For all parameter values 95\% confldence limits have been computed.

The coefficient of variation is defined as: $\mathrm{CV}=100 \mathrm{x}(\mathrm{SD} / \mathrm{mear})(\mathrm{s})$.

$\operatorname{Results}$

Fig. I shows the thermal inactivation curves for $\mathrm{CK}$ at $49^{\circ} \mathrm{C}$ and $53^{\circ} \mathrm{C}$, for GPI at $53^{\circ} \mathrm{C}$ and for ALT at $62^{\circ} \mathrm{C}$. Thermal inactivation curves of these enzymes correspond very closely to a mono-exponential function.

Table I. 1 and I.2 present results of mono-exponential fits on thermal inactivation curves of $8 \mathrm{ck}$ batches obtained from different dog hearts at respectively $49^{\circ} \mathrm{C}$ and $53^{\circ} \mathrm{C}$. At both temperatures convergence to a double-exponential function was not obtalned or resulted in insignificant improvement of the fit. The coefficient of variation for thermal inactivation rates of different $\mathrm{CK}$ batches was $3-4$ and the mean variation within one and the same batch was $3 \%$. 


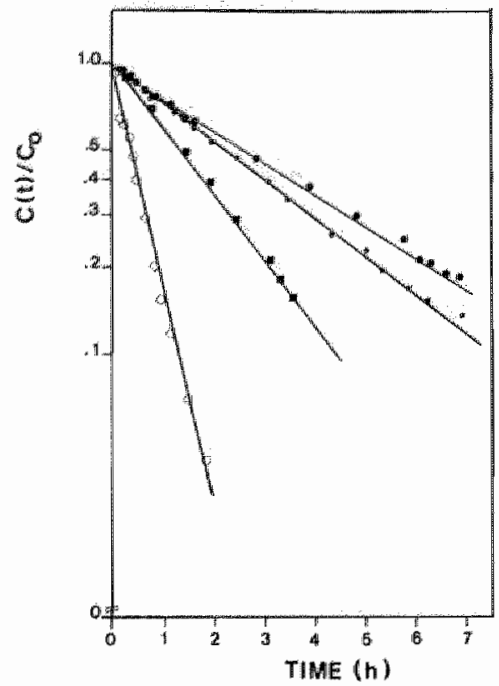

Fig. I

In watho thermal inactivation of:

$\mathrm{CK}$ at $49^{\circ} \mathrm{C}$ :

$\mathrm{CK}$ at $53^{\circ} \mathrm{C}: 0$

GPI at $53^{\circ} \mathrm{C}$ :

ALT at $62^{\circ} \mathrm{C}$

Clearance curves are best described by a mono-exponential function, as indicated in the figure $(-)$.

Table I.1 Monomponential fits after in vitro thermal inactivation of different CK preparations at $49^{\circ} \mathrm{C}$.

\begin{tabular}{|c|c|c|c|c|c|c|c|}
\hline $\begin{array}{l}\text { Enzyme } \\
\text { preparation }\end{array}$ & $\begin{array}{c}c_{a} \\
(u / 1)\end{array}$ & $\begin{array}{l}\mathrm{SD} \\
(\mathrm{g})\end{array}$ & $\begin{array}{l}c_{0} \text { fit.t } \\
(\mathrm{u} / 1)\end{array}$ & $\begin{array}{l}d c_{o} \\
(5)\end{array}$ & $\begin{array}{c}k_{d} \\
\left(h^{-1}\right)\end{array}$ & $\begin{array}{l}d k_{a} \\
(\%)\end{array}$ & $\begin{array}{l}\text { Res } \\
(s)\end{array}$ \\
\hline P1 & 2567 & 3.6 & 2420 & 3.9 & 0.25 & 4.8 & 5.9 \\
\hline $\mathbb{P} 2$ & 2958 & 2.2 & 2873 & 2.1 & 0.25 & 2.5 & 3.3 \\
\hline$P^{3}$ & 3148 & 1.7 & 2933 & 3.3 & 0.24 & 4.3 & 5.0 \\
\hline $\mathrm{P} 4$ & 3494 & 2.1 & 3264 & 4.0 & 0.24 & 5.0 & 6.2 \\
\hline $\mathrm{P} 5$ & 8477 & 3.2 & 8368 & 2.3 & 0.25 & 2.7 & 3.6 \\
\hline P6 & 3665 & 1.0 & 3562 & 3.0 & 0.24 & 3.7 & 3.7 \\
\hline P7 & 3143 & 3.6 & 3134 & 5.0 & 0.27 & 5.7 & 6.4 \\
\hline $\mathbb{P B}$ & 8181 & 1.0 & 8129 & 3.0 & 0.25 & 3.5 & 3.8 \\
\hline Maan & 4434 & 2.3 & 3983 & 3.3 & 0.25 & 4.0 & 4.7 \\
\hline cov (a) & 54 & 46 & 71 & 29 & 4.0 & 28 & 27 \\
\hline
\end{tabular}

$\mathrm{C}_{1}$ : Enzme concentration at zero time estimated from 5 samples taken before tharmal inactivation was started $(\mathrm{U} / \mathrm{I})$.

Cit : obtalned best-it value for concentration at zero time.

$\mathrm{k}_{\mathrm{a}} \quad$ : Apparent disappearance constant $\left(\mathrm{h}^{-1}\right)$.

$\mathrm{dk}_{\mathrm{d}} \mathrm{dc}_{\mathrm{o}}: 95 \mathrm{~s}$ confidence $1 \mathrm{imits}$ expressed as a percentage of $\mathrm{k}_{\mathrm{d}} \mathrm{C}_{\mathrm{o}}$.

Res : Residue: quality of $f$ it expressed as mean residual devition per data point, expressed as a percentage of measured activity (a).

Cy : Stanard deviation as percentage of mean value (coefficient of variation).

For complete ata see appendix III; data of chaptex VII, tables I and II. 
Table I.2 Mono-exponential fits after sho vibo thermal inactiwation of 6 ok preparations at $53^{\circ} \mathrm{C}$.

\begin{tabular}{|c|c|c|c|c|c|c|c|}
\hline $\begin{array}{l}\text { Preparation } \\
\text { number }\end{array}$ & $\begin{array}{c}C_{\infty} \\
(0 / 1)\end{array}$ & $\begin{array}{l}\text { SD } \\
(2)\}\end{array}$ & $\begin{array}{l}C_{0} \text { tit } \\
(0 / 1)\end{array}$ & $\begin{array}{l}\mathrm{dC}_{\mathrm{O}} \\
(\mathrm{s})\end{array}$ & ${ }^{k g}$ & $\begin{array}{l}\text { (a) } \\
\text { (s) }\end{array}$ & $\begin{array}{l}\text { Tes } \\
\text { (is) }\end{array}$ \\
\hline P1 & 9693 & 1.5 & 9808 & 3.9 & 1.90 & 3.3 & 5.1 \\
\hline$p 2$ & 11754 & 1.0 & 11824 & 3.5 & 1.86 & 3.1 & 4.6 \\
\hline P3 & 10832 & 1.3 & 10779 & 4.1 & 1.74 & 3.8 & 5.3 \\
\hline $\mathrm{P}_{4}$ & 12390 & 1.8 & 12492 & 3.5 & 1.92 & 2.9 & 4.5 \\
\hline P5 & 1351 & 0.9 & 1313 & 7.0 & 1.86 & 6.2 & 8.8 \\
\hline$P 6$ & 11967 & 2.0 & 12078 & 5.5 & 1.85 & $4 \ldots 8$ & 7.1 \\
\hline $\mathrm{p} 7$ & 10514 & 2.8 & 10637 & 5.0 & 1.81 & 4.4 & 6.4 \\
\hline $\mathrm{P} 8$ & 11962 & 3.4 & 12157 & $2 . \mathbb{1}$ & 1.89 & 2.6 & 2.3 \\
\hline Mean & 10058 & 1.8 & 10136 & 4.3 & 1.85 & 3.9 & 5.5 \\
\hline $\mathrm{CW}(18)$ & 36 & 47 & 36 & 34 & 3.1 & $\$ 1$ & 35 \\
\hline
\end{tabular}

$c_{0}, c_{0} \mathbb{E} i t, k_{d} d k_{d}$ and res, see Table 1.1.

Table II Mono-exponential fits after in vitro thermal inactivation of different GPI preparations, obtained from heart or liver tissue at $53^{\circ} \mathrm{C}$.

\begin{tabular}{|c|c|c|c|c|c|c|c|}
\hline $\begin{array}{l}\text { Enzyme } \\
\text { preparation }\end{array}$ & $\begin{array}{c}C_{0} \\
(U / 1)\end{array}$ & $\begin{array}{l}\text { SD } \\
\left(z^{\prime}\right)\end{array}$ & $\begin{array}{l}C_{0} \text { fit } \\
(U / 1)\end{array}$ & $\begin{array}{l}\mathrm{dc}_{\mathrm{o}} \\
(8)\end{array}$ & $\begin{array}{l}k_{\mathrm{d}} \\
\left(\mathrm{h}^{-1}\right)\end{array}$ & 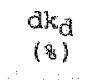 & $\begin{array}{l}x \in s \\
(\mathrm{~g})\end{array}$ \\
\hline $\mathrm{P} 1$ & 286 & 1.16 & 288 & 2.3 & 0.51 & 2.2 & 2.4 \\
\hline $\mathrm{P} 2$ & 442 & 1.0 & 447 & 1.8 & 0.50 & 1.7 & 1.9 \\
\hline P3 & 432 & 1.1 & 438 & 1.7 & 0.50 & 1.6 & 1.8 \\
\hline$P 4$ & 434 & 0.7 & 436 & 1.8 & 0.50 & 1.7 & 1.9 \\
\hline P5 & 399 & 0.4 & 405 & 1.9 & 0.47 & 2.0 & 2.0 \\
\hline P6 & 498 & 0.5 & 504 & 1.7 & 0.46 & 1.8 & 1.7 \\
\hline F7 & 405 & 0.5 & 409 & 1.8 & 0.46 & 1.9 & 1.9 \\
\hline $\mathrm{Pe}$ & 455 & 2.1 & 459 & 1.5 & 0.46 & 1.6 & 1.6 \\
\hline Mean & 449 & 0.9 & 423 & 1.8 & $0.4 \ddot{8}$ & 1.6 & 1.9 \\
\hline $\mathrm{CV}\left(\mathrm{s}^{\prime}\right)$ & 15 & 47 & 15 & 23 & 4.5 & 12 & 13 \\
\hline $\mathrm{p} 1 \mathrm{I}$ & 360 & 1.1 & 359 & 1.9 & 0.41 & 2.3 & 2.0 \\
\hline P2L & 354 & 0.3 & 354 & 1.0 & 0.38 & 1.3 & 1.0 \\
\hline P3I & 341 & 0.9 & 340 & 1.3 & 0.40 & 1.6 & 1.4 \\
\hline Mear & 352 & 0.8 & 351 & 1.4 & 0.40 & 1.7 & 1.5 \\
\hline $\mathrm{CV}$ (s) & 2.8 & 54 & 2.8 & 33 & 3.9 & 30 & 34 \\
\hline
\end{tabular}

$C_{o} C_{0} f i t, k_{d} d k_{a}, d C_{o}$, res and $C W$, see Table $I$.

For the complete data see appendix III; data of chapter VII, table III. 
Table II presents the results of mono-exponential fits of GPI thermal inactivation curves, obtained after thermal inactivation at $53^{\circ} \mathrm{C}$ of the same enzyme batches as used for $\mathrm{CK}$ thermal inactivations and some preparations obtalnea from different livers. Convergence to a double-exponential function was never obtained and the coefficient of variation within ore and the same batch was only $2.5 \%$. GPI preparations obtained from liver tissue have a significantly different thermal inactivation rate, as compared to GPI preparations obtained from heart tissue.

Table II Mono-xponential its after in vitro thermal inactivation of different ALT preparations at $62^{\circ} \mathrm{C}$.

\begin{tabular}{cccccccc}
\hline $\begin{array}{c}\text { Enzyme } \\
\text { preparation }\end{array}$ & $\begin{array}{c}\mathrm{PC}_{\mathrm{O}} \\
(\mathrm{U} / \mathrm{I})\end{array}$ & $\begin{array}{c}\mathrm{SD} \\
(\mathrm{s})\end{array}$ & $\begin{array}{c}\mathrm{C}_{\mathrm{O}} \\
(\mathrm{v} / 1)\end{array}$ & $\begin{array}{c}\mathrm{dC_{ \textrm {O } }} \\
(\mathrm{s})\end{array}$ & $\begin{array}{c}\mathrm{k}_{\mathrm{d}} \\
(\mathrm{h})\end{array}$ & $\begin{array}{c}\mathrm{dkd} \\
(\mathrm{g})\end{array}$ & $\begin{array}{c}\text { res } \\
(8)\end{array}$ \\
\hline PL1 & 324 & 1.5 & 312 & 4.9 & 0.28 & 6.6 & 5.3 \\
PL2 & 219 & 2.6 & 215 & 2.6 & 0.20 & 4.2 & 2.9 \\
PL3 & 485 & 2.8 & 481 & 5.2 & 0.19 & 8.4 & 5.7 \\
PL4 & 270 & 1.6 & 261 & 3.6 & 0.30 & 3.2 & 5.0 \\
PL5 & 554 & 2.3 & 554 & 1.6 & 0.23 & 2.5 & 2.0 \\
PL6 & 422 & 2.3 & 421 & 1.9 & 0.21 & 2.9 & 2.0 \\
\hline Mean & 379 & 2.2 & 374 & 3.3 & 0.24 & 4.5 & 3.8 \\
CV (6) & 34 & 24 & 35 & 46 & 19 & 22 & 45 \\
\hline
\end{tabular}

$C_{o}, C_{o}^{f t t}, d C_{o}, k_{d}, d k_{d}$, res and $c V$, see Table $I$.

For complete data see appendix III; data of chapter VII, table VI.

Table III presents the results of mono-exponential fits on ALT thermal inactivation curves after thermal inactivation at $62^{\circ} \mathrm{C}$ of 6 different ALT batches, obtained from different dog livers. ALT thermal Inactivation curves conformed very closely to a mono-exponential function. Convergence to a double-exponentil was never obtained. The coefflotent of variation for the thermal inactivation rate of different ALT batches was however 19\%, whereas variations within one and the same batch were only 3.3 .

Fig. II shows the thermal inactivation curves of AST and ID from $\mathrm{Pl}$ at $62^{\circ} \mathrm{C}$. These curves were best described by a double-exponential function.

Table IV.1 presents results of mono-exponential fits on AST thermal inactivation curves of 12 different AST batches after thermal inactivation at $62^{\circ} \mathrm{C}$. For the thermal inactivation rate of these prepara- 


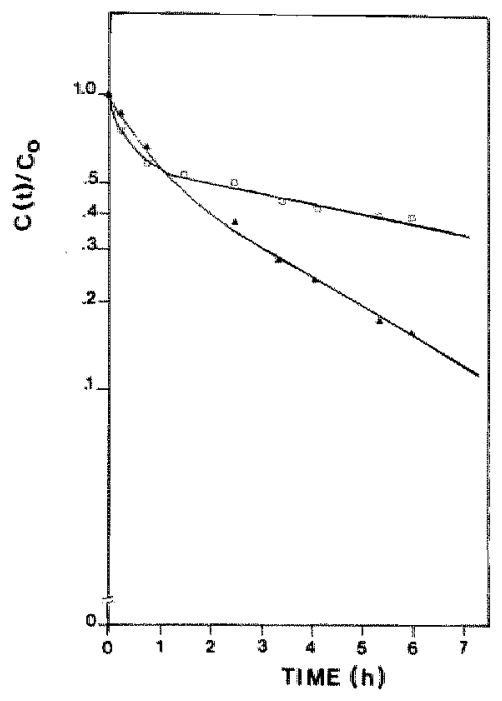

Ig. II

In vitro themal inactivation of:

$\mathrm{ID}$ at $62^{\circ} \mathrm{C}: \mathrm{C}$

AST at $62^{\circ} \mathrm{C}$ :

Curves are best aescribad by a donbleexponential function, as indicated in figure (-) .

Table IW.1 Mono-exponential fits aftex in vitro thermal inactivation at $62^{\circ} \mathrm{C}$ of different AST preparations from heart or liver tissue.

\begin{tabular}{|c|c|c|c|c|c|c|c|c|}
\hline $\begin{array}{l}\text { Enzyme } \\
\text { preparation }\end{array}$ & $\begin{array}{c}C_{O} \\
(U / 1)\end{array}$ & $\begin{array}{l}\mathrm{SD} \\
(8)\end{array}$ & $\begin{array}{c}\mathrm{C}_{\mathrm{O}} \\
(\mathrm{U} / \mathrm{L})\end{array}$ & $\begin{array}{l}d c_{o} \\
(s)\end{array}$ & $\begin{array}{c}k_{d} \\
\left(h^{-1}\right)\end{array}$ & $\begin{array}{l}d k_{d} \\
(8)\end{array}$ & $\begin{array}{l}\text { res } \\
(i)\end{array}$ & $\begin{array}{c}\operatorname{mASP} \\
\text { (a) }\end{array}$ \\
\hline P1 & 257 & 0.5 & 237 & 8.6 & 0.34 & 9.1 & 9.1 & 10 \\
\hline P2 & 231 & 1.1 & 222 & 3.4 & 0.21 & 5.7 & 3.7 & 12 \\
\hline E3 & 194 & 2.0 & 184 & 4.1 & 0.24 & 6.0 & 4.4 & 7 \\
\hline P4 & 211 & 1.4 & 197 & 6.4 & 0.29 & 7.8 & 6.8 & 9 \\
\hline P5 & 194 & 2.3 & 186 & 3.6 & 0.20 & 6.1 & 4.0 & 19 \\
\hline P6 & 145 & 1.2 & 130 & 10.8 & 0.33 & 11.7 & 11.3 & 19 \\
\hline p7 & 216 & 2.0 & 193 & 8.8 & 0.26 & 12.2 & 9.4 & 27 \\
\hline $\mathrm{pg}$ & 218 & 0.3 & 208 & 3.9 & 0.22 & 6.2 & 4.3 & 16 \\
\hline P1L & 181 & 1.5 & 169 & 6.1 & 0.29 & 7.5 & 6.8 & 21 \\
\hline $\mathrm{P} 2 \mathrm{~L}$ & 275 & 1.5 & 263 & 3.8 & 0.24 & 5.4 & 4.2 & 12 \\
\hline Mean & 212 & 1.4 & 199 & 6.0 & 0.26 & 7.7 & 6.4 & 15 \\
\hline $\mathrm{CV}(\mathrm{s})$ & 17.5 & 46 & 18.5 & 45 & 18.7 & 31 & 43 & $4 \|$ \\
\hline
\end{tabular}

$C_{O^{*}} S D, C_{O^{\prime}} d C_{O^{*}} k_{a}$, $d k_{a}$ and $r e s$, see Trable $I$.

mAST : Percentage of mitochondrial. AST as determined from collumn chromatographic method.

For complete data see appendix III; data of chapter VII, table V.

tions a coefficient of variation of 18.78 was observed. Part of these thermal inactivation curves showed improved double-exponential fits. The results of these fits are presented in table IV.2. A fraction of 
diffent themal stability is present in these preparations. The inhomogenet ty in the AST preparations as observed from the thermal inactivation curves is not related to the relative amounts of cytoplasmic and mitochondrial isoenzymes CAST and mAST. For the thermal inactivation rate of the heat stable fraction in each preparation a coefficient of variation of only $7 \%$ was observed, whereas for the heat lablle traction completely different clearance rates were observed $(\mathrm{CV}=54 \mathrm{a})$.

Table IV.2 Double-exponential fits after in vitro thermal inactivation at $62^{\circ} \mathrm{C}$ of afferent AST preparations.

\begin{tabular}{|c|c|c|c|c|c|c|c|c|c|c|c|}
\hline $\begin{array}{l}\text { Erryme } \\
\text { preparation }\end{array}$ & $\begin{array}{c}c_{1} \\
(0 / 1)\end{array}$ & $\begin{array}{l}\mathrm{dc} \mathrm{C}_{1} \\
\left(\mathrm{q}_{5}\right)\end{array}$ & $\begin{array}{c}\mathrm{C}_{2} \\
(\mathrm{U} / 1)\end{array}$ & $\begin{array}{l}\mathrm{ac}_{2} \\
(\mathrm{~s})\end{array}$ & $\left(\mathrm{n}^{-1}\right)$ & $a b$ & $\stackrel{a}{\left(n^{-1}\right)}$ & $\begin{array}{l}d a \\
(9)\end{array}$ & $\begin{array}{l}\text { Res } \\
(8)\end{array}$ & $\begin{array}{c}c_{1} / c_{1}+c_{2} \\
x 100\end{array}$ & $\underset{\text { MAST }}{\operatorname{mag}}$ \\
\hline p1 & 124 & 22 & 132 & 2.2 & 0.92 & 24 & 0.22 & 16 & 1.1 & 48.4 & 10 \\
\hline $\mathbb{P}_{3}$ & 24 & 28 & 169 & 3.4 & 4.88 & 89 & 0.22 & 4.0 & 1.3 & 12.4 & 7 \\
\hline$P_{4}$ & 50 & 39 & 160 & 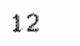 & 1.73 & 72 & 0.24 & 11 & 2.3 & 23.8 & 9 \\
\hline$p G$ & 64 & 27 & 81 & 5.0 & 1.23 & 41 & 0.22 & 19 & 2.5 & 44.1 & 19 \\
\hline B 7 & 52 & 20 & 164 & 1.5 & 7.27 & 80 & 0.22 & 6.1 & $2 . \mathbb{1}$ & 24.1 & 27 \\
\hline $\mathrm{PB}$ & 24 & 0 & 194 & 8.2 & $5 \ldots 31$ & 45 & 0.20 & 0.0 & 0.8 & 11.0 & 16 \\
\hline $\mathbb{P} \mathbb{L}$ & 41 & 32 & 139 & 9.0 & 1.98 & 63 & 0.25 & 8.0 & 2.0 & 22.8 & 21 \\
\hline Mean & 54 & 24 & 148 & 49 & 3.33 & 59 & 0.22 & 9.2 & 1.7 & 26.7 & 15 \\
\hline $\mathrm{CV}$ (8) & 63 & 51 & 24 & 254 & 74 & 39 & 7.2 & 73 & 38 & 54.0 & 47 \\
\hline
\end{tabular}

$c_{1}, c_{2}, a, b, a c_{1}, a c_{2}, d b$, da, and Res, see Table IV.

For LD the inhomogeneity of the enzyme batches as observed from the thermal inactivation curves can probably be clarified by the presence of the isoenzymes LDI and LD2.

The results of the double-exponential fits are presented in table $\mathrm{V}$. Vardations in the clearance rates of the slow and fast cleared fracthons were respectively 9.9 and 14.

Fig. IIT.1, 2 and 3 show the thermal inactivation rates of repectively GPI, ALT and LD as measured at different temperatures versus the reciprocal absolute temperature $(1 / \mathrm{T})$. For GPI and ALT $1 \mathrm{n} k+1$ versus $1 / T$ fits very closely to a mono-exponential function, 95 confidence limits were respectively $\pm 6 \%$ and \pm 4 . For $\mathrm{CK}$ the 958 confidence limit was somewhat larger \pm 138 , but no systematic deviation from a mono-exponential function was observed. The computed thermodynamic activation parameters are represented in table VI. For AST and LD the thermodynamic activation parameters $\triangle \mathrm{G}^{*}, \mathrm{AH}^{*}$ and $\Delta \mathrm{S}^{*}$ were not 


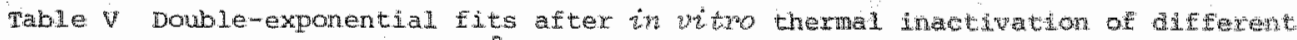
LD preparations at $62^{\circ} \mathrm{C}$.

\begin{tabular}{|c|c|c|c|c|c|c|c|c|c|c|c|c|}
\hline $\begin{array}{l}\text { Enzyme } \\
\text { prep. }\end{array}$ & $\begin{array}{c}c_{0} \\
(U / 1)\end{array}$ & $\begin{array}{l}\text { SD } \\
(B)\end{array}$ & $\begin{array}{c}C_{1} \\
(U / 1)\end{array}$ & $\begin{array}{l}d c_{1} \\
(8)\end{array}$ & $\begin{array}{c}c_{2} \\
(0 / 1)\end{array}$ & $\begin{array}{l}a C_{2} \\
(a)\end{array}$ & $\left.\stackrel{b}{\left(n^{-1}\right.}\right)$ & $\begin{array}{l}a b \\
(\mathrm{~g})\end{array}$ & $\left(n^{-1}\right)$ & da & $\begin{array}{l}\text { res } \\
\text { (b) }\end{array}$ & $\begin{array}{c}\mathrm{C}_{2} / \mathrm{C}_{1}+\mathrm{C}_{2} \\
100\end{array}$ \\
\hline P1 & 932 & 2.4 & 415 & 9.9 & 516 & 6.0 & 4.19 & 30 & 0.077 & 19 & 2.1 & 36 \\
\hline $\mathrm{p} 2$ & 805 & 1.8 & 327 & 9.8 & 478 & 5.2 & 4.34 & 30 & 0.087 & 15 & 1.9 & 37 \\
\hline P3 & 444 & 0.3 & 255 & 9.0 & 188 & 8.2 & 4.11 & 30 & 0.066 & 26 & 2.8 & 30 \\
\hline$P 4$ & 801 & 1.7 & 386 & 8.8 & 415 & 5.8 & 4.76 & 28 & 0.084 & 17 & 2.2 & 34 \\
\hline P5 & 715 & 3.0 & 316 & 10.1 & 398 & 5.9 & 4.51 & 31 & 0.088 & 17 & 2.2 & 36 \\
\hline P6 & 656 & 2.9 & 310 & 12.2 & 345 & 7.5 & 5.96 & 41 & 0.095 & 20 & 3.0 & 34 \\
\hline P7 & 756 & 1.4 & 302 & 9.8 & 433 & 5.2 & 3.85 & 30 & 0.093 & 14 & 1.8 & 38 \\
\hline$P 8$ & 771 & 1.9 & 340 & 8.0 & 430 & 4.5 & 5.03 & 25 & 0.087 & 13 & 1.8 & 36 \\
\hline Mean & 735 & 1.9 & 331 & 9.7 & 403 & 6.0 & 4.59 & 31 & 0.084 & 18 & 2.2 & 3.5 \\
\hline $\mathrm{CW}(\mathrm{s})$ & 19 & 45 & 15 & 12.7 & 25 & 20 & 14.4 & 15 & 9.9 & 23 & 20 & 7.1 \\
\hline
\end{tabular}

$c_{1}, c_{2}$ *a, b: obtained best-fit values for the double-exponential fit (see chapter V).

$\mathrm{dC}_{1}, \mathrm{dc}_{2}$, da, $\mathrm{b}$ : $95 \%$ confidence limits expressed as a percentage of obtained parameter values.

For complete data see appendix III; data of chapter VII, table IV.

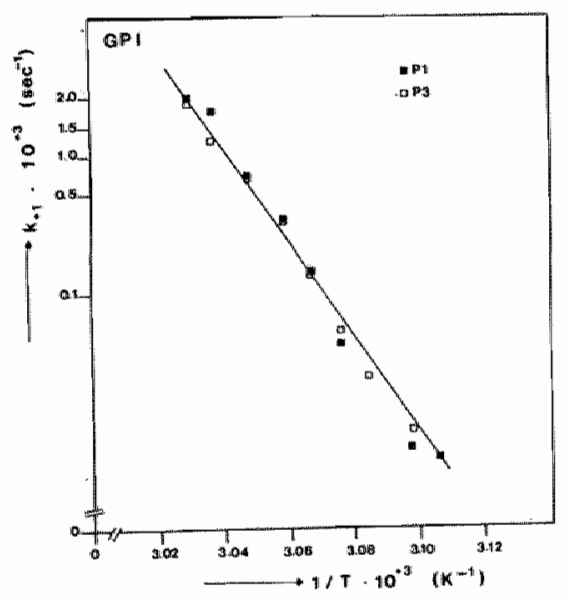

EIg. III. 1

Thermal inactivation xate of GPI at different temperatures.

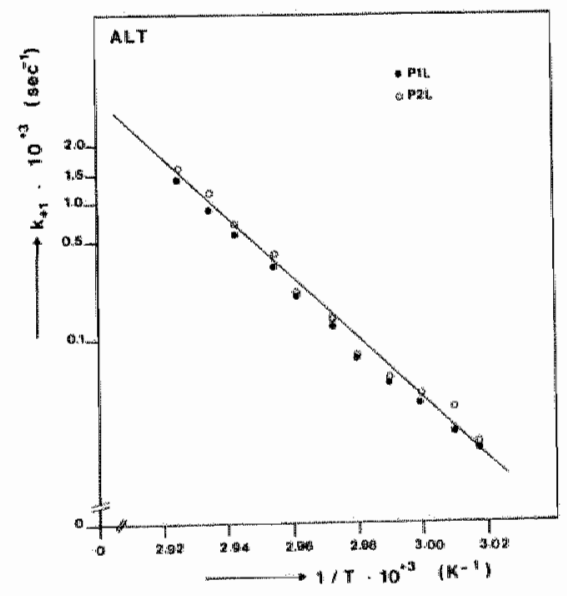

FIg. III.2

Thermal inactivation rate of AIT at different temperatures. 


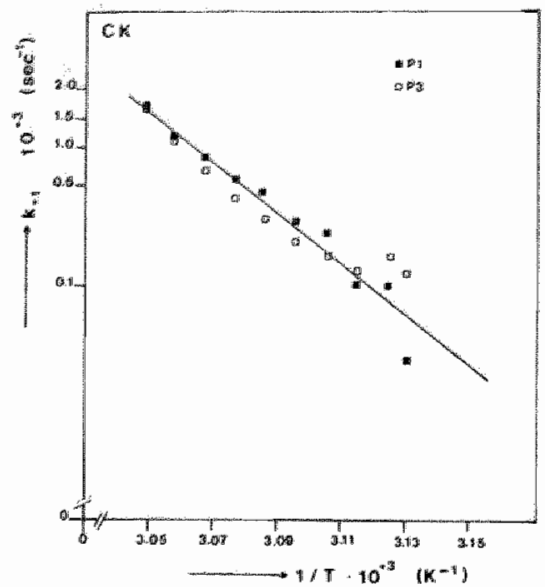

Fig. III.3

Mhermal inactivation rate of $\mathrm{CK}$ at different temperatures.

Table VI Thermodynamic activation parameters, as obtained from themal inactivation rates at diffexent temperatures.

\begin{tabular}{|c|c|c|c|c|c|c|}
\hline Enzyme & $\begin{array}{l}\text { Prepa- } \\
\text { ration }\end{array}$ & $\frac{d \ln k+1}{d 1 / T}$ & $\begin{array}{l}95 \text { conf. } \\
\text { limit }\end{array}$ & $\underset{\mathrm{kJ} J / \mathrm{mol}}{\Delta \mathrm{H}^{*}}$ & $\underset{\mathrm{kJI} / \mathrm{mol}}{\Delta \mathrm{G}^{*}}$ & $\begin{array}{c}\Delta s^{*} \\
\mathbb{J} / \mathrm{mol} \text {.degr }\end{array}$ \\
\hline $\mathbb{A L T}$ & P1L & -47355 & 2.4 & 391 & 104 & 861 \\
\hline ALT & $\mathrm{p} 2 \mathbb{L}$ & -51779 & 6.5 & 428 & 107 & 963 \\
\hline GPI & $P \mathbb{L}$ & -59361 & 9.5 & 496 & 104 & 1205 \\
\hline GPI & P2L & -59558 & 6.1 & 498 & 105 & 1205 \\
\hline GPI & P1 & -67358 & 5.4 & 560 & 104 & 1402 \\
\hline GPI & p3 & -64093 & 5.8 & 536 & 105 & 1322 \\
\hline $\mathrm{CK}$ & P1 & -38944 & 12.8 & 326 & 100 & 699 \\
\hline $\mathrm{CK}$ & P3 & -48058 & 14.2 & 402 & 100 & 933 \\
\hline
\end{tabular}

$k_{+1}$ : thermal inactivation rate $\left(\sec ^{-1}\right)$

$\Delta G^{\ddagger}$ : activation free energy

T: : absolute temperature (K)

$\Delta \mathrm{B}^{\ddagger}$ : activation onthalpy

$\Delta S^{*}$ : actiwation free entropy

for complete data see appendix III; data of chapter VII, table VII up to KI.

determined becalise these preparations contain fractions of different thermal stability.

Table VII shows that there seems to be no relation between in wivo half-life of CK, LD, AST, ALT and GPI in the circulation and molacular weight, thermal inactivation rate or thermodynamic activation parameters.

"Table VIII shows the mean in vivo clearance rates of CK and AST as obtained after repeated bolus injections of different enzyme preparations in four different dogs (Fig. IV). 


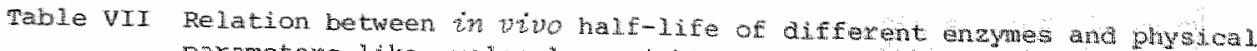
parameters like, molecular weight, thermal inactigtion rate or thernodynamic activation parameters.

\begin{tabular}{|c|c|c|c|c|c|c|c|c|c|}
\hline Enzyme & Source & $\begin{array}{l}\text { Th } \\
200 \\
(n)\end{array}$ & $\begin{array}{l}\text { Temp. } \\
{ }^{\circ} \mathrm{C}\end{array}$ & 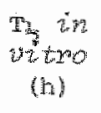 & $\begin{array}{c}.10-3 \\
.10-3\end{array}$ & $\begin{array}{l}\text { subunit } \\
\text { MW } \\
.10^{-3}\end{array}$ & $\begin{array}{c}\mathrm{Am} \\
\mathrm{kg} / \mathrm{mol}\end{array}$ & $\begin{array}{c}\mathrm{SH}^{*} \\
\mathrm{~kJ} / \mathrm{mol}\end{array}$ & $\frac{\Delta s^{i}}{\operatorname{mon} 1}$ \\
\hline $\mathrm{ALT}^{*}$ & liver & 31. & 62 & 2.89 & 180 & 90 & 106 & 410 & 912 \\
\hline CASTP & heart & 3.47 & 6.2 & 2.70 & 90 & 45 & - & - & - \\
\hline$\triangle A S T$ & Iiver & 3.54 & 62 & 2.55 & 90 & 45 & - & - & - \\
\hline$C K-M M$ & meart & 1.87 & 53 & 0.38 & 81 & 40.5 & 100 & 364 & 816 \\
\hline $\mathbb{L D}-1,2$ & heart & 1.58 & 62 & 8.3 & 140 & 18 & - & - & - \\
\hline GPI & liver & 1.58 & 53 & 1.73 & 134 & 67 & 105 & 497 & 1205 \\
\hline$G \mathrm{GI}$ & heart & 1.45 & 153 & 1.44 & 48 & 67 & 105 & 5.48 & 1362 \\
\hline
\end{tabular}

$T_{4}$ : half-ijfe (hours)

Temp. : temperatures of thermal inactivation tirk vitro ( $\mathrm{C}$ )

MW : moleculax weight

$\Delta G^{\frac{2}{4}}, \Delta H^{*}$ and $\Delta S^{*}$ see table VI.

In vivo half-1ives of AIT, GPI and AST see chaptex VI. For in vivo half-Iives of AST and CK see chapter $V$.

Table VTII In vivo clearance of four different CK and AsT preparations in four different dogs.

\begin{tabular}{|c|c|c|c|c|c|c|c|c|c|}
\hline \multicolumn{5}{|c|}{ Freparation dependent variation } & \multicolumn{5}{|c|}{ Dog dependent variation } \\
\hline $\begin{array}{l}\text { Prep. } \\
\text { number }\end{array}$ & $\begin{array}{c}k_{d} c k \\
\left(h^{-1}\right)\end{array}$ & $\begin{array}{l}\mathrm{CV} \\
(8)\end{array}$ & $\begin{array}{c}k_{\mathrm{a}}{ }^{\mathrm{AST}} \\
\left(\mathrm{h}^{-1}\right)\end{array}$ & $\begin{array}{l}\mathrm{CV} \\
\mathrm{Cr})\end{array}$ & $\begin{array}{l}\mathrm{Dog} \\
\text { number }\end{array}$ & $\begin{array}{l}k_{d} C_{k} \\
\left(n^{-1}\right)\end{array}$ & $\begin{array}{l}\mathrm{CV} \\
(8)\end{array}$ & $\begin{array}{c}k_{d} \text { AST } \\
\left(h^{-1}\right)\end{array}$ & $\begin{array}{l}\mathrm{CV} \\
\text { ("s) }\end{array}$ \\
\hline$P 1$ & 0.31 & 14.6 & 0.22 & 10.1 & $\mathrm{D} 1$ & 0.25 & 5.9 & 0.22 & 34 \\
\hline$P 2$ & 0.31 & 19.6 & 0.18 & 14.1 & $\mathrm{D} 2$ & 0.37 & 8.5 & 0.22 & 17 \\
\hline P3 & 0.35 & 18.7 & 0.19 & 14.3 & D3 & 0.34 & 10.4 & 0.22 & 19 \\
\hline $\mathrm{P} 4$ & 0.32 & 11.1 & 0.27 & 13.9 & D4 & 0.32 & 10.7 & 0.19 & 21 \\
\hline Mear & 0.32 & 16.0 & 0.22 & 13.2 & & 0.32 & 0.8 & 0.21 & 23 \\
\hline CV (要) & 5.9 & & 18.8 & & & 14.4 & & 7.1 & \\
\hline
\end{tabular}

k and CV see table I.

For complete data, 95 confidence limits of the parameters and residues see appendix III; complete data chapter VII, table XIII.

The AST preparations, which axe least sensitive to thermal inactivation in vitro (P2 and P3), also appeared to be more stable upon injection tin vivo. The in vitro more unstable AST preparations PI and PA (of. table IV.1) were also more rapidly cleared upon injection in 


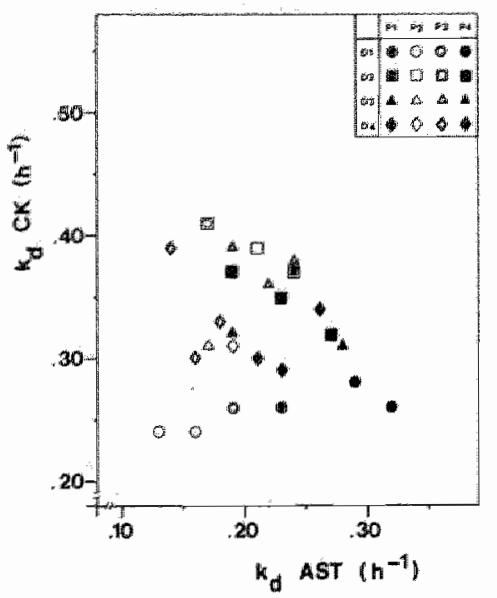

ELIS. IV

Clearance rates of CK and AST, measured simultaneous after intravenous bolus injections of enzyme preparations obtatned from heart tissue.

Wivo (of. table VIII). BY contrast to AST, variation in simultaneous measured $\mathrm{CK}$ clearance rates was largely animal dependent. In vitro no differences in thermal stability could be detected for these different $C K$ preparations (of. table I). The intra-individual variation in CK clearance rates was on $1 y$ 5-9\%, whereas the inter-individual varlation was $16 \%$.

Apart from the preparation dependent variation in AST clearance rates, inter-individual variation in AST clearance rates was only 79 (table VIII).

\section{Disousion}

It vivo clearance from the circulation of partially denatured proteins appears to be completely different from in vivo clearance of native proteins. Therefore it is necessary to ascertain that the properties of protein preparations used for turnover studies are identicall to those of the native proteins. Fahey et a. . (1958) demonstrated that the chromatographic elution profile of radioiodinated human serum albumin, as obtained from commercially available preparations was significantly different from the elution profile of native human serum albumin. However these authors did not relate these inhomogenelties to in vivo differences in clearance rates from the circulation as mentioned in the introduction. It has been demonstrated that alterations in the in vivo clearance rates were not always accompanied by molecular changes detectable by physical or chemical methods. Yalow et al. (1935) already emphasized the relative insensi- 
tiwlty of electrophoretic analysis in the detection of apparently subtile alterations in the albumin molecules, which have a higher clearance rate in the circulation. Rossing at. (1967) comparea two different albumin preparations, one prepared by alcohol fractionation (Ss-albumin) and the other prepared by sad fractionation (BW-albumin). The preparations were analyzed both by in vivo and in vityo studies. Paper-, immuno-, moving boundary electrophoresis, gel filtration and ultracentrifugation revealed that both preparations con-tained at least 90 monomeric albumin. Simultaneous injections of ss$125 \mathrm{I}-a$ lbumin and $\mathrm{BW}-{ }^{131} \mathrm{I}-\mathrm{albumin}$ and $\mathrm{BW}-125 \mathrm{I}$-albumin resulted howewer. in a significantly higher metabolic clearance rate and distribution volume for the $S S-a l b u m i n(p<.0001)$. The results appeared to be independent of the label used.

Posen et al. (1965) advocated the determination of thermal inactivation at $56^{\circ} \mathrm{C}$ to differentiate between alkaline phosphatase isoenzymes from liver, bone and bile. This method could even be used to determine the relative amounts of the isoenzymes present in serum of patients. Differences in thermal stability of isoenzymes are known for several enzymes. Thermally labile isoenzymes of CK (Nealon et at. 1976) appear to be more labile upon injection tiv vivo (Rapaport. 1975), as compared to the thermally more stable CK isoenzymes. In vivo clearance of $\mathrm{LD}-3,4,5 \mathrm{i} . e$. the heat labile iscenzymes, is also fast as compared to the in vivo clearance rate of heat stable LDI and LD2 (Boyd et al., 1969).

We used thermal inactivation curves to analyze the homogeneity and stability of different enzyme batches. We considered the possibility that variations in the molecular conformation, leading to a higher clearance rate $i n$ vivo, may be reflected in a difference in thermal stability of the molecules.

For CK and GPI enzyme batches appeared to be homogeneous and no $\mathrm{sig}-$ nificant differences were observed between thermal inactivation rates of 8 different batches obtained from heart tissue. GPI preparations obtained from liver tissue were also homogeneous, but the thermal inactivation rate was significantly different as compared to GPI from heart tisswe. It is tempting to speculate that liver GPI and heart GPI are different isoenzymes in analogy with alkaline phosphatase, CK and $\mathbb{L D}$. However caution is needed as will be discussed below. Biphasic thermal inactivation as observed for AST, seems not to be related to the relative amount of mitochondrial AST. Other mechanisms 
leading to relatively table or labile fractions are possible; for irstance binding of enzye to other constituents in plasma, dimerisation of the protein, exposure to lysosomal enzyme activity depending on the preparation procedures or multistep denaturation.

ALT preparations were also homogeneous, with respect to thermal inactivation, but significant differences between thermal inactivation rates of different enzyme batches were observed (CV $18.7 \%$ ).

For LD two fractions of completely different thermal stability were present in our preparations, probably corresponding to the amount of LD1 and LD2 in these preparations. The relative amounts of these fractions are practically the same in all preparations (CV = 7\%), as 1 in contrast to fractions present in only part of the AST preparations, where extremely large variations have been observed (CV $=54 \%$ ). Values of $\Delta G^{*}$ indicate that the change in free energy associated with the formation of the activated complex is of the same order of magnitude for all enzymes studied here. Values of $\Delta \mathrm{G}^{\ddagger}$ also correspond very closely to values as obtained from the literature for trypsin, trypsin kinase, thyroglobulin, lobster haemoglobin and enteropeptidase (Jaly et at., 1965).

The large value of $\Delta S^{\ddagger}$ for GPI Indicates that the transition from native state to the activated complex is accompanied by a large increase in degrees of freedom, unfolding, compared to this transition for ALI and $C K$. It should be noted however that thermal inactivation need not be a physiological process and values of for instance $\Delta G^{*}$ Eor biological denaturation can be largely influenced by the presence of biological activators such as enzymes.

McLendon et $a l$. (1978) demonstrated a relation between the free energy of unfolding $\Delta G$ and the intraceliular turnover rates of different enzymes. From results we obtained until now it seems that there is mo relation between thermodynamic activation parameters $\Delta \mathrm{G}^{*}$. $\Delta H^{*}, \Delta S^{*}$ and in $v i v o$ clearance rates. It should be noted however that In order to establish such a relationship above mentioned parameters should be determined for considerably more enzymes, but even the trend did not become apparent from our data.

In 1970 Dehlinger et a. found that the intracellular turnover rate of proteins is related to the natural logarithm of their subunit molecular weight. A higher intracellular turnover rate was found for the larger proteins. Whis observation led these workers to propose that a relation between the size of a protein and its rate of degra- 
dation is based on the overall chance of a protein to be hit by a protease, producing an initial rate limiting peptide bond clevage. From our results it seems that in dogs CK, AST, ALI, LD and GPI clearance rates from the circulation are not related to the natural. logarithms of their respective subunit molecular weights. Moreover for isoenzymes of the same molecular weight completely different olearance rates have been observed (Rapaport, 1975 and Boyd et a. , 1967). From this point of view a relation between molecular weight and wo clearance rate is not to be expected at all.

For different enzymes we observed that there is no relation between the thermal stability and the in vivo clearance rate from the circulation. However for any given enzyme the thermal stability of different enzyme preparations (AST) or of different isoenzymes (CK, LD and alkaline phosphatase) can be related to the in vivo stability. In these cases differences in molecular conformation of the enzyme are probably reflected in a different thermal stability.

It would be interesting to see whether variations in enzyme clearance rates as obtained after organ damage are introduced by variations as observed in our case for $C K, i$. e. animal dependent variation or by variations as observed for AST, i.e. preparation dependent variation, caused for instance by molecular differences in AST molecules. The latter variation could be easily eliminated by analysis of plasma samples in vitro and would allow in vitro estimation of AST clearance rates.

\section{References}

1. BECK, I.V., and Arnold, K.J. : Parameter esthation in engimeering and science. New York, willey and Sons, 197\%, pp. 386-387.

2. BERSON, S. M., Yalow, R.S., Schrelber, S.S., and Post, P.: Tracer exper mentes with 131 I labeled a lbumin: distribution and degradation studies. 3. C2:it. Invest. 32: 746-768, 1953.

3. LLOM, H.G.J., Crockett, D.J., and stewart, F. S.: rhe effeots of radiaton on the stability of radio-jodinated human serum alibumin. Br. J. Ratiot., 31:377-383, 1958.

4. BOND, J.S.: A comparison of the proteolytic susceptibildty of seyeral rat liver enzymes in Biochem. Biophys. Res, Commm. 43: $333-339,1971$.

5. BOYD, J.m.: The rates of disappearance al L-lactate dehyarogenase 1.soenzymes from plasma. Amr. Intern. Wed. 70: 799-805, 1969. 


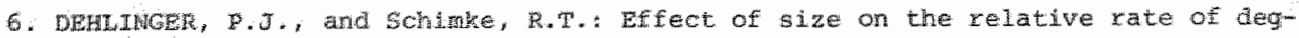
radation of rat 1 iver solide proterns.

Brochen. Brophys. Fea. Commat. 40: 1473-1400, 1970.

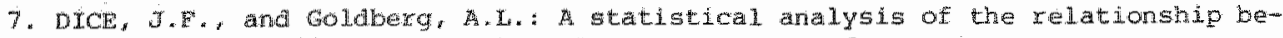
tween dugrative rates and molecular welghts or proteins.

Aroh. Biochen. Biophya. 170: 213-219, 1975.

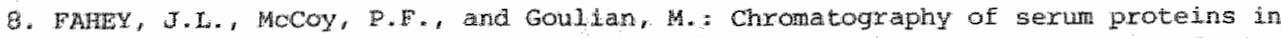
normal and pathologlo sera: The distribution of protein-bound carbohyarate and cholesterol, siderophilin, thyroxin-binding protein, alkaline and acid phosphatases, radiolodinated abumin and myeloma proteins.

J. Clin: Inoest. 37: $727-294,1958$.

9. FREMAN, T.: The biologlcal behaviour of normal and denatured human plasma albuminin.

CLim, ChM. Acta, 4: 788-792, 1959.

10. FREMAN, T. Gordon, A.H., and Humphey, J.H.: Distinction between catabolism of native ard denatuxed proteins by the isolated pexfused liver aftex carbon Lodaling.

$B x$, wixp. Pathol., 39:459-471, 1958.

11. GROrWER, M.G., Hawkes, R.B., and Mat thews, B. W. : Molleculax basis of thexmostability on the lysozyme from bacteriophage $T 4$.

Nature, 277: $667-669,1979$.

12. HOPGOOD, M.F*, and Ballard, J.F.: The relative stablilty of 1iver cytosol enzymes incubated in vitro.

Brochem. to $144: 371-376,1974$.

13. JOLX, M.: Malecular biology. Ahysical-chemical approach to the denaturation of proteins. Academic Press, London, 1965.

14. MCFARLANE, A.S.: Catabolism of plasma proteins. Lanceit, 2: $131-132,1963$.

15. MCLENDON, G.: A correlation between myoglobin thermodymamic stabilities and speciles metabolic rates.

Btochem. Brophys. Res. Commun. 77: 959-966, 1977.

16. MCLENDON, G., and Randany, E.: Is protein turnower thexmodynamically controlled?

J. Biot. Chem., 253: 6335-6337, 1978 .

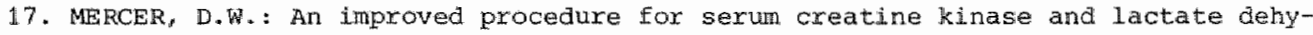
dzogenase isoenzymes on ion-exchange.

Clin. Chom., 21: 1102-1106, 1975

19. Morel, A.G., Gregorladi, G., and Scheinberg, H.I.: The role of silalic and ac1a in deternining the survival of glycoprotelns in the circulation.

I. Brol. Cham. 246: 1461-1467, 1971 .

19. NEALON, D.A., and Henderson, A.R.: The apparent Arrhenius relationships of the human creatine kinase isoenzymes using the oliver-Rosalki assay. chin. Chom. Acta, 66: 131-136, 1976.

20. POSEN, S., Nealle, C.N., and Clubb, J.S.: Heat inactivation in the study of human alkaline phosphatases.

Amm. Thermat. Med. , 62: 1232-1243, 1965.

21. RAPAPORT, $\mathrm{E}_{\text {. }}$ : The fxactional alsappearance rate of separate isoenzymes of creatine phosphokinase in the dog.

Corditovase. Res. , $9: 473-477,4975$. 
22. RIJK, P.P., and ganter, C.J.A.: "3l I-asialo-a,-acid glycoprotein. Investigation of its use for liver tests; metabolisin in the rat.

Lob. Methods, 88: 142-150, 1978 .

23. ROSSTNG, N., and Jemser, H.: Metabolic studies of ditserent album preparations.

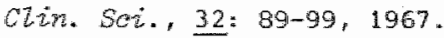

24. SAMPSON, E.j., Miller, A.S., Mekneally, S.S., Whitner, V.S., Hanon, W.H., ana Burtis, C.A.: Colum chromatographic separation of isoenzymes of aspartate aminotransferase.

Cin. Chem. 24: 1805-1812, 1978 .

25. SODETZ, J.M., Pizzo, S.V., and MCKee, P.A.: Relationship of silic acid to function and in wivo survival of human factox VIII/ von willebrand factor protein ."

F. Biol. Chen., 252:5538-5546. 1977.

26. YALOW, R.S., and Bexson, S.A.: Chemical and biological alternations induced by

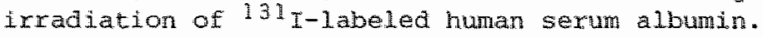

T. Clin. Inuest. " 36: 44-50, 1957. 


\section{Conclusions and summary}

Normally only very small amounts of tissue enzymes are present in the circulation, but after tissue injury the levels of tissue enzymes in plasma increase, due to leakage of enzymes from damaged cells. In this thesis the behaviour of tissue enzymes in the circulation is studied in order to validate and improve methods presently used for the quantitation of tissue damage on the bastis of enzyme levels in piasma.

A considerable part of the results presented in this thesis is obtained from intravenous and intramuscular injections and intravenous infusions of enzymes in the dog. These animals are commonly used in experimental models to study enzymatic infarct quantitation. Enzyme preparations as used for the experiments were obtianed from dog heart or liver. Pieces of heart or liver tissue were incubated in dog plasma under hypoxic conditions. Under these conditions enzymes leake from the tissue into the plasma, which was hereafter centrifuged and used for the experiments.

In most studies enzymatic infarct size is expressed in grams of necrotic tissue. In order to obtain the weight of necrotic tissue in grams the calculated total activity of enzyme released into the circulation has to be divided by the mean enzyme activity per gram of normal tissue. Selection of enzymes with small intra- and inter-individual variations in tissue enzyme content will minimize errors in this procedure.

We observed that for (1) CK, LD, GPI and (2) ALT enzyme activity is rather honogeneously distributed throughout respectively heat and liver tissue of the dog. Variations in enzyme activity per gram of normal tissue, in samples taken from various sites of the same organ are less than 5-78. Inter-individual variations in enzyme activity per gram of normal tissue were 5-10a. The use of a mean value for the enzyme content of normal tissue will therefore introduce only a small exror in the quantitation of acute heart or liver tissue damage.

Since 1971 creatine kinase (CK) is commonly used in diagnosis and quantitation of acute myocardial infarction. A correct estimation of $\mathrm{CK}$ clearance rate from the circulation is essential for a reliable 
estimation of enzymatic infarct gize. When the work for this thesis was started there existed a controversy in the literature on the model to describe the clearance and distribution of ck activity after intravenous injection in the dog. With the experiments described in chapter $V$ we were able to solve this controversy. Infusion of enzymes at a constant rate allowed us to a model independent estimation of enzyme clearance constants.

We conclue that for rapidly cleared enzyme, $i \cdot e$. half-lives of less than 3-5 hours, with molecular weights larger than 40,000-60,000 Daltons, diffusion to the extravascular space can be neglected, as compared to the clearance rate from the circulation and a one-compartment model is sufficient to describe the clearance and distribution of these enzymes. For slowly metabolized enzymes like ALT diffusion to the extravascular space cannot be neglected and clearance and distribution of such enzymes is best described by a two-compartment model (ef. chapter v).

From the literature (Tables I and II, chapter II) and from the results presented in chapters $V$ and VI we conclude that enzymes with molecular weights exceeding 40,000-60,000 Daltons extravasate with a rate of $1-4$ per hour. Extremely fast extravasation of enzymes with high molecular weights, i.e. transcapillary escape rates of 20-50: per houx as have been reported even in the recent literature (Table II, chapter II), are attributed to the presence of quickly metabolized, partly denatured fractions of enzyme activity in the preparations and not as has been suggested to a distribution of enzyme activity over different compartments.

Part of the contradictions in earlier work on the clearance of enzyme activity from the clrculation were caused by use of different and/or inferior enzyme preparations. In chapter VII we describe a method to investigate the stability and homogeneity of enzyme preparations used for in wivo studies. In witro thermal inactivation of enzymes at higher temperatures was used to analyze the stability and homogeneity of the enzyme preparations. It was assumed that differences in molecular conformation of an enzyme would be reflected in a different thermal stabllity of the enzyme. If this assumption is correct thermal inactivation curves at higher temperatures could be used to detect inhomogeneities and instabilities in the enzyme preparations. We demonstrated a preparation-dependent variation in the in vivo clearance constant of AST. Using enzyme preparations of the same 
thermal stability the inter-individual variation in Ast clearance rate could be reduced to 7-10\%. Vartation in CK clearance rates appeared to be mainly animal dependent and not preparation dependent. Al1 CK preparations used were of equal thermal stability.

From the results presented in chapter VII we conclude that there is no relation between physical parameters like molecular weight, thermal stability or thermodynamic activation parameters and the in vivo clearance rate of enzymes from the circulation. It should be noted however that in order to establish such a relationship above mentioned parameters should be determined for considerably nore enzymes, but even the trend did not become apparent from our data.

In most experimental studies enzymatic infarot size has been related to histologically assessed infarct size. The latter method is based upon specific staining techniques, marking either the damaged or the undanaged tissue. After excision and weighing of the damaged tissue the amount of tissue injury can be expressed in terms of grams of injured tissue. Histological assessment of infarct size has however a considerable experimental exror, which may cause a poor correlation with enzymatic infarct quantitation.

Therefore in our study plasma enzyme patterns comparable to those obtained after myocardial infarction were simulated by varying the rate of intravenous infusion of the enzyme preparation. The amount of enzyme infused was quantitated from the enzyme levels appearing in plasma and compared to the true amount of enzyme administered. This experimental set-up allows a very reliable check on methods presently used to estimate tissue damage from plasma enzyme levels. To quantitate the total activity infused a method was used, which allows estimation of individual clearance constants of rapidly cleared enzymes (AST or GPI), using a simultaneously measured slowly cleared enzyme (ALT) as a reference.

The use of fixed mean values of the clearance constants of these enzymes, i.e. $k_{\text {ALT }}=0.034 \mathrm{~h}^{-1}, k_{\text {AST }}=0.19 \mathrm{~h}^{-1}$ and $k_{\mathrm{GPI}}=0.38 \mathrm{~h}^{-1}$ resulted in erxors of respectively $7.7 \%, 17$ and $24 \%$ for the mean recoveries of ALT, AST and GPI activities in plasma. Comparison of these values with variations of respectively 128 and 178 obtained with individual estimates of AST and GPI clearance rates and variations of respectively $11 \%$ and 98 due to errors in the fitting procedure, as judged from computer simulations, we conclude that for AST as well as GPI the use of individual estimates of clearance rates 
rewits in reduced error in the calculated recovery. The best reguits were however obtained wth the slowly metabolized enzyme ALT, ustng the mean value of the clearance constant.

Sone additional Eactors, which may affect enzynatic quantitation of tissue damage are: (1) incomplete release of enzyme activity from necrotic cells, (2) local inactivation of enzyme activity at the place of tissue injury and (3) extravascular inactivation of enzyme activity.

In the present study intramucular injections of AST and ALT activity In the gluteus muscle of the dog were used to estimate the amount of enzyme actulty eventualiy recovered in plasma.

We demonstrated that after intramuscular injections at least 75 of the Alt activity adninistered was recovered in plasma, whereas the recovery for $A .5$ was $86 \%$.

These results are in striking contrast to the low recovery of Ch activity in plasma after acute myocardial infarction, as has been reported in the literature. This low recovery is probably introduced because $C K$ shows accelerated denaturation in dog lymph. After intramuscular injection ALT and AST release from muscle continued up to 40-50 hours after injection. These results indicate that especially for AST, an enzyme with a half-life of 3.5 hours, as estimated from plasma activity curwes after intravenous injection of the activity, there is very few local inactivation at the site of injection or during transport through the interstitial fludd. The high recoveries in plasma indicate that catabolism of these enzymes accurs in the vascular pool or in immediate contact with this pool and not in the extravascular space. 


\section{Conclusies en samenvatting}

Dit proefschrift handelt over het gedrag van weetselenzym in de circulatie. Weefselenzymen catalyseren specifieke biologische reacties in de cel. Onder normale, niet-pathologische onstandigheden komen deze enzymen siechts in zeer geringe concentraties voox in de circulatie, de zogenaande normalwaarde.

Storingen in de celfunctie, veelal veroorzakt door een tekort aan voldoende cellulaire energie om de normale physiologische processen in de cel te laten verlopen, leiden tot een verhoogde permeabiliteit van de celwand. Dit geeft aanleiding tot het vrijkomen val intracellulaire enzymen en andere stoffen in de interstitiele ruimte en in de circulatie. Het feit dat elk enzym meestal slechts én biologische reactie catalyseert makt het mogelijk om met een grote gevoeligheid en specificiteit de concentratie van een enzym, in bijwoorbeeld een plasmamonster te bepalen.

Elk celtype heeft een karakteristiek enzympatxoon. Leverceljen bijvoorbeeld, vervullen een belangrijke rol in de afbraak en synthese van eiwitten en bevatten aan ook een relatief hoge concentratie transaminases, die nodig zijn bij de omzetting van aminozuren. Spiercellen darentegen bevatten relatief weinig transaminases, maar wel. een hoge concentratie creatine kinase, een enzym dat verantwoordelijk is voor de opslag van energie in de vorm van creatine fosfaat. Beschadiging van een bepald celtype, geeft aanleiding tot een karakteristiek enzympatroon in het plasma, dat kan worden gebruikt om de plats van de beschadiging wast te stellen. Weefsel specifieke enzymen, isoenzymen en karakteristieke enzymquotienten in het plasma zijn een belangrijk hulpmiddel geworden bij de diagnose van een groot aantal ziekten.

Het uiteindelijke niveau van intracellulajre enzymen in het plasma is afhankelijk van het aantal beschadigde cellen, mar ook van de afbraaksnelhejd van het enzym in de circulatie en de duur van de uitstorting uit het weefsel.

In een aantal studies is een significante, hoewel niet indrukwekkende relatie gevonden tussen de maximale enzymactiviteit in het plasma en de histologisch bepalde infarctgrootte. De histologische infarctgrootte wordt bepald met behulp van specifleke kleuringstechnieken, die ofwel het necratische dan wel het niet-necrotische (vitale) weefsel kleuren. Na uitsnijden en wegen worat de totale weefselschade 
uitgedrukt in het antal gramen necrotisch weefsel. Het feit dat de correlatles tussen de maximale enzyactiviteit in het plasma en de histologische infarctgrootte onwoldoende zijn voor een naukkeurige schatting van de infarctgrootte uit plasmamonsters in individuele gevallen, is het gevolig van factoren als het nemen van onvoldoende plasmamonsters, individuele verschilien in de verdwijningsconstanten, mar ook van experimentele fouten bij het bepalen van de histologische infaretgrootte.

In modellen die de verdwijning van elwitten uit de circulatie beschrljwen moet dan ook rekening worden gehouden met verschijnselen als: het diffunderen van eiwt nar de extravasculaire ruimte, terugkeer van elwit vanult de extravasculaire ruimte en afbraak in de circulatie. Enzymen verdwijnen uit de circulatie met snelheden die karakteristiek zijn woor zowel het enzym als voor de species. Daarnaast bestaat binnen eên species ook nog een belangrijke interindividuele variatie in de verdwijningssnelheid van een enzym.

Sinds 1971 wordt gebruik gemaakt van verschillende modelien om acute weefselschade te quantiteren an de hand van enzymniveaus in het pllasma. Tot op heden zijn zowel redelijk goede als slechte resultaten verkregen.

Het doel van dit onderzoek is de bestaande methodes om acute weefselschade te quantiteren te validerem en verbeteren. Het merendeel van de resultaten werd verkregen uit intraveneuze en intramusculaire injecties en intraveneuze infusen in de hond. De hond is het standarara proefdier in experjmentele modelien om enzymatische infarctgraotte te bestuderen. De enzympreparaten werden verkregen door stukjes hart of leverweefsel onder hypoxische omstandigheden te incuberen in hondenplasma, warbij de enzymen uit het weefsel lekken en in het plasma komen. Het plasma werd verwolgens afgedraaid en gebruikt voor de experimenten.

De enzymatische infarctgrootte wordt meestal uitgedrukt in het aantal grammen necrotisch weefsel. Dit is uitsluitend gerechtvaardiga voor die enzymen warwoor zowel de intra- als de interindividuele variaties in de enzyminhoud per gram weefsel klein $z i j n$. Wij vonden dat voor: (1) CK, LD, GPI en voor (2) ALT de enzymactiviteit redelijk homogeen verdeeld is over respectivelijk hart-en leverweefsel. De variaties in de enzymativiteit per gram weefsel, in monsters genomen op verschillende platsen in hetzelfde orgaan liggen rond de 5-7\%. Interindividuele wariaties in de enzymactiviteit per gram weefsel 
liggen rond de 5-108.

Het gebruik van de gemiddelde warde voor de enzymactiviteit per gram normal weefsel, in plats van individuele waarden zal derhalve voor de bovengenoemde enzymen slechts een zeex geringe fout introduceren bij de quantitering van acute hartspier of leverschade.

Bij de berekening van de enzymatische infarcgrootte en meer algemeen bij de studie van het elwitmetabolisme speelt de afbraaksnelheid van een enzym, meestal uitgedrukt in de eerste-orde verdwijningsconstante $k$, ex belangrijke rol.

Bij de diagnose en quantitering van acute hartspierschade wordt veelal gebruik gemakt van het enzym creatine kinase. Toen met het werk voor dit proefschrift werd aangevangen bestond er in de literatuur een belangrijke controverse over het model om de verdwijning van CK uit de circulatie zo exact mogelijk te beschrijven. De experimenten beschreven in hoofdstuk $\mathrm{V}$ brachten de bestaande controverse tot een oplossing. Een methode warbij enzymen met een constante snelheid werden geinfundeerd stelde ons in stat toteen model onafhankelijke schatting wan de verdwijningsconstante van een enzym.

Wij concluderen dat voor enzymen, die relatief snel worden afgebroken, een halfwardetija kleiner dan 3-5 uur, en een molecuulgewicht grater dan 40.000-60.000 Daltons hebben, de diffusie naar de extravasculaire ruimte verwarloosbaar is t.o.v, de afbraaksnelheid vam deze enzymen in de circulatie en een én-compartiment model is voldoende om de verdwijning van deze enzymen uit de circulatie te beschrijven. Voor langzaam afgebroken enzymen, zoals ALT is de diffuste naar de extravasculaire ruimte niet meer te verwarlozen en is een twee-compartimenten model noodzakelijk.

Uit de resultaten beschreven in hoofdstuk VI is geconcludeerd dat eiwitten met een moleculgewicht groter dan 40.000-60.000 Daltons met een snelheld van 1-4\% per uur naar de extravasculaire ruimte diffunderen. Dit resultaat is in overeenstemming met studies van radioactief gelabelde plasma-elwitten, mar zelfs in zeer recente literatuur worden nog transcapillaire verdwijningssnelheden van 20-50: pex uur gevonden voox enzymen. Deze resultaten zijn warschijnlijk toe te schrijven aan de aanwezigheid van snel gemetaboliseerde fracties in de enzympreparaten en niet aan de gesuggereerde verdeling van de enzymen over meerdere compartimenten.

Het reticuloendotheliale systeem blijkt een belangrijke rol te spelen bij de verdwijning van niet-natieve elwitmoleculen uit de 
carculatie. De snelie veryijdering van beschadigde elwitmoleculen ult de ctrculatie kan worden gezien als een bescheming uan het organisme tegen beschadigde of anderszins veranderde moleculen.

In hoofdstuk VII is derhalve gezocht naar een methode on de samenstelling wan de gebruikte enzympeparaten te analyseren. In vitro themische inactivexing van de enzymen bij hoge temperatuux is gebruikt om die homogenitelt en de stabliteit wan de enzmpreparaten te bepalen. Verschllien in moleculaire conformatie van een enzym zouden immers mogelijk tot ulting kunnen komen in een veranderde thermische stabilitelt. Waneer deze veronderstelling correct is zouden thermische inactiverings curves kunnen worden gebruikt on de homogeniteit en stabiliteit van de enzympeparaten te bepalen.

Voor AST werd een preparaat afhankeijke varlatie in de in wivo verdwijningssnelheld gevonden. Indien gebruik gemakt wordt van preparaten van ddentieke thermische stabiliteit kan de interindividuele variatie in de AST verdwijningsconstante worden beperkt tot $7-10 \%$. Ex was geen verschil in de in vitro thermische stabiliteit van de $c k$ preparaten. De variatie in de CK verdwijningsconstante blijkt eerder hond- dan preparat-afhankelijk.

Uit de resultaten vermeld in hoofdstuk VII hebben wij geconcludeerd dat er voor de bestudeerde enzymen geen relatie bestaat tussen physische parameters als molecuulgewicht, thermische stabiliteit of thermodynamische activeringsparameters en de in vivo verdwijningssnelheid uit de circulatie.

zoals vermeld kumen fouten in de bepaling van de histologische infarctgrootte slechte correlaties met de enzymatische methode veroorzaken. Daarom werden in onze studie enzympatronen in plasma, vergelijkbaar met die na een hartinfarct, gesimuleerd door de snelheid warme de preparaten werden gefnfundeerd te variëren. De hoeveelheid geinfunderde enzmactiviteit werd vervolgens geschat op basis wan de enzyniveaus in het plasma en direct vergeleken met de in werkelijkheid toegedlende hoeveelheid enzymactiviteit. De totale hoeveelheid geinfundeerde enzymactiviteit werd bepald aan de hand van de enzymniveaus in het plasma, met behulp var een methode die ons in staat stelt de individuele verdwijningsconstanten van snel afgebroken enzymen (AST en GPI) te bepalen, gebruik makend van een gelijktijdig gemeten referentie enzym (ALT).

Het gebrulk van vaste gemiddelde warden voor de verdwijningsconstanten van deze enzymen, i.e. $k_{\text {ALT }}=0.034 \mathrm{~h}^{-1}, k_{\mathrm{AST}}=0.19 \mathrm{~h}^{-1}$ en $\mathrm{GPI}=$ 
$0.38 \mathrm{~h}^{-1}$ resulteerde in fouten van respectievelijk $7.7 \mathrm{~g}, 17 \mathrm{~s}$ en 24 voor de geinfundeerde hoeveelheid ALT, AST en GPI. Vergelijken we deze waarden met variaties van 12 en 17 vexkregen met individuele schattingen van de AST en GPI verdwjuningssnelheden en variaties van respectievelijk 118 en 98 geintroduceerd door fouten in de procedure (geschat m.b.v. computer simulaties) dan kunnen we concluderen dat zowel voor AST als voor GPI het gebruik van individuele schattingen van de verdwijningsconstanten resulteert in een geringere fout. De beste resultaten werden echter verkregen met het langzaam afgebroken enzym ALT, zelfs indien gebruik werd gemakt van de gremiddelde warde voor de ALT verdwijningsconstante, d.w.z. de interindividuele variaw ties in deze grootheid worden verwarloosd.

Andere factoren die een invloed kunnen hebben op de enzymatische quantitering van weefselschade zign: (1) onvolledige uitstorting van enzymactiviteit uit necrotische cellen, (2) locale inactivering van enzymactiviteit op de plaats van de weefselbeschadiging en (3) extravasculaire afbraak van enzymactiviteit.

Intramusculaire injecties, diep in de gluteus spier van de hond, werden gegeven on de totale hoeveelheid enzymactiviteit die uiteindelijk vanuit de spier in de circulatie terechtkomt te schatten. Na een intramusculaire injectie wordt gedurende 40-50 wur enzymactiviteit in het plasma uitgestort. Het bleek dat na intramusculaire injectie ten minste 75 van de totaal toegediende hoeveelheid ALT uiteindelijk in het plasma terechtkomt, terwijl voor AST tenminste 86 van de geinjecteerde activiteit in het plasma verschijnt. Deze resultaten staan in sterke tegenstelling tot de lage opbrengst zoals in de literatuux beschreven voor $\mathrm{CK}$, na een acuut myocardinfarct. Deze lage opbrengst is vermoedelijk te verklaren door een snelle inactivering van ck activiteit in de lymfe. Deze resultaten bevestigen dat speciaal voor AST er zeer weinig inactivering is op de plats van injectie, maar ook tijdens het transport van de spier wia de lymfe en/of de interstitiële ruimte naar het plasma. De hoge opbrengsten in plasma voor AST en ALT duiden aan dat de afbrak van deze enzymen in het plasma compartiment of in de onmiddelijjke nabljheid wan dit compartiment plaatsvinat. 
It is a capital mistake to theorise before one has data. Insensib ${ }^{2}$ y one begins to twist facts to suit theories, instead of theories to suit facts.

By Sir Arthur Conan Doyle, 1928 SHERLOCK HOLWES, Short Stories, A Soandal in Bohemia, twerty-first impression, London, John Murray, 1976, page 7. 


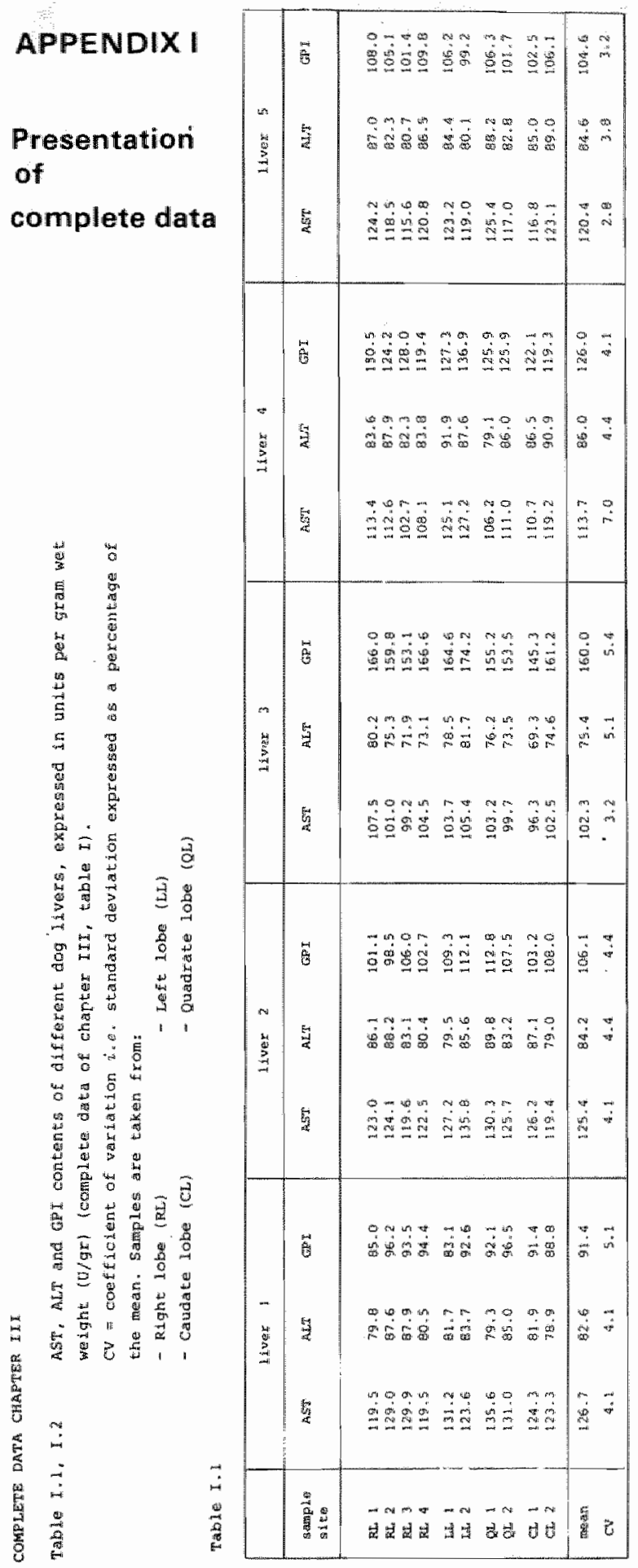

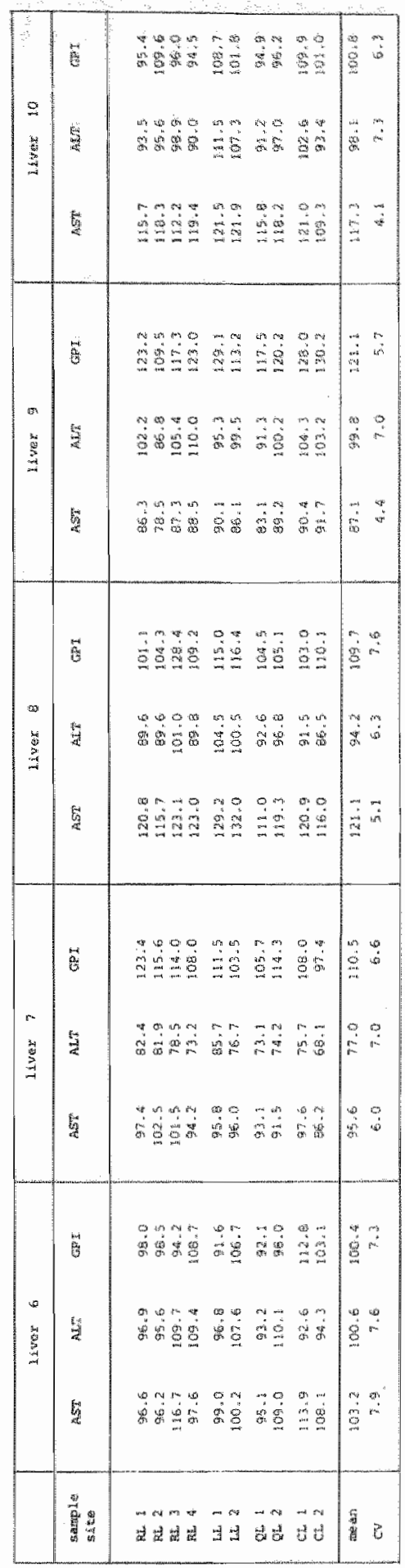




\begin{tabular}{|c|c|c|c|c|c|c|}
\hline & 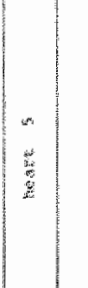 & 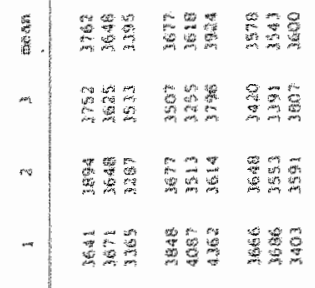 & & 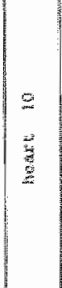 & , & 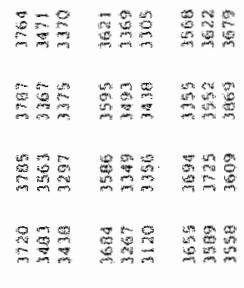 \\
\hline & : & 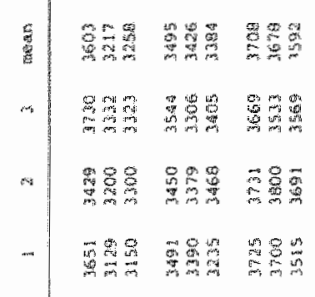 & & 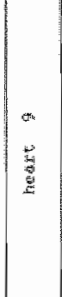 & 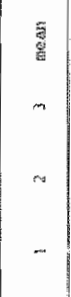 & 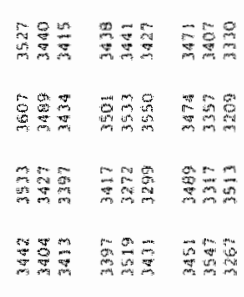 \\
\hline 垔 & 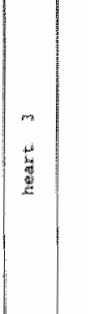 & 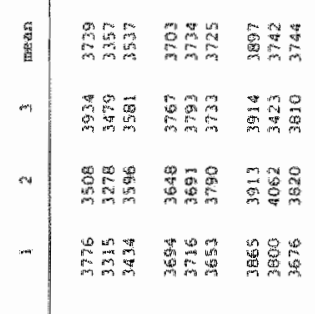 & & 蒡 & i & 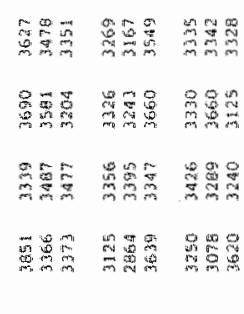 \\
\hline 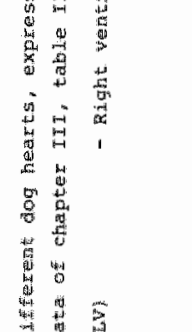 & 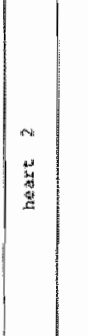 & 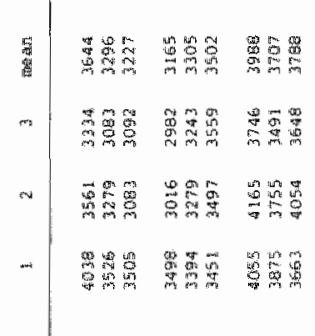 & & 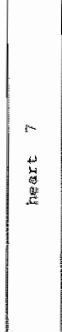 & s. & 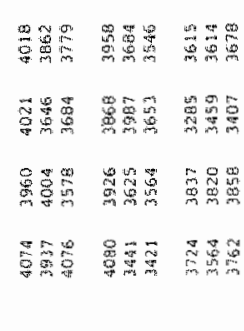 \\
\hline 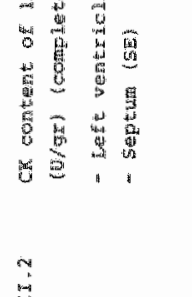 & 㟧 & 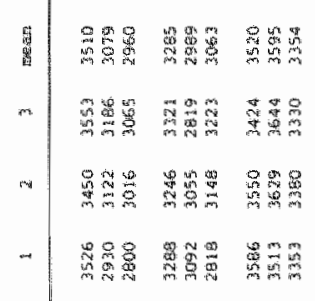 & & 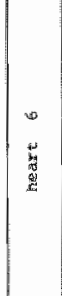 & 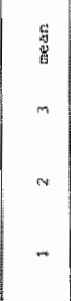 & 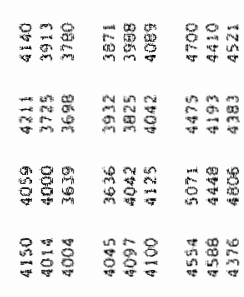 \\
\hline & ¿ & 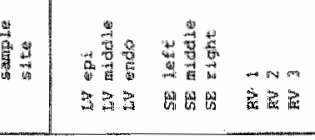 & 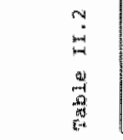 & 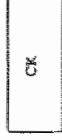 & 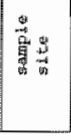 & 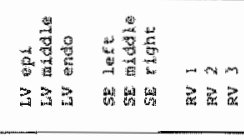 \\
\hline
\end{tabular}



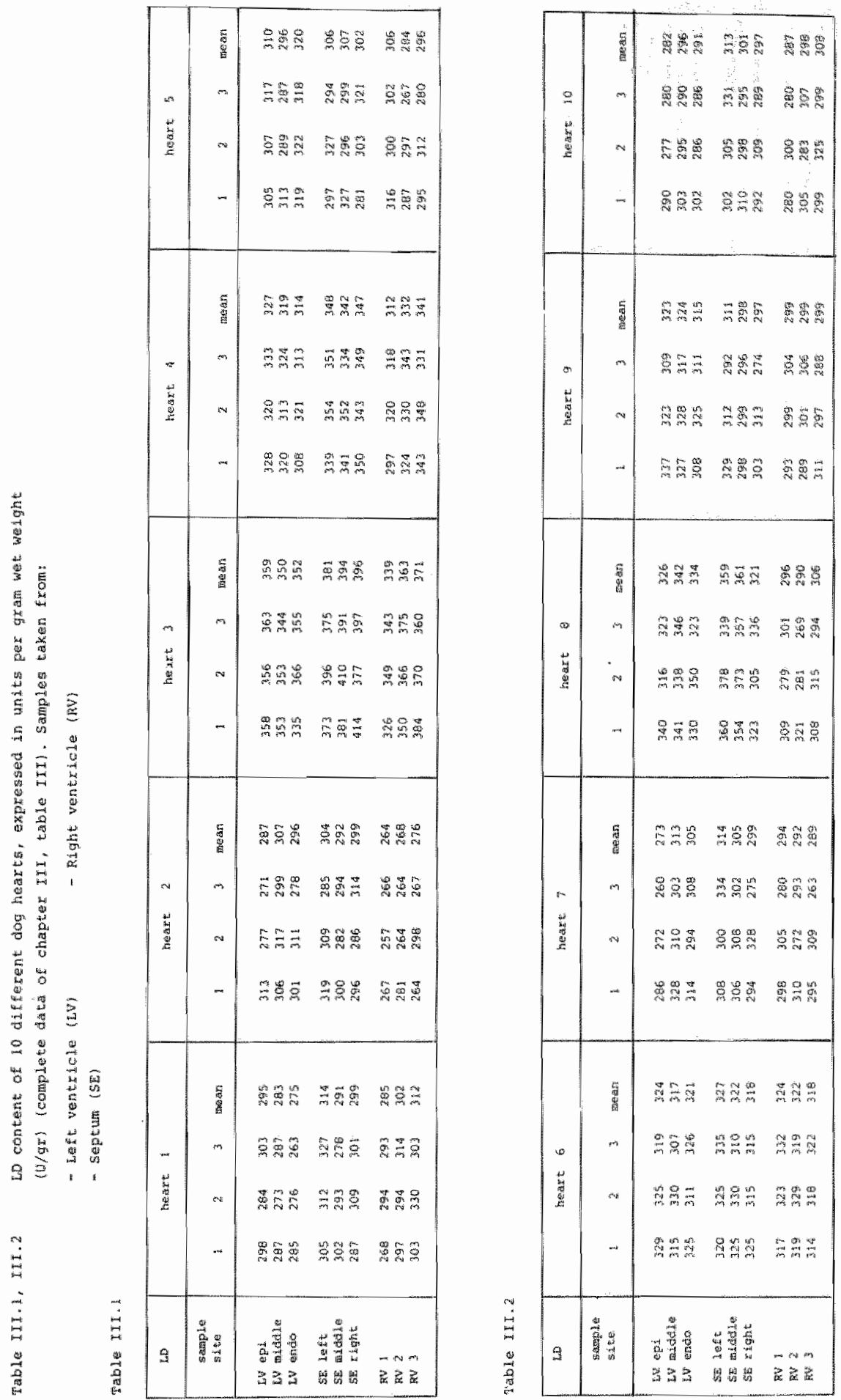

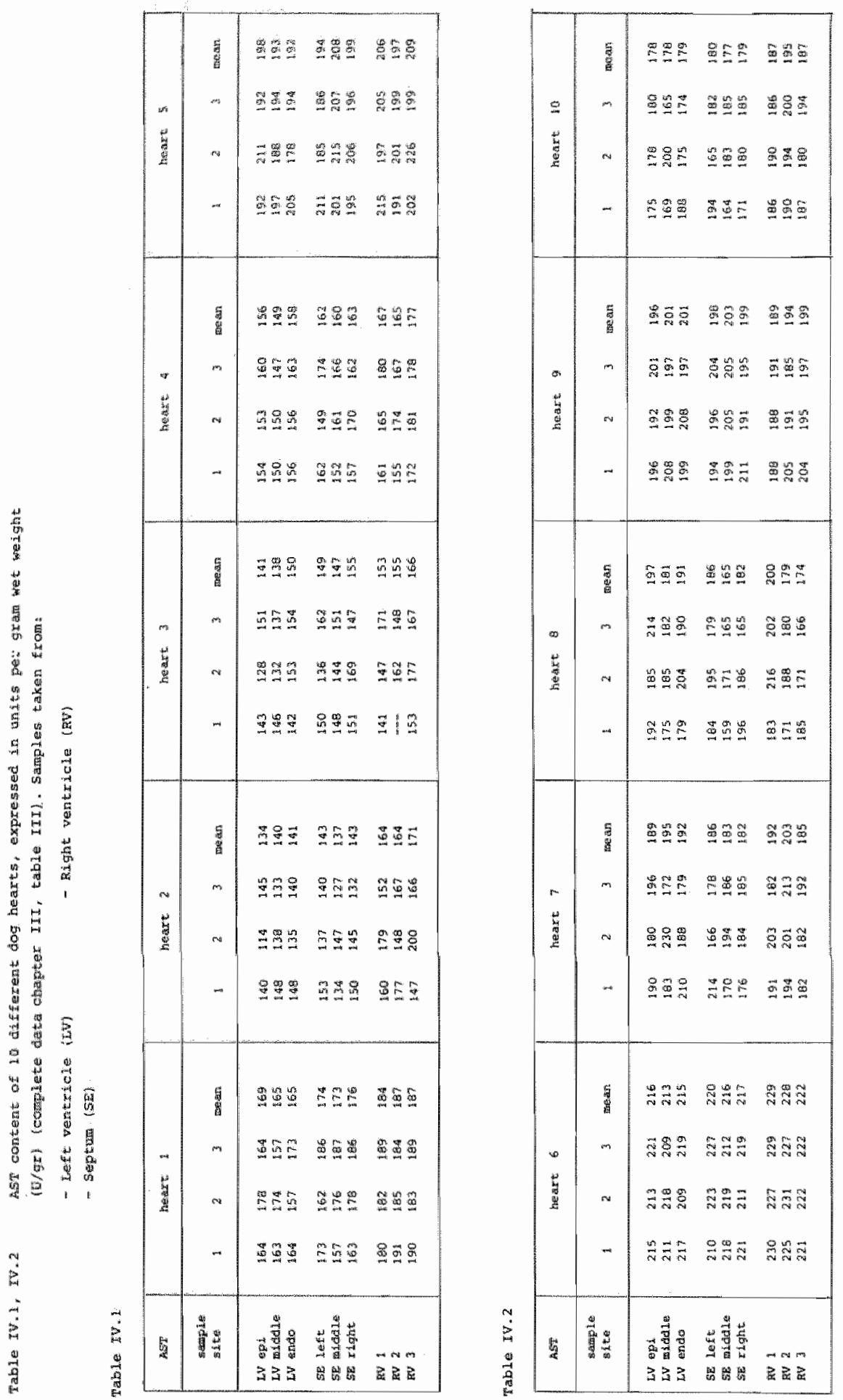

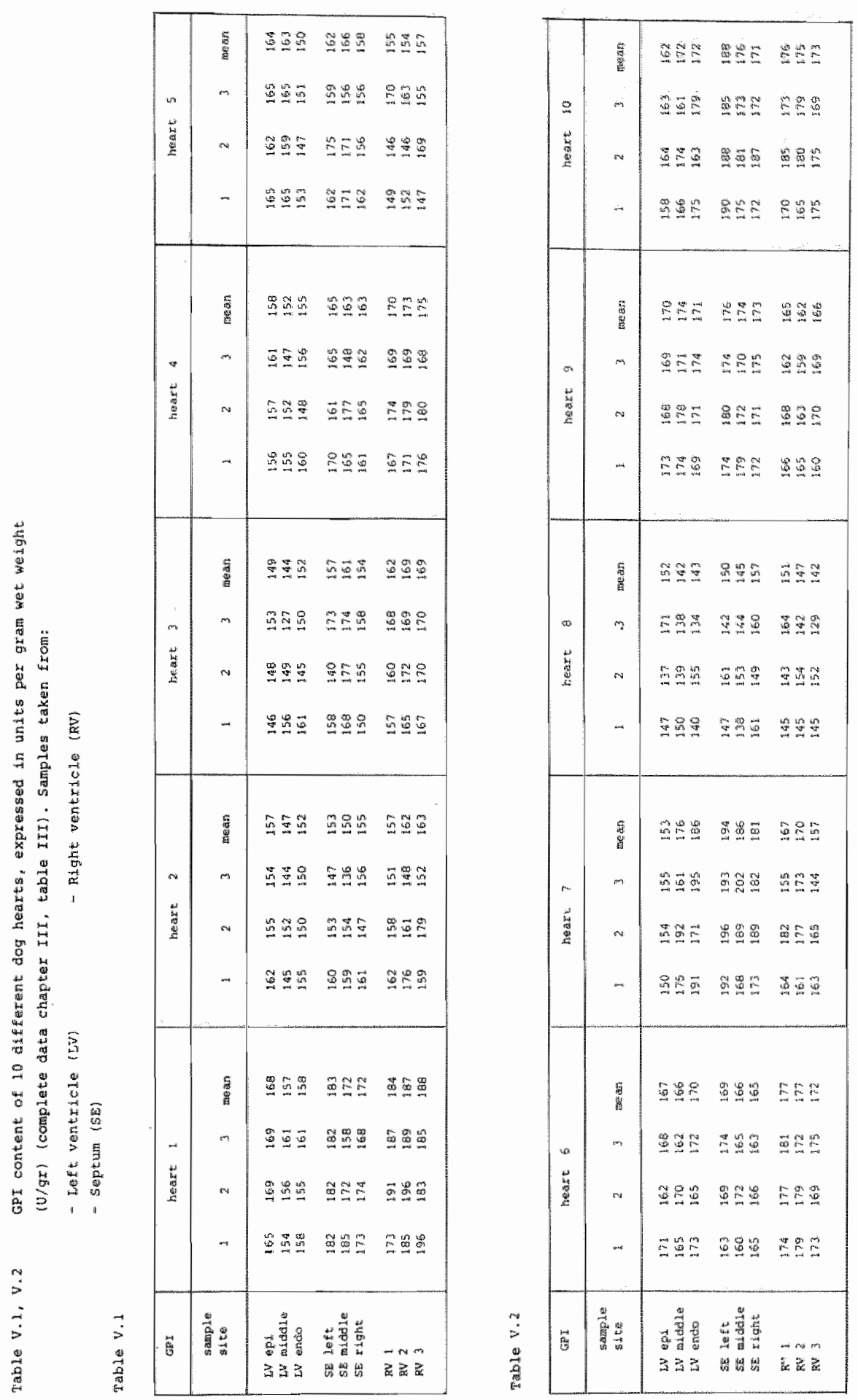


\begin{tabular}{|c|c|c|c|c|}
\hline 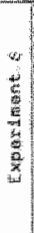 & 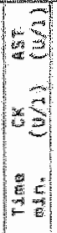 & 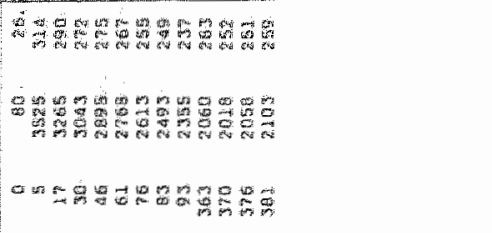 & 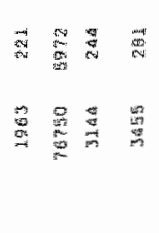 & \\
\hline & 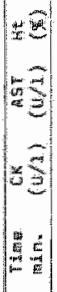 & 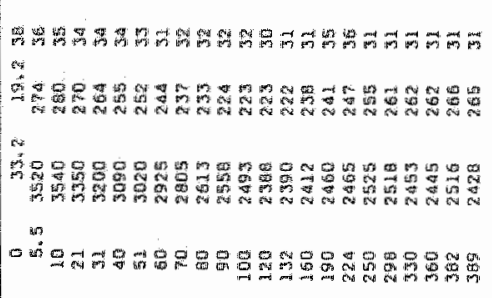 & 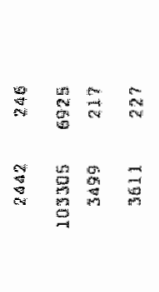 & \\
\hline & 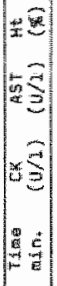 & 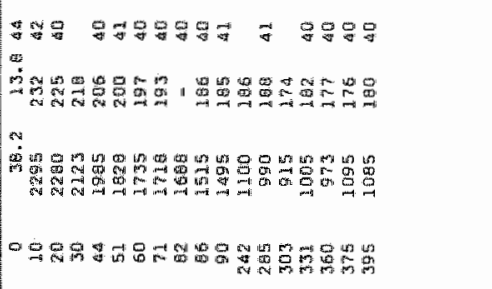 & 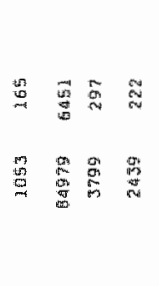 & \\
\hline 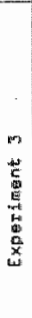 & 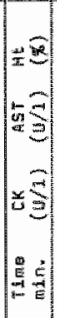 & 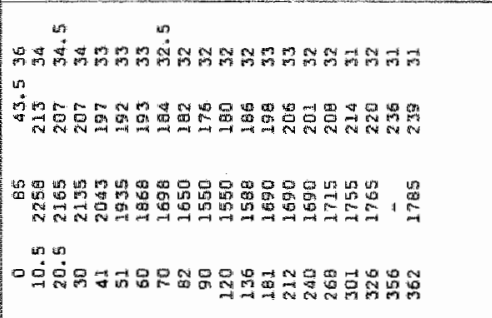 & 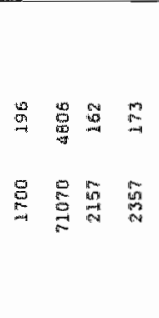 & \\
\hline 窝 & 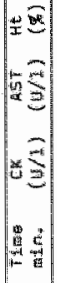 & 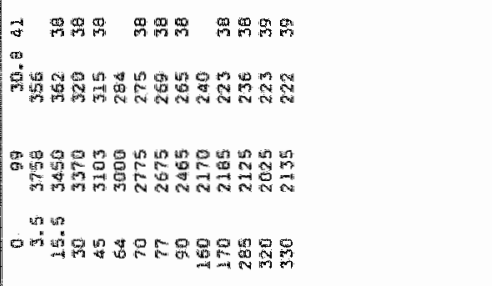 & 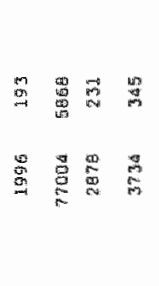 & 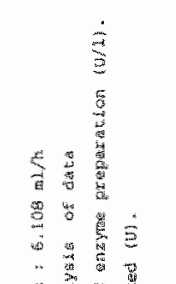 \\
\hline 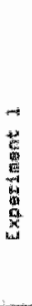 & 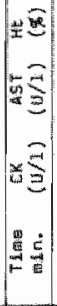 & 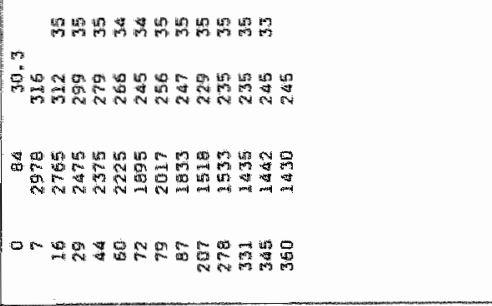 & 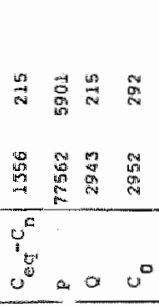 & 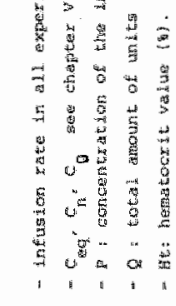 \\
\hline
\end{tabular}




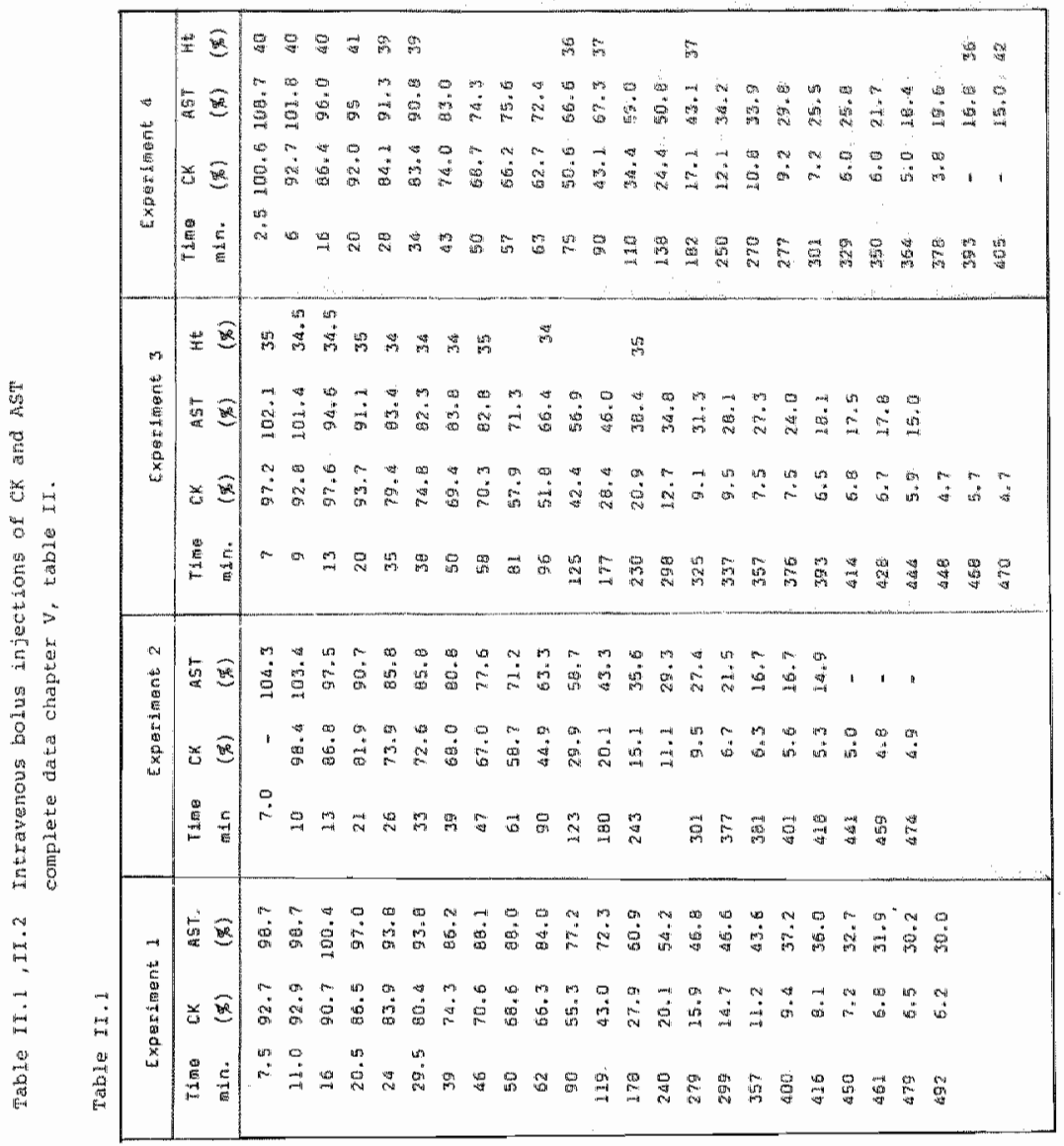




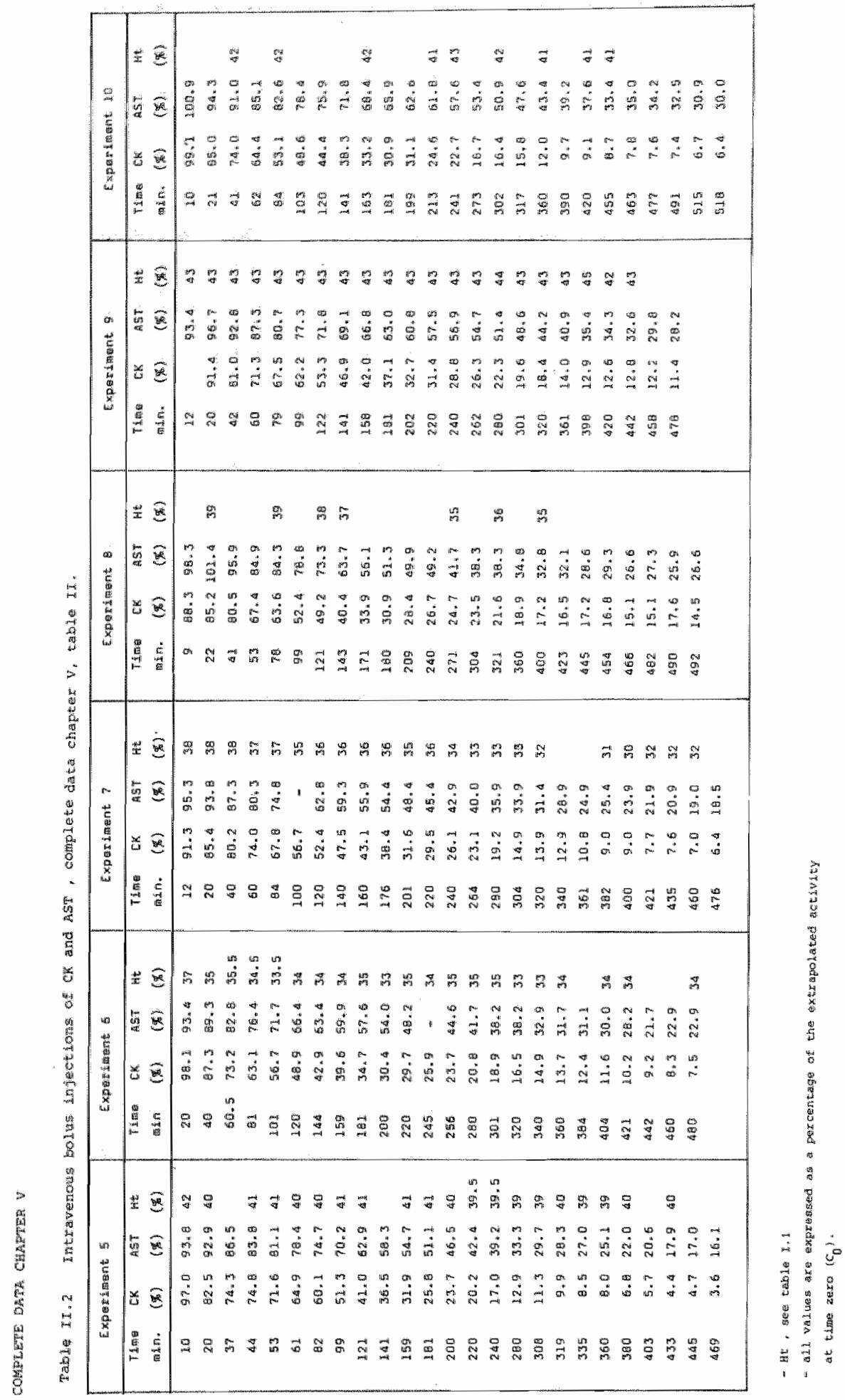




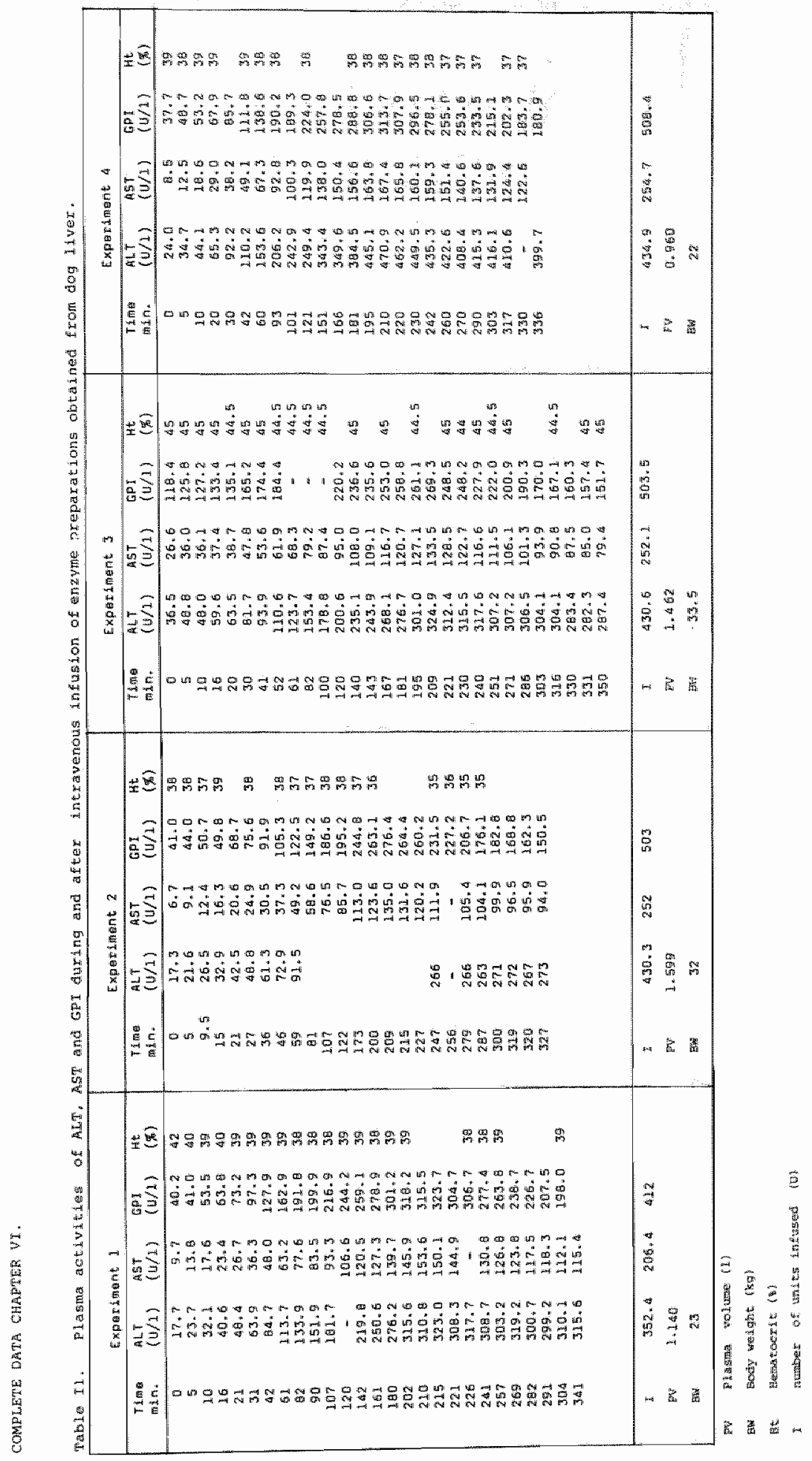




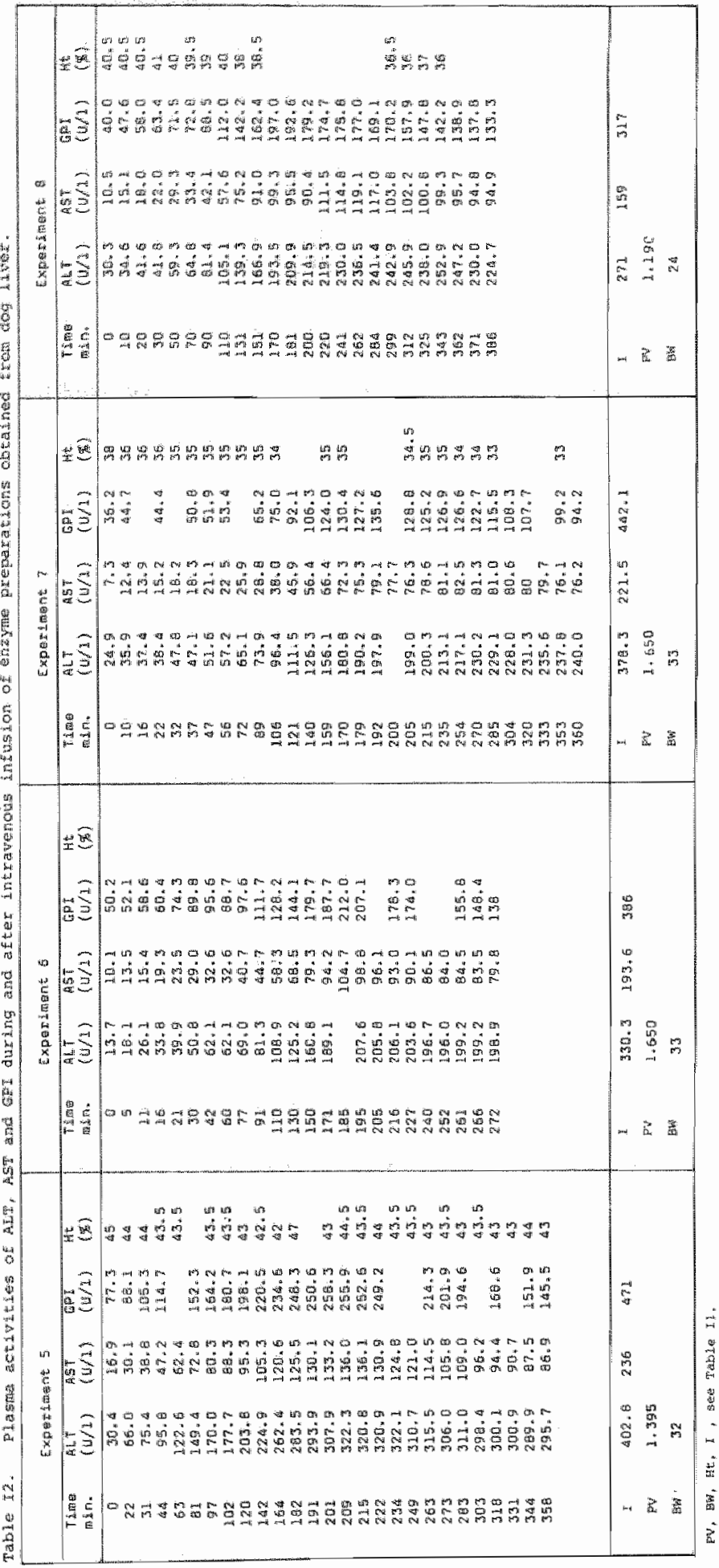




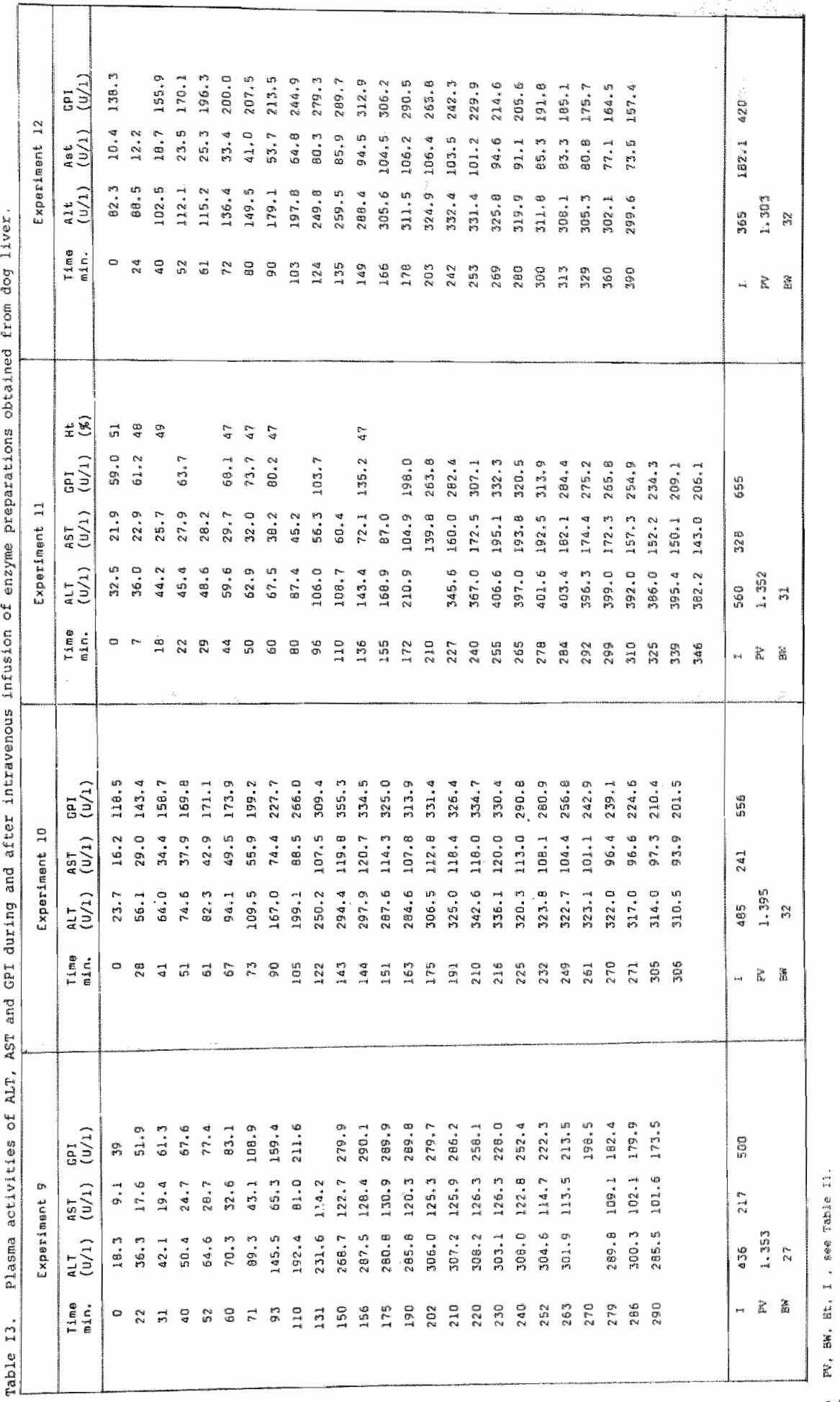




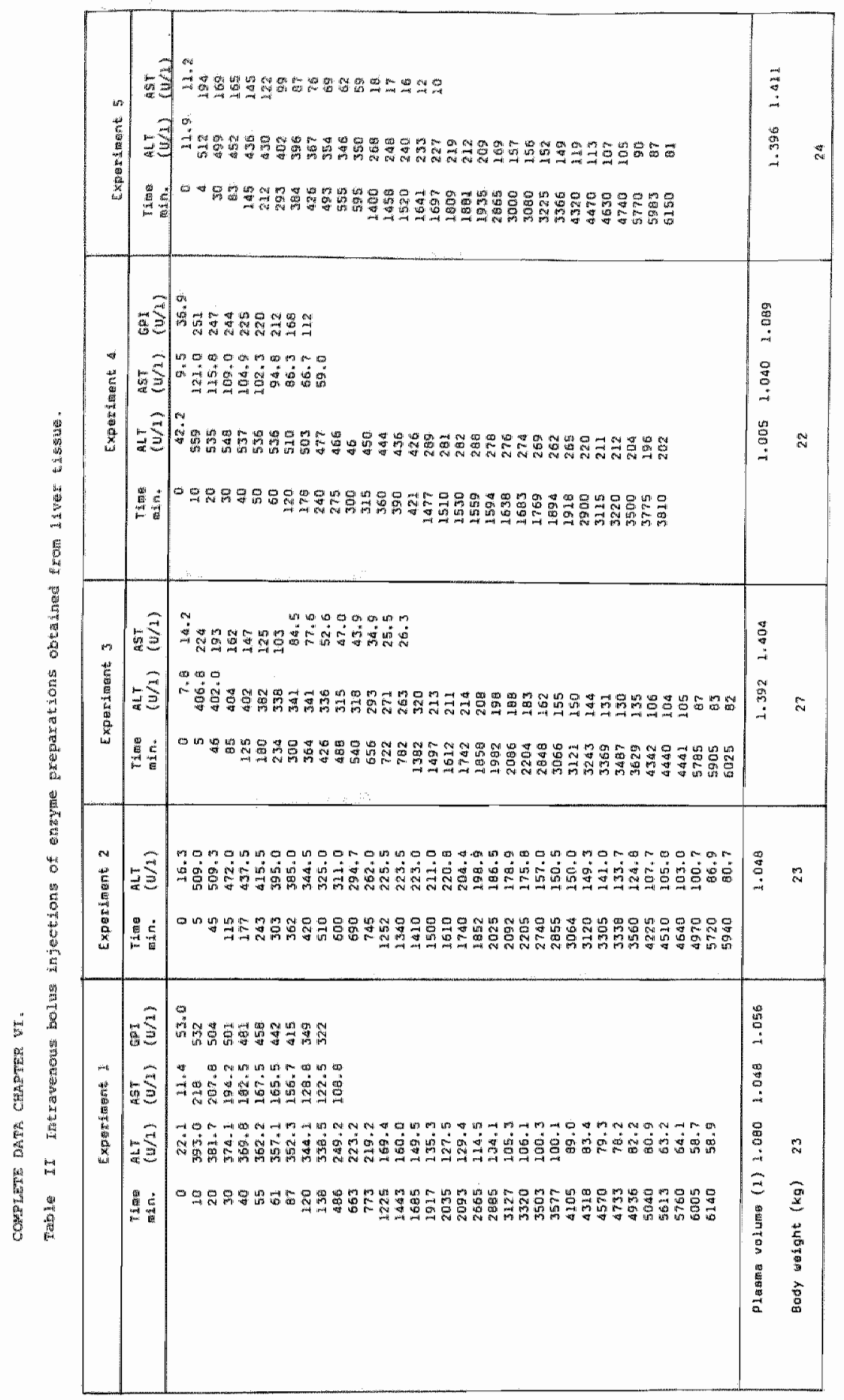




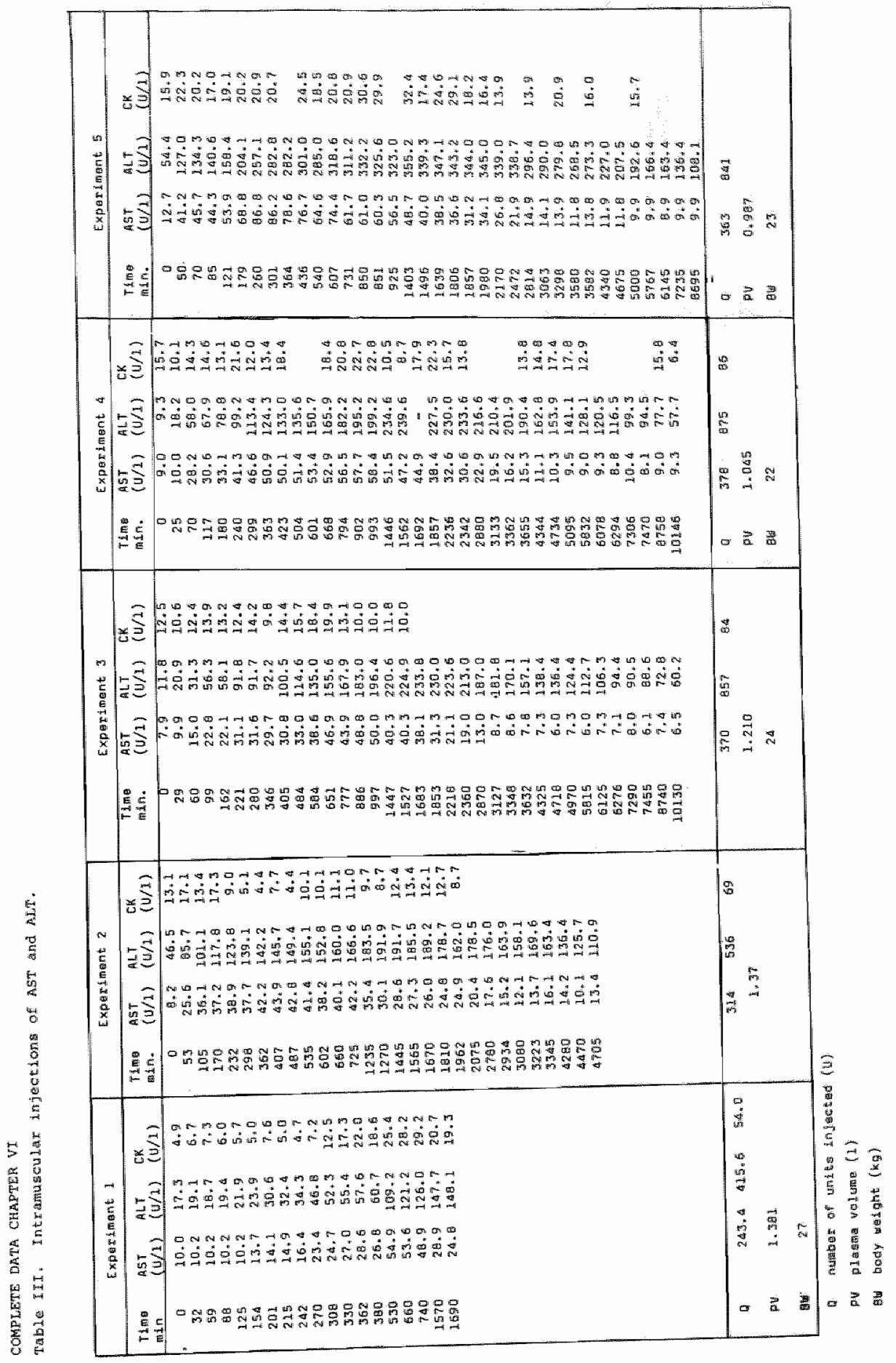



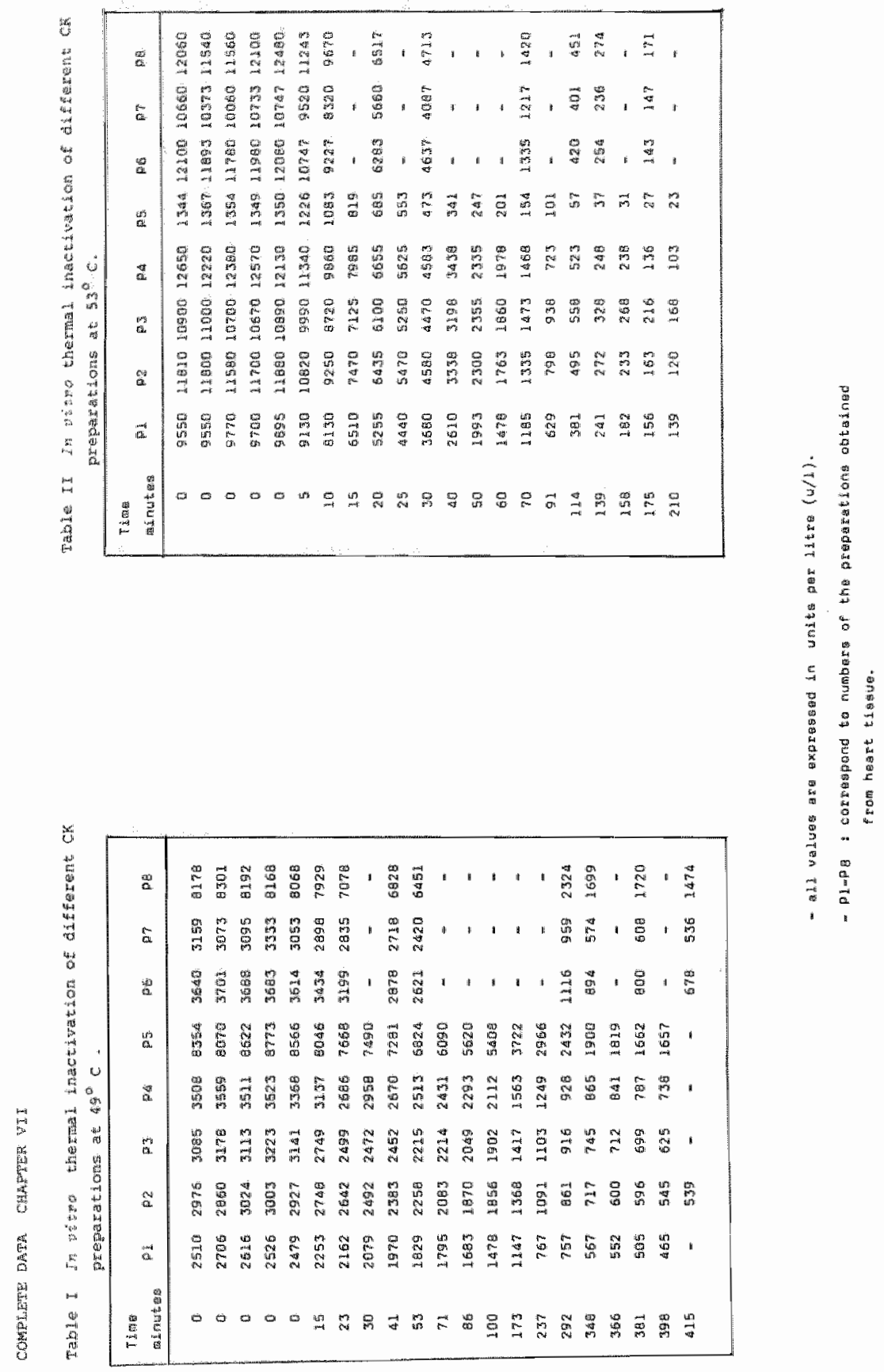


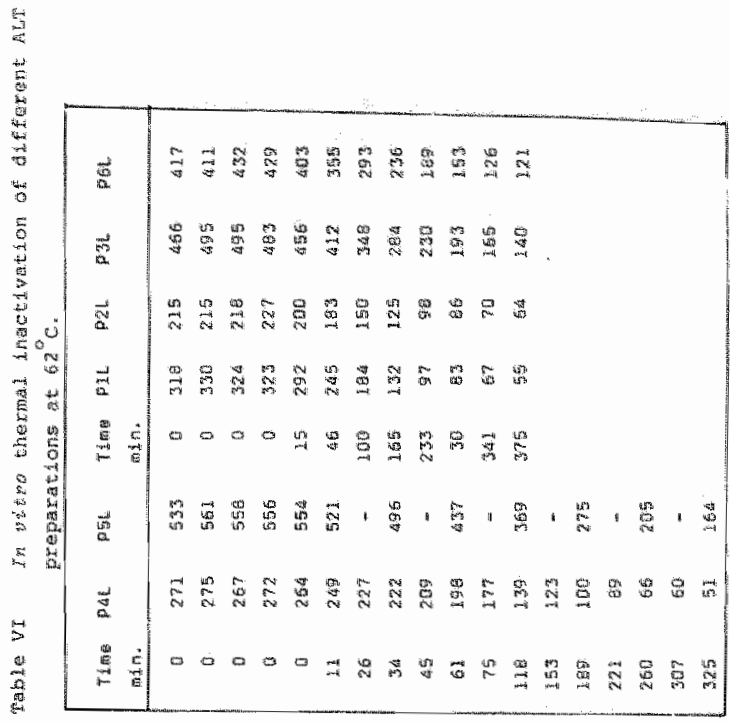

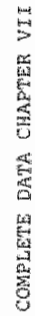

\begin{tabular}{|c|c|}
\hline$\vec{g}$ & 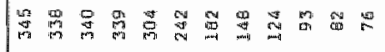 \\
\hline 芯 & 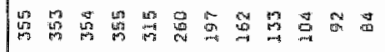 \\
\hline$\vec{a}$ & 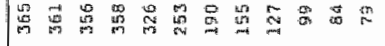 \\
\hline 현 & 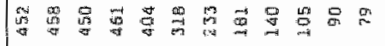 \\
\hline $\begin{array}{c}a \\
a\end{array}$ & $\int_{0}^{0}$ \\
\hline$\approx$ & 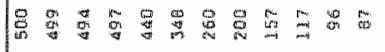 \\
\hline 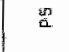 & 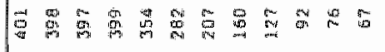 \\
\hline$\vec{B}$ & 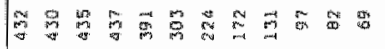 \\
\hline 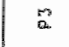 & 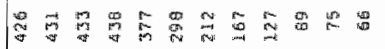 \\
\hline 被 & 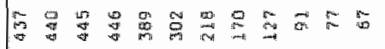 \\
\hline$a$ & 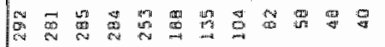 \\
\hline 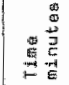 & a \\
\hline
\end{tabular}

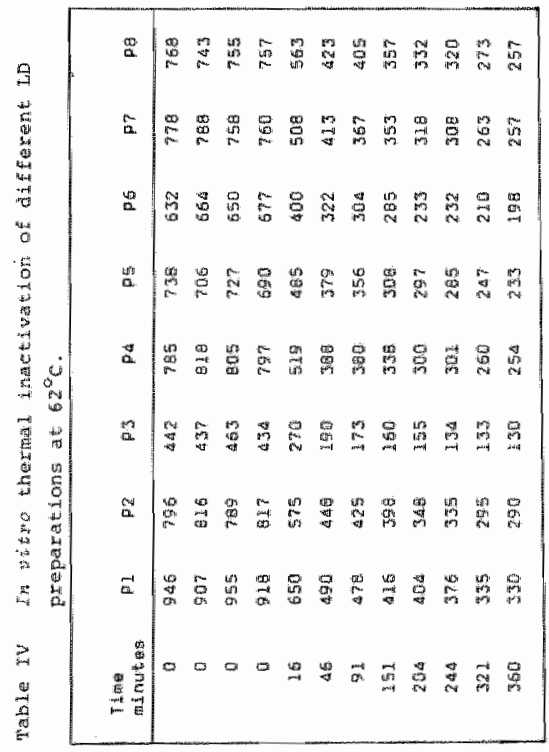

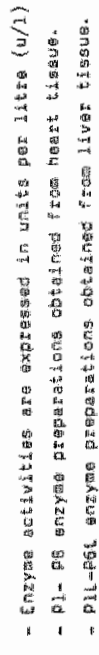



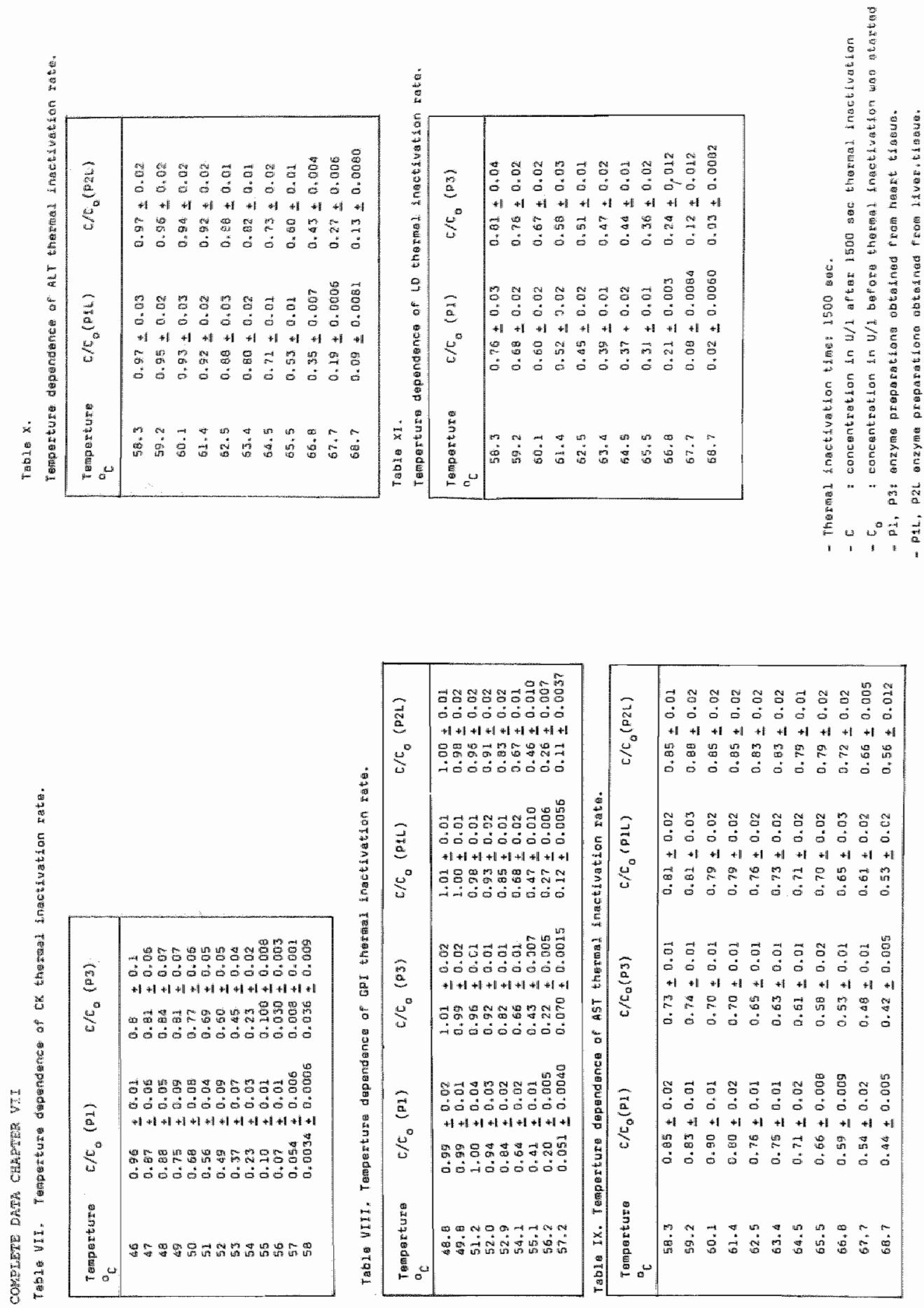

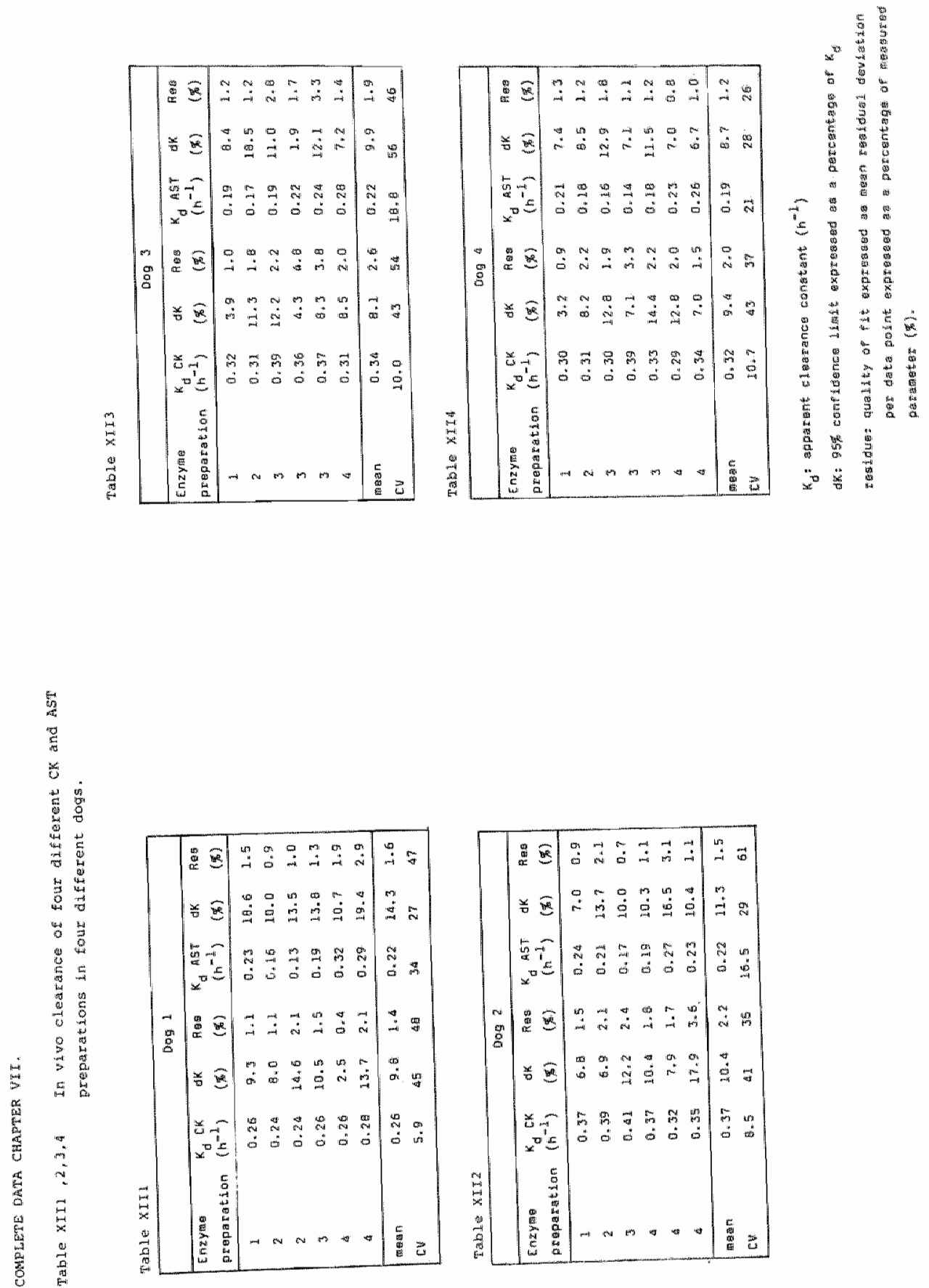


\section{APPENDIX \|}

\section{Mathematical models used}

Whe response on a known input in pasma

In this section we derive some formulas commonly used for the description of plasma activity for concentration curves as observed upon infusion or bolus injection of protein into the circulation. As discussed in chapter II.2. the dynamics of the plasma and extravascular concentration are given by (of. equation (12) and (13), chapter II. 2.).

$$
\begin{aligned}
& \frac{d}{d t} C_{i}=-k C_{i}+P / V_{i} C_{e}-P / V_{i} C_{i}+f(t) \quad\left(A_{1}\right) \\
& \frac{d}{d t} c_{e}=P / V_{e} C_{i}-P / V_{e} C_{e}
\end{aligned}
$$

with $C_{i} \quad$ - the plasma concentration (mol/l) or (0/1)

$\mathrm{C}_{e}$ - the concentration in the extravascular pool.

$k$ - the fraction of protein catabolized per hour in plasma: $k$ is the rate constant of the first order degradation reaction $\left(h^{-1}\right)$

$P / V_{i}$ - the tramscapillary escape rate (= TER), 2.e. the Eraction of protein escaping per hour Exom the vascular pool through the capillary wall to the interstitium $\left(\mathrm{h}^{-1}\right)$

$\mathrm{P} / \mathrm{V}_{\mathrm{e}}$ - the fraction of the extravascular pool of protein returning to the circulation $\left(\mathrm{h}^{-1}\right)$.

solutions of $A_{1}$ are in general combinations of exponential terms. The solution $C_{i}(t)$ and $C_{e}(t)$ in case of a bolus injection, $i, e, f(t)=0$ $t>0 ; c_{i}(0)=E_{0}$ and $c_{e}(0)=0$ is given by:

$$
\begin{aligned}
& c_{1}(t)=A e^{-a t}+B e^{-b t} \\
& c_{e}(t)=\frac{P / V_{e}}{b-a}\left(e^{-a t}-e^{-b t}\right)
\end{aligned}
$$

with $\mathbb{A}=\frac{P / V_{e}-a}{b-a} f_{0}, B=\frac{b-P / V_{e}}{b-a} E_{0} \cdot A+B=f_{O}$

$E_{O}=$ amount injected per litre of plasma

$a=\frac{\left(k+P / V_{i}+P / V_{e}\right)-V\left(\left(k+P / V_{i}+P / V_{e}\right)^{2}-4 k P / V_{e}\right)}{2}$ 


$$
b=\frac{\left(k+\mathbb{P} / V_{1}+P / V_{e}\right)+\left(\left(k+\mathbb{P} / V_{1}+P / V_{e}\right)^{2}-4 k \mathbb{P} / \mathbb{V}_{e}\right)}{2}
$$

The respons $c_{1}(t)$ and $c_{e}(t)$ for general $f(t)$ may be constructed from $\left(A_{2}\right)$ by conceiving the imput $f(t)$ as a series of bolus injections $f_{i}$ on $t=t_{1}$. Due to the Linearity of equation $\left(\mathbb{A}_{1}\right)$ the sum of a series inputs results in the sum of the corresponding responses:

$$
C_{i}(t)=\sum_{i=1}^{n} \mathbb{f}_{i}\left(A e^{-a\left(t-t_{i}\right)}+B e^{-b\left(t-t_{i}\right)}\right)
$$

and

$$
c_{e}(t)=\sum_{i=1}^{n} f_{i} \frac{p / v_{e}}{b-a}\left(e^{-a\left(t-t_{i}\right)}-e^{-b\left(t-t_{i}\right)}\right)
$$

In the limit of very many bolus injections on a dense set of times $t_{i}$ the above equations transform to

$$
\begin{aligned}
& C_{i}(t)=\int_{0}^{t} f(s)\left(A e^{-a(t-s)}+B e^{-b(t-s)}\right) d s \\
& C_{e}(t)=\int_{0}^{t} f(s)\left(\frac{P / V_{e}}{b-a}\left(e^{-a(t-s)}-e^{-b(t-s)}\right) d s\right.
\end{aligned}
$$

\section{Quantitiation}

often one encounters the situation that one wants to infer from the measured plasma activity curve $c_{i}(t)$ the amount of protein released into the plasma. I.e. disposing of $c_{i}(t)$, given in formula (A3) one must calculate $f(t)$ or preferably the integral $F(t)$ :

$$
F(t)=\int_{0}^{t} E(s) d s
$$

$F(t)$ is the cumulative input in plasma. An expression for $F(t)$ is obtained by interpretation of equation $\left(A_{1}\right)$ : The amount of protein released into the circulation must equal the surn of the quantity catabolized and the quantity still present the body $t . e \cdot v_{1} c_{i}+v_{e} c_{e}$. Per hour there is catabolized $\mathrm{kC}_{1}(t)$ from the plasma pool; hence the quantity catabolized up to time $t$ equals

$$
k \int_{0}^{t} c_{1}(s) d s
$$


and thus

$$
v_{\dot{L}} F^{\prime}(t)=v_{i} C_{i}(t)+v_{e} C_{e}(t)+v_{i} k \int_{0}^{t} C_{i}(s) d s
$$

Now we should express $c_{e}(t)$ in terms of $c_{i}(t)$. This is done by solwing equation $\left(e f . \mathbb{A}_{1}\right)$

$$
\frac{d}{d t} C_{e}=-P / V_{e} C_{e}+P / V_{e} C_{1}(t)
$$

in an analogeous way as we solved equation (A $)$.

The special exponential solution of $\left(A_{6}\right)$ with $C_{1}(t)=0$ is

$$
c_{e}(t)=e^{-\left(P / V_{e}\right) t}
$$

This special solution satisfies

$$
\frac{d}{d t} c_{e}(t)=-P / V_{e} c_{e} ; c_{e}(t=0)=1
$$

which is the solution of $\left(A_{6}\right)$ in the case $P / V_{e} C_{i}(t)$ is a bolus injection at $t=0$ in the extravascular space. Using the linearity of equation $\left(\mathbb{A}_{6}\right)$ and the superposition principle, $i . e$. the responses upon a sum of inputs $\left(\mathrm{P} / \mathrm{V}_{\mathrm{e}} \mathrm{C}_{i}(\mathrm{t})\right)$ is the sum of the responses upon each of the inputs, the general solution is written as loj. the derivation of formula $\mathrm{A}_{3}$ :

$$
c_{e}(t)=\int_{0}^{t} P / V_{e} C_{i}(s) e^{-P / V_{e}(t-s)} d s
$$

Insertion of this last expression for $C_{e}(t)$ in $\left(A_{5}\right)$ results in:

$F(t)=C_{i}(t)+k \int_{0}^{t} C_{i}(s) d s+P / v_{i} \int_{0}^{t} C_{i}(s) e^{-(P / V)(t-s)} d s \quad\left(A_{7}\right)$

Thus we have expressed the cumulative input into plasma in tems containing only observable plasma concentrations and the values of the model parameters $K, \mathrm{P} / \mathrm{V}_{\mathrm{i}}$ and $\mathrm{P} / \mathrm{V}_{\mathrm{e}}$

In the special case that the time interval $(0, t)$ is so short that the exponential term $e^{-\left(P / V_{e}\right)(t-s)}$ shows little variation on this time interval, we may in good approximation substitute $e^{-\left(P / V_{e}\right)(t-s)}$ in the thixth term of $\left(A_{7}\right)$ by a constant $c$, close to unity . Thus we obtain the approximation 


$$
F(t)=c_{1}(t)+k_{d} \int_{0}^{t} c_{1}(s) d s
$$

of $\left(H_{7}\right)$, weth $k_{\mathrm{d}}=\mathrm{k}+\mathrm{CP} / \mathrm{V}_{\mathrm{i}}$. 


\section{Thermal inactivation of enzymes}

S. Arrhenius, studying the influence of temperature on the rate of inversion of sucrose in 1889 , was the first to give a physical intecpretation of the observed relation between reaction rates and tenperature. He established the relation

$$
k=A \cdot e^{-E_{A} / R T^{2}}
$$

$k=$ rate of inversion

$R=$ gas constant

$\mathrm{A}=$ constant (so called "frequency factor")

$\mathrm{E}_{\mathrm{A}}=$ constant (so called "Arrhenius activation energy")

$\mathrm{F}=$ absolute temperature.

In analogy with the classical (Boltzmann) theory which states that the number of particles with energy (in a system with particles of different energies) depends on $\mathrm{E}$ according to exp (-E/RT). Arrhenius postulated an equilibrium between inert and activated molecules. Only activated molecules were able to take part in the activation process. Conversion of inert to activated state requires the energy $\mathbb{E}_{\mathbb{A}}$. About 1930 H.Eyring succeeded in deriving expressions for the empirical

quantities $A$ and $E_{A}$. He considered the activated state as an ordinary state possessing the usual thermodynamic propertles, with the exception that motion in a specific airection in phase space. 1.e. along the reaction co-ordinate, leads to irreversible denaturation. For the thermal inactivation of an enzyme $\mathrm{E}$ this implies:

$$
\mathbb{E} \underset{k-1}{\stackrel{k}{\stackrel{k}{*}}} \mathbb{E}^{*} \stackrel{k}{\longrightarrow} \mathrm{D}
$$

where $E$ denotes the native enzyme. $E^{*}$ the activated state, $D$ the denatured state and $k$ the rate of inactivation (denaturation). The number of activated molecules depends on the ecuilibrium constant $\mathrm{K}^{*}=k_{+1} / k_{-1}$ between inert and activated state, so we obtain:

$$
k=A \cdot K^{*}=A \cdot e^{-\left(\mathrm{AG}^{*} / \mathrm{RT}\right)}
$$

where the funciamental thermodynamic relation $\Delta \mathrm{G}=-\mathrm{RT}$ in $\mathrm{K}_{\mathrm{eq}}$ has been used for the change in free energy $\Delta G$ between inert and activated state. 
The frequency factor $A$ is ecuated to the vibrational frequency $v$ of the cxitical vibration leading to irreversible transition. Combining the guantum mechanical expression $\varepsilon=k_{B} T$ for the vibrational energy e(h and $k_{\mathrm{B}}$ are Planck's and Boltzmann's constant) we have $y=c / h=$ $\mathrm{k}_{\mathrm{B}} \mathrm{B}^{\mathrm{P}} / \mathrm{h}$ and equation (2) becomes

$$
k=\frac{k_{B}}{h} \cdot e^{-\left(\Delta G^{4} / R T\right)}
$$

or

$$
\Delta \mathrm{G}^{*}=\mathrm{RT} \ln \left(\frac{k_{\mathrm{B}} \mathrm{T}^{\mathrm{T}}}{\mathrm{k} h}\right)
$$

Substituting the thermodynamic relation $\Delta \mathrm{G}^{*}=\Delta \mathrm{H}^{*}-\mathrm{T}^{*} \mathrm{~S}^{*}$ in (3), with $\Delta \mathrm{H}^{*}$ and $\Delta \mathrm{S}^{*}$ the change in respectively enthalpy and entropy for the transition from inert to activated state, we obtain by differentiating $\ln k$ with respect to $1 / \mathrm{T}$ :

$$
\Delta H^{*}=-R \frac{d I n k}{d I / T}-R T
$$

From (4) and (5) we obtain

$$
\begin{aligned}
& \Delta \mathrm{S}^{*}=\left(\Delta \mathrm{H}^{*}-\Delta \mathrm{G}^{*}\right) / \mathrm{T} \\
& \Delta S^{*}=-\frac{R d i n k}{T d I / T}-\mathbb{R}-\mathbb{R} \ln \frac{k_{B} T}{k h}
\end{aligned}
$$




\section{Abbreviations}

a

ADP

ATP

bi

Bw

$c$

ceq

$\mathrm{C}_{i}$

$\mathrm{CL}$

C

co

$c(t)$

$\mathrm{CW}$

EIS

t.

FITC-dextran

9

$\Delta \mathrm{G}^{*}$

in

$\mathrm{HH}^{*}$

HIS

Ht

Ko

$\mathrm{K}_{+1}$

的

$\mathrm{K}$

LII

$\mathrm{LV}$

NADE

NADP

P

PV

QL

$\mathrm{R}$
Slow disapparance constant in case of biphasio charano $\mathrm{h}^{-1}$. Actenosine $5^{3}$-aphosphate.

Acriosine 5"-txphosphate.

Fast disapeararce constant in case of blphasic olearance th $^{-1}$ ). Body weight.

Extravascular enzyme activity (U/1).

Enzyme activity at equilibrium condions after constarte rate infu$\operatorname{sion}(\mathrm{U} / \mathrm{I})$.

Intravascular enzyme activity $(0 / 1)$.

Cawdate robe of the 1iver.

Normal steady state plasma enzyme activity (U/l).

Extrapolated activity at zero time (v/l).

Enzyme activity in plasma at time $t(0 / 1)$.

Coefficient of variation, i.e. standard deviation as a percentage ol the mean (s).

Enzyatic infarct size.

Rate of input of enzyme per ititre plasma (U/1.h.).

Fluorescein isothiocyanate labeled dextran.

Centrifugal acceleration (number of times gravity in the middle of the tube) (cm/ $\left.\mathrm{sec}^{2}\right)$.

Free energy of activation (J/mol). The difference in free energy between reactant (s) and transition state.

planck's constant $\left(6.6256 \cdot 10^{-34} \mathrm{~J} \cdot\right.$ sec $)$.

Enthalpy of activation; the difference in enthalpy between weactant (s) and transition state (J/mol).

Histologic infarct size.

Hematoirit value (⿻

True clearance rate $\left(h^{-1}\right)$.

Reaction $x$ ate constant $\left(\mathrm{h}^{-1}\right)$.

Equilibrium constant fox the Eonation of an actiwatad complex.

Boltzmann's constant; $1.381,10^{-23} \mathrm{~J} / \mathrm{adeg}$.

Left Iobe of the liver.

LeEt wentricle of the heart.

wicotinamide adenine atrucleotide.

Nicotinamide adenine dinucleotide phosphate.

Permeability constant $(1 / \mathrm{h})$.

Plasma volume (1).

Quadrate lobe of the liwer.

Gas constant $(8.3143 \mathrm{~J} /$ aegr.mol). 


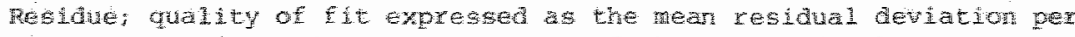
data polit expressed as a percentage of the mosured walues.

Ris luth lobe of the Liver.

KV

$15^{*}$

SE:

in

$5-1924$

$\mathrm{TER}$

Motis

U

Ve

$v_{i}$

Right wentriche of the reart.

Entropy of activaton the difference in entropy between reactant (s) and transitidat state.

septur of the heart.

dibsolute temperature iriegrees Relwin ${ }^{\circ} \mathrm{K}={ }^{\circ} \mathrm{C}+273.15$.

Lvang alue dye.

Transcapilaty escape rate (w/h)

Tress (hydroxymethyl) - aninoethane.

International unit. one unit of enzyne convexts ane micxomole of substrate per minute under the given conditions.

Fixtravascular volume (1).

Intravascular volume (1).

\section{Abbreviations used for enzymes}

EC

\begin{tabular}{|c|c|c|}
\hline RLD & DJdolase & $4 \cdot 1 \cdot 2 \cdot 13$ \\
\hline ALI & Aarine aminotxansterase & $2 \cdot 6 \cdot 1.2$ \\
\hline $\mathrm{AP}$ & Alkaline phosphatase & $3.1 \cdot 3.1$ \\
\hline 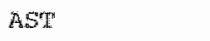 & Aspartate aminotransferase & 2.6 .1 .1 \\
\hline CAST & Cytoplasmic isoenzyme of AST & $2 \cdot 6 \cdot 1.1$ \\
\hline IXIST: & Mitochondrial isoenzymo of AST & 2.6 .1 .1 \\
\hline $\mathrm{CK}$ & Creatine kinase & $2.7 .3 \cdot 2$ \\
\hline$C K-M M_{j}$ & CK isoenzyme from muscle & 2.7 .3 .2 \\
\hline $\mathrm{CK}-\mathrm{MHE}$ & CK isoenzyme from heart & $2 \cdot 7 \cdot 3 \cdot 2$ \\
\hline $66 P-D$ & Glucose 6-phosphate dehydrogenase & 1.1 .1 .49 \\
\hline $\mathrm{GPI}$ & Glucosephosplutee isomerase & 5.3 .1 .9 \\
\hline HBO & $a$-Hyaroxyoutyrato dehyourogenase & 1.1 .1 .27 \\
\hline $\mathrm{HK}$ & Hexokinase & 2.7 .1 .1 \\
\hline $\mathrm{TCD}$ & Isocitrate dehychogenase & 1.1 .1 .42 \\
\hline $\mathbb{L D}$ & Wuatete dehyorogenase & 1.1 .1 .27 \\
\hline $\mathbb{H} D-1,2,3,4,5$ & $\mathrm{LD}+1 \mathrm{~s}$ ben 2 ymes & 1.1 .1 .27 \\
\hline $\mathrm{MD}$ & Malate dehydrogenase & $1 \cdot 1 \cdot 1 \cdot 37$ \\
\hline PK & Pytuvate kinase & 2.7 .1 .40 \\
\hline
\end{tabular}


Bij het gereedkomen van dit proefschxift wil ik ledereen, die hieraan op enigerlei wijze heeft bijgedragen van harte bedanken. Een aantal mensen wil ik toch bok nog graag met name noemen.

Hiexbij denk ik in de allexeerste plates an wim Hermens en abn George Willems, die door hun altijd aanwezige interesse in de proeven, de positieve kritiek, maar vooral de zeer vele suggesties het verschijner van dit proefschrift mogelijk hebben gemaakt.

ook Marijke krill, die een gedeelte var de proeven voor hat rekening heeft genomen mag ik zeker niet vergeten.

Vic Dreessen wil ik bedanken voor alle hulp bij het computerwerk.

Mijn promotor Prof. Dr. H.C. Hemker dank ik voor zijn interesse in het werk, de stimulerende invloed en voor de geboden faciliteiten binnen de Capaciteitsgroep Biochemie.

Voor steun bij het dierexperimentele werk dank ik ton van den Bogaard, Inger Simons-Achtenberg en Cees Verlaan, maar vooral Ruud kruger, die gedurende de afgelopen drie jaar op iedex moment bereia was me te helpen bij de experimenten en met wie ik altijd op zeez plezierige wijze heb samengewerkt.

De goede verzorging van de honden door Huub simons is zeker ten gunste van de experimenten geweest.

Voor het vele typewerk, dat gedurende de afgelopen manden is vexricht dank ik Mevr. E.M. Lelyveld-Janse, maar zeer in het bijzonder Rosy Borgman-Hanssen, die de uiteindelijke versite van dit manuscript op uiterst plezierige en ook professionele wijze heeft verzorgd en daarbij de nodige fantasie in de lay-out heeft gestopt.

ook mijn ouders, die zowel tijdens mijn studim. als tijdens de voorbereidingen voor dit proefschrift altijd zeer veel interesse hebben getoond en ook de nodige hulp hebben geboden, wil ik via deze weg nog eens van harte bedanken.

Gerbrand echter, heeft op velerlei wijzen een bijarage geleverd a an de totstandkoming van dit proefschrift. Vooral tijdens het schrijven is menig discussie thuis gevoerd over zowel de inhoud als de stijl. De laatste maanden soms misschien ook wel eens teveel. 



\section{CURRICULUM VITAE}

Op verzoek van de faculteit volgen hier enkele persoonlijke gegevens. Ik ben geboren op 27 februari 1954 te Amsterdam.

Na het eindexamen HBS-B aan het Develsteincollege te zwijndrecht in 1971, liet $i k$ mij in hetzelfde jaar inschrijven aan de kijksuniversiteit te Leiden.

In Juni 1974 werd het kandidaatsexamen in de studierichting $S_{4}$ (Scheien wiskunde met naturkkunde) afgelegd. In augustus 1977 behaalde ik het doctoralexamen met als hoofdvak Biochemie (Dr.J. E.Mellema/Prof. Dr.A.Rörsch), bijvak Medische Informatieverwerking (Dr. Ir.C.Muinstra/ Prof.Dr.A.C.Arntzenius) en tweede bijvak Röntgendiffractie (Prof.Dr. C. Romers).

van september 1974 tot oktober 1977 was ik student-assistent op het Laboratorium voor Fysiologie bij Dr.G. Kerkhof.

sinds oktober 1977 ben ik verbonden aan de Capaciteitsgroep Biochemie van de Medische Faculteit van de Rijksuniversiteit Limburg te Mastricht, alwaar dit proefschrift werd bewerkt.

Het onderzoek beschreven in dit proefschrift makt deel uit van het project quantitering van weefselnecrose en eiwitmetabolisme en is uitgevoerd onder leiding van Dr.W.Th. Hermens. 